\title{
A tall order: improving child linear growth
}

Citation for published version (APA):

Nseluke, M. H. (2018). A tall order: improving child linear growth: diets, transitions and maternal education. [Doctoral Thesis, Maastricht University]. Boekenplan. https://doi.org/10.26481/dis.20180619mn

Document status and date:

Published: 01/01/2018

DOI:

10.26481/dis.20180619mn

Document Version:

Publisher's PDF, also known as Version of record

\section{Please check the document version of this publication:}

- A submitted manuscript is the version of the article upon submission and before peer-review. There can be important differences between the submitted version and the official published version of record.

People interested in the research are advised to contact the author for the final version of the publication, or visit the DOI to the publisher's website.

- The final author version and the galley proof are versions of the publication after peer review.

- The final published version features the final layout of the paper including the volume, issue and page numbers.

Link to publication

\footnotetext{
General rights rights.

- You may freely distribute the URL identifying the publication in the public portal. please follow below link for the End User Agreement:

www.umlib.nl/taverne-license

Take down policy

If you believe that this document breaches copyright please contact us at:

repository@maastrichtuniversity.nl

providing details and we will investigate your claim.
}

Copyright and moral rights for the publications made accessible in the public portal are retained by the authors and/or other copyright owners and it is a condition of accessing publications that users recognise and abide by the legal requirements associated with these

- Users may download and print one copy of any publication from the public portal for the purpose of private study or research.

- You may not further distribute the material or use it for any profit-making activity or commercial gain

If the publication is distributed under the terms of Article $25 \mathrm{fa}$ of the Dutch Copyright Act, indicated by the "Taverne" license above, 


\section{A Tall Order: Improving Child Linear Growth}

Diets, transitions and maternal education

\section{Mutinta Hambayi Nseluke}





\title{
A Tall Order: \\ Improving Child Linear Growth \\ Diets, Transitions and Maternal Education
}

\author{
Mutinta Hambayi Nseluke
}


(C) 2018, Mutinta Hambayi Nseluke

ISBN: 978-90-8666-450-4

Published by Boekenplan, Maastricht www.boekenplan.nl

All rights reserved. No part of this publication may be reproduced, stored in a retrieval system, or transmitted in any form or by any means, electronic, mechanical, photocopying, recording or otherwise, without the written permission from the author. 


\section{A Tall Order: \\ Improving Child Linear Growth \\ Diets, Transitions and Maternal Education}

\section{DISSERTATION}

To obtain the degree of Doctor at Maastricht University, on the authority of the Rector Magnificus,

Prof. Dr. Rianne M. Letschert

in accordance with the decision of the Board of Deans, to be defended in public

on Tuesday, 19 June 2018, at 16:00 hours

by

Mutinta Hambayi Nseluke 


\section{Promoter and Supervisor:}

Prof. Dr. Wim Groot

\section{Co-Supervisor}

Dr. Nyasha Juliana Tirivayi

\section{Members of the Degree Committee}

Prof. Dr. Franziska Gassmann, (Maastricht University, Chairperson)

Prof. Dr. Martin Bloem, (Johns Hopkins Bloomberg School of Public Health)

Prof. Dr. Cathal O'Donoghue, (Queens University of Maastricht)

Prof. Dr. Chris de Neubourg, (Tilburg University) 


\section{Acknowledgements}

This is the day that the Lord has made. I will rejoice and be glad in it.

To my children, I dedicate this achievement to you. I could not have done it without you as my inspiration. Chikwa Trevor Hambayi Mwanaangu musankwa (beloved son) and Malilamaj Dyregaard Keela kangu (last born jewel), thank you for choosing me to be your mother. I love you both more than words can ever express. With commitment, I want you to know that all is possible. Believe in yourselves. Always remember God is ever watching over you.

This dissertation would not have been possible without my supervisors. To Professor Dr. Wim Groot and Dr. Nyasha Tirivayi, thank you for diligently and patiently guiding me through this journey. You both have busy schedules but you always found time to speak with me and offer constructive comments. I have a deep sense of respect and appreciation for the time and effort you both put into my work, guiding me and for going over and above what was expected of you. Thank you Wim for your steadfastness and unwavering support despite my high and low moments. To Nyasha, thank you first for telling me about Maastricht University and for allowing me to call you at odd hours to ask when I was lost. To both of you, your standards are impeccable. As such, any mistakes and inconsistencies in this dissertation are my own.

My sincere gratitude goes to Dr. Mindel van de Laar, for making it possible for part time fellows like me to realize their lifelong dream. It's amazing how you steered the ship, ever so gently, believing in all of us, with a very deep sense of respect for our diversity, a true mark of a leader. To our coordinators Carlos, Guney, Saba, Charlotte and Shivani, thank you for keeping your cool all the time.

To my classmates of GPAC 2013 fellows, Brenda, Paul, Ali, Clovis, Luiz, Andrea, Sylvia and Camillo, it seems like yesterday when we all came together. Congratulations on your PhDs! 
To my family- Father, I am lost for words. You believed that I could do anything and be anything I wanted. I wish you were here to see it all. To my mother - with a smile, I now realize how hard it must have been to raise us, all seven children. As your only daughter, I now know that motherhood is a joyful journey, a lifelong commitment. I am lost in many ways without your guidance but I know that you are an angel in heaven that knows me by name. I miss you. To my brothers, my memories of your contributions in my life are many and solid. I am so lucky to have had academic role models. You always make feel special. Always.

Dr. Brenda Yamba, my ageless and timeless friend. It's no coincidence that we got accepted to the same university, same time, and same class. Do you remember the days when we would find the "gap" in literature? Laugh and not sleep to read? I am blessed because God gave me my keeper, a friend of all times. This journey has been a shared pleasure. We did it!

Violet Chanza Black, a daughter in more ways than one. You were there every day, happy, dependable. I am grateful for the humbleness you bring in our family. Your future is so bright. May you always be richly blessed because you are such a shining star. I will walk with you.

There are people in my life that I have come to love and call family. Friends that stand by me in all times; Dr. Joyce Luma, Beatrice Kawana, Tasha Libanga, Dr. Margaret Wazakili , the Chaavas, the Mlambos, Kiki Gbeho and Louise Sow Holdbrook. You understood when I had silent episodes. I knew you were there and I could count on you day and night. I am grateful to you all and cherish that you are part of my family's life.

I met some remarkable minds along this journey; Chris Chibwana, John Mazunda, Henry Kankwamba, Wondi Mesfin, Louise Nennen and Valerio Guiffrida. I am grateful to you all for patiently teaching me econometrics, and clarifying details to me whenever I did not understand. What I have learnt I owe to you. Thank you. May all your dreams come true. 
To Dr. Steve Kodish, thank you for patiently urging me on and taking time to read my drafts. It's a privilege to meet someone who believes in your abilities. Dr. Saskia de Pee, the house scientist, for answering my questions amidst your busy schedule. Dr. Marshall Makate, for the undivided and unassuming support during the last mile of my journey. I truly admire your humble intellect. Thank you all for always being so reassuring even when I doubted myself.

To my aunties, cousins, nieces, sister-in-laws and nephews, too many to mention by name. My true legacy. Thank you for everything. You define who I am.

To my treasured friends that I met in Malawi, the "EmotiCons" and "RSC "groups; Priscilla, Lola, Becky, Zuleika, Stella, Violet and Nankali, for being such brilliant powerful women and a fun group to be with. The parties took my mind away when I was stressing. We bonded and our different personalities made us accepting of each other. We grew stronger. Thank you for making my stay in Malawi so memorable and for becoming my lifelong friends.

My children's chapter is incomplete without a mention of their other halves. With no regrets, thank you both for the seasons we shared and for our two lovely children. It was meant to be.

Last but above all, to the children of Malawi, this dissertation would not have been possible without the information on your experiences. I will always be indebted to you. I wish you well. To the people of Malawi, thank you for your kindness and for embracing me as your own during my tour of duty. I was home away from home and fortunate to live among people so humble and truly rich in spirit. I pray that you continue to be richly blessed. 



\section{TABLE OF CONTENTS}

LIST OF TABLES....................................................................................

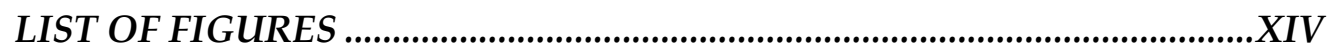

LIST OF ABBREVIATIONS........................................................................

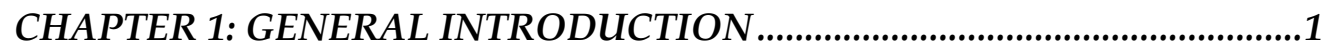

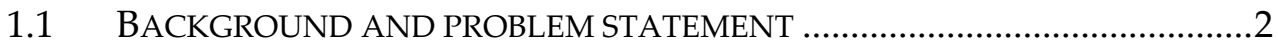

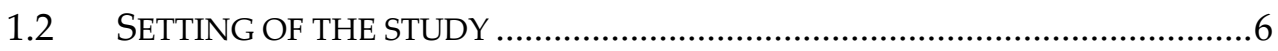

1.3 THEORETICAL AND CONCEPTUAL FRAMEWORK.......................................

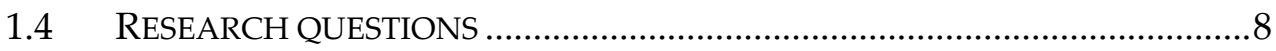

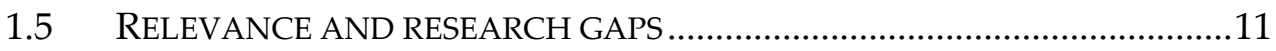

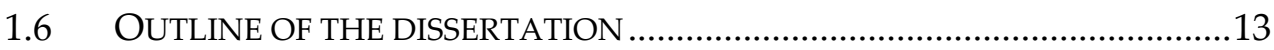

CHAPTER 2: THE IMPACT OF SUPPLEMENTING DIETS WITH LOCAL ANIMAL SOURCE FOODS ON STUNTING IN CHILDREN AGED 6-59 MONTHS IN SUB SAHARAN AFRICA: A SYSTEMATIC REVIEW.

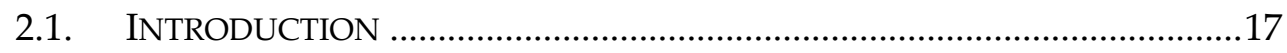

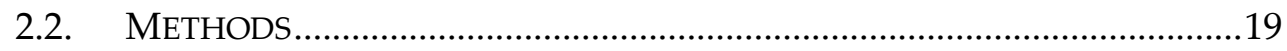

2.2.1. Search strategy and information sources..........................................19

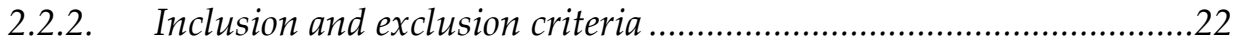

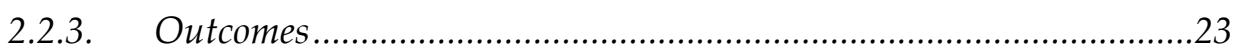

2.2.4. Methodological quality appraisal ..................................................24

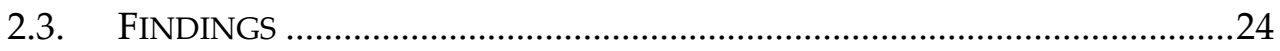

2.3.1. Methodological quality of studies ...................................................24

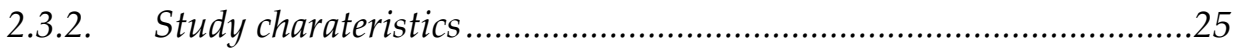

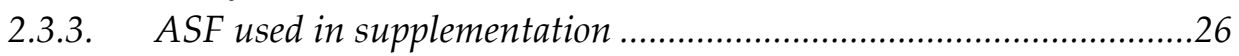

2.3.4. How the food supplementation was done ........................................26

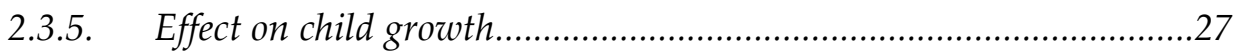

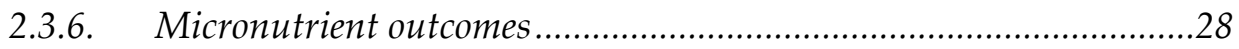

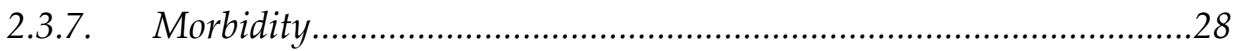

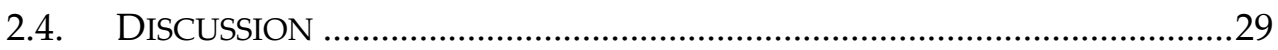

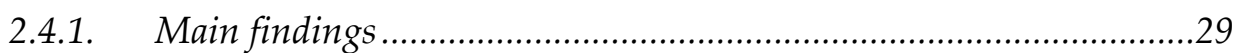

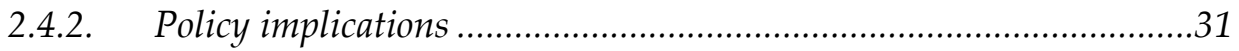

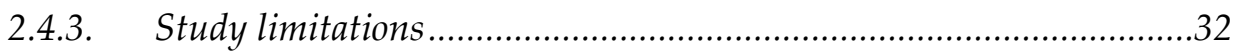

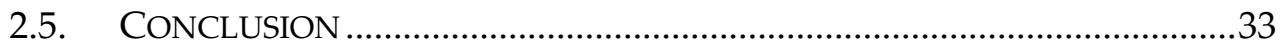




\section{CHAPTER 3: DO FOOD GROUPS MATTER IN RESOURCE POOR SETTINGS? ASSESSING THEIR ROLE IN CHILD LINEAR GROWTH:

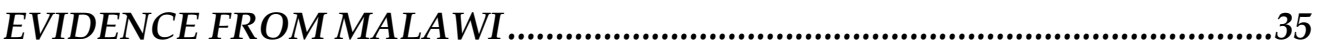

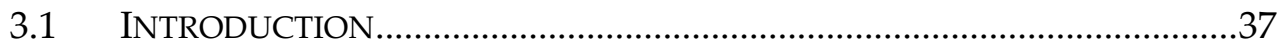

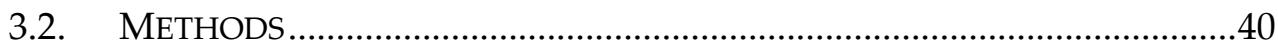

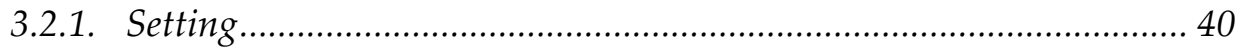

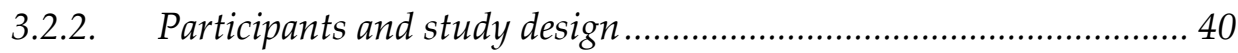

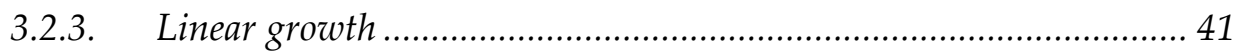

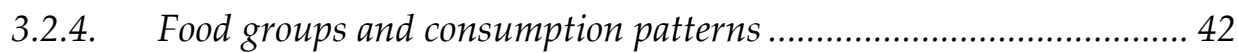

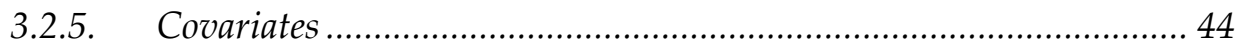

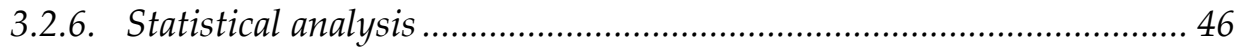

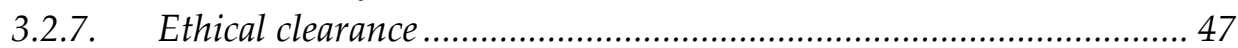

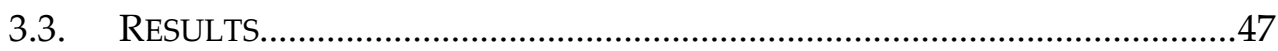

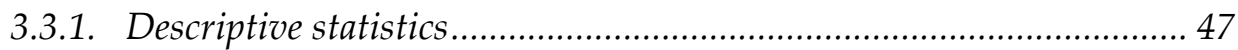

3.3.2. Heterogeneity in the association between consumption of food groups and linear growth ...................................................................................... 50

3.3.3. Association between consumption of food groups and linear growth 50

3.3.4. Milk products and linear growth.................................................. 51

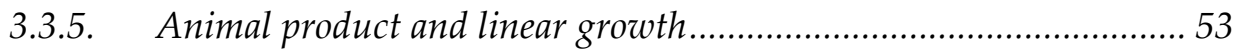

3.3.6. Individual animal foods and linear growth .................................... 54

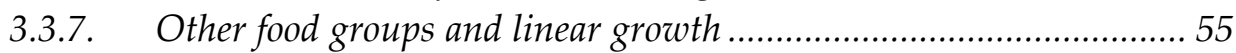

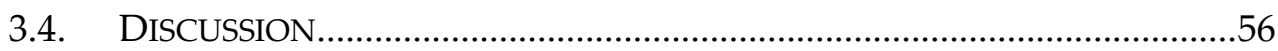

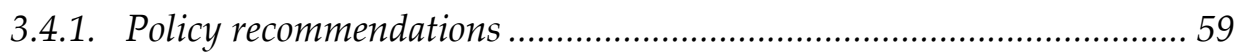

3.4.2. Strengths, limitations and areas for future research .........................6 60

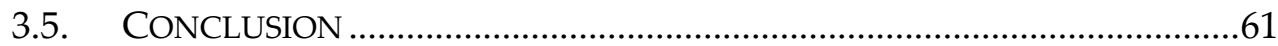

\section{CHAPTER 4: DETERMINANTS OF TRANSITIONS IN EARLY CHILDHOOD}

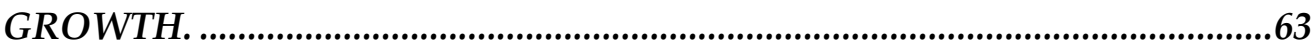

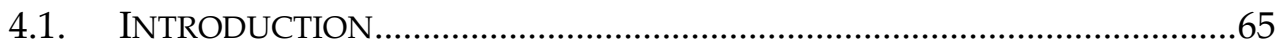

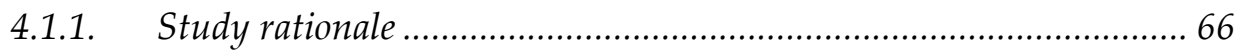

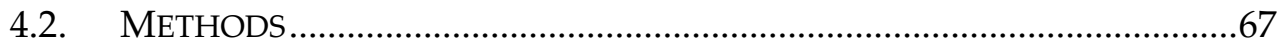

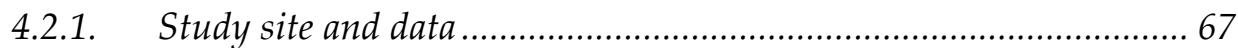

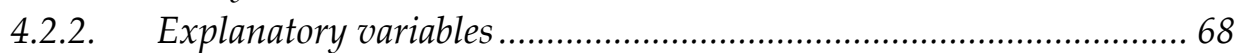

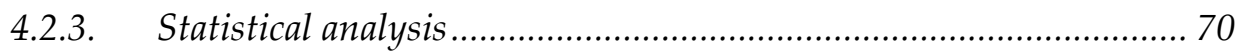

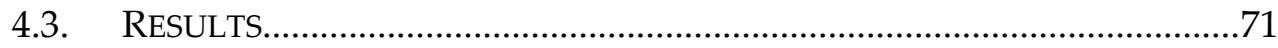

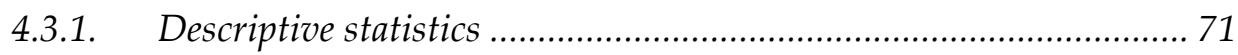

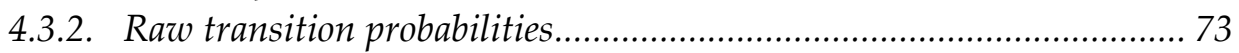

4.3.3. Determinants of becoming stunted (worsening) ................................ 77 


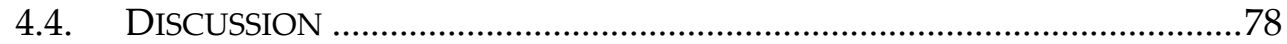

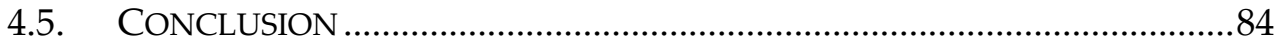

CHAPTER 5: MATERNAL EDUCATION AND ITS CAUSAL EFFECT ON CHILD GROWTH: EVIDENCE FROM A NATURAL EXPERIMENT IN

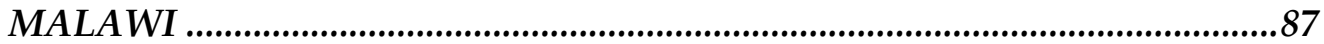

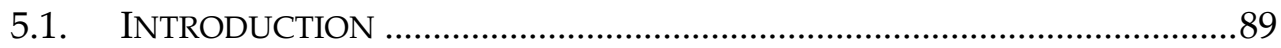

5.1.1. Relevant Literature health and nutrition outcomes................................91

5.1.2. Free Primary Education (FPE) Reforms in Malawi................................95

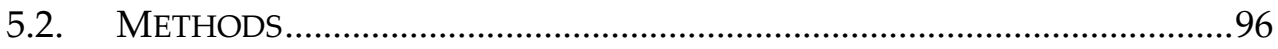

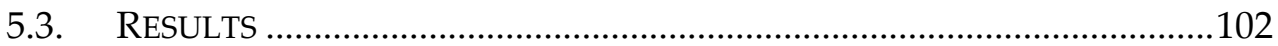

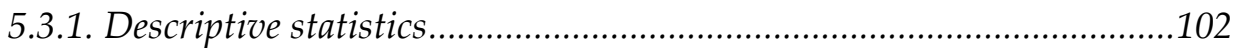

5.3.2. Effect of maternal education on height-for-age (HAZ) and stunting....104

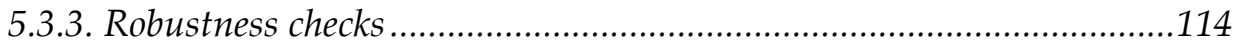

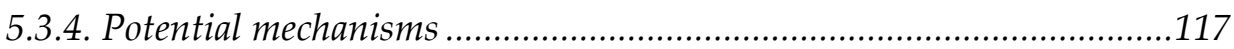

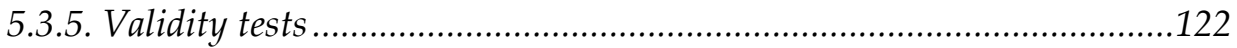

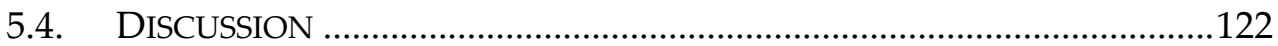

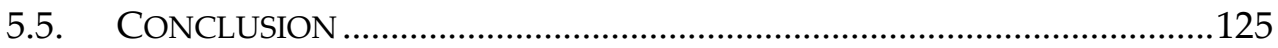

CHAPTER 6: GENERAL DISCUSSION......................................................127

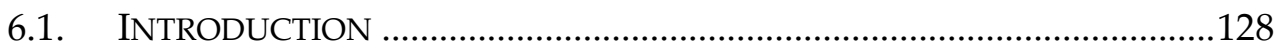

6.2 CONCLUDING STATEMENTS BASED ON FINDINGS .................................129

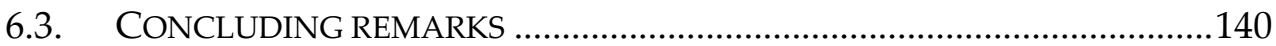

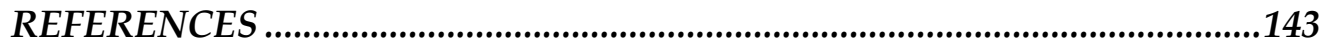

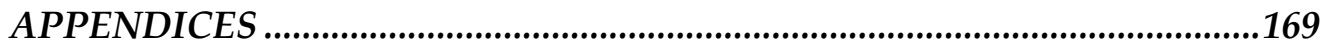

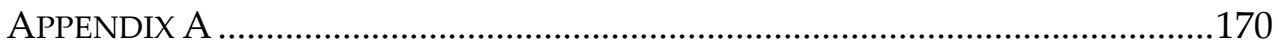

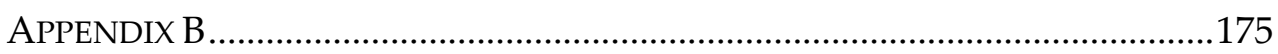

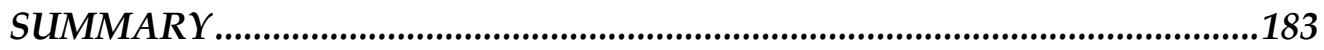

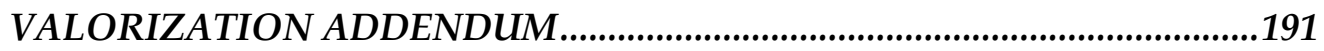

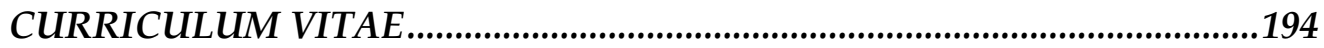

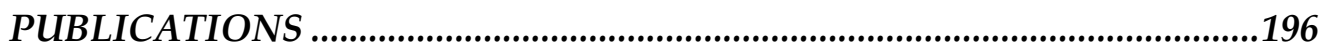




\section{LIST OF TABLES}

Table 1.1: Unit of observation, method, and empirical chapter outcomes measures....... 11

Table 2.2: Impact on linear growth of studies in which local animal source foods (ASF) were provided daily

Table 3.1: Summary statistics of consumption patterns and nutritional status; 2010 and 2013

Table 3.2: Associations between consumption of food groups and child linear growth (HAZ).

Table 3.3: Heterogeneity in the association between the milk food group and linear growth: age (in months) and wealth status interactions

Table 3.4: Heterogeneity in the association between consuming animal product and linear growth: interactions with age (in months), wealth and maternal education.

Table 4.1: Sample characteristics at baseline and follow up

Table 4.2: Raw transition probability matrix 74

Table 4.3: Probability of recovery from stunting or worsening in stunting..... 75

Table 5.1: Summary statistics for selected variables of the analysis with pairwise t-tests. 102

Table 5.2: The effect of FPE on maternal education in Malawi.... 109

Table 5.3: The effect of maternal education on child height-for-age z-scores and stunting in Malawi.

Table 5.4: Heterogeneity in the impact of maternal education on child HAZ and stunting

Table 5.5: The effect of maternal education on child growth in Malawi- robustness across age bandwidths.

Table 5.6: Impact of eligibility to the Malawi FPE reform in 1994 on child growth: reduced form estimates.

Table 5.7: Child level mechanisms through which maternal education impacts child growth in Malawi.

Table 5.8: Maternal and household level mechanisms through which maternal education impacts child growth in Malawi

Table A3.1: Missing values by food groups and individual foods 
Table A3.2: Classification and composition of food groups .........................................171

Table A3.3: Bivariate regression: age in months and age group on quantity of food

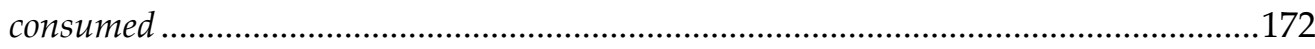

Table B5.4: Summary statistics for selected variables of the analysis (with no t-tests) 181 


\section{LIST OF FIGURES}

Figure 2.1. Flow chart of evidence search and selection............................................... 20

Figure 2.2. Trends in stunting (percent)by age and the daily type of food provided...... 27

Figure 4.1. Probabilities of becoming nonstunted by mother education and food

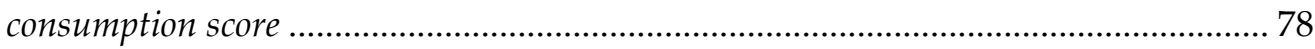

Figure 4.2 Probabilities of worsening by age and food consumption score..................... 78

Figure 5.1: The impact of the 1994 free primary education on maternal education in

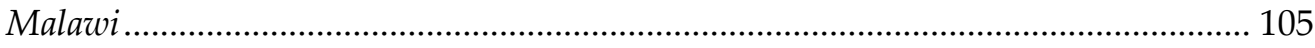

Figure 5.2: Impact of the (FPE) policy on maternal education levels in Malawi ......... 106

Figure 5.3: The impact of free primary schooling on maternal education by place of

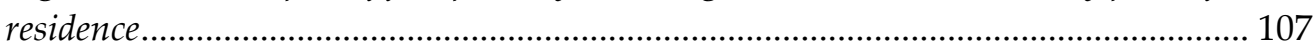

Figure 5.4: The effect of FPE on height-for-age and child stunting in Malawi. .......... 110

Figure B5.1: Primary school completion (or higher) by region of residence................. 175

Figure B5.2: Distribution of the respondent's age at policy enactment in 1994 to check

for potential discontinuities or bunching at the age 13 cut-point. .............................. 176

Figure B5.3: Checking the smoothness of respondent's age at policy enactment in 1994

to check for discontinuity by dataset used in the analysis - validity checks.................. 177

Figure B5.4: Smoothness of the respondents' age at policy enactment in 1994: maternal

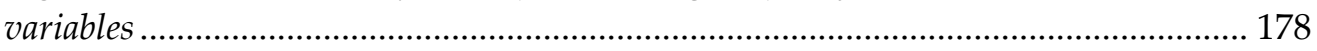

Figure B5.5: Smoothness of the respondents' child characteristics used in the analysis:

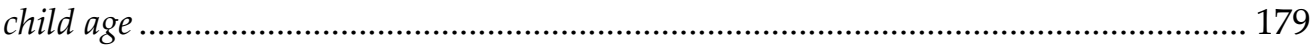

Figure B5.6: Checking the smoothness of the household wealth used in the analysis... 180 


\section{List of Abbreviations}

ASF

ECA

FAO

FPE

GDP

HAZ

HANCI

ICA

IUGR

LAZ

LBW

MDHS

MUAC

MGDS

NSO

NEPAD

OECD

RCT

RDD

SUN

UNICEF

WHO

WFP

WHA

SDG

SSA

SBCC

WHZ

WAZ
Animal Source Food

Economic Commission for Africa

Food and Agriculture Organization

Free Primary Education

Gross Domestic Product

Height for Age Zscore

Hunger and Nutrition Commitment Index

Integrated Context Analysis

Inter Uterine Growth Retardation

Length- for-Age z score

Low Birth Weight

Malawi Demographic Health Survey

Mid Upper Arm Circumference

Malawi Growth and Development Strategy

National Statistical Office (Malawi)

New Partnership for Africa Development

Organization for Economic Co-operation and Development

Randomized Controlled Trial

Regression Discontinuity Design

Scaling Up Nutrition

United Nation Children Emergency Fund

World Health Organization

World Food Program

World Health Assembly

Sustainable Development Goal

Sub Saharan Africa

Social and Behaviour Change Communication

Weight -for -Height z score

Weight -for - Age z score 

CHAPTER 1: General Introduction 


\subsection{Background and problem statement}

This dissertation examines the relationship between diet, maternal education and stunting. The thesis further studies determinants of childhood growth transitions. Low height-for-age, or stunting, is failure to reach linear growth potential in early childhood due to recurrent illness and chronic malnutrition (Fenske, Burns, Hothorn, \& Rehfuess, 2013). Stunting is the most prevalent form of malnutrition, affecting 155 million children (UNICEF, 2017). A major concern about stunting, a form of chronic malnutrition, is that it has many effects on the individual's health, later child schooling, and therefore has enormous economic implications. Reducing stunting is widely accepted as a smart investment (Hoddinott, Alderman, Behrman, Haddad, \& Horton, 2013). Hoddinott, Alderman, et al. (2013) find that an individual stunted at age 36 months was predicted, as an adult, to have $66 \%$ percent lower per capita consumption, presenting a direct measure of the economic cost of stunting (Hoddinott, Alderman, et al., 2013). In addition, the World Bank estimates that for every dollar invested in reducing stunting, there is a return of ten dollars and an increase of 4-11\% in Gross Domestic Product (Shekar, Kakietek, Dayton Eberwein, \& Walters, 2016). Furthemore, Spears (2012) demonstrated that being one standard deviation taller showed an association with better future writing skills.

As a result, nutrition is now a dominant feature of the global agendas. In 2010, the Scaling up Nutrition movement, representing sixty countries to date, was formed to collectively champion nutrition (SUN, 2017). In 2012, the World Health Assembly (WHA) set targets to reduce stunting by $40 \%$ for each country by 2025 (WHO, 2014), while the 2015, Sustainable Development Goals (SDGs, 2015) aim to end malnutrition in all its forms by 2030 (Baye, 2017). In the history of global development goals, reducing stunting is today explicitly included as an indicator, giving it a new focus and prominence. As stunting persists globally, there is now growing recognition that strategies that are effective for preventing stunting in a way that also address the other outcomes that are associated with, but not caused by, stunting are still unclear. This is 
because the extent to which different determinants impact linear growth have yet to be elucidated.

Given the above background, the existing literature provides strong evidence that dietary diversity, especially the frequent consumption of animal source foods, tends to be positively associated with linear growth in children (Arimond \& Ruel, 2004). In particular, food groups have been used to predict nutrient adequacy for children. However, there are counter arguments. Ali et al. (2013), points to the fact that evidence is mixed on whether or not consuming few or more foods groups determines poor linear growth. In South Africa, poor diets were not the primary cause of stunting and wasting but a result of poor sanitation (Theron, Amissah, Kleynhans, Albertse, \& MacIntyre, 2007). Long et al. (2012), in a study in Kenya, concluded that energy intake is important for toddler linear growth and the role of meat is less certain (Nancy F. Krebs et al., 2012). A. James and G. Palmer (2015) observes that in as much as the consumption of food groups is promoted, an ambiguous relationship between quantity and frequency of each food group or food item consumed and nutrition outcomes exists, which has not clearly been demonstrated.

However, over the past decades, research has emphasized that child linear growth is typically determined by the interaction of diet and maternal education, decisions and behaviors such as those related to the prevention of illness and child feeding practices (Wamani, Åstrøm, Peterson, Tumwine, \& Tylleskär, 2006). Diet is considered a strong determinant of child wellbeing in resource-poor settings (Daphna K Dror \& Lindsay H Allen, 2011; Grossman, 1972). A diverse diet is an important source of nutrients required not only for rapid growth in early childhood, but also for maintaining a stronger immune system. Yet, numerous studies show that stunting peaks during the introduction of solid food to infants, suggesting that there are unmet nutrient needs from the diet, as well as other underlying factors (Arimond \& Ruel, 2004; Meenakshi et al., 2010; Prendergast \& Humphrey, 2014). Due to the fundamental link between diet and illness as immediate causes of undernutrition (UNICEF, 1990), efforts to improve linear growth have often 
focussed on short term solutions such as micronutrient supplementation (Angeles, Schultink, Matulessi, Gross, \& Sastroamidjojo, 1993; Chhagan et al., 2010). A recent study found that, the use of lipid based nutrient supplements did not always improve linear growth (Prendergast \& Humphrey, 2014).

Therefore, if the required nutrients are unmet over a long time, a child will become stunted and suffer from micronutrient deficiencies. This underlies the relationship between stunting and the increased risk of morbidity and mortality, as well as suboptimal brain development (De Pee, 2018). However, scholars suggest that benefits of becoming nonstunted, especially below the age of 24 months, occur fairly quickly, such as reduced infant and child morbidity (Anna Lartey, 2015; Teivaanmäki, Cheung, Kortekangas, Maleta, \& Ashorn, 2015a). In that case, becoming nonstunted reflects adequacy of the diet and hence also micronutrient status improvement. While crossing the threshold from being stunted may not in general change the child's height dramatically (de Onis \& Branca, 2016), there is limited knowledge about child growth transitions of individuals between age intervals to inform the benefits and where stunting is likely to remain permanent (Teivaanmäki et al., 2015a). Furthermore, since the 'stunting syndrome' increases morbidity and mortality (Prendergast \& Humphrey, 2014), it is a valuable endeavor to look at which children are likely to have become nonstunted and those who are likely to remain stunted (HAZ $<-2 \mathrm{SD}$ ) and the factors associated with these states. Luo and Karlberg (2000) in an earlier study observed that deficits in height can reduce over time if determinants of stunting are removed.

Yet, the debate on measurement, terminology and outcome interpretation of linear growth or deficts is unresolved. Widely varying terms describing the changes in linear growth have emerged. For example, terms such as "transition" "nonstunted" (Elizabeth A Lundeen et al., 2014; Teivaanmäki et al., 2015a) or "normality" (de Onis \& Branca, 2016), or described as "catch up growth" (Crookston, Penny, Alder, Dickerson, Merrill, Stanford, et al., 2010) exist in literature and some are contested (Jef L Leroy, Marie Ruel, Jean-Pierre Habicht, \& Edward A Frongillo, 2015). Therefore, measuring height deficts or 
catch up growth is beyond the scope of this dissertation. Rather the focus of this dissertation is on the proportion of children who remain on either side of the threshold and the likelihood of reduced risk to illness and death. Further, the focus is to establish under what conditions transitions occur. For clarity, in this dessertation, the terms 'growth transitioning' and 'nonstunted' are preferred and used interchangeably to reflect a change in the children's primary outcome using absolute $\mathrm{z}$ score scales (HAZ), if above the threshold, similar to previous studies (Crookston, Penny, Alder, Dickerson, Merrill, Stanford, et al., 2010; Elizabeth A Lundeen et al., 2014; Raaijmakers et al., 2017; Teivaanmäki et al., 2015a).

Most research argues that maternal education is the single most important factor explaining differences in child nutrition outcomes, (Black et al., 2008; Marshall \& Makate \& Makate, 2016; Miller \& Rodgers, 2009; W Henry Mosley \& Lincoln C Chen, 2003). Maternal education is documented to enhance behaviors and decisions. Educated women have greater knowledge on health risks to stunting (Frost, Forste, \& Haas, 2005), have the ability to communicate with health-care providers (Chou, Liu, Grossman, \& Joyce, 2010; Grepin \& Bharadwaj, 2015; Güneş, 2015) are socio economically better off and less likely to live in poverty (Grossman, 2006). Therefore, improvements in maternal education may have larger and long term payoffs in terms of child wellbeing than those that focus on health care only (Chou et al., 2010). In addition, educated mothers invest more time in prenatal care and make more informed dietary choices (Desai \& Alva, 1998; Güneş, 2015).

But, claims of correlation between mother's education and child health have previously been contested. Much of the previous literature does not establish causal pathways between education and child stunting in the developing world where stunting is a major problem (Makoka, 2013; Phiri, 2014). Only if education has a causal impact can investing in education reduce stunting. Furthermore, critics cast doubt that the causal relationship is not significant in all developing countries (Desai \& Alva, 1998; Chou, Liu, Grossman, \& Joyce, 2010). 
To conclude this section, the background section discussed the stunting problem, its scale and its consequences. The background further highlighted the empirical debates on the relationship between diet and maternal education on stunting, as well as the debate on child growth transitions. The next sections proceeds as follows: Section 1.2 presents the research questions; 1.3 describes the study relevancy and research gaps; 1.4 presents the setting of the study and 1.5 outlines the dissertation structure.

\subsection{Setting of the study}

This dissertation uses data from Malawi to answer the questions raised below. Malawi, a low-income country in Sub-Sahara Africa, is the study context. It has a high rate of stunting, and has had an education reform policy since 1994 favoring girls, thus providing a natural experiment for studying the causal impact of the increased education of mothers on the stunting of their offspring. In 2017, about 1.4 million children under 5 years (37\%) were stunted (UNICEF, 2017), which is classified by WHO as a severe public health problem (WHO, 2006). Another relevant aspect to this study setting are consumption patterns in Malawi. The diet is dominated by staples which provides $70 \%$ of the calories and, therefore, there is limited diversity from other quality foods (Jan Meerman, 2014). The most likely cause of growth failure is likely due to the lack of adequate nutrients.

However, there are national policies that support the improvement of both nutrition and education in Malawi. This is evident as the Malawi government currently has strong political will to positively impact nutritional status and has set ambitious targets for reducing stunting (Meerman, 2008). For example, in 2011, the Malawi government engaged in unprecedented efforts to reduce the decades' long stunting problem by scaling up a range of nutrition actions and adopting a delivery approach that packages high impact nutrition interventions together as part of the nutrition strategy. Although Malawi has had a gender-focused education policy since the 1994 education reforms, promoting the enrollment of girls by waiving fees and allowing pregnant girls 
to return to school after giving birth, the "thinning down" of enrolment and the lack of school progression for girls is a major concern (Chimombo et al. (2000).

With these considerations in mind, this dissertation aims to investigate the extent to which local diets and maternal education are predictive of child linear growth and their short and long-term contribution to stunting. The dissertation also seeks to assess the factors contributing to childhood growth transitions in Malawi.

\subsection{Theoretical and Conceptual framework}

Optimal child nutrition and development is determined by dietary, behavioral, and health determinants, influenced by underlying food security, caregiving resource, and environmental conditions (Gelli et al., 2017). Our study is inspired by the Mosley Chen child survival theory (W. H. Mosley \& L. C. Chen, 2003). The child survival theory predicts that child growth or failure is a cumulative process influenced by a combination of biological, household and environmental conditions. However, in literature the causes of stunting are nonlinear and interrelated (Wamani et al., 2006). To illustrate, the thesis adopts the UNICEF conceptual framework in order to explore determinants of stunting (UNICEF, 1990). The UNICEF framework encompasses the theories and stands out in providing a multilevel framework for understanding concepts of both proximal and distal factors. In the conceptual framework, the causes of stunting are complex. Proximal determinants of linear growth are adequate dietary intake and good health (lack of disease), which in turn themselves are influenced underlying and basic factors at various levels (Black et al., 2008). Depending on the context, common factors that determine child linear growth are education of mother (Semba et al., 2008), wealth status (Frongillo, de Onis, \& Hanson, 1997), water and sanitation (Fink, Günther, \& Hill, 2011), and child birthweight and age (Stevens et al., 2012). The interplay of above factors is detailed when answering each of the sub- research question in the chapters. 


\subsection{Research questions}

This dissertation studies local dietary patterns, maternal education and factors that explain linear growth transitions in children between the ages of 6-59 months. Assessing determinants of stunting requires the exploration of a complex structure and a large number of potential variables at various levels (Remans et al., 2011, Stevens et al., 2012). The research questions are aligned with four separate chapters in the dissertation.

The first research question follows arguments advanced on the role of diet in linear growth. Scholars posit that diet is a central pillar that supports linear growth in resource poor settings during complementary feeding, (Adelheid W Onyango, Borghi, de Onis, Casanovas, \& Garza, 2013). Typically, non-diverse diets consist of staples, legumes and vegetables, often monotonous with inadequate nutrients to promote child growth. Since suboptimal child feeding practices in early childhood is one of the main factors leading to rapid failure in linear growth, the first question in this research is:

Q1: What is the evidence on the impact of locally available foods, especially Animal Source Foods (ASF) on stunting?

The second question addresses inconsistencies in the results of the association between consumption of each food group and its contribution to linear growth. It is argued that in most cases the relationship has not clearly been demonstrated in various contexts (James \& Palmer, 2015). As a result, it is commonly assumed that dietary inadequacy is such a common occurrence in resource poor settings that it cannot be addressed by local diets alone without nutrient supplements (Schönfeldt \& Gibson Hall, 2012). With increasing emphasis on local diets and food based approaches for healthy diets, it is necessary to define in each context the set of foods (and possibly food groups) that can contribute to improving dietary quality. The use foods or food groups is one of the valid methods for assessing overall diet quality (Kant, 1996). A major advantage of using food groups in studying consumption patterns is 
that it shows which food items from the local diet promote child growth, which can be useful in designing dietary guidelines. With a focus on quantity and frequency of consumption, the second question is therefore:

Q2: What is the association between the quantity and frequency of the consumption of food groups and linear growth?

Given the growing evidence suggesting that children go through growth transitions or shifts in childhood and mid adulthood (Martorell, Khan, \& Schroeder, 1994; Prentice et al., 2013; A. D. Stein et al., 2010), the third question explores the phenomenon of transitions in stunting. Unlike, the aforementioned studies, other studies place emphasis on defining catch-up growth between the ages of 12-59 months and in older children (Hirvoven 2014; Coley et al 2006) or a study on increases in height for age deficits (E. A. Lundeen et al., 2014). Evidence is contradictory suggesting that growth transitions are unlikely in poor settings (Jef L. Leroy, Marie Ruel, Jean-Pierre Habicht, \& Edward A. Frongillo, 2015). One of the limitations with this explanation is that it does not explain what determinants are most likely to affect child growth. Hence the third research question is:

Q3: What are the probabilities of transitioning between stunting and nonstunting in early childhood, and what are their determinants?

Finally, though existing research recognizes the critical role of maternal education in child care and feeding practices, past empirical research in Malawi has focused on the effects of maternal education on child mortality (Marshall Makate, 2016) or has explored correlations and not the impact between maternal education and stunting (Chirwa \& Ngalawa, 2008; Makoka, 2013). Given the lack of causal studies assessing the effects of maternal education on child linear growth in Malawi and the limited number of causal studies in sub-Saharan Africa (Keats, 2016), the fourth and final research question is: 
Q4: Does higher maternal schooling reduce stunting among children?

The main outcome variable is stunting expressed by a child's height for age $\mathrm{Z}$ score (HAZ). The World Health Organization defines stunting as HAZ <-2 (WHO, 2006). In economic terms, stunting is the most single important composite indicator of nutrition and a marker of economic development (Hoddinott, Alderman, et al., 2013). Growing evidence suggests that preventing stunting reduces the number of children who become acutely malnourished (Ruel Marie, 2008). Moreover, stunting in early childhood is a strong indicator of child well-being because it is associated with morbidity and mortality risk, and learning capacity and productivity. Throughout the thesis, stunting or linear growth are the main outcome measure.

This dissertation utilizes quantitative methods in answering the research questions to generalize findings and to establish cause and effect. Table 1.1 shows the unit of observations, sample size and methods used to measure linear growth outcomes. 
Table 1.1: Unit of observation, method, and empirical chapter outcomes measures

\begin{tabular}{|c|c|c|c|c|}
\hline Chapter & $\begin{array}{l}\text { Unit of } \\
\text { observation }\end{array}$ & Sample size & Methods & Outcome measures \\
\hline 2 & Articles & 4 & $\begin{array}{l}\text { Systematic } \\
\text { review } \\
\text { (PRISMA) }\end{array}$ & $\begin{array}{l}\text { Linear growth, } \\
\text { stunting, morbidity, } \\
\text { micronutrient } \\
\text { deficiencies }\end{array}$ \\
\hline 3 & $\begin{array}{l}\text { Households } \\
*\end{array}$ & 514 & $\begin{array}{l}\text { Random Effects, } \\
\text { Bivariate, } \\
\text { Multivariate } \\
\text { regressions }\end{array}$ & $\begin{array}{l}\text { Child linear growth, } \\
\text { stunting }\end{array}$ \\
\hline 4 & Children & 530 & $\begin{array}{l}\text { Markov } \\
\text { transition } \\
\text { model, Probit } \\
\text { and marginal } \\
\text { effects }\end{array}$ & $\begin{array}{l}\text { Child linear growth, } \\
\text { growth transition (non- } \\
\text { stunted), stagnation or } \\
\text { worsening, }\end{array}$ \\
\hline 5 & $\begin{array}{l}\text { Treated and } \\
\text { Control } \\
\text { cohorts of } \\
\text { mothers }\end{array}$ & $\begin{array}{l}\text { Women } \\
(\mathrm{n}=10,086) \\
\text { Children } \\
(\mathrm{n}=14,190)\end{array}$ & $\begin{array}{l}\text { Regression } \\
\text { Discontinuity } \\
\text { Design, IV } \\
\text { Regressions }\end{array}$ & $\begin{array}{l}\text { Child linear growth, } \\
\text { stunting, }\end{array}$ \\
\hline
\end{tabular}

Notes: * proxy for child consumption. Sample for household consumption is 514 due to missing or implausible values. Missing values tabulated in Table A4.1. Nonstunted is defined as $\mathrm{HAZ}>2$.

\subsection{Relevance and research gaps}

The study contributes to the literature in four ways.

First, at a global level, the explicit inclusion of stunting as an indicator in the Sustainable Development Goals (SDGs, 2015) lends relevancy to this research topic. Since global agendas are "aspirational" and require contextualizing, this dissertation addresses identified gaps in the understanding of the interplay between diet, child growth transitions, maternal education and will contribute to evidence based stunting solutions in Malawi.

Secondly, this dissertation draws on various data sources; the Malawi Welfare Monitoring Survey panel dataset, the Malawi Demographic Health Survey 
(MDHS) and a systematic review of the available literature. Both the quantitative surveys (DHS and Malawi Welfare Monitoring Survey panel dataset) are nationally representative and allow for measurement of anthropometric and social economic indicators. The panel data further allows for the measurement of food quantities consumed. However, the minimum amounts of animal source foods (ASF) sufficient to prevent stunting, and the frequency at which they should be consumed, are still unclear. This dissertation attempts to fill this gap.

Thirdly, theories predict that risk factors such as lack of inputs - inadequate diet, illness or time - can depreciate health (Grossman, 1972). Much uncertainty still exists about the predictive nature of the proximate and distal determinants of growth transitions (Teivaanmäki et al., 2015a). This research seeks to examine the determinants of childhood growth transitions. The findings on child growth transitions generated by this study can provide as a base for future studies in determining growth trajectories for children below the age of five years. This study is the first to analyse age growth patterns using a transitions model. The study takes advantage of nationally representative panel data that combines socio economic and consumption modules. The findings can also inform evidence based food and nutrition strategies given the focus on identifying the underlying determinants of stunting among young children under 5 years.

Finally, existing research has paid little attention to the impact of female education on stunting in developing countries compared to work done in examining the impact of female education on child health and mortality outcomes (Grepin \& Bharadwaj, 2015; Marshall \& Makate \& Makate, 2016). In addition, much of the previous literature does not establish causal pathways between education and child stunting (Makoka, 2013; Phiri, 2014). Apart from one study from Keats (2014), in Uganda, there is a general lack of research to date on the causal effects of maternal education on child linear growth in subSahara Africa and particularly in Malawi. To my knowledge, this is the first analysis to utilize the education policy reform of Malawi to determine the 
impact of maternal education on child linear growth. This analysis exploits the discontinuity in age exposure to the education reform to measure causal impacts of between maternal educations on child stunting. Therefore, the study fills this gap in literature.

\subsection{Outline of the dissertation}

Chapter 2 systematically reviews the literature on the impact of animal source food on a local non-diverse diet. The reviewed randomized Controlled Trials (RCTs) provided a food based supplement to a local diet. Findings on impact of each food item and the impact on the main outcome indicator are presented.

Chapter 3 examines the relationship between food groups and the importance of quantity and frequency of consumption on linear growth. The chapter describes the per capita quantity consumption trends and examines the association between food groups and linear growth in the Malawi context. The chapter demonstrates how the interactions between food groups with age, wealth and education are associated with linear growth.

Chapter 4 looks at stunting transition dynamics. Patterns of growth shifts above the stunting threshold, deterioration or stagnation from baseline in 2010 and to follow up in 2013 are measured using a Markov model (Odongo, Bisaso, Kitutu, Obua, \& Byamugisha, 2015). Using panel data that measures the same children over time, this chapter presents evidence on the potential for bidirectional transitioning.

Chapter 5 explores the causal effect of maternal schooling on child linear growth. The analysis exploits the 1994 free primary education reform as a natural experiment to test the hypothesis that higher maternal education levels improves child growth patterns. In particular, mechanisms through which maternal education influences child growth are explored. 
Chapter 6 presents cross cutting concluding statements drawn from the five chapters. The findings are briefly discussed and policy considerations are suggested. The chapter also discusses the strengths and limitations of the dissertation and proposes areas for future research. 


\section{CHAPTER 2: The Impact of Supplementing Diets with Local Animal Source Foods on Stunting in Children Aged 6-59 Months in Sub Saharan Africa: A Systematic Review.}

This chapter draws upon:

Mutinta Hambayi, Nyasha Tirivayi, Groot W, The Impact of supplementing diets with local animal source foods on stunting in children aged 6-59 months in Sub Saharan Africa: A Systematic Review. Submitted for publication. 


\section{Abstract}

Evidence is mixed on local food groups most effective in preventing stunting in resource-poor settings. The main focus of this literature review was to assess whether supplementing diets with ASF improved linear growth and/or reduced stunting among children aged 6-59 months.

We used the Preferred Reporting Items for Systematic Reviews and MetaAnalysis (PRISMA) flow diagram to guide the search for relevant literature. Studies assessing fortified foods or food used for treating malnutrition were excluded.

The four interventions supplemented diets with: (i) milk or milk and eggs $(\mathrm{n}=2)$; (ii) caterpillar powder $(\mathrm{n}=1)$; and (iii) meat $(\mathrm{n}=1)$. Studies instructed caregivers to add milk and caterpillar powder to cereal porridge $(n=3)$. All studies provided child feeding messages promoting consumption of the usual family diet. In one intervention, the addition of milk to cereal porridge improved linear growth unlike the consumption of a meat supplement. In addition, interventions that used milk improved weight for height and weight for age, while supplementing with caterpillar powder reduced anemia.

Interventions that supplement diets with milk show the most potential for improving linear growth and other nutritional outcomes. However, further research is needed as few intervention studies were available. 


\subsection{Introduction}

The role of dietary diversity, defined as the number of different foods eaten over a given period of time, in relation to nutrition is well established(Arimond \& Ruel, 2004). However, the role of local diets in preventing stunting is debated (Theron et al., 2007). Stunting is a syndrome characterized by being too short for age due to failure to reach one's genetic potential in linear growth (Frongillo et al., 1997). It starts during conception and can continue after birth (Victora, de Onis, Hallal, Blössner, \& Shrimpton, 2010). Height-for-age is one of the measures used to detect stunting (WHO, 2006). Stunting affects 155 million children globally (UNICEF, 2017) with 90\% of the global burden of stunting found in 34 countries - of which 22 are in SSA.

In SSA, stunting has been endemic and chronic for decades, affecting four in every ten children (World Bank, 2010). The negative effects of stunting can last a lifetime, affecting health, schooling abilities and economic productivity in adulthood (Shekar et al., 2016). Prevention of stunting in early childhood is therefore important for human and economic development (Hoddinott, Behrman, et al., 2013). Generally, there is concern that policy frameworks and programs have failed to prevent stunting in Africa, and stunting remains a major public health problem in low-income settings where food insecurity is a foremost challenge.

The peak incidence for growth faltering is during complementary feeding among children 6-24 months of age due to their high demand for nutrients (Arimond \& Ruel, 2004; Meenakshi et al., 2010). Complementary feeding refers to timely introduction of safe, adequate nutritional foods in addition to breastfeeding at six months of infant age(Lassi, Das, Zahid, Imdad, \& Bhutta, 2013). However, complementary foods for children from local diets are often staple based, bulky and monotonous with limited nutrients to promote growth(Adelheid W. Onyango, 2003). This has led to assertions that dietary inadequacy is a common occurrence in resource poor settings such that linear growth cannot be achieved from such diets alone without nutrient 
supplements (Schönfeldt \& Gibson Hall, 2012). However, these explanations tend to overlook the fact that there is no consensus on what constitutes an ideal food based intervention for preventing stunting (Theron et al., 2007).

To improve diets, several strategies that include fortified complementary foods or providing food based supplementary feeding are promoted. Several studies reccommend supplementing with foods of animal origin, including worms and insects as sources of vital nutrients for child growth in diets. It however remains unclear what the minimum amounts of animal source foods (ASF) are required to prevent stunting are and what frequency they be consumed. Supplementary feeding, defined as the provision of extra food to children or families beyond the normal ration of their home diets, is an intervention aimed at improving the nutritional status or preventing the nutritional deterioration of the target population(Sguassero, de Onis, Bonotti, \& Carroli, 2012).

Although there is evidence that supplementary feeding has largely been implemented for recovery from malnutrition, the real impact on child linear growth remains unknown(Sguassero et al., 2012). While the majority of interventions focus on fortified food supplements, it is arguably not yet clear whether such supplements compared to foods items, are the solution and only guarantee of achieving nutrition security given that nutrition also involves other underlying factors such as child care practices, water and sanitation.

This study adds to the existing literature by highlighting the potential foods that promote linear growth and the need to combine diet with a set of interventions that control other underlying determinants, which if not addressed can be mutually reinforcing in causing stunting. 


\subsection{Methods}

\subsubsection{Search strategy and information sources}

The main focus of this literature review was to assess whether supplementing diets with ASF improved linear growth and/or reduced stunting. The flow chart of evidence search and selection is shown in Figure 2.1. We use the Preferred Reporting Items for Systematic Reviews and Meta-Analysis (PRISMA) flow diagram to guide the search for relevant literature (see Table 2.1). We searched relevant databases and search engines with literature from peer reviewed journals. The primary search of literature was conducted in PubMed and thereafter the Cochrane database of systematic reviews, MEDLINE, Wiley, Web of Science and Google Scholar. The search covered all title qualifying publications from 2000 onwards. The year 2000 was selected as the cut-off because stunting began to emerge as a research topic around that time. The following key words or key word phrases were used: randomized controlled trials, quasi-experimental, complementary feeding, prevention stunting, local diets, meat or milk, or fish or eggs or insects, children, underfive or 6 to 59 months, child growth, supplementation and Africa. Both freetext and subject headings were searched in the Medical Subject Headings (MeSH) database (Lefebvre, Manheimer, \& Glanville, 2008). 
Figure 2.1. Flow chart of evidence search and selection

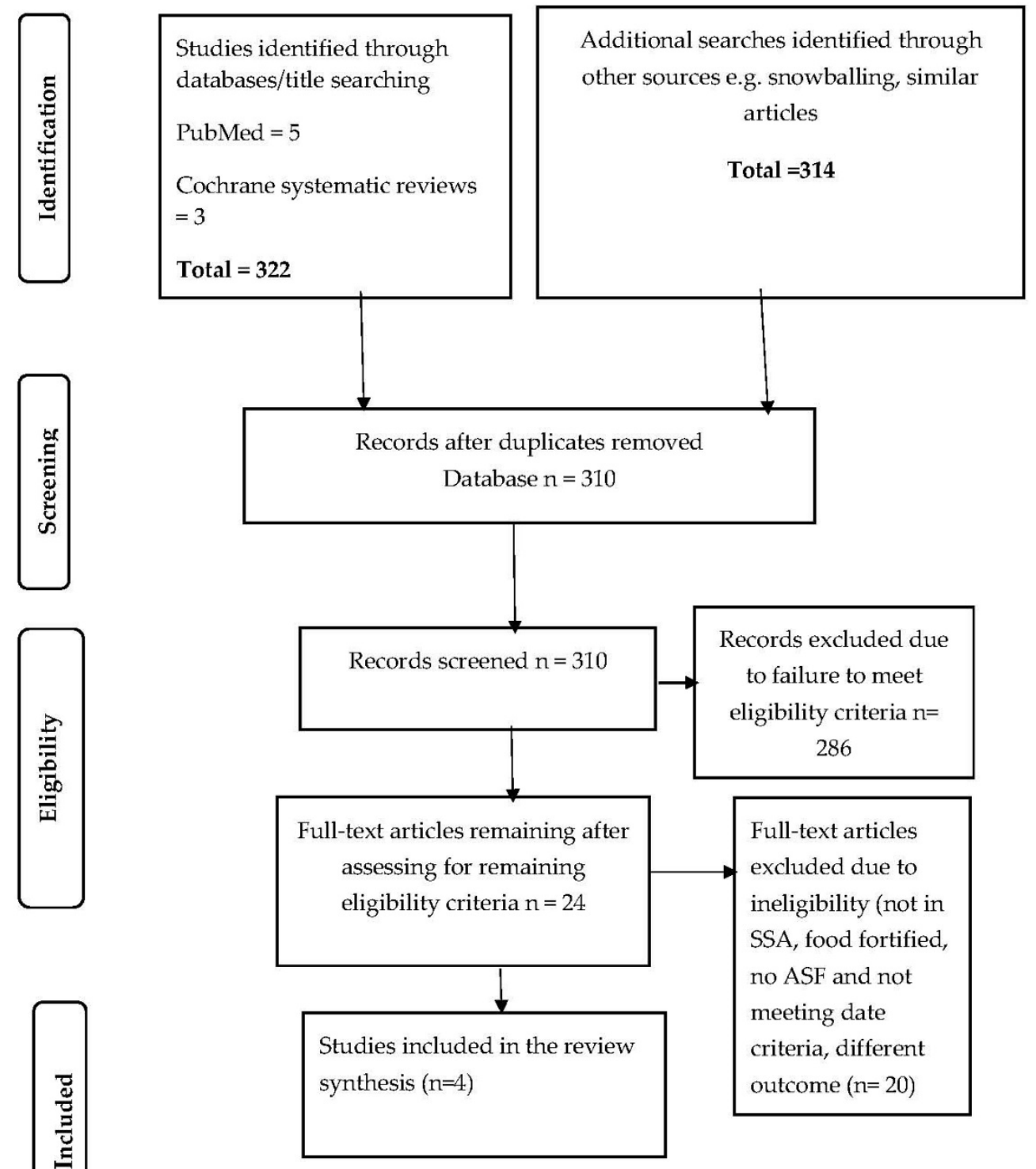


We utilized a snowball technique whereby one selected study led to a relevantto-criteria heading or topic and their reference lists were used to identify relevant studies (Figure 2.1). The search for literature was followed by the screening of abstracts and full text considerations (Jenkins, Shanks, \& Houghtaling, 2015). Key information on study design, characteristics, outcomes and results was extracted using a search phrases in Table 2.1. Data extraction was carried out and verified independently.

Table 2.1: Primary PubMed Search January 2017

\begin{tabular}{|c|c|c|}
\hline Search & Query & $\begin{array}{l}\text { Items } \\
\text { found }\end{array}$ \\
\hline$\# 16$ & Similar articles for PubMed (Select 22152430) & $\underline{93}$ \\
\hline$\# 15$ & Similar articles for PubMed (Select 25631295) & $\underline{113}$ \\
\hline$\# 14$ & Similar articles for PubMed (Select 22952176) & $\underline{108}$ \\
\hline$\# 11$ & $\begin{array}{l}\text { Search randomised controlled trials stunting } \\
\text { prevention diet meat }\end{array}$ & $\underline{5}$ \\
\hline$\# 10$ & $\begin{array}{l}\text { Search (randomized controlled } \\
\text { trial"[Publication Type] OR "randomized } \\
\text { controlled trials as topic"[MeSH Terms] OR } \\
\text { "randomised controlled trials"[All Fields] OR } \\
\text { "randomized controlled trials"[All Fields]) AND } \\
\text { ("growth disorders"[MeSH Terms] OR } \\
\text { ("growth"[All Fields] AND "disorders"[All } \\
\text { Fields]) OR "growth disorders"[All Fields] OR } \\
\text { "stunting"[All Fields]) AND ("prevention and } \\
\text { control"[Subheading] OR ("prevention"[All } \\
\text { Fields] AND "control"[All Fields]) OR } \\
\text { "prevention and control"[All Fields] OR } \\
\text { "prevention"[All Fields]) AND ("diet"[MeSH } \\
\text { Terms] OR "diet"[All Fields]) AND } \\
\text { ("meat"[MeSH Terms] OR "meat"[All Fields])) } \\
\text { Schema: all }\end{array}$ & \\
\hline
\end{tabular}




\subsubsection{Inclusion and exclusion criteria}

Only studies from SSA were included in order to ensure the review contained similar local food contexts (Paul et al., 2011), to account for the peculiar circumstances of the high disease burden in Africa known to contribute to stunting (Zulfiqar A. Bhutta et al., 2008), and to strengthen the predictive power of theories by applying the cultural relevancy. The inclusion and exclusion criteria were:

- Study design: only randomized controlled trial (RCTs), quasiexperimental, or randomized comparative studies evaluating supplementary feeding in comparison to a control group or alternative feeding were included (Sguassero et al., 2012). We excluded observational studies in order to strengthen the robustness of our findings (Remans et al., 2011).

- Animal source foods: For the purpose of this study, we consider locally available ASF to comprise milk and milk products, meat, eggs, poultry, fish and small birds (Ayele \& Peacock, 2003). Insects such as worms, caterpillars, which are part of local diets in many SSA countries, are also considered a food of animal origin (Bauserman et al., 2015).

- Statistical analysis: We only selected studies that employed quantitative and econometric methods in analysis such as logistic regressions. Therefore, descriptive studies were not included.

- Intervention and target group: Studies met the criteria if they targeted children aged 6-59 months as the unit of analysis, ASF were provided as part of complementary feeding and stunting or linear growth were a primary or secondary outcome of the intervention. We included studies that compared non-fortified foods with fortified foods, although only the results related to the non-fortified foods are reported here, as this study assesses the effect of typical complementary foods on stunting (K. G. Dewey \& Adu-Afarwuah, 2008). Studies were excluded if they assessed minerals and vitamin supplementation, 
fortified foods, fortified ready- to-use food products, and supplements used in the treatment of malnutrition.

The search was further supplemented by accessing systematic reviews and published papers where the treatment and outcomes met the inclusion criteria. This gave us confidence that we exhausted both saturation and chronology in the referenced literature. We used three earlier nutrition systematic reviews to close any gaps and cross check study overlaps, an indication of iteration in the search process (Moher, Liberati, Tetzlaff, \& Altman, 2010). We found a review by K. G. Dewey and Adu-Afarwuah (2008) that searched for studies from 1999 to 2008 and included seven efficacy trials, out of which six were from SSA. All six studies were excluded, five for using fortified supplements (AduAfarwuah et al., 2007; Kuusipalo, Maleta, Briend, Manary, \& Ashorn, 2006; Obatolu, 2003; Oelofse et al., 2003; Owino et al., 2007) and one for not meeting the year criteria and for using fortified supplements (Lartey, Manu, Brown, Peerson, \& Dewey, 1999). In the review by Sguassero et al. (2012), one out of the eight studies published between 2005 to 2012 was from SSA. The study from SSA was also excluded in our review for using fortified food supplements. The most recent systematic review covered eight RCTs from developing countries. These studies were excluded since they were all conducted outside of our geographical focus of SSA (Lassi et al., 2013)

\subsubsection{Outcomes}

The framework for analyzing nutrition outcomes in the review follows WHO classification guidelines (WHO, 2006) The primary outcomes are height gain expressed in cm, length- or height-for- age-z score (LAZ/HAZ) and stunting. These outcomes were measured at baseline and at the end of interventions or quartely intervals. Other anthropometric and health indicators such as weightfor- height z score (WHZ), underweight (WAZ), anaemia and morbidity are also described if studies reported them. Prevalence rates of undernutrition are standard deviations of $<-2$ from the $\mathrm{WHO}$ reference growth standards $(\mathrm{WHO}$, 2006) 


\subsubsection{Methodological quality appraisal}

We evaluated the methodological strength of the studies at two levels. First, we followed the quality appraisal criteria proposed by (Brannon, Taylor, \& Coates, 2014; Moher \& Tricco, 2008). The criteria assesses whether a study has:

1. A clear study objective, answerable question and protocol,

2. Prespecified eligibility inclusion criteria,

3. Reproducible methodology for stated evidence,

4. Critical statement of findings and their validity, and

5. Structured presentation of findings

Secondly, the quality of the studies was assessed using a grading methodology that accounted for: 1) selection bias, 2) study design, 3) confounders, 4) blinding, 5) data collection methods, and 6) participation rate. Risk of bias was assessed for all studies using the following ratings: $1=$ low, $2=$ medium and $3=$ high (Oxman \& Group, 2004). Well-designed RCTs were considered to be of high quality. Quasi-experimental studies were deemed to be of medium quality, although this depended on study design and confounders. Randomized comparative studies were considered to be of medium quality. These studies randomly assigned different types of supplements and compared their relative impacts. The quality assessment and ratings were verified independently.

\subsection{Findings}

\subsubsection{Methodological quality of studies}

We found 322 titles in our initial search of which only four met the inclusion criteria (Figure 2.1). The four studies investigated a combined total of 930 children in three African countries. Three of the studies were published in 2012 and one was published in 2015. Regarding the study design and causal inference, all studies were prospective, two of the studies were RCTs 
(Bauserman et al.; Nancy F. Krebs et al., 2012), one was quasi-experimental (Tomedi et al., 2012) and one was a randomized comparative study (Long et al., 2012). All the studies reported statistically significant effects, either as mean effects or as changes in both primary and secondary outcomes over the duration of the supplementation. Effects were indicated by p-values or percentage changes. Studies also reported differences between treatment and comparison groups. The results are, therefore, not directly comparable but give a plausible general indication of the observed effect. Risk of bias was low in the RCTs which were rated as high quality. Risk of bias was considered to be medium in the quasi-experimental and randomized comparative studies.

\subsubsection{Study charateristics}

The results are presented in a narrative form. Table 2.2 summarizes the characteristics and findings of the selected empirical studies. Characteristics include author, type of study, site, age group, type of ASF, duration of intervention, and growth outcomes. The sample size ranged from 81 to 532 children (Nancy F. Krebs et al., 2012; Long et al., 2012). Baseline characteristics for treatment and control groups were similar within the 6-59 month age group in each study. The target group for the interventions were children aged 6-59 months. Interventions recruited children of ages ranging from six months (Nancy F Krebs et al., 2012) to 11 months (Long et al., 2012). All interventions lasted for a time between 5 to 12 months, with an average duration of 8.7 months. Two studies had mean enrollment ages of 6 and 14 months respectively (Nancy F. Krebs et al., 2012; Tomedi et al., 2012). We found that at enrolment there were high or severe stunting rates among children (Nancy $\mathrm{F}$ Krebs et al., 2012; Tomedi et al., 2012) or ill (Bauserman et al., 2015; Long et al., 2012). Over $90 \%$ of the children were still breastfeeding by age of 24 months in all four studies. 


\subsubsection{ASF used in supplementation}

Different ASF were used in the interventions. Tomedi et al. (2012) povided milk and eggs and five other non-ASF (Table 2.2). The other three studies each provided milk (Long et al., 2012), meat (Long et al., 2012), a precooked beef product (Nancy F Krebs et al., 2012) and a caterpillar powder (Bauserman et al., 2015). Three studies instructed care givers to add the ASF to a maize, rice or millet porridge (Bauserman et al., 2015; Long et al., 2012; Tomedi et al., 2012). The precooked beef was crumbled into boiled water and consumed as a puree or added to usual child food (Nancy F Krebs et al., 2012). The ration sizes ranged from $30-50 \mathrm{~g}$ for meat, eggs and caterpilar powder, to approximately $121 \mathrm{~g}$ of milk per child per day. Caregivers in all studies received nutrition counseling to enhance knowledge on dietary diversity, health and sanitation and to encourage the feeding of children using locally available foods. Information on hygienic practices was also given. Compliance was monitored in all the studies by home visits, sachet counting and 24 hour recall of food intake.

\subsubsection{How the food supplementation was done}

All studies reported that complementary feeding was typically non-diverse and reliant on starchy foods at baseline. Similar to earlier reviews, the main intervention strategy therefore was to provide complementary ASF, and determine whether daily intake improved child growth (K. G. Dewey \& AduAfarwuah, 2008). Other objectives were to improve micronutrient status and energy intake (Tomedi et al., 2012). We found that the location for and regularity of ASF supplementation differed across the four studies. One study fed children on a designated feeding site, for five days per week (Long et al., 2012). In the other three studies, food items were prepared and consumed at home (Bauserman et al., 2015; Nancy F. Krebs et al., 2012; Tomedi et al., 2012). Of these three, two provided pre-packed daily rations delivered weekly while one study distributed monthly food rations (Tomedi et al., 2012). 


\subsubsection{Effect on child growth}

All four studies measured child growth either as height gained in centimeters, linear growth (LAZ/HAZ) and /or as stunting rates. Outcomes were measured at quarterly intervals (Bauserman et al., 2015; Nancy F. Krebs et al., 2012; Long et al., 2012) or at baseline and endline(Tomedi et al., 2012). Figures 4.1 illustrates trends in stunting by age in months and according to types of food given at baseline and endline. It shows that stunting was common at baseline and increased by endline, in three out of the four studies (Bauserman et al., 2015; Nancy F Krebs et al., 2012; Tomedi et al., 2012). However, in one study, stunting remained fairly high but stable (Long et al., 2012). The stunting rates at baseline and endline ranged from $26 \%$ to $69 \%$ compared to $26 \%$ to $71 \%$ in the control group. There were no signficant differences between groups.

Figure 2.2. Trends in stunting (percent)by age and the daily type of food provided

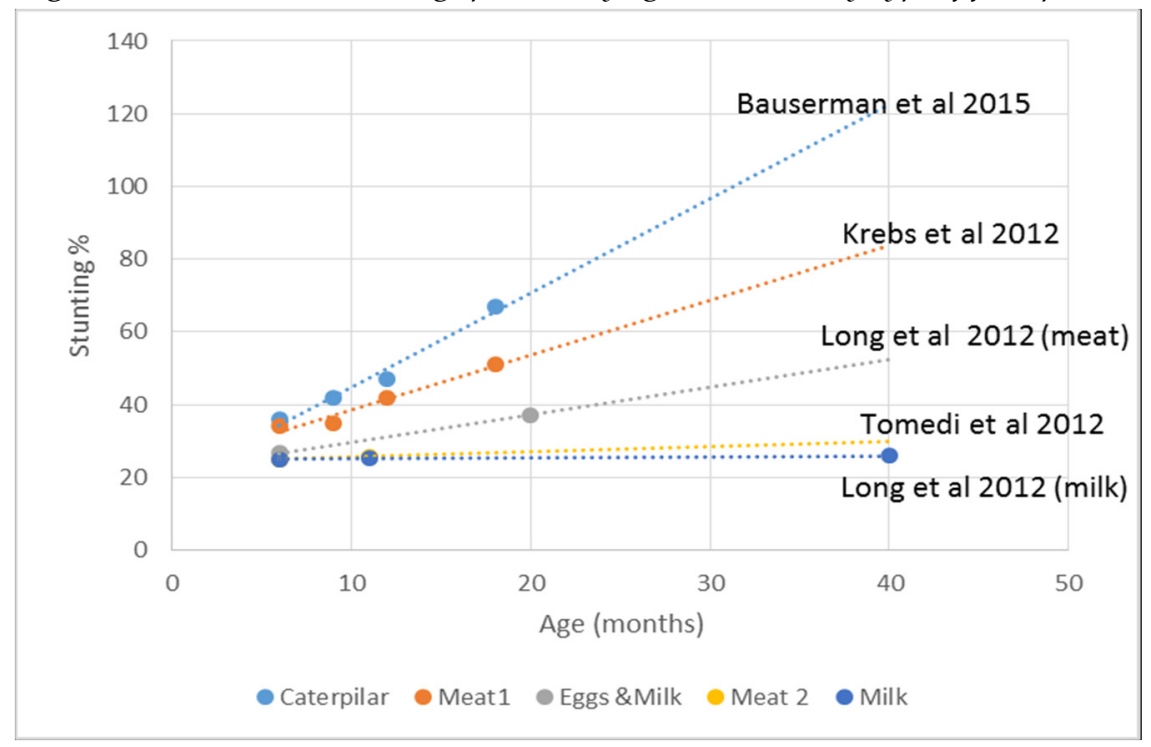

The studies found diverse effects of ASF supplements on child growth, micronutrients and morbidity outcomes. Milk significantly improved child growth HAZ in Long et al. (2012) study (milk, $0.32 \pm 309$; meat, $0.15 \pm 321$; plain porridge, $0.25 \pm 0.034$ ) but had no impact in another study (Tomedi et al. (2012). However, in both studies WHZ, WAZ, and mid upper arm circumference 
(MUAC), there were significant higher in the intervention group compared to the control groups (Long et al., 2012; Tomedi et al., 2012). Furthermore, Tomedi et al. (2012) found significantly fewer wasted and underweight children in the intervention group than in the control group $(0 \%$ v. $8.9 \%$ $\mathrm{P}<0.0001$ : $6.3 \%$ v.23\%; $\mathrm{P}<0.0001)$. Similar to other studies, maternal characteristics of education and height were associated with significant changes in length z scores (Long et al., 2012; Tomedi et al., 2012).

Interventions that used meat supplements had no signficant impact on height after five to 12 months duration (Nancy F. Krebs et al., 2012; Long et al., 2012). In one of them, stunting (LAZ<-2 zscore) increased from 33\% to 50\% (Long et al., 2012). The impact of the meat supplements on LHZ and LAZ were inconsistent or modest (See Table 2.1). After one year, the intervention that used caterpillar powder had no impact on height or weight.

\subsubsection{Micronutrient outcomes}

Only two studies reported micronutrient outcomes. The results show contrasting effects. The precooked beef supplement resulted in a modest decrease in anaemia but significant iron deficiency effect. Meanwhile, the caterpilla powder supplement increased haemoglobin, reduced anaemia by 24 percentage points but ferritin was lower in the intervention group.

\subsubsection{Morbidity}

Illness among children was common across studies. Moderate to severe mobidity was reported at $25 \%$ and $58 \%$,respectively (Long et al., 2012). There were no differences in illnesses between groups in two studies (Nancy F Krebs et al., 2012; Tomedi et al., 2012). while less morbidity observed in the caterpillar study group was $44 \%$ versus $66 \%$ in control(Bauserman et al., 2015). 


\subsection{Discussion}

\subsubsection{Main findings}

The review identified interventions that supplemented local diets with ASF on stunting among children 6-59 months. The review found that few studies have been designed to capture the effect of non fortified food supplements in Africa, as previously observed especially (Daphna K Dror \& Lindsay H Allen, 2011; Sguassero et al., 2012). Although ASF are perceived to be a vital source of micronutrients necessary for growth, we found that only milk supplementation increased linear growth, in line with other findigs (Daphna K Dror \& Lindsay H Allen, 2011). Another study found that milk and eggs reduced wasting and underweight (Tomedi et al., 2012). Three of the four studies reviewed found no significant effects of meat on stunting and mixed effects on haemoglobin concentrations.

Support for the role of milk in enhancing linear growth is found in the literature, since milk has type I and particularly type II nutrients, which are the building blocks of tissue and are important for biochemical pathways (Daphna K Dror \& Lindsay H Allen, 2011). It is also plausible that milk may have had an effect among young children since it may have been a more familiar food in their diets compared to other ASF. Interestingly, the intervention period for the milk study was the shortest at five months and yet there were positive impacts (Long et al., 2012). One explanation may also be that the milk intervention by Long et al (2012) was delivered at designated feeding sites where intake was observed and monitored. The caterpillar and beef product interventions lasted 12 months but they had no impact on growth outcomes. The lack of effect by some ASF (meat) may also be explained in part by the fact that in some of the studies there were high levels of morbidity and stunting at the baseline.

In addition, it appears that the milk intervention studies that improved weight and linear growth enrolled children whose average age was higher than the 
other studies. For instance, the two milk interventions had mean enrollment ages of 11 months and 14 months, respectively (Long et al., 2012; Tomedi et al., 2012). It could be that breastfeeding in these older children was less in intensity than in the other studies with younger children, and that these older children were probably eating more of the supplements. This therefore raises more questions regarding the age at which ASF supplements could be effective. To our knowledge, one study in this review was the first ever to compare the effect of a single animal source food (meat) with that of fortified food blends (Nancy F. Krebs et al., 2012). However, neither the meat or fortified blend reversed progression to stunting (Bauserman et al.; Nancy F. Krebs et al., 2012; Tomedi et al., 2012).

Overall, we found that milk supplements showed the most potential in improving linear growth and reducing wasting and underweight unlike meat and caterpillar supplements which had no effects. The mixed evidence is consistent with results from previous reviews of various age groups in other developing contexts (Ali et al., 2013; K. G. Dewey \& Adu-Afarwuah, 2008; Mary \& Marie, 2004). Previous studies have also found mixed results when they examined the effects of supplementing diets with one or more local food foods of animal orgin (Darapheak, Takano, Kizuki, Nakamura, \& Seino, 2013; Theron et al., 2007). Others have suggested that post-natal measures of child growth may not be a sensitive indicator of growth due to other constraints that limit optimal growth especially height gain (Kathryn G Dewey \& Mayers, 2011). A body of literature argues that stunting is complex and may not be reversible (Adelheid W Onyango et al., 2013).

In addition, stunting may have different origins in diverse settings (Nancy F. Krebs et al., 2012). In one study (Tomedi et al., 2012), similar to other findings in Lassi et al. (2013), we also speculate that existing food insecurity and lean seasons could have influenced the effectiveness of interventions. In addition, although compliance was measured, rations consumed at home are often subject to sharing according to many cultural norms (Nancy F. Krebs et al., 
2012; Tomedi et al., 2012). Moreover, it is yet not determined how long such interventions should last in developing contexts.

\subsubsection{Policy implications}

Findings show that among the reviewed ASF interventions, milk supplements appear to have the most promise for child growth in sub-Saharan Africa. However, milk consumption is currently low, and declining in developing countries including sub-Saharan Africa (Daphna K Dror \& Lindsay H Allen, 2011). Strategies that promote milk consumption could include behavior change communucation that promote milk consumption for children. This could be combined with the expansion of dairy projects by rural households, including the production of milk from small ruminants such as goats and sheep. Yet, the promotion of milk consumption in children's diets is not without challenges. In the African context, cows are usually the main source of milk but are also an asset endowment that is beyond the reach of the poorest households. Furthermore, unless boiled, unpastuerised milk harbors dangerous microorganisms that can lead to foodborne diseases(Tebug et al., 2012). The alternative would be to promote fermented milk such as yoghurt which requires processing facilities.

We reccomend rethinking the promotion of milk powder, such as premixing with maize meal prior to cooking to avoid dilution with unsafe water. However, milk powders are heavily taxed which makes them expensive and inaccessible to poorer households. The caterpillar powder effect on heamoglobin is a promising finding given the levels of aneamia in Sub Saharan Africa and the availability of caterpillars in some environments. As the evidence is still nascent and limited, there is need for more research to fully inform policy and strategies. 


\subsubsection{Study limitations}

Despite the fact that these studies met the criteria for this review, we still find several limitations regarding their results. One study instructed parents to give meat as the only complementary food in the "early weeks" of the study, or with a minimum of other foods for an unspecified duration to maximize the $15 \mathrm{~g}$ intake of meat per day (Nancy F. Krebs et al., 2012). The study did not state whether this instruction was adhered to by parents or if other locally available foods were withheld, as most children were enrolled from the age of six months which is considered the appropriate age to introduce other foods. This could have biased the study's findings.

As other studies note, there are inconsistencies regarding the number of different ASF given in these types of interventions(Girard, Self, McAuliffe, \& Olude, 2012). Hence the complex interactions and cumulative effects cannot be captured well by attempting to study the effects of single dietary components (Masset, Haddad, Cornelius, \& Isaza-Castro, 2012), yet this was the approach of three of the reviewed studies (Bauserman et al., 2015; Nancy F Krebs et al., 2012; Long et al., 2012). We also note that none of the studies reported their findings by age groups, which would have shown whether there were any potential effects or benefits that were heterogeneous with age or other explanatory variables like maternal education.

Since growth velocity varies by age and risk to stunting increases between 6 and 18 months in areas endemic to stunting, the lack of age group analysis may have masked some positive results (World Bank, 2010). The diverse age distribution in the study makes age related interpretation difficult. The reviewed studies did not recommend any other intervention that could be delivered alongside food interventions e.g. water and sanitation, and disease control. Future research could address the above identified weaknesses and further investigate the effects of using one or more ASF supplements on nutritional status. There is need for further research on whether there is an optimal age where animal source food supplements would be effective. 


\subsection{Conclusion}

This review set out to assess the effects of supplementing diets with locally available ASF on stunting. The review identified four studies that supplemented diets with unfortified ASF. We found that interventions that supplement diets with milk show the most potential for improving linear growth and other nutritional outcomes. The minimal impacts of other ASF points to the complex nature of addressing stunting. The findings of our review certainly contribute to the discourse on effect of ASF on preventing stunting. We therefore recommend strategies that promote ASF consumption such as the promotion of milk production through small ruminants and behaviour change communication to create demand for such foods. However, further research is needed as few intervention studies were available. 


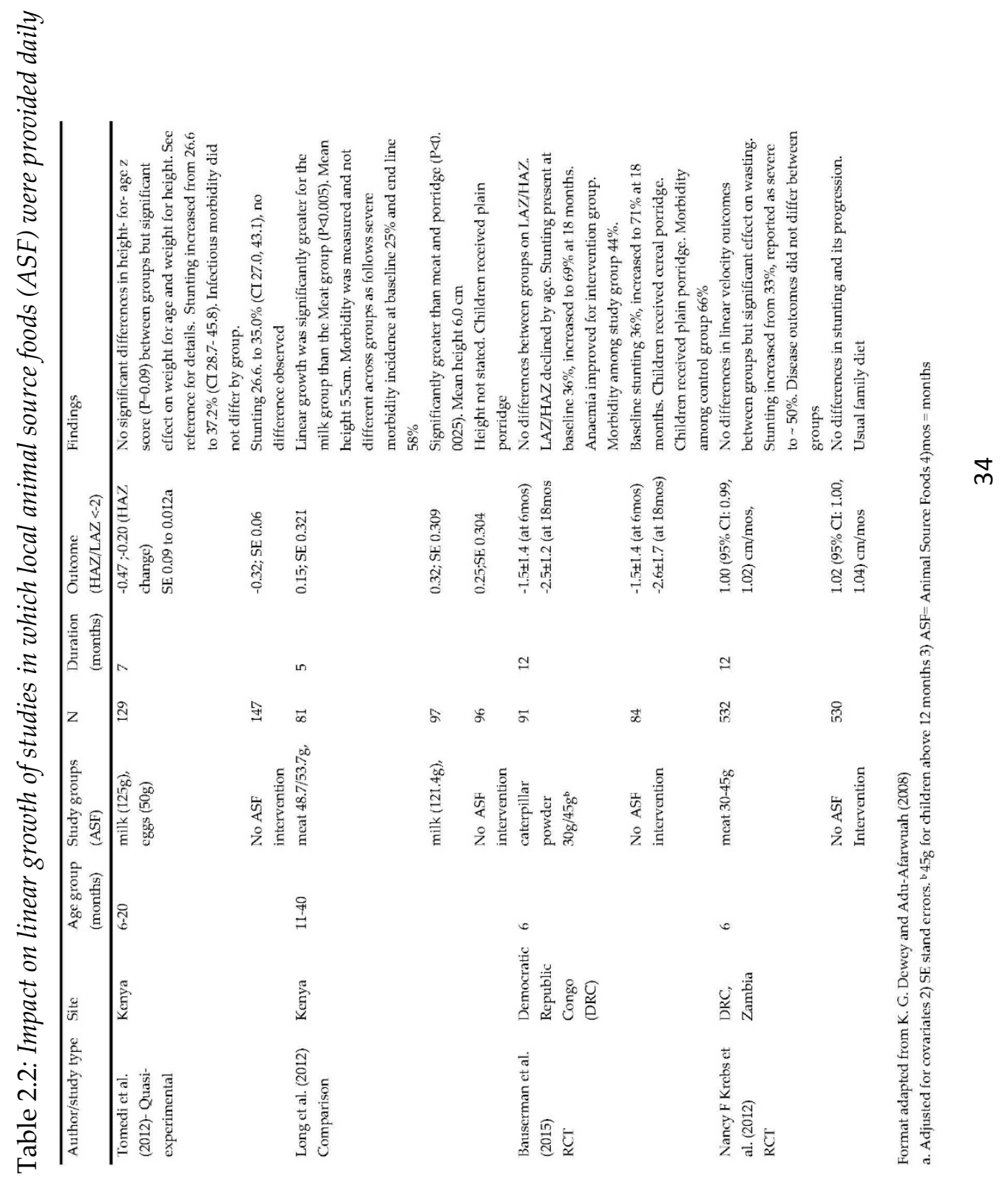




\section{CHAPTER 3: Do Food Groups Matter in Resource Poor Settings? Assessing their Role in Child Linear Growth: Evidence from Malawi}

This chapter draws upon:

Mutinta Hambayi, Nyasha Tirivayi, Groot W. Do food groups matter in resource poor settings? Assessing their role in child linear growth: Evidence from Malawi. Submitted for publication. 


\section{Abstract}

We examined the association between consumption of food groups and child linear growth.

Panel data from the 2010 and 2013 World Bank Welfare Monitoring Surveys of Malawi were used. Associations between frequency of consumption of food groups and height for age z-scores (HAZ) were assessed using random effects models adjusted for child, household and socio-economic characteristics.

Subjects: Children aged 6-59 months ( $\mathrm{n}=514)$ from 3246 households.

Findings show that in the households, a person consumed an average of $50 \mathrm{~g}$ of animal products and $7 \mathrm{~g}$ of milk, 1-3 days per week. In the fully adjusted models, a one day increase in the consumption of animal products was positively associated with an increase in HAZ of 0.045 for children $(\mathrm{P}<0.05)$. There was evidence of heterogeneity by age of child and wealth of households. An increase in the frequency of consumption of milk products and eggs in households with poor children was associated with a HAZ that was $1.093(\mathrm{p}<0.05)$ and $0.731(\mathrm{P}<0.001)$ higher (respectively) than that of nonpoor children. Among children aged over 24 months, the frequency of milk products consumed and quantity of animal products consumed was associated with a higher HAZ than younger children (0.0806) for milk products, $\mathrm{P}<0.05$; HAZ of 0.002 for animal products, $\mathrm{P}<0.05$ ).

The findings suggest the importance of animal source foods in children's growth and how the benefits may differ by age, type of food or food group and wealth status. 


\subsection{Introduction}

There is evidence that dietary diversity is positively associated with linear growth (Ruel, 2003; Arimond \& Ruel, 2006; Hatloy et al., 1998; Kennedy et al., 2007). These studies suggest that the frequent consumption of food groups, especially ASF, predict nutrient adequacy just as well as, or better than, individual foods. However, other studies argue that although the consumption of food groups is promoted in nutrition programs, the relative contribution of each food group to nutrition status is still unclear (Darapheak, Takano et al. 2013, Snapp \& fisher 2014). In Chapter 2 of this dissertation we found that that interventions that supplement diets with milk show the most potential in improving linear growth but uncontrolled underlying determinants may have undermined effects of other animal source foods in the RCTs (Bauserman et al., 2015; Nancy F Krebs et al., 2012).

Earlier studies noted the role of specific amino acids for prevention of diarrheal morbidity in children in a study in Ghana (Ghosh et al., 2010). Real life work to establish new data on dietary quality in complementary food for children was recommended (Tome et al., 2014). A recent study gives an extensive historical account of the debate on the lack of quality protein and the amino acids gap "fiasco" found in diets that are staple dominant that may cause adverse child growth and stunting (Semba, 2016). In Malawi, for example, stunted children had 10-20\% less serum concentration of essential amino acids necessary for growth compared to non-stunted children (Semba, 2016). The authors further suggest that it may be time to re-include protein and reengage the protein malnutrition discussion in global health with a balanced view that includes all protective nutrients such as from milk and animal source foods.

Yet, in South Africa, poor sanitation was found to be the primary cause of stunting, not poor diet (Theron et al., 2007). However, Long et al. (2012), concluded that energy intake was important for toddler growth in Kenya, 
but the contributing role of meat was reportedly less certain (Nancy F. Krebs et al., 2012). In most instances, while thresholds for dietary diversity are met for most local diets, the high prevalence of stunting persists (Jones, Ngure, Pelto, \& Young, 2013). Furthermore, food consumption and dietary diversity score thresholds have been described as setting the bar too low, suggesting that the amount of food, not diversity, is the problem (Jones et al., 2013; Kennedy et al., 2010).

As noted in the introduction section, diets in Malawi are monotonous consisting of a starchy staple consumed by majority of population with less dietary diversity from other nutrient rich sources (Meerman, 2014). In Malawi, other studies have examined the effects of frequency of different foods consumed on linear growth. Most of these studies were cross sectional in nature, were limited in sample size, or did not measure actual consumption patterns (Chikhungu \& Madise, 2014; Espo et al., 2002; Maleta, Virtanen, Espo, Kulmala, \& Ashorn, 2003). A recent study in Malawi found that frequency of food consumption was not a problem, but the amount food consumed per meal was low for about a third of children (Government of Malawi, 2011). Evidence of the association between quantities of food groups/individual foods consumed and linear growth is limited. This is particularly important in Malawi as the dietary diversity indicators show that the majority of the population consumes an average of four or more food groups, but the association between per capita quantity and frequency of food consumption and stunting in Malawi matters (Verduzco-Gallo, Ecker, \& Pauw, 2012). James and Palmer (2015), asks a key question "What are the minimum amounts of Animal Source Foods (ASF) that suffice to prevent stunting, and at what frequency should they be consumed?" To date, evidence from the few available randomized controlled trials assessing the impact of ASF on linear growth is mixed (Nancy F Krebs et al., 2012; Long et al., 2012), debated (Noriega \& Lindshield, 2014), but mostly suggested (Allen, 2012; Darapheak et al., 2013). 
The scope of the analysis is therefore to assess whether the frequency of consumption of local foods by households, particularly foods of animal origin, positively influences linear growth in children. ASF can provide a variety of growth-promoting micronutrients that cannot be adequately provided by relying on plant source foods in developing countries (Murphy \& Allen, 2003).

In the absence of actual food consumption surveys, which are often rare and expensive in developing countries (Hels, Hassan, Tetens, \& Thilsted, 2003), scholars differ on how to estimate individual consumption and child nutrition outcomes using household level information. Either adult equivalents (Deaton \& Muellbauer, 1986) or per capita consumption are proposed (Tedford, Capps, \& Havlicek, 1986). According to Claro, Levy, Bandoni, and Mondini (2010) adult equivalents are used mainly in economic studies to allow comparisons of food expenditure by households with different family compositions while in other fields, like nutrition, there has been little recognition of their importance and only a few use adultequivalent scales to assess dietary patterns (Claro et al., 2010). He further argues that most adult-equivalent scales currently used in nutritional studies are based on physiological coefficients, like calorie requirements (Claro et al., 2010) to benchmark food insecurity and vulnerability (Maxwell et al., 1999).

However calories are a poor predictor of individual nutrition outcomes since no dietary diversity or micronutrients necessary for growth are captured in the Adult Equivalent (AE) calorie estimations (Headey \& Ecker, 2013). AE values, as a thumb of rule, are $25 \%$ higher than per capita values (Sahn, 1984) but they underestimated the consumption of meat and vegetables in other studies (Buse \& Salathe, 1978) and therefore not as useful for key nutritionally vulnerable groups(Coates, Rogers, Blau, Lauer, \& Roba, 2017).

This study contributes to the existing dietary assessment literature by providing the ability to measure changes in food consumption patterns over 
time relative to nutrition guidelines, or policy initiatives (Kantor, 1998). For this reason, and while this may seem counter-intuitive, our study contributes to the discourse by examining the "approximate" trends in quantities consumed, and association between per capita and frequency of food group consumption on child linear growth.

\subsection{Methods}

\subsubsection{Setting}

This study uses data for Malawi. Details and background information on the local context of Malawi can be found in Chapter 1. The period 2010 to 2013 in Malawi was marked by economic and weather-related shocks. However, even in normal rainfall years, many households suffer from poverty and food insecurity, and dietary intake is inadequate (Ecker 2013, ICA 2014). It is estimated that $37 \%$ of young children are stunted, and stunting causes $23 \%$ of diseases and $45 \%$ of all deaths among children below the age of five (ECA \& NEPAD, 2013). In economic terms, stunting results in a loss in health, learning and productivity of up to $10 \%$ of the Gross Domestic Product (GDP) or US\$600 million in Malawi (ECA \& NEPAD, 2013). The typical dietary pattern for both adults and children in Malawi consists of a daily consumption of maize, a starchy staple, accompanied by pulses or nuts or other vegetables, and occasionally ASF within a meal. Malawi's nutritionists adopted a six food group model in 2001 to promote a diverse diet. Families are expected to eat at least one food from the six groups daily but this is uncommon in many households.(Government of Malawi, 2011)

\subsubsection{Participants and study design}

The analysis draws on a two-wave nationally representative panel dataset from Malawi. The surveys were conducted in 2010 and 2013. These datasets are from the third and fourth World Bank supported Living Standards 
welfare monitoring survey designed to provide information on the welfare and social economic status of Malawians (NSO 2014). The first round collected data from 3,246 households between March and November 2010/11). The second round collected data from 4,000 households between April and December 2013. The increase in the number of households was a result of tracking split-off individuals and bringing their new households into the sample. A total of 1,100 children in the 6-59 months age range had their anthropometric measurements of height and weight taken and recorded during the two waves. The same children were measured twice, in 2010 and in 2013. The complete dataset on selected variables is available for 600 children before cleaning. Each survey wave captured information on household demographics, food consumption and income, and agricultural activities, social economic status. Information on the amounts of food eaten 7 days prior to the interview was collected using a 7-day recall method.

As part of data cleaning and harmonization, values that were 3 times above the standard deviation for each food group or specific food were counted as missing values. The outliers were the result of quantities that were poorly encoded in the responses. Ultimately, the sample of children with requisite food consumption data comprised 514 children captured from 3246 households in 2010 and 2013, resulting in a total of 1028 observations. The panel is fixed and balanced with the same children and household variables observed on all variables (Greene 2008: 184).

\subsubsection{Linear growth}

The main dependent variable was linear growth expressed as HAZ. The HAZ can show us the extent to which linear growth changes, unlike a stunting dummy variable. All z-score values that did not fit in the ranges of $-6 \leq \mathrm{HAZ} \leq 6$ were excluded from the analyses (Verduzco-Gallo et al.). Interpretations of HAZ follow the World Health Organization's Child 
Growth Standards released in 2006 (WHO, 2006) where stunting is defined as $\mathrm{HAZ}<-2$.

\subsubsection{Food groups and consumption patterns}

The main independent variables were food groups and selected individual foods. Eighty types of food are recorded in the data. Kant (1996) proposed that the use of foods or food groups is one of the valid methods for assessing overall quality of diet. We use the food group classification that has been used in other studies (Jones et al., 2013). One modification in this study is that we classify cereals and tubers into separate groups although both are referred to as staples when discussed. The food groups were classified as follows: grains and cereals; roots and tubers; nuts and pulses; milk and milk products; meat and fish; fats and oils; fruits; vegetables; and spices or condiments. Throughout the text we will refer to the meat and fish group as "animal source food products". Individual foods that are also included in the analysis are eggs, fish, meat and milk. The composition of each food group is detailed in Table A3.2.

Consumption patterns were measured as frequency and quantity of foods consumed. We also analyzed the consumption patterns by constructing a binary variable denoting whether a food was consumed or not. Quantity of food consumed ${ }^{1}$ was constructed using conversion factors ${ }^{2}$ that transformed

\footnotetext{
${ }^{1}$ The guidelines for analyzing the data provided conversion factors by unit and also by region because certain products such as potatoes, were bigger in certain regions compared to others. Therefore, the consumption module $(G)$ with the conversion factor file was merged in order to transform all units into comparable $\mathrm{kg}$. However, certain products did not have conversion factors. For example, some missing values such as a litre was equated to $1 \mathrm{~kg}$. However, products that could not be transformed to a comparable kg unit, were not taken into account in the calculation of the total quantities (Verduzco-Gallo, Ecker, \& Pauw, 2014).

${ }^{2}$ In order to estimate household food, food quantities recorded in non-metric units were first converted into metric units. The unit list includes 16 non-metric units, of which the large majority are volume-based units requiring item-specific conversion factors. This is due to the
} 
the different units into comparable ' $\mathrm{kg}$ ' following Verduzco-Gallo et al. (2012).

Table A3.1 shows the percentage of missing conversion factors by food group. Since quantity was reported at the household level, the total was divided by the household size to derive per capita values. This was based on the assumption that food is shared in the household. Furthermore, as the variable was measured on a weekly basis, the total was also divided by 7 to derive daily per capita consumption.

Similarly, no adult equivalents conversion factors were applied (VerduzcoGallo et al., 2014). In our analysis, we focus on per capita consumption for several reasons. First, we are interested in understanding food group diversity not calories. Secondly, adult equivalents could overestimate quantities consumed by children because intra-household allocation is unknown and could also underestimate the consumption of meat and vegetables for nutritionally vulnerable groups (Buse \& Salathe, 1978; Coates et al., 2017). Thirdly, we want our results to be comparable to previous studies that also used per capita consumption (Verduzco-Gallo et al., 2014).

Fourthly, our data assessed consumption using conversion factors and not actual food consumption measurements. Finally, commonly used equivalence scales like those developed by the OECD are frequently based on the allocation of a) total household spending or total consumption and not just food consumption and b) based on the allocation in households in high income/western countries and not on the allocation within poorer countries like Malawi. This may make the use of these standardized

fact that products differ in terms of their mass volume densities. In the IHS3 dataset, only about one-fifth of food items are reported in metric units, i.e. the vast majority of quantities are reported in volume- or count-based units such as pails, plates, or bunches. A new feature in the IHS3 is to further distinguish several of the non-metric units by size, e.g., small, medium, and large, or heaped and flattened in O. Ecker and M. Qaim (2011). 
equivalence scales in our study somewhat arbitrary and the use of these equivalence scales may create another source of bias on the results. Because of these sensitivities, one must carefully consider summary policy implications derived from cross-national comparisons of poverty and/or allocation inequality (Buhmann, Rainwater, Schmaus, \& Smeeding, 1988). We therefore assess per capita quantities as a near plausible approach especially since in 2010 and 2013, we follow the same children in the same households that show minimum variation in their per capita consumption over the panel years (see Table 3.1).

The variable denoting whether a food was consumed or not was constructed from asking respondents if in the previous week (7 days), they consumed (yes or no) or others in the household consumed any specified food (Baumann, Webb, \& Zeller, 2013; Remans et al., 2011). Studies find that consumption recalls of 3 days begin to approximate dietary habits in a population, although a 7 day recall is commonly used (Kennedy, Ballard, \& Dop, 2011). Frequency of food consumption was measured by asking the number of days a food or food group was consumed by anyone in the household during the week (7 days) prior to the survey. Variables take the value of 1 if an individual in the household consumed at least one of the foods in the food group in the previous week and 0 if no individual consumed any food in the group. For the individual foods, the variable takes the value of 1 if the food was consumed within the household and 0 if otherwise. The binary and frequency measures of consumption will be applied at child level for ease of interpretation and based on the assumption of food sharing within the household.

\subsubsection{Covariates}

The selection of our covariates was guided by findings in the literature, particularly the UNICEF conceptual framework for the causes of malnutrition (UNICEF, 1990). Among the children between the age of 6-59 
months, we selected the following covariates: gender of the child, age in months, difference in age with previous child, birth order, total number of children, mother education, age group, wealth status, household amenities such as electricity and pit latrines, experience of a household shock such as drought or floods, if a child is part of nutrition program, number of meals per day, illness in the last 2 weeks, clinic attendance by children under five, area, region and year dummy. Information on breastfeeding was not collected and therefore was not assessed.

Our empirical strategy also includes assessing whether associations between food group consumption and linear growth are heterogeneous by age, wealth and maternal education due to the following reasons. First, numerous studies have found that the relationship between food consumption and linear growth varies according to the age of the child (Arimond \& Ruel, 2004) and household wealth (Fenske et al., 2013). Disparities in stunting prevalence by wealth strata reflect the bidirectional relationship between poverty and undernutrition (Black et al., 2013; Christine P Stewart, Lora Iannotti, Kathryn G Dewey, Kim F Michaelsen, \& Adelheid W Onyango, 2013). Moreover, our data is from a country where $39 \%$ of the population live below the poverty line (Mussa \& Paul, 2011). Non-poor and poor binary variables were constructed using the household consumption expenditure poverty line (Verduzco-Gallo et al., 2012).

Secondly, proper nutrition from conception to 2 years of age can profoundly affect a child's ability to grow, learn and work as an adult (Remans et al., 2011). We therefore analyzed whether associations varied by whether a child was below or above 24 months of age in order to capture the dynamics during this critical window of growth (Prentice et al., 2013). We also analyzed the data using age in months as a continuous variable. Finally, we focused on variations by maternal education since low maternal education is another risk factor for malnutrition (Makoka, 2013; Pryer, Rogers, \& 
Rahman, 2004). In the analysis of heterogeneity, the reference groups are the non-poor, children below 24 months and children with uneducated mothers.

\subsubsection{Statistical analysis}

We used random effects (RE) regression models to determine the association between foods groups/foods and linear growth. RE models were chosen over fixed effects models since one of the covariates, maternal education, was constant over time, (Mani, 2012a). Maternal education is an important determinant of linear growth in developing countries (Imdad, Yakoob, \& Bhutta, 2011b; Makoka, 2013). We also expect that differences across entities in age, wealth status and education influence the dependent variable, hence the use of RE regressions (Torres-Reyna, 2007). The Hausman test was used to test whether fixed effects or RE models were the most appropriate in this study. A failure to reject the null hypothesis confirmed our choice for the RE models (Mani, 2012a). The regression analysis was performed for each of the food groups separately.

The RE regressions were adjusted for the covariates.

In order to assess whether associations between food group consumption and HAZ are heterogeneous by age, wealth and maternal education, interaction terms were used. The three measures of consumption (quantity, frequency and whether one consumes) were interacted with wealth groups, maternal education and age groups.

The analysis estimates the individual effects of other covariates using interaction terms; maternal education, and age and asset poverty. The assumption is that if the interacted term's individual effects are corrected with other covariates in the model, then the fixed effect model is consistent and the random effects model is inconsistent. On the other hand, if the individual effects are not correlated with the other covariates in the model, both random and fixed effects are consistent and random effects is efficient. 
Since the fixed effects model is efficient in both situations, intuitively, Hausman's approach is to compare the behaviour of an inefficient, but consistent estimate to that of a possibly inconsistent estimate. This test therefore indirectly tests the condition that there is no correlation between the covariates and the unit effects (Esarey \& Jaffe, 2017).

As the dependent variable, HAZ, is continuous, linear RE regressions were used. All the statistical analyses were carried out using the statistical software package Stata version 13

\subsubsection{Ethical clearance}

The analysis used publicly available data from the World Bank which is anonymous and exempted from institutional ethical review. It can be downloaded after registration with the National Statistics office of Malawi from http://go.worldbank.org/.

\subsection{Results}

\subsubsection{Descriptive statistics}

Table 3.1 presents the summary statistics on food consumption and linear growth. Among the 514 children in the sample, 23\% and 21\% were stunted in 2010 and 2013 respectively. The mean HAZ was $-1.076( \pm 1.213)$ and -1.213 $( \pm 1.130)$. The HAZ did not vary or improve significantly by age group or age (Table 3.1).

Results show that staples and vegetables were consumed daily by almost everyone (99\%), followed by tubers consumed 3 times a week. From 2010 to 2013, there was a significant increase in the quantities of nuts and pulses consumed $(\mathrm{P}<0.05)$. Frequency of per capita consumption of ASF was limited 
and ranged from 1-3 days per week. On average, per capita consumption of animal products per day ranged between $47 \mathrm{~g}-54 \mathrm{~g}$ ( $\pm 61 \mathrm{~g}-77 \mathrm{~g})$. Even smaller quantities of each ASF were consumed per person i.e. about 22-23g of meat $( \pm 37 \mathrm{~g}-42 \mathrm{~g})$., $7 \mathrm{~g}$ of milk $( \pm 25 \mathrm{~g}), 16 \mathrm{~g}-18 \mathrm{~g}$ of fish $( \pm 26 \mathrm{~g})$ and $3 \mathrm{~g}$ of eggs $( \pm 5 \mathrm{~g})$. With the exception of fish, which was consumed by $73 \%$ of households, 2.7 times per week, less than $50 \%$ of the households consumed meat or eggs. Milk was consumed by only $22 \%$ of the households, once to twice per week. Between the two rounds, there was a decline in the quantities of milk consumed $(\mathrm{P}<0.05)$.

Table 3.1: Summary statistics of consumption patterns and nutritional status; 2010 and 2013

\begin{tabular}{|c|c|c|c|c|c|}
\hline \multirow[b]{2}{*}{ Child characteristics } & \multicolumn{2}{|c|}{$\begin{array}{l}2010 \\
(n=514)\end{array}$} & \multicolumn{2}{|c|}{$\begin{array}{l}2013 \\
(n=514)\end{array}$} & \multirow[b]{2}{*}{ t-test } \\
\hline & Mean & SD & Mean & SD & \\
\hline Gender ( $1=$ male $)$ & 0.512 & 0.500 & 0.512 & 0.500 & 0.000 \\
\hline \multicolumn{6}{|l|}{ Nutrition status } \\
\hline Stunted (1= yes) & 0.235 & 0.425 & 0.212 & 0.409 & 0.898 \\
\hline Height Age z-score (HAZ) & -1.076 & 1.219 & -1.213 & 1.130 & 1.870 \\
\hline 6-11 months & -0.897 & 1.219 & $\mathrm{n} / \mathrm{a}$ & $\mathrm{n} / \mathrm{a}$ & $2.223^{* * a}$ \\
\hline 12-24 months & -1.155 & 1.212 & $\mathrm{n} / \mathrm{a}$ & $\mathrm{n} / \mathrm{a}$ & \\
\hline 36-47 months & $\mathrm{n} / \mathrm{a}$ & $\mathrm{n} / \mathrm{a}$ & -1.186 & 1.103 & \\
\hline 48-59 months & $\mathrm{n} / \mathrm{a}$ & $\mathrm{n} / \mathrm{a}$ & -1.223 & 1.141 & $0.3265^{b}$ \\
\hline
\end{tabular}

\section{Per capita food quantity, daily}

\section{(in grams)}

Food groups

Grains and cereals

Roots and tubers

$\begin{array}{lllll}421.4 & 268.2 & 406.3 & 273.9 & 0.895 \\ 118.1 & 118.4 & 118.4 & 115.8 & -0.045 \\ 31.87 & 45.09 & 46.97 & 48.71 & -5.126^{* * *} \\ 156.2 & 141.4 & 154.2 & 116.1 & 0.254 \\ 54.08 & 77.00 & 47.43 & 61.11 & 1.532 \\ 7.460 & 25.56 & 7.050 & 24.03 & 0.265\end{array}$

Nuts and pulses

Vegetables

Meat, Fish (animal products)

Milk/Milk products 
Meat

$\begin{array}{llll}21.97 & 41.91 & 23.10 & 36.76\end{array}$

$-0.458$

Fish

18.72

26.08

16.96

26.09

1.066

Eggs

3.063

4.965

$3.189 \quad 5.085$

$-0.397$

Food consumed in the last 7 days

(yes or no)

Group of food product

Cereals, Grains and Cereal

Products, \%

Roots, Tubers, and Plantains, \%

0.802

0.399

0.796

0.404

0.233

Nuts and Pulses, \%

$0.881 \quad 0.324$

$0.946 \quad 0.227$

$3.681^{* * *}$

Vegetables, $\%$

$0.992 \quad 0.0880$

$0.994 \quad 0.0762$

0.379

Meat, Fish (animal products), \%

0.875

0.330

0.848

0.359

1.265

Milk/Milk Products, \%

0.228

0.420

0.224

0.417

0.149

Meat, \%

0.486

0.500

0.508

0.500

$-0.686$

Fish, \%

0.733

0.443

0.683

0.466

1.785

Eggs, \%

0.354

0.479

0.360

0.480

$-0.195$

\section{Frequency of food consumption}

\section{(number of days)}

Group of food product

Cereals, Grains and Cereal

$\begin{array}{llll}6.766 & 0.976 & 6.840 & 0.849\end{array}$

1.297

Products

Roots, Tubers, and Plantains

$2.877 \quad 2.205$

2.842

2.264

0.251

Nuts and Pulses

2.827

1.983

3.525

2.040

$5.566^{* * *}$

Vegetables

5.751

1.741

6.232

1.520

$4.714^{* * *}$

Fruits

1.747

1.974

1.846

2.115

0.781

Meat, Fish (animal products)

2.700

1.984

2.533

1.987

1.351

Milk/Milk Products

$1.136 \quad 2.262$

0.877

1.953

$1.963^{* *}$

${ }^{1}$ Continuous variables tested using a two-sample $t$ test with equal variances $/ 2 \mathrm{t}$-test significance : ${ }^{* *} \mathrm{p}<0.05,{ }^{* * *} \mathrm{p}<0.001 ; \mathrm{n} / \mathrm{a}$ panel age range and 36 months later, a $\mathrm{t}$-test between 6-11\& 12-24 months, b t-test between 36 -47\& 48-59 months. Regression analysis is separate for each food groups separately. 


\subsubsection{Heterogeneity in the association between consumption of food groups and linear growth}

Tables 3.3 to 3.5 show that there is heterogeneity in the association between food consumption and linear growth, varying by age, wealth and maternal education.

\subsubsection{Association between consumption of food groups and linear growth}

Table 3.2 shows the results of the regressions assessing the association between consumption of food groups and linear growth. The results show that consuming ASF during the week was positively associated with an increase in HAZ by $0.403(\mathrm{P}<0.001)$. Similarly, for every additional day of animal product consumption, HAZ values increased by $0.045(\mathrm{P}<0.05)$, holding all other factors constant. Consuming eggs or fish within the household was associated with an increase in HAZ by $0.174(\mathrm{P}<0.05)$. Among other food groups, having consumed vegetables was associated with a decline in HAZ by 0.93 ( $\mathrm{p}<0.05)$. Per capita quantity consumed for any other food group was not significantly associated with child linear growth. See TableA3.5. Data on the number of days individual foods were consumed were not available. 
Table 3.2: Associations between consumption of food groups and child linear growth (HAZ)

Dependent variable: HAZ-

Height for Age Z Score

\begin{tabular}{llll}
\hline VARIABLES & Coefficient & S.E & Observations \\
& & & \\
\hline $\begin{array}{l}\text { Consumption of food groups } \\
\text { and or food item (yes or no) }\end{array}$ & & & \\
Cereals & 0.54 & -1.166 & 1,028 \\
Roots and tubers & -0.0449 & -0.0959 & 1,028 \\
Pulse and nuts & -0.112 & -0.133 & 1,028 \\
Vegetables & -0.93 & $(0.442)^{* *}$ & 1,028 \\
Milk \&milk products & 0.089 & -0.102 & 1,028 \\
Animal products & 0.403 & $(0.113)^{* * *}$ & 1,028 \\
Meat & -0.0559 & -0.0839 & 1,028 \\
Eggs & 0.174 & $(0.0827)^{* *}$ & 1,028 \\
Fish & 0.174 & $(0.0855)^{* *}$ & 1,028 \\
Number of days of & & & \\
consumption & & & \\
Cereals & & -0.0418 & 1,026 \\
Roots and tubers & 0.0384 & -0.0173 & 1,028 \\
Pulses an nuts & 0.00223 & -0.0189 & 1,028 \\
Vegetables & -0.0201 & -0.0228 & 1,028 \\
Milk and milk products & -0.0256 & -0.0199 & 1,027 \\
Animal Products & -0.00806 & $(0.0211)^{* *}$ & 1,028 \\
\hline
\end{tabular}

Notes 1) Standard errors in parentheses, 2) $\left.{ }^{* * *} \mathrm{p}<0.01,{ }^{* *} \mathrm{p}<0.05 .3\right)$ Data source: http://go.worldbank.org/ 2010 and 2013 4) Regressions adjusted for; gender of the child, age in months, age difference with previous child, birth order, total number of children, mother education, age group, wealth status, amenities, external shocks, part of nutrition program, number of meals, illness in last 2 weeks, under five clinic attendance, area, region and year dummy 4) Total sample $=514$

\subsubsection{Milk products and linear growth}

For children above the age of 24 months, every additional day of consuming milk, was associated with a HAZ that was $0.806(\mathrm{P}<0.05)$ higher than for children below the age of 24 months. Furthermore, for each additional month 
in age, there was a positive association between the per-capita quantity and frequency of consuming milk products and HAZ as shown in Table 3.3. The consumption of milk by poor children was associated with a HAZ that was $1.093(\mathrm{P}<0.05)$ higher than that of non-poor children. Additional analysis on quantities of foods from bivariate regressions show that poor children consumed fewer animal products than non-poor children, while there was no significant difference in animal product consumption across age groups. See Table A3.4

Table 3.3: Heterogeneity in the association between the milk food group and linear growth: age (in months) and wealth status interactions

\begin{tabular}{llll}
\hline Food groups & $\begin{array}{l}\text { Quantity } \\
\text { consumed }\end{array}$ & $\begin{array}{l}\text { Number of days } \\
\text { consumed }\end{array}$ & $\begin{array}{l}\text { Consumed yes } \\
\text { or no }\end{array}$ \\
\hline Milk products $x>24$ & 0.00562 & $0.0806^{* *}$ & 0.134 \\
months & $(-0.00298)$ & $(-0.0347)$ & $(-0.173)$ \\
Observations & 1,027 & 1,028 & 1,028 \\
Milk products $x$ age & $0.000187^{* *}$ & $0.00229^{* *}$ & 0.00487 \\
Observations & $(-8.3 \mathrm{E}-05)$ & $(-0.0009)$ & $(-0.0045)$ \\
Milk products x poor & 1027 & 1,028 & 1,028 \\
& 0.0191 & 0.196 & $1.093^{* *}$ \\
Observations & $(-0.0151)$ & $(-0.145)$ & $(-0.539)$ \\
\hline
\end{tabular}

Notes: Authors' calculations from data. 1) Standard errors in parentheses, 2) *** $\mathrm{p}<0.01$, ** $\mathrm{p}<0.05$. 3) Data source http://go.worldbank.org/ 2010 and 2013 4) Regressions adjusted for; gender of the child, age in months; age difference with previous child, birth order, total number of children, mother education, age group, wealth quintile, amenities, external shocks, part of nutrition program, number of meals, illness in last 2 weeks, under five clinic attendance, area, region and year dummy. 5) The reference category for age group is 6-24 months, for wealth status it is non-poor and for maternal education it is no education. 


\subsubsection{Animal product and linear growth}

Table 3.4 presents results of the association between consuming animal products and linear growth among children aged 6-59 months. We find that for older children, a 1-gram increase in the consumption of animal products was associated with HAZ that was 0.002 higher than that of younger children $(p<0.05)$. For each additional month in age, there was a positive association between per capita quantity of animal product consumption and HAZ. This result is in line with Table 3.3 and shows that the consumption of animal and milk products is associated with higher linear growth among older children compared to younger children. Results also show that an additional day in the consumption of animal products led to a decrease in HAZ by 0.119 $(\mathrm{P}<0.05)$, for children with a primary educated mother compared to children with uneducated mothers. Results for the wealth interaction terms were not statistically significant.

Table 3.4: Heterogeneity in the association between consuming animal product and linear growth: interactions with age (in months), wealth and maternal education

\begin{tabular}{llll}
\hline $\begin{array}{l}\text { Food groups interacted with } \\
\text { age, wealth and maternal } \\
\text { education }\end{array}$ & $\begin{array}{l}\text { Quantity } \\
\text { consumed }\end{array}$ & $\begin{array}{l}\text { Number of days } \\
\text { consumed }\end{array}$ & Consumed yes or no \\
\hline Animal product $x>24$ months & $0.00212^{* *}$ & 0.0355 & -0.0194 \\
& $(-0.00108)$ & $(-0.0364)$ & $(-0.208)$ \\
Observations & 1,027 & 1,028 & 1,028 \\
Animal product $x$ age & $6.20 \mathrm{e}-05^{* *}$ & 0.00128 & 0.000446 \\
& $(-2.84 \mathrm{E}-05)$ & $(-0.001)$ & $(-0.0055)$ \\
Observations & 1027 & 1,028 & 1,028 \\
Animal product $x$ poor & 0.0053 & 0.0636 & 0.227 \\
& $(-0.00739)$ & $(-0.066)$ & $(-0.242)$ \\
Observations & 1027 & 1,028 & 1,028 \\
Animal product $x$ primary & -0.00229 & $-0.119^{* *}$ & 0.285 \\
& $(-0.0019)$ & $(-0.0538)$ & $(-0.269)$ \\
Animal product $x$ secondary & -0.00094 & -0.0384 & 0.352 \\
and higher & $(-0.0021)$ & $(-0.0649)$ & $(-0.468)$ \\
Observations & 1,027 & 1,028 & 1,028 \\
\hline
\end{tabular}


Notes: Authors calculations from data. 1) Standard errors in parentheses, 2) *** $\mathrm{p}<0.01$, ** $\mathrm{p}<0.05$. 3) Data source_http://go.worldbank.org/, 2010 and 2013 4) Regressions adjusted for: gender of the child, age in months, age difference with previous child, birth order, total number of children, mother education, age group, wealth quintile, amenities, external shocks, part of nutrition program, number of meals, illness in last 2 weeks, under five clinic attendance, area, region and year dummy. 5) The reference category for age group is 6-24 months, for wealth status it is non-poor and for maternal education it is no education.

\subsubsection{Individual animal foods and linear growth}

The results in Table 3.4 show that poor children who consumed animal products had a HAZ that was $0.828(\mathrm{P}<0.05)$ higher than non-poor children. Similarly, an additional day in which poor children consumed eggs was associated with a HAZ that was $0.731(\mathrm{P}<0.01)$ higher than that of non-poor children. Furthermore, a 1 gram increase in the quantity of eggs consumed by poor children led to HAZ that was $0.108(\mathrm{P}<0.01)$ higher than that of nonpoor children. Again, this shows that poor children benefitted the most from consuming eggs compared to non-poor children. This is consistent with the results on the consumption of milk products in Table 3.4. There was a negative association between the consumption of eggs and HAZ for children with primary educated mothers. A 1 gram increase in egg consumption for a child with a primary educated mother was associated with a HAZ that was $0.056(\mathrm{P}<0.05)$ lower than that of children with an uneducated mother. Finally, the results for fish consumption were not statistically significant (Table 3.5). 
Table 3.5: Heterogeneity in the association between animal foods and linear growth: age (in months), wealth and mother education status interactions

\begin{tabular}{|c|c|c|}
\hline Food groups & Quantity consumed & Consumed yes or no \\
\hline Meat $x$ poor & $0.0349(-0.0208)$ & $0.828^{* *}(-0.349)$ \\
\hline Observations & 1027 & 1,028 \\
\hline Fish $\mathrm{x}$ poor & $-0.0042(-0.00798)$ & $0.0644(-0.22)$ \\
\hline Observations & 998 & 1,028 \\
\hline Eggs $\mathrm{x}$ poor & $0.108^{* * *}(-0.0389)$ & $0.731^{* * *}(-0.264)$ \\
\hline Observations & 998 & 1,028 \\
\hline Egg x primary & $-0.0555^{* *}(-0.0244)$ & $-0.291(-0.215)$ \\
\hline \multicolumn{3}{|c|}{$\begin{array}{l}\text { Notes: Authors calculations from data. 1) Standard errors in parentheses, 2) } \\
\text { p }<0.01,{ }^{* *} \mathrm{p}<0.05 .3 \text { 3) Data source: } \mathrm{http}: / / \text { go.worldbank.org/., } 2010 \text { and } 2013 \text { 4) } \\
\text { Regressions adjusted for; gender of the child, age in months; age difference with } \\
\text { previous child, birth order, total number of children, mother education, age group, } \\
\text { wealth quintile, amenities, external shocks, part of nutrition program, number of } \\
\text { meals, illness in last } 2 \text { weeks, under five clinic attendance, area, region and year } \\
\text { dummy. 5) The reference category for age group is 6-24, for wealth status it is non- } \\
\text { poor and for maternal education it is no education. 6) } \mathrm{N}=514\end{array}$} \\
\hline
\end{tabular}

\subsubsection{Other food groups and linear growth}

Annex 5 presents results on the association between consuming food groups other than ASF and linear growth among children in the 6-59 months age group. The consumption of vegetables, tubers, pulses and nuts for children from poor households was associated with a statistically significant decrease in HAZ. Having consumed vegetables was associated with a decline in HAZ by $0.93(p<0.05)$. Other non-ASF groups showed no statistically significant associations with linear growth. 


\subsection{Discussion}

This chapter presents empirical evidence on the association between food group consumption and linear growth, examining the role of quantity and frequency of food consumption among children aged $6-59$ months.

Our findings highlight that in non-diverse diets, linear growth is feasible by increasing the frequency of consumption and adding small quantities of locally available ASF in the diet.

In the sample, children are about 1.2 standard deviation, shorter than a child population group of the same age and gender. Overall, the diet consisted mostly of starchy staples and vegetables food groups with relatively low intakes of ASF, consistent with other studies which found that households in resource poor contexts are dependent on staples which enable them to avoid hunger with less expensive foods (Cornelsen et al., 2016; VerduzcoGallo et al., 2012). We find that consuming ASF and milk was associated with an increase in HAZ by 0.403 and 0.174 respectively. This is consistent with the findings from the systematic review in chapter 2. However, the consumption of vegetables was associated with a decrease in HAZ, while other non-ASF groups had no statistically significant associations with linear growth. Although per capita consumption of ASF is limited, our results show that an increase in the frequency of consumption of animal products is associated with an increase in HAZ.

Our results are consistent with the findings in empirical literature. Earlier studies noted the role of specific amino acids for prevention of diarrheal morbidity in children in a study in Ghana (Ghosh et al., 2010). Real life work to establish new data on dietary quality in complementary food for children was later recommended (Tome et al., 2014). A recent study gives an extensive historical account of the debate on the lack of quality protein and the amino 
acids gap "fiasco" found in diets that are staple dominant that may cause adverse child growth and stunting (Semba, 2016). In Malawi, for example, stunted children had $10-20 \%$ less serum concentration of essential amino acids necessary for growth compared to non-stunted children (Semba, 2016). The authors further suggest that it may be time to re-include protein and reengage the protein malnutrition discussion in global health with a balanced view that supports the inclusion of all protective nutrients such as those found in milk and animal source foods.

Similarly, a study in Kenya showed that child height gain was associated with milk and eggs consumption for children below the age of 6-59 months (Mosites et al., 2017). We find that the consumption of fish and eggs was each associated with an increase in HAZ by $0.174(\mathrm{P}<0.05)$. Fish is an important source of the diet consumed by $73 \%$ of the households and a source of livelihood in Malawi. Consuming fish provides iron, zinc, and calcium, vital micronutrients in children's diets (Béné \& Heck, 2005). Eggs contain an array of nutrients as substantiated by Schönfeldt and Gibson Hall (2012). In the context of relatively high child chronic malnutrition due to inadequate dietary quality, even small increases in ASF consumption can lead to improved health and cognitive outcomes for children (Cornelsen et al., 2016; Long et al., 2012).

Our study finds that ASF consumption and linear growth varies by age of child, household wealth, and maternal education. Dietary quantity is particularly important for children above 23 months, children in poor households and children with uneducated mothers. While it is established that the age range of 6-23 months is a vulnerable period for child growth (Zongrone, Winskell, \& Menon, 2012), we find that older than 23 months children appear to benefit most from consumption of ASF, although there were no significant differences in per capita quantity or frequency consumed across age groups. One possible explanation is that children above 24 months initially had a lower HAZ compared to younger children. Hence, they could 
be exhibiting some growth transitioning. Breastfeeding continues mostly until 24 months for most children in Malawi (Malawi, 2010).

Comparing dietary intake of children by breastfeeding status shows that a higher proportion of non-breastfeeding children are consuming solid and semisolid foods than breastfeeding children (Malawi, 2010). In a study comparing milk, meat, and energy-only supplements in Kenyan children, the height response depended on the initial HAZ, and milk produced the most improvement in linear growth (Long et al., 2012). The fact that we find a benefit for ASF among children that are above 24 months, suggests focusing in children below 24 months in certain contexts may disadvantage children above the 24 months age group. Such evidence may support a complementary approach focused on identifying and targeting children well after the age of two years who are at risk of growth faltering (Elizabeth A Lundeen et al., 2014; Prentice et al., 2013).

We also find that poor children consuming milk, meat and eggs when analyzed as individual foods had higher linear growth than non-poor children. The result suggests that poor children benefitted more from eating meat, eggs and milk compared to non-poor children despite consuming quantities that were less than those of their non-poor counterparts. Studies have shown that when children with little or no ASF in their diets received milk, their height improved (Allen, 2012; Golden, 1995). Support for the role of milk in enhancing linear growth is found in the literature, because milk has type I and particularly type II nutrients ${ }^{3}$, which are the building blocks of tissue and are important for biochemical pathway (Daphna K Dror \&

\footnotetext{
${ }^{3}$ A child responds to a deficiency of an essential nutrient either by continuing to grow and consuming body stores with eventual reduction in the bodily functions (Type I) or by reducing growth and avidly conserving the nutrient to maintain the concentration of the nutrient in the tissues (Type II). There are no characteristic symptoms to distinguish which Type II nutrient deficiency an individual has; all deficiencies result in the poor growth, stunting Golden (1995)
} 
Lindsay H Allen, 2011). Conversely, a study in Cambodia found a negative association between milk consumption and linear growth among poor children (Darapheak et al., 2013). Our study also finds no association between maternal primary education and the consumption of ASF, unlike other studies.

Choi et al. (2011) found that children from more educated mothers consumed ASF compared to children with illiterate mothers. In other studies, the effects of maternal education on child nutrition was found to depend on socio economic conditions and less on education attainment (Reed, Habicht, \& Niameogo, 1996). Overall, and contrary to other studies, both milk and other ASF were positively associated with the linear growth of poor children, older children and children with uneducated mothers (Darapheak et al., 2013; Long et al., 2012).

In our study, other foods such as cereals, tubers vegetables and pulses had limited or negative effects on height gains especially for the younger age group and children from poor households. The general negative effect of vegetables may relate to the predominant diets of staples and vegetables which normally contain high anti-nutrient content such as phytates (Iannotti, Barron, \& Roy, 2008). However, careful selection of locally available foods combined with modifications to household food preparation and processing practices to reduce phytate intake, can reduce simultaneously dietary inadequacies of key nutrients even in rural households with very limited resources but ASF should be promoted (Yeudall, Gibson, Cullinan, \& Mtimuni, 2005).

\subsubsection{Policy recommendations}

Our analysis shows that in non-diverse diets, linear growth is feasible and can be improved through increasing the frequency or quantity of ASF consumption. Promotional strategies could include agriculture related 
strategies that promote frequent access to small ruminants, eggs and milk and also to nutritious indigenous insects. Given that the cost of animal foods is generally prohibitive for poor households, distinguishing a category of "special foods" such as eggs, milk, small dried or fresh fish, edible insects, with illustrations of how these foods can be combined and in what amounts, could facilitate children getting these foods at least four to five times a week (Government of Malawi, 2011). In this respect, our analysis has been illustrative and in part facilitates an evidence based approach for feeding guidelines in this context.

\subsubsection{Strengths, limitations and areas for future research}

Per capita estimations used in this analysis are based on the consumption conversion factors described by Verduzco-Gallo et al. (2014). Since quantity was estimated using conversion factors, rather than actual measurements of quantities of food consumed, we cannot rule out biases. This is because nonstandardized local units are imprecise and food quantities acquired may have been overestimated or underestimated (Fisher \& Lewin, 2013). We support our results by comparing our per capita calculations to that of similar studies using the same dataset and find similarities in food quantities consumed in Malawi(Verduzco-Gallo et al., 2014). In poor contexts diets for adults and children do not differ (Hotz \& Gibson, 2001; Adelheid W Onyango et al., 2013). In South Africa per capita consumption of vegetables, meat, vegetables and eggs for children 1-5 years closely mirror our findings (Nel \& Casey, 2003). A key strength of our study is that the regressions used panel data which likely accounted for unobserved confounding factors. Inclusion of a child level module is however recommended in future welfare surveys to allow research on child-level consumption data.

Similarly, the presence of random measurement errors in anthropometric measurements makes it difficult to obtain unbiased estimate of HAZ (Mani, 2012b). However, since the panel data did not follow children from birth, we 
were unable to determine the influence of other potential factors such as initial HAZ. This is an area for future research. Our study adds to the discourse on quantity and frequency of food consumption, and it attempted to overcome the identified methodological challenge of estimating a near direct or 'dose- response" of animal food groups on linear growth (Allen, 2012)

\subsection{Conclusion}

Overall, our study shows that despite their limited consumption in Malawi, ASF contributed to linear growth unlike other food groups. In order to be effective, dietary guidelines should promote consumption of specific animal source food items, such as milk and eggs from a local diet that show an association with linear growth. Findings suggest that giving milk and eggs, 2-3 times per week can be beneficial. The findings further suggest the importance of ASF in child growth even in non-diverse diets and how their benefits may differ by age, type of food group/food and household social economic status. Promoting the consumption of ASF should remain part of child growth promotion strategies in resource-poor settings. 



\section{CHAPTER 4: Determinants of Transitions in Early Childhood Growth.}

This chapter draws upon:

Mutinta Hambayi, Nyasha Tirivayi, Groot W .Determinants of Transitions in Early Childhood Growth. Submitted for publication. 


\section{Abstract}

We assessed the probabilities and determinants of transitions in growth among children aged 6-59 months, in a sample of children $(n=530)$ from the World Bank welfare monitoring survey conducted in 2010 and 2013 in Malawi

We utilize panel data to assess transitions in child height using a two state Markov model. We compare the probabilities of children becoming nonstunted, defined as HAZ ( $<-2 \mathrm{z}$-score), to the probabilities of children's becoming stunted. Probit models are used to explore determinants of transitions in growth and covariates include child age, gender, illness history, mother education level, participation in nutrition programs and asset poverty.

Result show that of the 530 children, 21\% were stunted in 2010. About $65 \%$ of the children became non-stunted, 35\% remained in their prior state and $16 \%$ became stunted (worsened). Around $70 \%$ of boys had a positive growth transition compared to $58 \%$ of girls, while more non-poor children $(78 \%)$ recovered compared to poor children (46\%).

Participation in nutrition programs was associated with positive transition (49.4 percentage points; $\mathrm{P}<0.001$ ) and prevented worsening (23pp; $\mathrm{P}<0.001$ ). An additional year of the mother' schooling was also associated with shifting to non-stunted state (3.8pp; $\mathrm{P}<0.001)$. Worsening of growth was more likely among asset poor (32.7pp: $\mathrm{P}<0.001)$ and younger children (6pp; $\mathrm{P}<0.001$ ), children with recent history of illness (15.3pp; $\mathrm{P}<0.05)$ and children living in the central region (9pp $\mathrm{P}<0.05)$. We conclude that there is potential for children to become non-stunted from being stunted. Strategies to promote transitioning and prevent negative linear growth in childhood growth should be evidence-based and comprehensive. 


\subsection{Introduction}

Stunting is a global pandemic affecting 155 million (UNICEF, 2017). Of all the stunted children, $57 \%$ and $37 \%$ live in Asia and Africa, respectively (UNICEF, 2017). In most cases, if stunted below the age of two years, it is suggested that the associated consequences are largely irreversible (Adelheid W Onyango et al., 2013; Victora et al., 2010). However, there is evidence suggesting that children go through growth transitions or shifts in childhood and mid adulthood (Martorell et al., 1994; Prentice et al., 2013; A. D. Stein et al., 2010). As discussed in chapter 1, transitioning both to and from stunting, measured as a change in HAZ is documented in literature (Crookston, Penny, Alder, Dickerson, Merrill, \& Stanford, 2010; Teivaanmäki et al., 2015a). Linear growth improvements and becoming non-stunted is associated with improved nutrient intake and a three-fold reduced risk to morbidity and mortality. Furthermore, studies suggest that removing a risk factor that induces an absolute centimeter deficit in height in a child, can over time decrease as each single encounter with a risk factor becomes relatively less important in a longer history of cumulative risk (Luo \& Karlberg, 2000; Teivaanmäki, Cheung, Kortekangas, Maleta, \& Ashorn, 2015b). Elizabeth A Lundeen et al. (2014) further observes that child growth trajectories are predicted in part by child size during the first year of life but there is still significant variation in growth patterns after that first year. Taken together, the studies suggest the potential for non-stunted children to have reduced risk to disease in the short term and likely to overcome their height deficits overtime if linear growth continue to improve.

At the center of the debate is the measurement of the dynamics of child growth which has been dominated by areas of contention in the literature detailed in Chapter 1. These concern methodological concerns for calculating catch up growth (Jef L. Leroy et al., 2015), whether recovery or catch up is at all possible, as suggested (Elizabeth A Lundeen et al., 2014), and if possible, what factors would be associated with catch up or growth failure(Crookston, 
Penny, Alder, Dickerson, Merrill, \& Stanford, 2010; I. Outes \& C. Porter, 2013). In addition, the debate is also about using absolute $\mathrm{z}$ score scales measure to catch up growth (de Onis \& Branca, 2016; Jef L Leroy et al., 2015). For example, no definition of catch up growth is established and change in HAZ has been used to describe catch-up growth (Crookston, Penny, Alder, Dickerson, Merrill, Stanford, et al., 2010).

In this chapter, we focus on the HAZ indicator because HAZ compares children across countries and allow to compare with literature that used the same approach. We detailed in chapter 1 , the consequencies of being stunted, benefits of becoming non-stunted and different terms used to describe children who were stunted and become non-stunted, using the the $\mathrm{z}$ scale (HAZ) cut off (Elizabeth A Lundeen et al., 2014; Teivaanmäki et al., 2015a). Therefore, the terms growth transition or nonstunted, explained in the introductory chapter are used in this dissertation.

\subsubsection{Study rationale}

In this chapter we investigate the determinants and probabilities of transitions from stunting to non-stunting and vice versa in early childhood growth in Malawi. Malawi, is a poor and high stunting burden country and therefore a good case for assessing whether growth transitions occurred among children aged 6-59 months. The study follows the Mosley Chen child survival theory (W. H. Mosley \& L.C.Chen, 2003) described in the introduction. The child survival theory predicts that child growth or failure is a cumulative process influenced by a combination of biological, household and environmental conditions. In this regard, the determinants of stunting are multifaceted and can reflect poor diet quality, breastfeeding practices, long term burden of infectious disease and adverse environmental exposure (Semba et al., 2008). However most studies show that becoming non-stunted reflects adequacy in nutrient intake, improved micronutrient status (De Pee, 
2018) which reduces risk to morbidity and mortality. (Prendergast \& Humphrey, 2014).

In Malawi, earlier studies that measured child growth from fetal age to 15 years noted that there is limited knowledge about the transition in growth between age intervals, (Elizabeth A Lundeen et al., 2014; Teivaanmäki et al., 2015a). Our study seeks to fill this research gap. Our study differs from Teivaanmäki et al. (2015a) in its methodological approach and age range. We are particularly interested in assessing if and how a child aged between 6-59 months who are stunted become non-stunted. We build on the classical way of measuring child growth by using a Markov type model. The Markov model, accounts for the nonlinear dependence chain of the determinants of transitions conditioned on the child's prior state (Caputo, Foraita, Klasen, \& Pigeot, 2003). Our analysis uses longitudinal data (Chen et al., 2016) that gives a distribution to predict transitions which satisfies the Markov property. The Markov model is preferred because it explains a set of transitions expected in literature, which are, for example relevant for age related analysis in stunting and likely to be determined by probability of distribution.

The scope of the analysis is to explore the probabilities and determinants of a positive and negative growth transitions (worsening) to fill the gap in understanding the risk to proportion of stunting in the Malawi context.

\subsection{Methods}

\subsubsection{Study site and data}

As explained in detail in Chapter 1, Malawi is a low income country with a high disease burden that experiences climatic and economic shocks. The consumption patterns are dominated by non-diverse diets (Allen, 2012). As a result, the country's children suffer from all forms of malnutrition. It is 
estimated that about 37\% of the children are stunted each year (DHS 2015). The study's sample is drawn from nationally representative longitudinal surveys conducted in 2010 and 2013 by the World Bank under the Living Standards series. This is the same sample we used in Chapter 3 for the analysis of dietary diversity. Our analytical sample comprises a panel of 530 children between the ages of 6-59 months out of a sample of 1,100 household. Height and weight data were collected at child level. The survey measured supine length for children below 24 months and standing height for children above 24 months. In addition, data on household demographics, amenities, household members' illness, food consumption and income, agricultural activities and social economic status information were captured. The data are publicly available from the World Bank website, are anonymized, and exempted from institutional ethical review. It can also be downloaded after registration with the National Statistics office of Malawi from http://go.worldbank.org/ or site: http://www.nsomalawi.mw/

\subsubsection{Explanatory variables}

The seminal UNICEF conceptual framework depicts the complexity and interplay of factors described in the child survival theory (W Henry Mosley \& Lincoln C Chen, 2003; U. WHO, 2013). In the UNICEF framework three main levels, broadly grouped as distal, intermediate and proximal factors, are distinguished (Wamani et al., 2006). The distal factors are household and environmental characteristics. Proximal factors are birth order, health services utilization and immediate factors are dietary intake and disease. These may be influenced by household practices such as child care and health seeking behaviors (Fenske et al., 2013). Unmodifiable factors that affect nutrition status are biological i.e. age and child gender.

In our analysis we include mothers' education as a distal covariate as it has been shown to improve child health outcomes through knowledge of dietary choices, and healthy practices (Chou et al., 2010; Vikram, Vanneman, \& 
Desai, 2012). We also include the food consumption score, which is a validated composite measure of food security and a proxy for dietary diversity (Jones et al., 2013). Dietary diversity and feeding frequency promote an adequate nutrient intake necessary for optimal growth (Zongrone et al., 2012). In addition, asset poverty as a distal household factor that directly impact household food security and ultimately transitions in growth. Distal environmental factors such as household amenities like sanitation and electricity are included as these facilities have been linked to a lower risk of severe stunting (Fink et al. (2011).

The analysis also includes modifiable and non-modifiable proximal factors such as age, birth order, gender, incidence of child illness, participation in nutrition programs and growth monitoring clinics. Briefly, we find in the literature that child growth risks associated with modifiable and nonmodifiable proximal factors are: age due to rapid growth during their early years in life especially below the age of two years. Studies show that a large proportion of linear growth deficits that make up the under-5 stunted burden are accumulated during the first 1000 days of a child's life due to a combination of poor feeding practices and infections (Kathryn G Dewey \& Huffman, 2009). For birth order (J. R. Behrman \& Taubman, 1986) suggests that older children are favored in intra-household food allocation as an investment endowment, which may make them less vulnerable to stunting. Child gender (Cleland \& Van Ginneken, 1988), child gender feeding preference (J. R. Behrman, Pollak, \& Taubman, 1986) and child prioritization are risk factors to child feeding in some contexts (Ingo Outes \& Catherine Porter, 2013). Child illness hampers appetite, reduces food intake and is an immediate risk to sudden weight loss and can trigger a rapid transition in state. Preventive and curative services such as participation in growth nutrition programs are dual in purpose, as a source of mothers' knowledge on child feeding practices (Fenske et al., 2013) and serve to control childhood illnesses thereby promoting physical growth (WHO 2003). 


\subsubsection{Statistical analysis}

Examining determinants of stunting implies the exploration of a complex association structure including a large number of potential variables influencing the outcome at various levels (Stevens et al., 2012). Any empirical strategy examining the determinants of undernutrition, must recognize the existence of such a dependence chain (Caputo et al., 2003).

The statistical analysis was performed in several steps. The main dependent variables are the transitions from stunting to non-stunting and vice versa during the period 2010-2013. First, we categorized stunting as a binary variable. The variable; stunted and non-stunted, is expressed as HAZ, stunted if $\mathrm{HAZ}<-2$ and non-stunted if $\mathrm{HAZ}>-2$, following World Health Organization's Child Growth Standards (WHO, 2006). We then analyzed the similarities and differences between stunted and non-stunted children across the years. Chi-square tests were used to test the association between child nutritional status and a range of child, household and socio economic characteristics (Chikhungu \& Madise, 2014).

We also assessed the dynamics of transitions becoming stunted and nonstunted using a Markov model (Odongo et al., 2015). Markov modelling assesses the outcome conditioned on the explanatory variables and the past state in outcome (Chen et al., 2016). We use panel data to assess stunting in 2013 conditioned on the child's state in 2010. Hence the analysis can be described as a first order two state Markov chain (Islam \& Chowdhury, 2006).

We consider two stunting transitions as follows;

- State $1 \rightarrow 2$ - Positive growth transition : non-stunted in 2013 while stunted in 2010

- State $2 \rightarrow 1$ - Worsening: stunted in 2013 while non-stunted2010; 
We assumed no change in states if a child remains non-stunted or stunted given the prior state in $2010(t-1)$. Using the xttrans command in the Stata13 software package, the raw unadjusted Markov transition probabilities for each change in state are estimated by a simple non parametric count method, similar to other literature (Odongo et al., 2015).

Finally, we estimated the determinants of the transitions through multivariable probit regressions. We analyzed transitions for two groups, positive growth and worsening, conditioned on the prior state in 2010 (Islam and Chowdhury 2006), controlling for distal, immediate and proximal factors. In longitudinal data, the Markov models permit the separate prediction of covariate effects on the outcome and determine how two or more processes change together (Diggle \& Verbyla, 1998). The coefficients from the probit models were reported as marginal effects with statistical significance set at $\mathrm{p}<0.05$ at the $95 \%$ confidence interval. We assessed the goodness of fit and multicollinearity between predictor variables by checking the correlation of the coefficients after running the regression and were satisfied that the correlation was low; $r<-0.5$ (Chikhungu \& Madise, 2014).

\subsection{Results}

\subsubsection{Descriptive statistics}

Table 4.1 describes the child and household characteristics of the sample. Table 4.1 shows that stunted and non-stunted children were on average the second born child and similar in age at follow up ( $\sim 50$ months). Surprisingly dietary diversity and the number of meals eaten did not differ between groups. However, the mean age for stunted and non-stunted children differed significantly at baseline (respectively $14.5 \pm 6$; $16.7 \pm 6$ : $\mathrm{P}<0.001$ ). The data show that younger children were more likely to be stunted, while older 
stunted children, were likely to be more severely stunted (HAZ $<-2.3$ vs $<-2.5$ $\mathrm{P}<0.001)$. The differences between stunted and non-stunted children were significant in both years $(\mathrm{P}<0.001)$. Initially, boys were significantly more stunted than girls $(59 \%$; $48 \%$ : $\mathrm{P}<0.001)$ but not at follow up. At follow up the difference between boys and girls in stunting had disappeared. Stunted children were more likely to report illnesses compared to their counterparts across the years ( $40 \%$ vs $35 \%$ and $39 \%$, vs $37 \%$ ). Less than $10 \%$ of the stunted children participated in a nutrition program and the trend declined over the years. As children grow older, participation in growth monitoring clinics is significantly higher for stunted children $(60 \%$ vs $47 \%$; $\mathrm{P}<0.05)$ respectively.

Table 4.1: Sample characteristics at baseline and follow up

\begin{tabular}{|c|c|c|c|c|}
\hline \multirow[b]{2}{*}{ Variable } & \multicolumn{2}{|l|}{2010} & \multicolumn{2}{|l|}{2013} \\
\hline & Stunted & $\begin{array}{l}\text { Non- } \\
\text { stunted }\end{array}$ & Stunted & $\begin{array}{l}\text { Non- } \\
\text { stunted }\end{array}$ \\
\hline \multicolumn{5}{|l|}{ Child characteristics } \\
\hline Total number of children & 126 & 404 & 110 & 420 \\
\hline Age (months) & $\begin{array}{l}16.71 \\
(6.03)\end{array}$ & $\begin{array}{l}14.45 \\
(6.14)^{* * *}\end{array}$ & $\begin{array}{l}49.36 \\
(4.83)\end{array}$ & $\begin{array}{l}49.66 \\
(5.25)\end{array}$ \\
\hline Child is male (\%) & $\begin{array}{l}0.59 \\
(0.49)\end{array}$ & $\begin{array}{l}0.48^{*} \\
(0.50)\end{array}$ & $\begin{array}{l}0.47 \\
(0.50)\end{array}$ & $\begin{array}{l}0.52 \\
(0.50)\end{array}$ \\
\hline Birth order & $\begin{array}{l}2.52 \\
(1.04)\end{array}$ & $\begin{array}{l}2.49 \\
(1.09)\end{array}$ & $\begin{array}{l}1.98 \\
(0.78)\end{array}$ & $\begin{array}{l}2.04 \\
(0.83)\end{array}$ \\
\hline Number meals eaten & $\begin{array}{l}2.83 \\
(0.74)\end{array}$ & $\begin{array}{l}2.88 \\
(0.78)\end{array}$ & $\begin{array}{l}2.74 \\
(0.62)\end{array}$ & $\begin{array}{l}2.75 \\
(0.90)\end{array}$ \\
\hline HAZ & $\begin{array}{l}-2.33 \\
(0.95)\end{array}$ & $\begin{array}{l}-0.67^{* * *} \\
(1.06)\end{array}$ & $\begin{array}{l}-2.55 \\
(0.86)\end{array}$ & $\begin{array}{l}-0.86^{* * *} \\
(0.99)\end{array}$ \\
\hline $\begin{array}{l}\text { Child in a nutrition program } \\
(\%)\end{array}$ & $\begin{array}{l}0.08 \\
(0.27)\end{array}$ & $\begin{array}{l}0.13 \\
(0.34)\end{array}$ & $\begin{array}{l}0.08 \\
(0.28)\end{array}$ & $\begin{array}{l}0.07 \\
(0.24)\end{array}$ \\
\hline $\begin{array}{l}\text { Growth monitoring clinic } \\
\text { participation (\%) }\end{array}$ & $\begin{array}{l}0.87 \\
(0.34)\end{array}$ & $\begin{array}{l}0.88 \\
(0.33)\end{array}$ & $\begin{array}{l}0.60 \\
(0.49)\end{array}$ & $\begin{array}{l}0.47 \\
(0.50)\end{array}$ \\
\hline Child illness past 2 weeks & $\begin{array}{l}0.40 \\
(0.49)\end{array}$ & $\begin{array}{l}0.35 \\
(0.48)\end{array}$ & $\begin{array}{l}0.18 \\
(0.39)\end{array}$ & $\begin{array}{l}0.16 \\
(0.37)\end{array}$ \\
\hline
\end{tabular}




\section{Household characteristics}

\begin{tabular}{lllll} 
Household size & 5.76 & 5.77 & 6.12 & 6.13 \\
Mother education level & $(1.96)$ & $(2.26)$ & $(1.96)$ & $(2.09)$ \\
(years) & 4.52 & 5.29 & 3.91 & 5.13 \\
Poor by asset proverty (\%) & $(3.27)$ & $(3.62) * *$ & $(3.26)$ & $(3.66)^{* * *}$ \\
& $(0.36$ & 0.31 & 0.57 & 0.43 \\
Food consumption score & 55.52 & 53.31 & 54.67 & $(0.50)^{* * *}$ \\
Experienced unusual food & $(19.06)$ & $(19.02)$ & $(17.59)$ & $(17.82)$ \\
prices & 1.68 & 1.77 & 1.14 & 1.21 \\
Free food assistance (yes) & $(0.47)$ & $(0.42)$ & $(0.35)$ & $(0.40)$ \\
Toilet ownership (yes) & 1.98 & 1.98 & 1.90 & 1.95 \\
& $(0.15)$ & $(0.13)$ & $(0.30)$ & $(0.22)$ \\
Has electricity \% & 0.79 & 0.76 & 0.65 & 0.71 \\
Socioeconomic characteristics & & $(0.43)$ & $(0.48)$ & $(0.45)$ \\
Northern & 3.02 & 24.72 & 2.45 & 0.11 \\
Central Region (\%) & 9.81 & 25.85 & 9.62 & $(0.31)^{* *}$ \\
Southern Region $(\%)$ & 10.94 & 26.66 & 8.68 & 24.72 \\
\hline
\end{tabular}

\subsubsection{Raw transition probabilities}

Table 4.2 shows the raw unadjusted probabilities of a positive growth transition and worsening (becoming stunted). The results show that bidirectional state transitions occurred. Among those stunted in 2010, 65\% became non-stunted by 2013. Among those not stunted in 2010, 16\% had worsened in 2013 (became stunted). Among all children in the sample, the unadjusted probabilities of becoming non-stunted in 2013 are higher (65\%) than worsening (16.3\%). However, the results show a high probability of children remaining in prior state for a third $(35 \%)$ of children that were stunted in 2010, mirroring the current level of 37\% stunting in Malawi (DHS 2015). Positive transitioning (if stunted in 2010), differed by gender and 
poverty status. More boys than girls $(70 \% ; 58 \%)$ and more non-poor than poor children ( $78 \%$ and $46 \%$ ) respectively, were more likely to achieve a nonstunted state. Over half (54\%) of the poor children remained in their prior stunted state compared to only $22 \%$ non-poor children.

Table 4.2: Raw transition probability matrix

\begin{tabular}{lll}
\hline All children & \multicolumn{2}{c}{ Stunting status at time t (2013) } \\
\hline Stunting at time t-1 (2010) & Non-stunted $(\mathrm{N}=420)$ & Stunted $(\mathrm{N}=110)$ \\
Non-stunted $(\mathrm{N}=404)$ & 83.66 & 16.34 \\
Stunted $(\mathrm{N}=126)$ & 65.08 & 34.92 \\
State prevalence & 79.25 & 20.75 \\
Girls & Non stunted $(\mathrm{N}=202)$ & Stunted $(\mathrm{N}=58)$ \\
Non stunted $(\mathrm{N}=208)$ & 82.69 & 17.31 \\
Stunted $(\mathrm{N}=52)$ & 57.69 & 42.31 \\
Boys & Non stunted $(\mathrm{N}=215)$ & Stunted $(\mathrm{N}=52)$ \\
Non-stunted $(\mathrm{N}=193)$ & 84.46 & 15.54 \\
Stunted $(\mathrm{N}=74)$ & 70.27 & 29.73 \\
poor & Non stunted $(\mathrm{N}=99)$ & Stunted $(\mathrm{N}=35)$ \\
Non stunted $(\mathrm{N}=99)$ & 83.84 & 16.16 \\
Stunted $(\mathrm{N}=35)$ & 45.71 & 54.29 \\
Non poor & Non stunted $(\mathrm{N}=207)$ & Stunted $(\mathrm{N}=40)$ \\
Non-stunted $(\mathrm{N}=189)$ & 85.71 & 14.29 \\
Stunted & 77.59 & 22.41 \\
(N=58) & & \\
\hline
\end{tabular}

Table 4.3 shows the probit regression results on the transition from stunting to non-stunting and vice versa during the period 2010-2013. All explanatory variables are taken at their 2010 values. Of all the predictor/explanatory variables explored, only participation in nutrition programs significantly predicted positive or negative growth transition over the time period. Factors that were associated with positive growth transition were 
participation in nutrition programs and the mother's years of education. Sick children and those in asset poor households were less likely to become nonstunted. The educational level of the mother and participating in nutrition programs were significantly promotive of positive growth transition by 3.8 and 49.4 percentage points (pp) $(\mathrm{P}<0.001)$, respectively. A child who had been ill in the previous two weeks was 15pp $(\mathrm{P}<0.01)$ less likely to recover Asset poverty was associated with a reduction in recovery of $32.7 \mathrm{pp}$ $(\mathrm{P}<0.001)$. Regressions show that more months in age are negatively associated with worsening. The result is also positively associated with positive growth transition, but not statistically significant. Similarly owning a toilet marginally reduced becoming stunted by $0.1 \mathrm{pp}$ and was associated with an increase in worsening by $6.7 \mathrm{pp}$ but not statistically significant

Table 4.3: Probability of recovery from stunting or worsening in stunting

\begin{tabular}{|c|c|c|c|c|}
\hline Variable & $\begin{array}{l}\text { Positive } \\
\text { growth } \\
\text { Transition } \\
2013\end{array}$ & $\begin{array}{l}\text { Marginal Effects } \\
2013\end{array}$ & $\begin{array}{l}\text { Negative growth } \\
\text { transition } \\
\text { (Worsened) } \\
2013\end{array}$ & $\begin{array}{l}\text { Marginal } \\
\text { Effects } \\
2013\end{array}$ \\
\hline Child age in month & $\begin{array}{l}0.017 \\
(0.027)\end{array}$ & $\begin{array}{l}0.005 \\
(0.008)\end{array}$ & $\begin{array}{l}-0.028^{* *} \\
(0.014)\end{array}$ & $\begin{array}{l}-0.006^{* *} \\
(0.003)\end{array}$ \\
\hline Child is male & $\begin{array}{l}0.211 \\
(0.275)\end{array}$ & $\begin{array}{l}0.065 \\
-(0.084)\end{array}$ & $\begin{array}{l}-0.017 \\
-(0.157)\end{array}$ & $\begin{array}{l}-0.004 \\
-(0.035)\end{array}$ \\
\hline Birth order & $\begin{array}{l}0.159 \\
(0.207)\end{array}$ & $\begin{array}{l}0.049 \\
(0.063)\end{array}$ & $\begin{array}{l}0.018 \\
(0.105)\end{array}$ & $\begin{array}{l}0.004 \\
(0.024)\end{array}$ \\
\hline $\begin{array}{l}\text { Number of meals } \\
\text { per day }\end{array}$ & $\begin{array}{l}0.020 \\
(0.204)\end{array}$ & $\begin{array}{l}0.006 \\
(0.063)\end{array}$ & $\begin{array}{l}-0.173 \\
(0.113)\end{array}$ & $\begin{array}{l}-0.039 \\
(0.025)\end{array}$ \\
\hline $\begin{array}{l}\text { Child in a nutrition } \\
\text { program }\end{array}$ & $\begin{array}{l}1.608^{* * *} \\
(0.540)\end{array}$ & $\begin{array}{l}0.494^{* * *} \\
(0.155)\end{array}$ & $\begin{array}{l}-1.022^{* * *} \\
(0.333)\end{array}$ & $\begin{array}{l}-0.230^{* * *} \\
(0.075)\end{array}$ \\
\hline $\begin{array}{l}\text { Growth monitoring } \\
\text { clinic participation }\end{array}$ & $\begin{array}{l}-0.112 \\
(0.407)\end{array}$ & $\begin{array}{l}-0.034 \\
(0.125)\end{array}$ & $\begin{array}{l}0.233 \\
(0.250)\end{array}$ & $\begin{array}{l}0.052 \\
(0.056)\end{array}$ \\
\hline $\begin{array}{l}\text { Child ill past } 2 \\
\text { weeks }\end{array}$ & $\begin{array}{l}-0.498^{*} \\
(0.282)\end{array}$ & $\begin{array}{l}-0.153^{*} \\
(0.084)\end{array}$ & $\begin{array}{l}-0.169 \\
(0.165)\end{array}$ & $\begin{array}{l}-0.038 \\
(0.037)\end{array}$ \\
\hline Household size & $\begin{array}{l}-0.142 \\
(0.119)\end{array}$ & $\begin{array}{l}-0.044 \\
(0.036)\end{array}$ & $\begin{array}{l}-0.060 \\
(0.049\end{array}$ & $\begin{array}{l}-0.014 \\
(0.011)\end{array}$ \\
\hline
\end{tabular}




\begin{tabular}{|c|c|c|c|c|}
\hline $\begin{array}{l}\text { Mother years of } \\
\text { education }\end{array}$ & $\begin{array}{l}0.124^{* *} \\
(0.049)\end{array}$ & $\begin{array}{l}0.038^{* * *} \\
(0.014)\end{array}$ & $\begin{array}{l}-0.012 \\
(0.025)\end{array}$ & $\begin{array}{l}-0.003 \\
(0.006)\end{array}$ \\
\hline Poor by asset & $-1.065^{* * *}$ & $-0.327^{* * *}$ & -0.115 & -0.026 \\
\hline poverty & $(0.342)$ & $(0.095)$ & $(0.198)$ & $(0.044)$ \\
\hline \multirow[t]{2}{*}{ Has toilet } & -0.004 & -0.001 & 0.298 & 0.067 \\
\hline & $(0.340)$ & $(0.104)$ & $(0.200)$ & $(0.045)$ \\
\hline \multirow{2}{*}{$\begin{array}{l}\text { Food consumption } \\
\text { score }\end{array}$} & -0.005 & -0.002 & 0.001 & 0.000 \\
\hline & $(0.008)$ & $(0.003)$ & $(0.005)$ & $(0.001)$ \\
\hline \multirow{2}{*}{$\begin{array}{l}\text { Free food } \\
\text { assistance (yes) }\end{array}$} & omitted & omitted & 0.246 & 0.055 \\
\hline & omittea & omittea & $(0.618$ & $(0.135)$ \\
\hline \multirow[t]{2}{*}{ Toilet Ownership } & -0.004 & -0.001 & 0.298 & 0.067 \\
\hline & $(0.340)$ & $(0.102)$ & $(0.200)$ & $(0.045)$ \\
\hline \multirow[t]{2}{*}{ Central region } & 0.178 & omittod & $0.416^{* *}$ & $0.090^{* *}$ \\
\hline & $(0.279)$ & omitted & $(0.200)$ & $(0.043)$ \\
\hline \multirow[t]{2}{*}{ Southern } & ( & $0 \Omega 0$ & 0.341 & 0.071 \\
\hline & 0.000 & 0.000 & $(0.209)$ & $(0.044)$ \\
\hline \multirow[t]{2}{*}{ Rural } & 0.448 & 0.136 & 0.142 & 0.031 \\
\hline & $(0.382)$ & $(0.112)$ & $(0.228)$ & $(0.048)$ \\
\hline \multirow[t]{2}{*}{ Constant } & 0.278 & & 0.617 & \\
\hline & $(1.283$ & & $(0.639)$ & \\
\hline \multirow{2}{*}{$\begin{array}{l}\mathrm{N} \\
\text { Pseudo R2 }\end{array}$} & 107 & 107 & 404 & 404 \\
\hline & 0.178 & & 0.079 & \\
\hline \multirow{2}{*}{$\begin{array}{l}\text { Log likelihood } \\
\text { chi2 }\end{array}$} & -58.571 & & -165.525 & \\
\hline & 28.446 & & 32.871 & \\
\hline $\begin{array}{l}\text { Correctly classified } \\
\text { (VIF) }\end{array}$ & $86.64 \%$ & & $86.64 \%$ & \\
\hline
\end{tabular}

Notes: 1) Standard errors in parentheses, 2) ${ }^{* * *} \mathrm{p}<0.001,{ }^{* *} \mathrm{p}<0.05 .{ }^{*} \mathrm{P}<0.01$ 3) Control variables: age in months, sex of child, birth order, number of meals, illness in last 2 weeks, under five clinic attendance, part of nutrition program, mother education, asset poverty, toilet ownership, free food, region 4) Northern and Urban as reference 5) we excluded electricity in model since only .7\% households had electricity to avoid small sample bias 6) observations correctly predicted with multicollinearity test using Variance Inflation Factor. 


\subsubsection{Determinants of becoming stunted (worsening)}

Participation in a nutrition program reduced the chances of becoming stunted but age of child and region of residence were disadvantageous. Participating in nutrition programs was associated with a reduction in worsening by 23pp $(\mathrm{p}<0.001)$ A younger child was more likely to worsen by 6pp $(\mathrm{p}<0.05)$ compared to an older child. Similarly, living in the central region was associated with an increase in worsening by $9 p p(p<0.05)$. Unexpectedly, we found a positive but non-significant association of dietary diversity (food consumption score) on worsening but the association is not statistically significant. Children who were frequently fed were likely to become non-stunted and less likely to worsen but the probability is not statistically significant. Toilet ownership had no significant effect.

In additional analysis, local polynomial regression analysis was used to plot the probabilities of becoming non-stunted or worsening against selected continuous explanatory variables in our probit models. Child age, mother education level and food consumption score. Figure 4.1 shows that the probabilities of positive growth transition rise steeply with increasing mother education level and food consumption score. The probability of worsening decreases as children grew older, consistent with the probit regression results in Figure 4.1. We found an inverse relationship between food consumption score and worsening up to around 54 units, beyond which the probability fluctuates and regains an upward trend. See Figure 4.2. 
Figure 4.1. Probabilities of becoming nonstunted by mother education and food consumption score
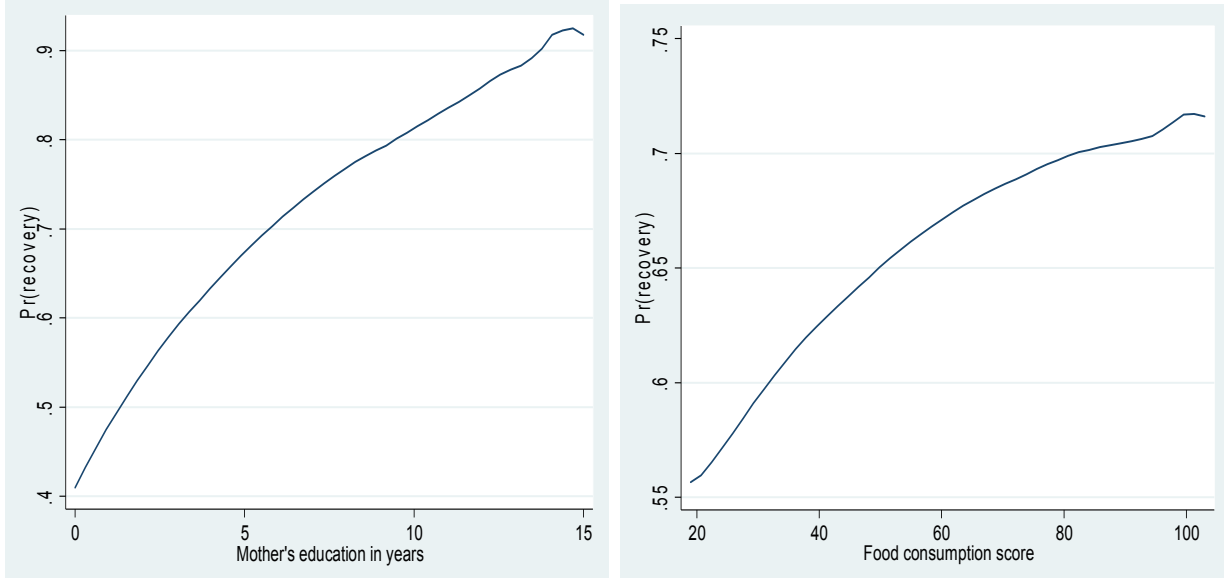

Figure 4.2 Probabilities of worsening by age and food consumption score.
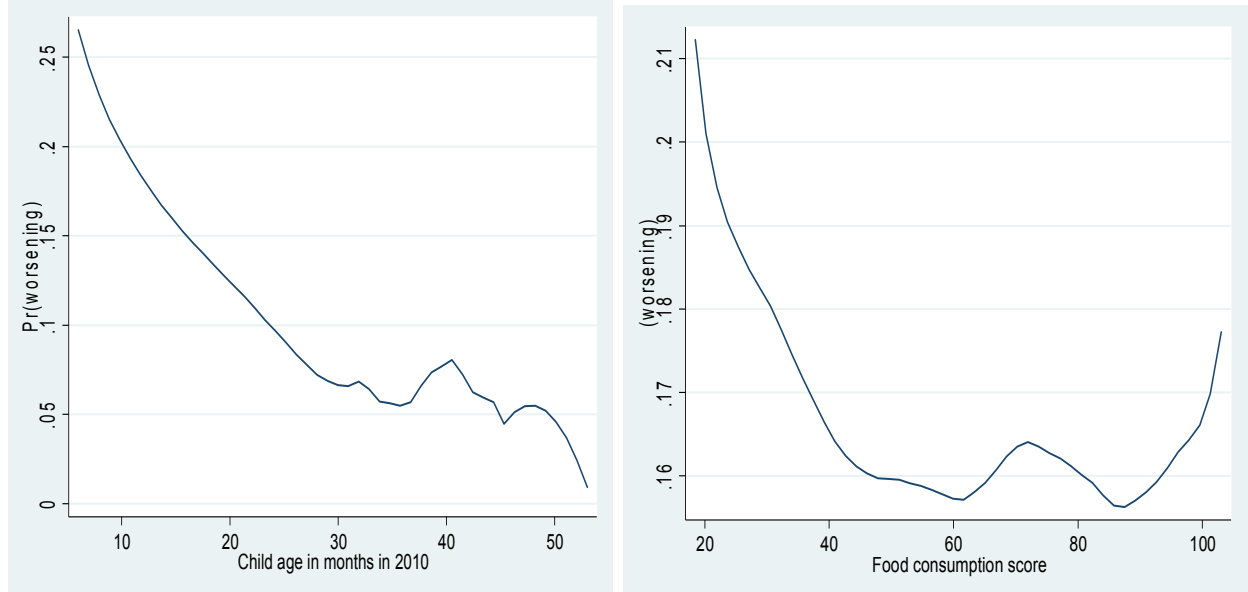

\subsection{Discussion}

The purpose of this analysis was to explore the probabilities and determinants of becoming stunted and non-stunted among children in Malawi. In our study, stunting affects one in every five children (21\%). We used a Markov chain model to show growth dynamics among children 6-59 
months (Chen et al., 2016). Though not entirely comparable except for measurement of growth trajectories, one important distinction from studies that reported on "catch up growth" in mid childhood and puberty (Prentice et al., 2013), is that our result examines early childhood transitions based on the child's previous growth patterns using z scores scales (Crookston et al., 2010). To our knowledge, this is the first study to apply a Markov type model on child growth in Malawi. The findings show that there are considerable transitions in the children's first five years of life.

Despite differences in the approach for measuring worsening and positive growth, we come to the same conclusion as Teivaanmäki et al. (2015a) that bidirectional state transitions occur among children in Malawi. Our results show that the potential for to become non-stunted exists among children under five years in Malawi and elsewhere (Aryeh D Stein et al., 2010). In Chapter 1 and in the introduction to this chapter we raised the issue of becoming non-stunted and the debate if this implies the reversibility or irreversibility of consequences associated stunting. As substantiated in literature, our findings suggest that children who become non-stunted may have reduced risk to disease and death since improved linear growth signifies improved nutrient intake and immunity (De Pee, 2018). This, however, does not say anything about the reversibility of the consequences of stunting such as brain development which is beyond the scope of the analysis.

The unadjusted probabilities shows that transitions to a positive shift from the threshold defining "normality" in HAZ (de Onis \& Branca, 2016) occurred for $65 \%$ of the children. The gender and poverty dynamics were most interesting in this regard. More boys were stunted than girls at baseline but shifting to non-stunted state was lower for girls in our sample, similar to other findings (Aheto, Keegan, Taylor, \& Diggle, 2015) but contrary to others (Chikhungu \& Madise, 2014; Espo et al., 2002). Due to a lower rate in becoming non-stunted among girls the difference in stunting rates between 
boys and girls in 2010 had disappeared by 2013. The cause of this discrepancy is not well established in literature but there is a belief that differences may be precipitated by some cultural norms of gender preference (I. Outes \& C. Porter, 2013). In 2010 boys were more likely to be stunted than girls. Our result however show that in 2013 there is no longer a difference in the stunting rate between boys and girls as boys appear to shift to the right side of the threshold more than girls. Probably the differences may be attributed to unmeasured factors such as parental care-giving behavior (Beka, Wambui, Zewditu, \& Girum, 2009). Consistent with other studies, over half $(54 \%)$ of the poor children remained in their prior stunted state compared to only $22 \%$ non-poor children. The low positive transitioning in the poor group is not a surprising finding, since poverty remains a major cause of undernutrition in sub-Sahara Africa (Akombi, Agho, Merom, Renzaho, \& Hall, 2017). In Ethiopia economic growth reduced undernutrition (Biadgilign, Ademe, \& Yesigat, 2016) but not was the case in India (Joe, Rajaram, \& Subramanian, 2016) suggesting that addressing undernutrition stems from a myriad set of factors requiring comprehensive strategies and not only poverty reduction approaches.

We also found that $16.3 \%$ of the children became stunted, consistent with the $16.7 \%$ found in Teivaanmäki et al. (2015a). Over a third of the children remained in the same state from 2010 to 2013. Boys and non-poor children were less likely to exit their non-stunted condition compared to girls and poor children. This shows that among some children it was difficult to transition from a prior state. Over the years, levels of stunting in Malawi have in general stagnated (Ecker, Breisinger, Pauw, Fan, \& Pandya-Lorch, 2012). In our study $35 \%$ of the children remain in the stunted state which mirrors the 37\% prevalence of stunting in Malawi (DHS 2015). This result only partially substantiates the argument that if children remain in the same environment, achieving optimal linear growth is an unlikely possibility (Jef L. Leroy et al., 2015). The above findings reveal transition dynamics of 
children that suggest some benefits of being non-stunted at an early age and the best timing to prevent stunting (Zulfiqar A Bhutta et al., 2008).

The regression results show that several factors are associated with transitions from or into stunting. The results show that stunting determinants span across all levels of the conceptual framework. Proximal determinants are child age, sex and history of illness (Chirwa \& Ngalawa, 2008) and participating in nutrition programs. Distal household and socio economic determinants were mother education and asset poverty status. Interestingly, dietary diversity was a positive determinant of recovering but was not statistically significant. Results for sanitation were less conclusive.

Our findings consistently show that the older a child is, the less likely they are to become stunted (National Statistical Office/Malawi \& ICF, 2017). Studies suggest that older children can ask for, or find, food themselves, compared to younger children who are at risk to stunting due to transitioning from breastfeeding to poor diets (Chirwa \& Ngalawa, 2008; Zongrone et al., 2012). Another immediate cause of stunting may relate to effect of illness. Our result shows a higher prevalence of illness among stunted children. Chikhungu and Madise (2014) found illness in Malawi to be a major predictor of malnutrition. In Pakistan, risk factors for worsening varied at different ages, relate more to feeding at early ages, and as children grow older previous "stunting status" becomes the predominant factor predicting their current status, corroborating our findings and consistent with the Markov principle(Saleemi, Ashraf, Mellander, \& Zaman, 2001). Literature has further clearly shown the importance of early age, the first 1,000 days as the most critical period to prevent chronic malnutrition lifelong consequences (Black et al., 2008). However, we demonstrate potential to transition positively in older children though not statistically significantly. Further research is recommended to explore potential to examine the rate at which children who cross the threshold catch up with growth the growth deficit, detailed in the introduction, with more panel data series. 
Of all the predictor variables explored, only nutrition programs significantly predicted positive transitioning and or not worsening. Nutrition programs are not only intended to measure weight but monitor physical growth and counsel parents in order to motivate actions that improve growth (WHO 1986). These findings confirm the benefits of nutrition programs in resource poor settings as both protective and growth promoting. . The findings are also notable and could be the result of policy. Concerted efforts by the Malawi government to address malnutrition in general and stunting in particular may be paying off. In 2011, Malawi introduced the scaling up nutrition strategy, which is designed to deliver a package of interventions to address chronic malnutrition (Kodish, Aburto, Hambayi, Kennedy, \& Gittelsohn, 2015).

The educational level of the mother was significantly promotive of the nonstunted state. The nexus between mother levels of education and better nutrition outcomes is found in the literature (Güneş, 2015). The beneficial effect of the mother's education on promoting nutrition outcomes is explained by the mother's autonomy in decision making, ability to communicate and translate health knowledge from health workers into child care actions. Ruel, Habicht, Pinstrup-Andersen, and Gröhn (1992), concluded that mother's knowledge could contribute to child growth but a household must have minimum resources otherwise education alone is not sufficient, hence education acts as proxy to high social economic status. Household wealth in turn is associated with increased access to animal source foods and health care resources(Chou et al., 2010; Makoka, 2013).

Interestingly, the finding that the food consumption score had no statistically significant effect on growth transitions provokes further debate on whether FCS is an ideal indicator for measuring dietary diversity. Baumann et al. (2013), concluded in a study in Laos that the FCS in its original form underestimated the food insecurity level but that the closeness of fit to the benchmark classification improves when small amounts of food items are 
excluded from the assessment. This is problematic in the Malawi context since food quantities are a major cause of concern and dietary quality is improved by adding small quantities, especially of animal source foods to children's diets. Furthermore, food consumption and dietary diversity score thresholds have been described as setting the bar too low, suggesting that quantity and not diversity is the problem (Jones et al., 2013; Kennedy et al., 2010). In our analysis, this limitation may, however, have been magnified by the fact that the food consumption score was calculated at household level.

Our results are further indicative of other underlying factors affecting the dynamics of child growth. In 2010, Malawi experienced unfavorable climatic conditions that affected agriculture. The literature highlights that climatic conditions such as drought undermine child linear growth (Akombi et al., 2017). This may explain in part the higher levels of stunting in 2010 compared to 2013. Our results of no significant results on sanitation merit further research. The analysis found less than $10 \%$ ownership of toilet facilities.

However while the case on association between poverty and stunting is made (Dunbar, Lewbel, \& Pendakur, 2013; Ecker et al., 2012), there is limited evidence on which single intervention can effectively prevent early childhood growth transitions based on the determinants, as found in this study, or whether an integrated package incorporating different interventions is more effective (Shekar et al., 2016). The debate is endless on the priority underlying drivers of stunting to address (Beka et al., 2009). The causes probably vary in different settings, as well as over time (Beka et al., 2009), confirming this analysis.

Our analysis was limited by the use of panel data with only two data points which makes it difficult to explore dynamics beyond two state transitions and in between the survey rounds. However since linear growth, is an indicator of a cumulative process (W. H. Mosley \& L. C. Chen, 2003), we are 
confident that the transitions estimated accommodate the changes that may have occurred between baseline and follow up. In our findings, we show that determinants of positive transitioning and worsening differ by age and gender. The question remains; under what conditions is positive transitioning most likely? Our results should inform efforts to intervene at an early age but paying attention to all under five year olds. We are careful to emphasise that programs take an approach of targeting all under-five year olds to promote such positive transitioning, due to widespread vulnerabilities in this context. Though debated, other scholars document this phase as mid childhood recovery (Aryeh D Stein et al., 2010). A single intervention would not address stunting if determinants are heterogeneous. As such we suggest an evidence based, sector-wide and comprehensive package of interventions that seek to address determinants at all levels. In our findings, only about $10 \%$ children participate in nutrition programs. Yet, we demonstrate the value of these programs as avenues to promote child growth. A policy consideration would be to extend health facility based services to communities by adapting the well known parent care group model (Perry et al., 2014). A long term and sustainable goal would be to provide conditions for achieving higher years of schooling than the current 5 years in Malawi to improve behaviour on childcare.

Due to limited data points, we could not further explain whether transitions positive or negative are specific to an age category or the causal effect of maternal education on stunting. We therefore recommend further research as well as research on the reversibility of consequences of stunting.

\subsection{Conclusion}

The study set out to explore probabilities of child growth dynamics and their determinants in Malawi. This analysis supports the view that there are transitions in child growth, especially a positive transition above the 
stunting threshold, in Malawi. This result corroborates the finding in Teivaanmäki et al. (2015a). We found that among children 6-59 months, about six in ten children became non-stunted. Transitions differ by gender. Boys were more vulnerable to stunting at a young age, while growth dynamics were less for girls than for boys. Factors that were associated with crossing the threshold were participation in nutrition programs and the mother's years of education. These factors emphasizes the importance of mothers knowledge and may relate to the fact that the mothers as primary caregivers have influence on decisions and knowledge as seen in both in the child survival theory and in literature. The knowledge gained from participating in nutrition programs as well as through formal maternal education enhances ability to implement those behaviors that are good for child health and contribute to child growth (Semba et al., 2008). We also found that worsening occurred for some children and stunting persisted in others. Worsening of growth was more likely among asset poor, younger children, children with recent history of illness and children living in the central region. Results from this analysis contribute to the discourse on identifying appropriate sector linkages to improve linear growth outcomes. 



\section{CHAPTER 5: Maternal Education and its Causal Effect on Child Growth: Evidence from a Natural Experiment in Malawi}

This chapter draws upon:

Mutinta Hambayi, Nyasha Tirivayi, Groot W. Maternal Education and its Causal Effect on Child Growth: Evidence from a Natural Experiment in Malawi. Submitted for publication. 


\section{Abstract}

We examined the causal effect of maternal education on child growth. We use the 1994 Free Primary Education reform in Malawi as a natural experiment. We utilize the exogenous variability in schooling from the policy reform and a discontinuity in age to model the causal effects on child stunting. Our analysis exploits two waves of nationally representative data.

We find that a one year increase in schooling for a mother increases child height for age by about 0.202 standard deviations or $13 \%$. Maternal education also reduces stunting by 7 percentage points or $17.6 \%$. The findings are robust to different specifications. Further analysis shows that the mechanisms through which maternal education improves child growth are: increased milk consumption, age at first birth, child birth size, access to prenatal care, utilization of preventive and curative services for children; the presence of an educated father and reduced maternal agriculture labor participation.

Our findings suggest that keeping girls in school can be an effective strategy for improving child linear growth. 


\subsection{Introduction}

Female education is considered to be the single most important factor explaining differentials in child health outcomes (Black et al., 2013). As a matter of policy, investing in women's education is seen as an important developmental goal for improving child health and lowering infant and child mortality, especially in developing countries (Desai \& Alva, 1998). Studies have observed that the education of women in industrialized countries has resulted in healthy families (Desai \& Alva, 1998). Since then, the literature has paid significant attention to the links between maternal education and improved child health (Frost et al., 2005; Imdad, Yakoob, \& Bhutta, 2011a).

Caldwell (Caldwell, 1994) argues that the influence of education on child health should not be considered in isolation from the wider context, and research should isolate the effects of education in various contexts. Yet, empirical evidence of causal effects remains scant in developing countries. To date, the few empirical studies available focus on the link between maternal education and child mortality (Grepin \& Bharadwaj, 2015; Marshall \& Makate \& Makate, 2016), HIV status and reproductive outcomes (Duflo, Dupas, \& Kremer, 2012) but not on nutrition outcomes. Güneş (2015) is the first to empirically investigate the causality between tuition-free maternal education and stunting in a developing country (Güneş, 2015). Evidence is only emerging in Sub Sahara Africa (Keats, 2016). This is despite the region accounting for 20 of the 24 countries with stunting rates of over $40 \%$ (UNICEF, 2015). To our knowledge, no studies have determined the causal impact of maternal education on child linear growth in Malawi.

In this study, we test the hypothesis that increasing maternal education levels improves linear growth thereby reducing stunting. We therefore examine the causal effect of a mother's education on HAZ and stunting. The 
analysis explores exogenous variation in education for a cohort of mothers who benefitted from the Free Primary Education (FPE) policy introduced in 1994. We use a fuzzy regression discontinuity approach estimated via a two stage least squares (2SLS) framework in which we exploit the variation in schooling caused by the free primary education policy (FPE) in Malawi in 1994 to identify the education effects. This identification strategy is similar to that used in previous related studies (J. A. Behrman, 2015; Marshall Makate, 2016) who have used this to identify effects of maternal education on HIV status and child mortality. In addition, we also explore the mechanisms through which maternal education affects HAZ and stunting. Examples of such mechanisms include: dietary patterns for children, health seeking behaviors, the sanitation environment, maternal age at first birth and the father's education level.

Malawi is an interesting case since the policy reform explicitly favored girls' education (Kadzamira \& Rose, 2003). Malawi is also an ideal setting as it is home to 1.4 million stunted children under the age of five years (about 37\%) since data were first collected in 1992. Levels above 37\% are considered, a severe public health problem by WHO standards (National Statistical Office/Malawi \& ICF, 2017; WHO, 2006). Past empirical research in Malawi has focused on the effects of maternal education on child mortality (Marshall \& Makate \& Makate, 2016) or have explored correlations (Chirwa \& Ngalawa, 2008; Makoka, 2013). Given the lack of causal studies assessing the effects maternal education on child linear growth in Malawi and limited number of causal studies in sub-Saharan Africa (Keats, 2016), our study provides new insights to literature. The data for analysis are obtained from the nationally representative Malawi Demographic and Health Surveys (MDHS) conducted in 2010, and 2015.

These sections are organized as follows. Section 5.1 introduces the chapter, 5.1.1 reviews empirical literature on the subject and Section 5.1.2 provides an overview of the free primary education policy in Malawi. Section 5.2 
describes the data source, variables used and the identification strategy. Section 5.3 presents the results. Section 5.4 discusses the results, study limitations and concludes the chapter.

\subsubsection{Relevant Literature health and nutrition outcomes}

Empirical theory suggests several pathways for the prevention of stunting through the mother's education (Abuya, Onsomu, Kimani, \& Moore, 2011). In Kenya, mothers with primary education had $94 \%$ lower odds of having stunted children than mothers with no education (Abuya et al., 2011). Conceptually, stunting, a form of chronic malnutrition can be prevented through a set of immediate determinants of adequate and quality dietary intake and the disease environment which directly influence nutrition outcomes (UNICEF, 1990). In the case of maternal education, the foremost implicit assumption is that improved literacy would lead to higher socio economic status, appropriate diet choices, and improved health seeking behaviors (Grossman, 2006; Makoka, 2013). Therefore, the gains in high education levels for women translate into mothers' capabilities and efficiency in utilizing both preventive and curative services (Andersen, 1973; Caldwell, 1994). In Frost et al. (2005) the benefits of maternal education that are examined include health knowledge, modern attitudes towards health care, female autonomy, and positive reproductive behavior. For educated mothers, the autonomy in decision making, lies in the enhanced ability to communicate with health workers and to translate promotive child care actions, such as immunizations (Vikram et al., 2012). Choi et al. (2011) found that children with educated mothers consumed ASF and were less unlikely to have unhealthy eating patterns compared to children with illiterate mothers (Vikram et al., 2012).

Many empirical studies have found a positive relationship between maternal education and child growth. Phiri (2014) in a study of a diverse context of 16 countries, found low levels of education or the lack of education, to be 
important risk factors for child stunting. In another study of 42 developing countries, maternal education was the second most important predictor of child nutritional status after GDP (Boyle et al., 2006). Other studies found an inverse relationship between the level of stunting and maternal education after controlling for socio-economic and environmental factors (Miller \& Rodgers, 2009; Wamani et al., 2006). A study in Lesotho found that a mother's knowledge could contribute to child growth in wealthy households whereas in poor households knowledge alone was not sufficient for improving child growth. (Ruel et al., 1992). In India, one study found that stunting was significantly higher among uneducated mothers, children from low socio economic strata and children who had been ill prior to the surveys (Meshram et al., 2012).

Caldwell (1994), argued that different levels of education among mothers can result in different effects on children and their health. Evidently, the different levels of maternal education required to reduce the likelihood of stunting were found to differ between countries, from 9 years in Malawi to 11 years in Tanzania and Zimbabwe (Makoka, 2013). The odds of child stunting decreased with increasing levels of formal education of the mother or father(Semba et al., 2008). Furthermore, a meta-analysis of empirical studies found that moving from illiteracy to primary education level did not affect stunting, while maternal higher education had the strongest negative relationship with child stunting followed by secondary education(Phiri, 2014).

Although there is a correlation between mothers' education and child growth, the causal relationship is far from established as it is not significant in developing countries (Desai and Alva, 1998; Chou, Liu, Grossman, \& Joyce, 2010). Methodologically, it is a challenge to identify and isolate the independent and causal effects of maternal education on child growth by fully accounting for bias from observed and unobserved factors. In Desai and Alva (1998) introducing controls for husbands' education and access to water 
and sanitation diminished the impact of maternal education on infant mortality and height-for-age. Thus, contrary to the standard estimates, mother's schooling did not appear to improve substantially children's health outcomes, though it did seem to increase their nutrient intake (Wolfe \& Behrman, 1987). Wolfe and Behrman (1987) suggest that the effect of female education on health outcomes may be overstated in studies that do not control for a woman's childhood environment during which health related skills and habits are acquired. (Wolfe \& Behrman, 1987) found that when unobserved childhood and family characteristics are controlled for, the impact of women's schooling on nutrition is quite robust, but diminishes on other health outcomes.

Emerging literature treats the exogenous changes in education produced by education reforms as natural experiments. Since more formal education typically leads to higher income, policies to increase, the former appear to have large returns for more than one generation throughout the world(Chou et al., 2010). A natural experiment is therefore preferred for this analysis to explore the inter-generational effect of increased girl's schooling on nutrition status of their offspring (Semba et al., 2008). The term natural experiment describes a naturally-occurring contrast between a treatment and a comparison condition(Cook, Campbell, \& Shadish, 2002). A natural experiment employs a transparent exogenous source of variation in the explanatory variable that determine the treatment assignment induced by a policy change or a compulsory law (Meyer, 1995).

In this case while randomized controlled trials are typically considered the gold standard for causal inference, the use of a discontinuity cut off from a natural experiment is known as a Quasi-experiment, in behavior sciences and recently popularized in economics(Cook et al., 2002). A quasiexperiment is not quite a natural experiment, hence the term "Quasi-" but a class of methods that take advantage of exogenous sources of variation in exposure assignment to emulate random treatment assignment (Oldenburg, 
Moscoe, \& Barnighausen, 2016). The exogenous variable is an instrument in the instrumental variable analysis (IV) that is a cause of the exposure but is otherwise unrelated to the outcome and, as such, is outside or 'exogenous' to the causal structure under study assignment (Oldenburg et al., 2016). The validation of the design and causal inference from regression-discontinuity (RD) is judged by use of graphical analysis as detailed in the model.

In many scenarios, an intervention threshold may not be adhered to strictly, resulting in some subjects receiving (or not receiving) the intervention contrary to what would be indicated by their assignment variable(Cook et al., 2002). Therefore estimation of the causal effect of the intervention must account for this 'fuzziness' present in the observed data (Oldenburg et al., 2016).

A number of studies have used this causal approach in natural experiments to identify the impacts of education and outcomes such as fertility (Chicoine, 2012; Osili \& Long, 2008), HIV infection and stigma(J. A. Behrman, 2015; Grépin \& Bharadwaj, 2015; Tsai \& Venkataramani, 2015). These studies address the endogeneity of schooling by using the exogenous variation in exposure to education reforms as an instrumental variable to estimate health and nutrition impacts (Güneş, 2015; Keats, 2016; Marshall Makate, 2016). Studies from Zimbabwe and Uganda found that additional years in schooling reduced child mortality (Grepin \& Bharadwaj, 2015; Güneş, 2015; Keats, 2016; Marshall Makate, 2016). Fewer studies have examined the impact of maternal education on child growth outcomes. Gunes (2015) found that a marginal increase of education from 5 to 8 years increased child nutrition status among children below 5 years of age in Turkey. In Keats (2016), children born from women with an additional year in schooling were 15 percentage points less likely to be stunted. These studies utilized a two stage least squares regressions (2SLS) framework to demonstrate causality after controlling for several conceptually relevant covariates. This study aims to contribute to this nascent body of literature by examining the causal 
effects of maternal education on child growth and exploring the causal pathways.

\subsubsection{Free Primary Education (FPE) Reforms in Malawi}

Background characteristics on Malawi can be found in Chapter 1 of this dissertation. In Malawi, primary school completion is attained after 8 years over an age range of 6-13 years (J. A. Behrman, 2015). Postcolonial education policies from 1973-1980 and 1985-1995 shifted emphasis from increasing tertiary and secondary levels to increasing universal primary education (Kadzamira \& Rose, 2003). Following the first democratically elected government of Malawi in 1994, primary school fees were abolished and primary school became accessible to Malawians of all backgrounds (de Hoop, 2010). The 1994 policy abolished constraining factors for poor families and removed, for example, all forms of fees and the wearing of uniforms. As in many African countries, the introduction of free primary education in the 1980's to mid-90s, aimed to reduce poverty through the socio economic benefits that comes with education (Avenstrup, Liang, \& Nellemann, 2004; Kadzamira \& Rose, 2003).

The policy had a gender focus. It encouraged the participation of girls in primary schools, return of pregnant girls to school after giving birth and waived fees for girls in secondary schools in 1995 (Kadzamira \& Rose, 2001). Net enrolments prior to FPE were $58 \%$ for girls, increasing to $73 \%$ by 1996 ; and $58 \%$ for boys, but only increasing to $68 \%$ by 1996 . In $1999 / 2000$, male and female gross enrolment rates were comparable at 157.9 and $158.3 \%$, respectively (Riddell, 2003). Overall the elimination of fees resulted in increased primary enrollment from 1.9 million in 1993/94 to 2.9 million by 1999/2000 (Marshall Makate, 2016). By 2011, the Gross Enrolled Rate (GER), rose from $71 \%$ to $110 \%$, which is slightly above $100 \%$ due to grade repetitions (J. A. Behrman, 2015). However, the massive enrollments did not match the inputs into the education system as the quality of education declined 
resulting in repetition and dropout rates in the region of 17 per cent and 16 per cent, respectively (Chirwa \& Matita, 2009).

\subsection{Methods}

The data sets used in this analysis are from two waves of the Malawi Demographic and Health Surveys (MDHS) collected in 2010 and 2015. The MDHS is a cross sectional nationwide survey conducted by ICF international in collaboration with the Malawi government. The sample for this analysis is 10,086 ever married women of reproductive age (15-49 years). We choose the ever married women to highlight the potential for teenage marriage and its implications on nutrition (Kalanda, Verhoeff, \& Brabin, 2006). The objective of the MDHS is to record demographic and health information, mainly of women and children (National Statistical Office/Malawi \& ICF, 2017). The standardized modules include, but are not limited to; maternal schooling, child health, anthropometry, knowledge and feeding practices, history of child illness and service utilization, wealth index, water and sanitation. The survey utilizes a stratified two-stage cluster sample frame from the Malawi population and housing census. At the first stage, clusters are sampled randomly, and the next stage is followed by the random sampling of the listed households. Given that we use data pooled across multiple surveys, we adjusted the original sampling probability weights provided in the MDHS making sure that each survey had equal representation in the sample (Makate, 2017). This adjustment is necessary to minimize any potential biases associated with pooling across these surveys especially in the computation of the descriptive statistics. Details on how to obtain the dataset can be accessed at http://www.measuresdhs.com.

The main outcome variables are stunting and height for age. Height for age is an anthropometric indicator, height for age z-score (HAZ), that reflects the growth of a child during the pre- and post- natal period (Abuya et al., 2011). 
Stunting is a binary variable equaling one if the child's height- for- age $z$ score is less than minus two standard deviations (i.e. HAZ <-2) and zero otherwise (i.e. HAZ > -2). This definition is consistent with the World Health Organization's Child Growth Standards (WHO, 2006). Stunting, unlike wasting, is a linear growth failure that develops through a slow cumulative process, a sign of chronic malnutrition (Fenske et al., 2013). Stunting in childhood is a strong composite marker of child well-being as it is associated with morbidity and mortality risk (WHO 2015).

Maternal education is measured by total years of schooling at survey date, an indicator of school completion. For control variables, we include conceptual causes of stunting found in the seminal UNICEF conceptual framework (UNICEF, 1990). Other child-level explanatory variables; biological factors of age, child gender, are all observed at the survey date. We also include birth order to control for the respondents' parity. Studies find birth order and short birth intervals a risk to stunting (Fenske et al., 2013). We control for potential geographical differences by including regional fixed effects and an urban residence dummy variable. As argued in Buor (2003), depending on opportunities, services can differ between rural and urban areas. The years of schooling for the husband were excluded as a potential determinant of nutrition due to its high correlation with maternal schooling (Chou et al., 2010). Given that we focus on examining the impact of mother's education on the nutrition outcomes of the next generation, our explanatory variables are all post-treatment variables as in previous studies (Makate, 2016; Grépin, 2015).

To explore the impact of maternal schooling on child nutrition outcomes (height for age and stunting), we start with a very basic formulation that expresses child growth outcomes as a function of maternal education and several other relevant control variables. The naïve model of the effect of maternal education on child growth is expressed as follows:

$$
N_{i}=\beta_{0}+\beta_{1} \text { meduc }_{i}+X_{i}^{\prime} \gamma+\delta_{i}+r_{i}+\varepsilon_{i}
$$


here, $N_{i}$ represents the nutrition outcomes (i.e. height-for-age z-scores and stunting) for the $i^{\text {th }}$ child, $m e d u c_{i}$ is maternal education (i.e. years of schooling or the probability of completing primary school or higher) as observed at the survey date; $X_{i}$ is a vector of individual and household-level characteristics believed to influence child nutrition such as the child's age in months, gender, birth order, mother's height, indicator for head of household status, and indicators for household wealth; $\delta_{i}$ are the survey fixed effects, $r_{i}$ are the region fixed effects, $\beta_{0}$ is the intercept term, and $\varepsilon_{i}$ is a disturbance term. Our interest lies in the parameter estimate, $\beta_{1}$ which measures the degree of association of the mother's education level on child nutrition outcomes. This coefficient, $\beta_{1}$ cannot be seen as having a causal impact on child nutrition due to potential biases emanating from other unobserved factors influencing both mother's education and child nutrition, the endogeneity problem. To circumvent the issue of endogeneity, we therefore exploit the exogenous variation in schooling opportunities emanating from the FPE in Malawi in 1994. The FPE increased primary school prospects for individuals' contingent on their age at the time of policy implementation. The policy change provides a 'quasi-experiment' and observational data for the analysis.

We utilize the fuzzy regression discontinuity design (RDD) approach in our identification strategy. The regression discontinuity (RD) design is a quasiexperimental design that estimates the causal effects of a treatment by exploiting naturally occurring treatment rules (Geneletti, O'Keeffe, Sharples, Richardson, \& Baio, 2015). Alternatives to a "fuzzy RDD" are maximum likelihood-based and a Bayesian approaches. Although Calonico et al (2015) proposes data-driven way of producing the graphs demonstrating smoothness around the discontinuity or a maximum likelihood, other authors argue that the estimation of the LATE variance is not necessarily straightforward with a maximum likelihood-based approach. (O'Keeffe \& Baio, 2016). 
The rationale for adopting the fuzzy RD model. which, is based on the observation that exposure to the FPE policy was probabilistic (J. A. Behrman, 2015). Given the non-compulsory nature of the FPE, it is quite plausible that some children who would have otherwise enrolled for primary school missed out due to other reasons such as early labor market participation and early marriage, a common phenomenon in many African countries including Malawi (UNICEF, 2014). Therefore estimation of the causal effect of the intervention must account for this 'fuzziness' present in the observed data (Oldenburg et al., 2016). In such instances the two-stage least squares approach has often been preferred, because an approximation for the variance of the local average treatment effect can be computed relatively easily and validated in this kind of "fuzzy RD design (Keeffe \& Baio, 2016)". Following Behrman (2015) our empirical strategy compares the growth outcomes of children of mothers who were aged 11-13 years old in 1994 to those aged 14-16. The fuzzy RD naturally leads to a simple two-stage least squares (2SLS) estimation strategy (Angrist, Imbens, \& Rubin, 1996)in which the binary indicator variable for exposure to the FPE is used as the instrumental variable (Van der Klaauw, 2002)

Following previous studies (Behrman, 2015; Grépin and Bharadwaj, 2015; Makate \& Makate, 2016), the first stage of our 2SLS model takes the following form:

$$
\begin{aligned}
\text { meduc }_{i}=\pi_{0}+ & \pi_{1} D_{i}+\pi_{2} D_{i} \times\left(\text { age }_{i, 1994}-13\right) \\
& +\pi_{3}\left(1-D_{i}\right) \times\left(\text { age }_{i, 1994}-13\right)+X_{i}^{\prime} \gamma+\delta_{i}+r_{i} \\
& +\epsilon_{i}
\end{aligned}
$$

where $D_{i}$ equals one if the individual's age in 1994 was 13 years or younger and zero for otherwise. As is standard practice in RD models, we incorporate the linear age approximates below and above the age 13 cut-point to fully exploit the discontinuity in schooling. The vector $X_{i}^{\prime}$ includes the control variables mentioned earlier. We then estimate equation (2) using ordinary least squares (OLS) to generate the predicted values of mother's education, 
$\widehat{\operatorname{medu}} c_{l}$. We then use the predicted values of schooling in the second stage model formulated as follows:

$$
\begin{aligned}
N_{i}=\mu_{0}+\mu_{1} \widehat{\widehat{m e d u}} c_{l}+\mu_{2} D_{i} \times\left(\text { age }_{i, 1994}-13\right) \\
+\mu_{3}\left(1-D_{i}\right) \times\left(\text { age }_{i, 1994}-13\right)+X_{i}^{\prime} \gamma+\delta_{i}+r_{i} \\
+\varepsilon_{i}
\end{aligned}
$$

here, $\widehat{\operatorname{medu}} c_{l}$ is the predicted level of education computed in equation (2) with $\mu_{1}$ giving us an estimated causal effect of mother's schooling on child nutrition. In the case when $N_{i}$ is a binary variable to measure child stunting, we also considered using a probit regression estimated using ioprobit in Stata. Given the challenges with convergence in some of our models and for ease of interpretation, we opted to use a linear probability model. Besides, the marginal effects generated by both models are nearly similar. The education effect, $\mu_{1}$ shown in equation (3) measures the complier-average causal effect of mother's schooling, which can also be termed the local average treatment effect (LATE) (Angrist et al., 1996), which we cannot generalize to other data contexts except for the Malawi analytical sample data used here. In other words, the effect we measure is for those individuals whose additional schooling could be influenced by the instrumental variable (i.e. age 13 years and younger in 1994). The group of women fitting this description are termed "compliers", borrowing the terminology of (Angrist et al., 1996). We cluster the standard errors at the region of residence and mother's age in 1994 to correct for any possible within-group error correlations.

Our confidence in the 2SLS model rests on the following assumptions. First, it must be the case that after accounting for the relevant explanatory variables, the instrumental variable only influences our main outcomes through exposure to the policy change (Wooldridge, 2010). In this case, this assumption suggests that within the preferred age bandwidth, assignment to the treatment cohorts should not have influenced child growth except through its impact on mother's schooling. Though this assumption is rather difficult to test, we provide additional robustness checks in the succeeding 
section to support our empirical estimates. Secondly, it ought to be the case that the instrumental variable highly correlates with mother's schooling. Our first stage results show that this assumption is indeed satisfied. Additionally, we provide a formal test of the quality of our instrumental variable and provide the first stage F-statistics. An F-statistic of 10 or higher suggests that the chosen instrumental variable is strong (Staiger, 1997). We show that for our main estimates shown in Table 5.3, this assumption is indeed satisfied. Additionally, we furnish smoothness tests of all the explanatory variables considered in the analysis to show that the impact of schooling that we report is not biased by potential discontinuities in other explanatory variables. See Figures B5.1-6.

We conduct several robustness checks to test the sensitivity of our empirical estimates. First, as is known in the standard RD literature, the precision of the estimates largely depends on the size of the age bandwidth considered with shorter bandwidths preferred (Angrist et al., 1996). We considered broader age bandwidths of 9-18 years and 10-17 years and a narrower bandwidth of 12-15 years. It is worth noting that there is always a trade-off between bias and precision, with shorter or narrower and wider bandwidths associated with imprecise and biased estimates, respectively (Lee, 2010). Thus, we consider four different age bandwidths to check whether the education impact (i.e. found using our preferred age bandwidth of 11-16 years in 1994) is robust to variations in the noted age bandwidths. The results from these analyses are presented in Table 5.5. Lastly, we assumed a sharp RDD and performed reduced form estimations that identify "intent to treat" analysis effects i.e. estimate the impact of eligibility to the Malawi FPE reform in 1994 on linear growth and stunting. In this case, child linear growth outcomes are the dependent variables in equation 2 . The results from these analyses are presented in Table 5.6. Overall, the results from the robustness checks show that our main estimates are strongly robust to these alternative specifications. 


\subsection{Results}

\subsubsection{Descriptive statistics}

Table 5.1 presents the descriptive statistics for our preferred age bandwidth of women aged 11-16 years in 1994; treated $(n=6505)$, control, $(n=3580)$ including the results from the pairwise t-tests. Approximately $16 \%$ of the sample is urban based, but the women did not differ in wealth status. The average years of schooling is 5.23 years, but it differed by cohort. The treated group stayed longer in school than the control group (5.5 years vs 4.9 years). About $14 \%$ of the respondents were illiterate; less in the treated than control group (12\% vs $17 \%$ ). School dropout is high with only $9 \%$ completing primary school (suggesting a 91\% drop out). Only about $2.1 \%$ acquired higher education.

Table 5.1: Summary statistics for selected variables of the analysis with pairwise t-tests

\begin{tabular}{|c|c|c|c|c|}
\hline & $\begin{array}{l}\text { Aged 11- } \\
13 \text { in 1994 }\end{array}$ & $\begin{array}{l}\text { Aged 14- } \\
16 \text { in } 1994 \\
\end{array}$ & SD & $\begin{array}{l}\text { Aged 11-16 } \\
\text { in 1994 }\end{array}$ \\
\hline Variables & -1 & -2 & $(1)-(2)$ & -3 \\
\hline \multicolumn{5}{|l|}{$\begin{array}{l}\text { Mother-level } \\
\text { variables }\end{array}$} \\
\hline Years of schooling & 5.599 & 4.977 & $0.622^{* * *}$ & 5.324 \\
\hline No education & 0.117 & 0.172 & $-0.055^{* * *}$ & 0.141 \\
\hline Incomplete primary & 0.576 & 0.565 & 0.011 & 0.571 \\
\hline Complete primary & 0.087 & 0.082 & $0.005^{* *}$ & 0.085 \\
\hline $\begin{array}{l}\text { Incomplete } \\
\text { secondary }\end{array}$ & 0.139 & 0.102 & $0.037^{* * *}$ & 0.123 \\
\hline $\begin{array}{l}\text { Complete } \\
\text { secondary }\end{array}$ & 0.059 & 0.059 & 0 & 0.059 \\
\hline Higher education & 0.022 & 0.019 & 0.003 & 0.021 \\
\hline Age at survey date & 29.787 & 32.816 & $-3.029^{* * *}$ & 31.125 \\
\hline Age in 1994 & 11.911 & 14.861 & $-2.95^{* * *}$ & 13.214 \\
\hline
\end{tabular}




$\begin{array}{lllll}\text { Age at first birth } & 18.756 & 19.049 & -0.293^{* * *} & 18.886 \\ \text { Wealth index (1-5) } & 3.029 & 2.97 & 0.059 & 3.003 \\ \text { Toilet - flush } & 0.025 & 0.031 & -0.006 & 0.027 \\ \text { Toilet - pit latrine } & 0.887 & 0.887 & 0 & 0.887 \\ \text { Toilet - other type } & 0.007 & 0.004 & 0.003 & 0.006 \\ \text { Toilet - none } & 0.081 & 0.077 & 0.004 & 0.079 \\ \text { Number of women } & 6506 & 3580 & 2926 & 10086 \\ \text { Number of children } & 9129 & 5061 & & 14190\end{array}$

\section{Child-level}

variables

\begin{tabular}{|c|c|c|c|c|}
\hline Age in months & 31.001 & 30.627 & $0.374^{* * *}$ & 29.809 \\
\hline Child is female & 0.495 & 0.493 & 0.002 & 0.500 \\
\hline Child year of birth & 2009 & 2005 & $3.582^{* * *}$ & 2006 \\
\hline $\begin{array}{l}\text { Height-for-age z- } \\
\text { score }\end{array}$ & -1.475 & -1.834 & 0.359 & -1.820 \\
\hline Stunting & 0.374 & 0.489 & -0.115 & 0.485 \\
\hline Child size (1-5) & 2.623 & 2.691 & -0.068 & 2.692 \\
\hline Ever vaccinated & 0.906 & 0.853 & $0.053^{* *}$ & 0.868 \\
\hline $\begin{array}{l}\text { Had fever in last } 2 \\
\text { weeks }\end{array}$ & 0.325 & 0.339 & -0.014 & 0.351 \\
\hline Fever treatment & 0.62 & 0.471 & 0.149 & 0.478 \\
\hline Given meat & 0.118 & 0.104 & $0.014^{* *}$ & 0.112 \\
\hline Given fish & 0.216 & 0.202 & 0.014 & 0.21 \\
\hline Given milk & 0.051 & 0.047 & 0.004 & 0.049 \\
\hline
\end{tabular}

Geographical variables

$\begin{array}{lllll}\text { South region } & 0.457 & 0.486 & -0.029^{* * *} & 0.47 \\ \text { Central region } & 0.424 & 0.407 & 0.017^{* *} & 0.417 \\ \text { North region } & 0.119 & 0.108 & 0.011 & 0.114 \\ \text { Urban area } & 0.159 & 0.133 & 0.026 & 0.147\end{array}$

Notes: ${ }^{* *}$ Significant at $1 \%$ level; ${ }^{* *}$ significant at $5 \%$ level; ${ }^{*}$ significant at $10 \%$ level. All the data is extracted from the child-recode data files of the Malawi Demographic and Health Survey (MDHS) conducted in 2010, and 2015. Summary statistics are weighted to be nationally representative of the Malawian general population. 
Teenage marriage and motherhood was common. Women by age 18.8 years had a first birth. Stunting levels among children were high and comparable, though slightly lower for the exposed than non-exposed group (37\% vs 49\%) respectively. The mean HAZ score is -1.82 almost at the $<-2$ cut off. Over $87 \%$ of the children were ever vaccinated. About $35 \%$ had a history of fever in the last two weeks prior to the survey. Yet, we observe that less than half of the mothers sought treatment for their children's fever ailments. Giving meat and milk to toddlers was uncommon, with little difference between the two groups $(11 \%$ and $5 \%)$ respectively. However, one in five children ate fish during the week.

\subsubsection{Effect of maternal education on height-for-age (HAZ) and stunting.}

First, we present graphical evidence of the age discontinuity in exposure to the reform. We build on eligibility to reform to estimate impact of FPE on the likelihood of completing primary school for the treated group. Then we present the results of the first stage regressions. In the results from second stage regressions, causal estimates are presented.

Figure 5.1 shows the overall impact of FPE policy on education schooling and completion. The result shows that abolishing primary school fees yielded the expected result. The impact is far larger for primary than secondary or tertiary levels. In Figure 5.2, it appears that possibilities of being in primary and secondary school favored girls below the age of 13 than their older counterparts. This observation supports our empirical strategy in which we compare the growth outcomes of children born to women who were aged 11-13 years in 1994 to those aged 14-16 in 1994. 
Figure 5.1: The impact of the 1994 free primary education on maternal education in Malawi
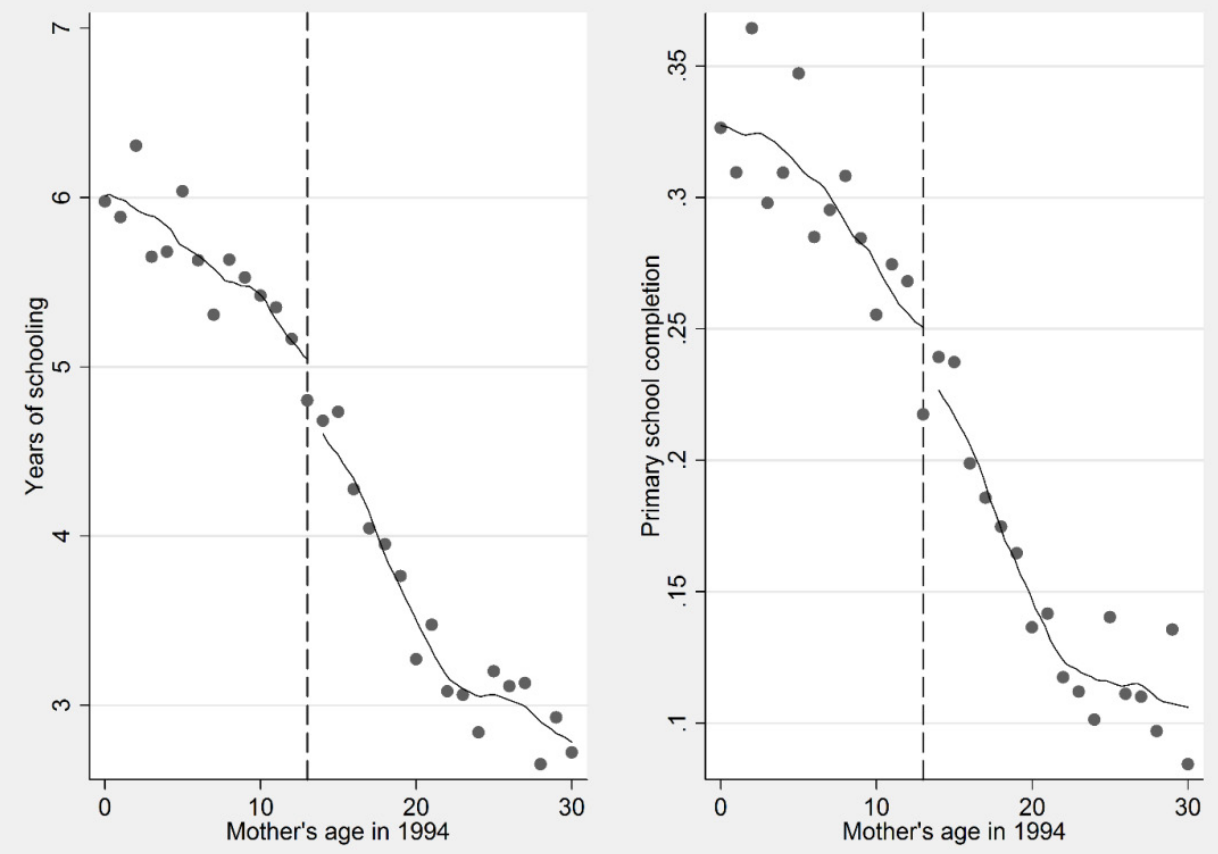

We also observe that illiteracy reduced proportionally in the treated than control group (by about $10 \%$, vs $25 \%$ ) respectively. The benefits of FPE were nationwide but appeared more for girls in the Northern region than other regions (Figure B5.1). 
Figure 5.2: Impact of the (FPE) policy on maternal education levels in Malawi

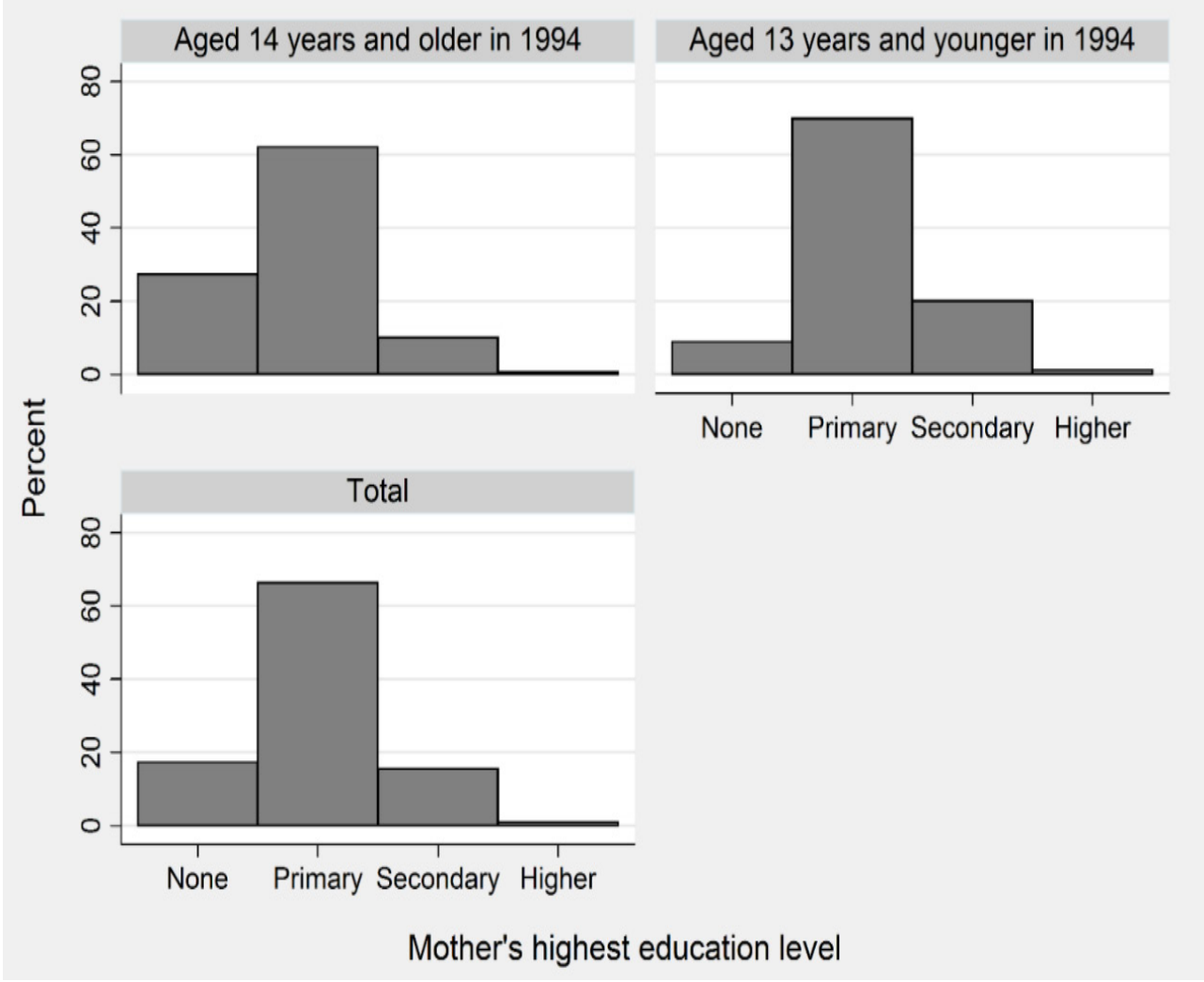


Figure 5.3 explores the claim that illiteracy is a function of residence due to differences in opportunities and amenities (Buor, 2003). Consistently, we find that the benefits of FPE differ by area of residence between groups. Treated adolescents in urban areas had a higher probability of primary school learning than rural areas (about $60 \%$ vs $28 \%$ ), respectively. However, the discontinuity is more distinct for rural than urban areas, signifying that exposure to the policy was beneficial, nonetheless. This observation provides further support to our estimation strategy.

Figure 5.3: The impact of free primary schooling on maternal education by place of residence
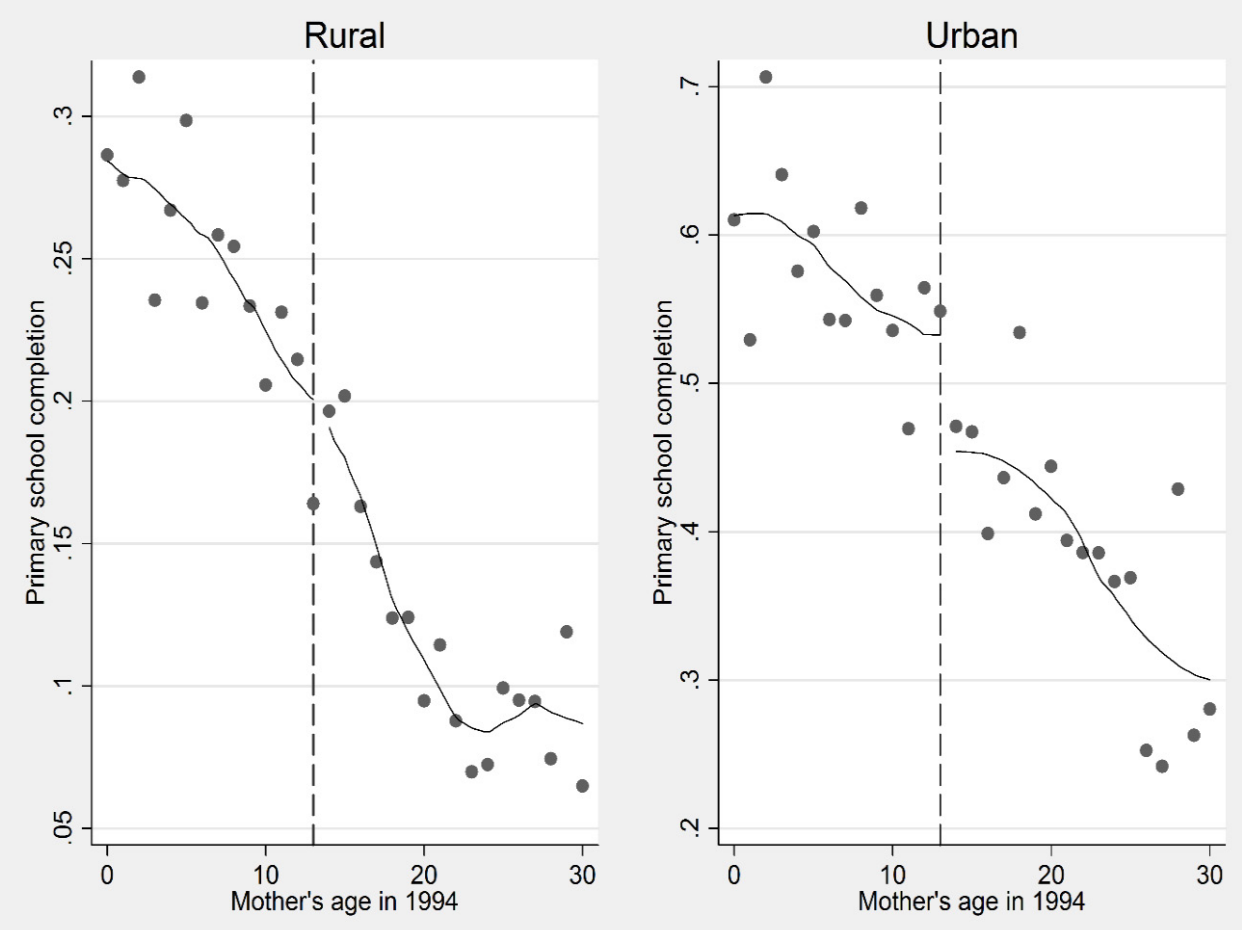

The first stage regression results (equation 2) confirm the graphical evidence of an age discontinuity in exposure to FPE. The first stage regressions estimate the impact of exposure to FPE (proxied by the dummy indicator for 
age less than 13 years in 1994) on maternal education (proxied by years of completed schooling). Table 5.2 explores the impact of FPE on years of completed schooling and the probability of completing primary school or higher levels of education. The impact is also stratified by urban/rural residence to examine any possible heterogeneity in the impact of the reform.

In Table 5.2, overall column; girls who were 13 years and younger were more likely to increase schooling by an approximate 0.546 years than their $14-16$ year old counterparts. This result is comparable to previous studies for Malawi see for example (Makate, 2016). It is also consistent with the graphical analysis in Figure B5.1. Given that the average years of schooling in the overall analysis sample was 5.541, exposure to the school reform translates into a $9.85 \%\left(\frac{0.546}{5.541} * 100\right)$ estimated increase in the years of education. The increase in years of schooling was highly significant at $1 \%$ for both urban and rural areas ( 0.771 or $9.25 \%$ and 0.496 or $10 \%)$, respectively, given the average of 8.334 and 4.956 for this sample in urban and rural areas respectively.

Table 5.2 further shows how likely women were to complete school. Prospects of completing primary school or higher education levels for individuals who were 13 years and younger in 1994 were 25.7 percentage points (pp) higher than those older than 13 years in 1994 and statistically significant at the $1 \%$ level. Those treated were significantly more likely to complete schooling in rural areas (24.9 pp) at $1 \%$ level compared to their counterparts. In the urban sample, the effect on the likelihood of completing primary school of higher education levels was not statistically significant. 
Table 5.2: The effect of FPE on maternal education in Malawi

\begin{tabular}{|c|c|c|}
\hline $\begin{array}{l}\text { Overall } \\
\text { (age 11-16) }\end{array}$ & $\begin{array}{l}\text { Urban } \\
\text { sample }\end{array}$ & $\begin{array}{l}\text { Rural } \\
\text { sample }\end{array}$ \\
\hline Coefficient & Coefficient & Coefficient \\
\hline
\end{tabular}

Years of schooling

\begin{tabular}{|c|c|c|c|c|c|}
\hline $\begin{array}{l}\text { Age below } 13 \text { years in } \\
1994\end{array}$ & $0.546^{* * *}$ & $(0.103)$ & $0.771^{* * *}$ & $(0.072)$ & $0.496^{* * *}$ \\
\hline $\begin{array}{l}\text { Mean of the } \\
\text { dependent variable }\end{array}$ & 5.541 & & 8.334 & & 4.956 \\
\hline Observations & 11873 & & 2058 & & 9815 \\
\hline
\end{tabular}

\section{Likelihood of}

completing primary

school

Age below 13 years in

1994

Mean of the

0.857

0.947

0.839

dependent variable

Observations

11873

2058

9815

Note: ${ }^{* * *}$ Significant at $1 \%$ level; ${ }^{* *}$ significant at $5 \%$ level; ${ }^{*}$ significant at $10 \%$ level. Reported are regression coefficient estimates and robust standard errors in parentheses. All regressions are clustered at two different dimensions, first by the region of residence and the respondent's age in 1994. We include controls for the region of residence as observed at survey date, survey fixed effects, and an urban dummy indicator (where applicable).

Figure 5.4 is a graphic illustration of the discontinuity effect of FPE on child growth. The left side of the two vertical lines in each graph for HAZ and stunting depicts the treated cohort, girls with 13 years or below in 1994 and the right of the vertical lines, the control group. The result shows a clear impact of the 1994 policy reform on height-for-age and stunting. Maternal access to FPE is inversely associated with linear growth failure and stunting. 
Looking at the HAZ pattern, children from the treated group have relatively better HAZ scores than those from unexposed mothers. Similarly, stunting prevalence shows that one in two unexposed mothers had a stunted child, far worse than the treated group, as seen from Figure 5.4.

Figure 5.4: The effect of FPE on height-for-age and child stunting in Malawi.
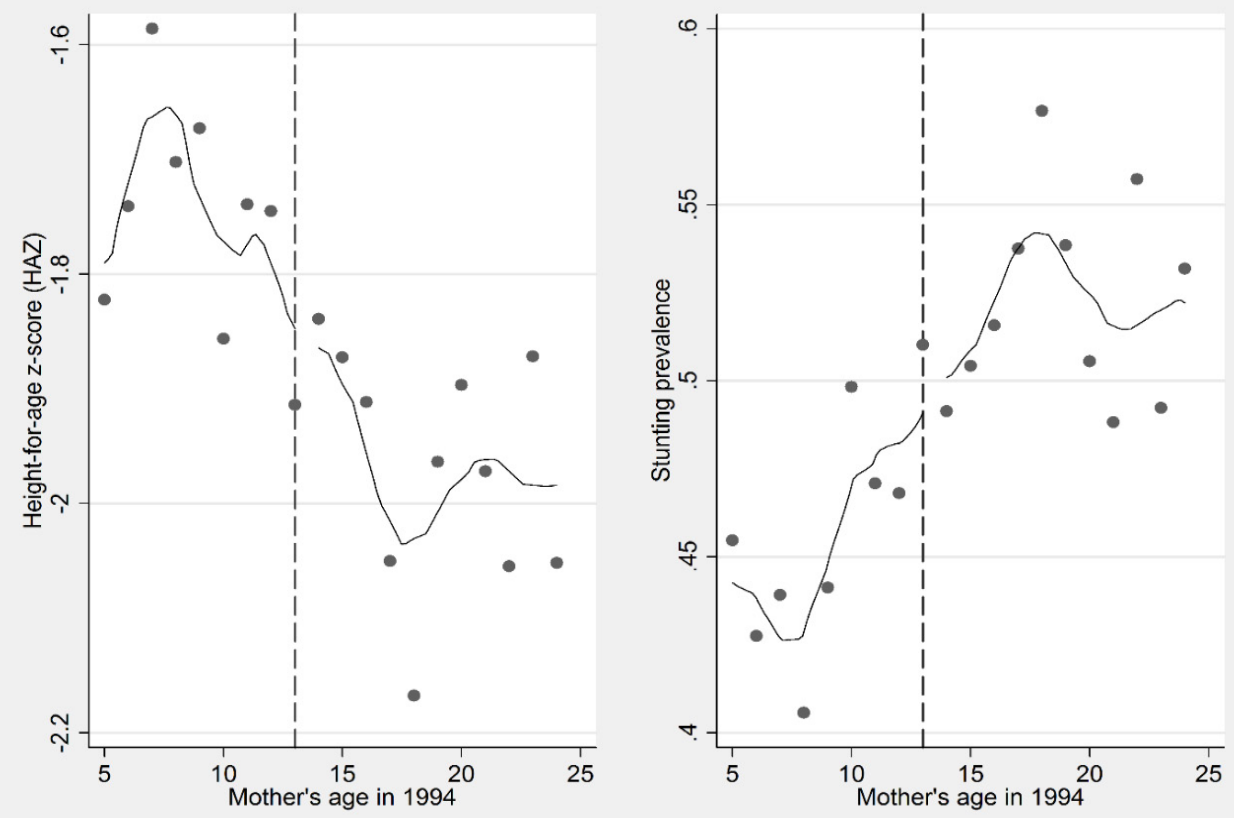

In the second stage regressions (equation 3), HAZ and stunting are a function of the predicted schooling levels from the first stage and other relevant control variables. In Table 5.3, we proceed to present coefficients from IV estimates after controlling for potential endogeneity of mother's schooling. First, we show the naïve OLS estimates in the top-most part of Table 5.3. The OLS estimates are generated from estimating equation (1) in which we assume that education is exogenous (i.e. without instrumentation). The OLS results are presented in the upper part of column (1) for HAZ and column (2) for stunting. The results are based on the overall sample of women aged 
11-16 years in 1994. In the OLS model, results are insignificant but show the expected signs. An additional year in school is associated with an increase in HAZ by 0.019 standard deviations. Intuitively, exposed mothers have toddlers who are taller by 0.019 standard deviations than their counterparts. Given the average HAZ scores for children in our analysis sample, the oneyear increase in schooling is associated with an approximate $1.22 \%$ increase in HAZ scores. Similarly, an additional year in school is associated with a decrease in stunting by about 0.5 percentage points and an equivalent of about $1.26 \%$ decline given the average stunting rate in the analysis sample.

Table 5.3: The effect of maternal education on child height-for-age z-scores and stunting in Malawi

\begin{tabular}{llllll}
\hline & HAZ & & \multicolumn{2}{l}{ Stunting } & \\
\cline { 2 - 2 } Specifications & $(1)$ & & $(2)$ & \\
\hline$\underline{\text { OLS Estimates }}$ & 0.019 & $(0.010)$ & & -0.005 & $(0.003)$ \\
Years of schooling & 2298 & & & 2298 &
\end{tabular}

\section{SLS Estimates (IV)}

Years of schooling

Observations

First stage F-statistic

P-value

Mean of the dependent variable

Notes: ${ }^{* * *}$ Significant at $1 \%$ level; ${ }^{* *}$ significant at $5 \%$ level; ${ }^{*}$ significant at $10 \%$ level. Robust standard errors are shown in parentheses and clustered at the region and mother's age in 1994 levels. All models include controls for linear age slopes (above and below the age 13 cut-point), child's gender ( $=1$ if female), child's age in months including its square, mother's age at first birth, mother's height (in logarithms), binary indicator for female-headed households, year of survey fixed effects, region fixed effects, Indicators for household wealth quintiles (1-5). 
The bottom section of Table 5.3 provides the 2SLS estimates (i.e. where education is instrumented). The 2SLS estimates in column (1) of Table 5.3 show that a one-year increase in schooling by the mother increases the HAZ score for her offspring by about $0.202(\mathrm{P}<0.001)$. Given that the average HAZ score in the analysis sample stood at about -1.549 , this translates to an increase of approximately $13.04 \%$ (i.e. $\left.\left(\frac{0.202}{1.549}\right) * 100\right)$. Similarly, an additional year in school lowers stunting by about $7 \mathrm{pp}$, which translates to a $17.6 \%$ decrease in stunting given at the sample mean of $39.6 \%$.

Exploring the potential heterogeneity in the impact of education reveals significant differences by the area of residence and child's gender. Specifically, in Table 5.4, we found that with an additional year in schooling, the treated group in rural areas were more likely to have taller toddlers as shown in the increased HAZ of $0.238(\mathrm{P}<0.001)$, a $14.90 \%$ increase. Boys had a larger and significant increase in HAZ of $0.344(\mathrm{P}<0.001)$ than girls. Except for the positive coefficient among girls, the reduction in stunting is not significant while we find a highly significant $19.42 \%$ reduction in stunting for boys. 
Table 5.4: Heterogeneity in the impact of maternal education on child HAZ and stunting

\begin{tabular}{|c|c|c|c|c|}
\hline \multirow[b]{2}{*}{ 2SLS Estimates } & \multicolumn{2}{|l|}{ HAZ } & \multicolumn{2}{|l|}{ Stunting } \\
\hline & $(1)$ & & $(2)$ & \\
\hline \multicolumn{5}{|l|}{ Urban sample } \\
\hline Years of schooling & 0.055 & $(0.127)$ & -0.016 & $(0.024)$ \\
\hline Observations & 311 & & 311 & \\
\hline First stage F-statistic & 2.382 & & 2.382 & \\
\hline P-value & 0.018 & & 0.018 & \\
\hline Mean of the dependent variable & -1.243 & & 0.267 & \\
\hline \multicolumn{5}{|l|}{$\underline{\text { Rural sample }}$} \\
\hline Years of schooling & $0.238^{* * *}$ & $(0.051)$ & $-0.081^{* * *}$ & $(0.016)$ \\
\hline Observations & 1987 & & 1987 & \\
\hline First stage F-statistic & 18.826 & & 18.826 & \\
\hline P-value & 0.017 & & 0.017 & \\
\hline Mean of the dependent variable & -1.597 & & 0.417 & \\
\hline \multicolumn{5}{|l|}{ Girls sample } \\
\hline Years of schooling & 0.038 & $(0.048)$ & -0.049 & $(0.031)$ \\
\hline Observations & 1128 & & 1128 & \\
\hline First stage F-statistic & 3.712 & & 3.712 & \\
\hline P-value & 0.015 & & 0.015 & \\
\hline Mean of the dependent variable & -1.470 & & 0.372 & \\
\hline \multicolumn{5}{|l|}{ Boys sample } \\
\hline Years of schooling & $0.344^{* * * *}$ & $(0.026)$ & $-0.089^{* * *}$ & $(0.009)$ \\
\hline Observations & 1170 & & 1170 & \\
\hline First stage F-statistic & 35.416 & & 35.416 & \\
\hline P-value & 0.022 & & 0.022 & \\
\hline Mean of the dependent variable & -1.626 & & 0.420 & \\
\hline
\end{tabular}

Notes: ${ }^{* * *}$ Significant at $1 \%$ level; ${ }^{* *}$ significant at $5 \%$ level; ${ }^{*}$ significant at $10 \%$ level. Robust standard errors are shown in parentheses and clustered at the region level and mother's age in 1994. All models include controls for linear age slopes (above and below the age 13 cutpoint), child's gender (=1 if female), child's age in months including its square, mother's age at first birth, mother's height (in logarithms), binary indicator for female-headed households, year of survey fixed effects, region fixed effects, Indicators for household wealth quintiles (1$5)$. 
We observed that the OLS estimates are smaller than the IV estimates as shown in Table 5.3. This discrepancy in the OLS and 2SLS estimates can be explained by the fact that the latter estimates represent the local average treatment (LATE) effects while the former represent the average treatment effect (ATE). The larger LATE effect might be a reflection of the self-selection effect. It is plausible that high ability students in Malawi took greater advantage of the free education policy while those of lower abilities might have opted out of school despite the free schooling, hence the larger LATE. The larger IV estimates are also consistent with the findings in (Güneş, 2015). Some scholars point to the difference and preference to report Local Average Treatment Effects (LATE), since FPE in Malawi was gradual and not a "big bang" seen elsewhere (Behrman, 2015). Similarly, unlike in Ghana, the FPE reform was not necessarily compulsory necessitating a selection effect based on parental attitudes (Nishimura et al., 2009).

\subsubsection{Robustness checks}

We conducted a series of robustness checks to test the sensitivity of our estimates. Table 5.5 shows that our main results for HAZ and stunting are robust across wider and narrower bandwidths, and remain significant even in much narrower age bandwidths. The narrower bandwidth estimates provide further evidence that there are significant effects of maternal education of mothers who changed their educational attainment due to the change in the policy reform(Güneş, 2015). 
Table 5.5: The effect of maternal education on child growth in Malawi- robustness across age bandwidths.

\begin{tabular}{|c|c|c|c|c|}
\hline \multirow[b]{2}{*}{ 2SLS Estimates } & \multicolumn{2}{|l|}{ HAZ } & \multicolumn{2}{|c|}{ Stunting } \\
\hline & (1) & & (2) & \\
\hline \multicolumn{5}{|l|}{ A: Aged 9-18 in 1994} \\
\hline Years of schooling & $0.119^{*}$ & $(0.049)$ & $-0.042^{* *}$ & $(0.015)$ \\
\hline Observations & 3896 & & 3896 & \\
\hline First stage F-statistic & 30.142 & & 30.142 & \\
\hline P-value & 0.034 & & 0.034 & \\
\hline Mean of the dependent variable & -1.610 & & 0.407 & \\
\hline \multicolumn{5}{|l|}{ B: Aged 10-17 in 1994} \\
\hline Years of schooling & $0.119^{*}$ & $(0.052)$ & $-0.041^{*}$ & $(0.018)$ \\
\hline Observations & 3095 & & 3095 & \\
\hline First stage F-statistic & 22.189 & & 22.189 & \\
\hline P-value & 0.026 & & 0.026 & \\
\hline Mean of the dependent variable & -1.586 & & 0.402 & \\
\hline \multicolumn{5}{|l|}{ C: Aged 12-15 in 1994} \\
\hline Years of schooling & $0.209^{* * *}$ & $(0.022)$ & $-0.078^{* *}$ & $(0.026)$ \\
\hline Observations & 1549 & & 1549 & \\
\hline First stage F-statistic & 14.988 & & 14.988 & \\
\hline P-value & 0.009 & & 0.009 & \\
\hline Mean of the dependent variable & -1.558 & & 0.402 & \\
\hline
\end{tabular}

Notes: ${ }^{* *}$ Significant at $1 \%$ level; ${ }^{* *}$ significant at $5 \%$ level; ${ }^{*}$ significant at $10 \%$ level. Robust standard errors are shown in parentheses and clustered at the mother and age in 1994 level. All models include controls for linear age slopes (above and below the age 13 cut-point), child's gender ( $=1$ if female), child's age in months including its square, mother's age at first birth, mother's height (in logarithms), binary indicator for female-headed households, year of survey fixed effects, region fixed effects, Indicators for household wealth quintiles (1-5).

Table 5.6 reports the results of the intent to treat analysis (ITT) which assumes a sharp RDD). The sharp RDD design to treatment exposure and 
years of schooling is significant for both growth outcomes. Similarly, we find a significant impact of maternal education on linear growth and stunting for all age bandwidths. Overall, we find that the ITT estimates are consistent with the IV estimates, reinforcing the robustness of the causal impact of maternal education on child HAZ and stunting.

Table 5.6: Impact of eligibility to the Malawi FPE reform in 1994 on child growth: reduced form estimates

\begin{tabular}{|c|c|c|c|c|}
\hline \multirow[b]{2}{*}{ Sharp RD estimates } & \multicolumn{2}{|l|}{ HAZ } & \multicolumn{2}{|l|}{ Stunting } \\
\hline & (1) & & (2) & \\
\hline Age 9-18 in 1994 & & & & \\
\hline $\begin{array}{l}\text { Indicator for age } 13 \text { or younger in } \\
1994\end{array}$ & $0.135^{* *}$ & $(0.050)$ & $-0.048^{* * *}$ & $(0.016)$ \\
\hline Observations & 3896 & & 3896 & \\
\hline Mean of the dependent variable & -1.610 & & 0.407 & \\
\hline Age 10-17 in 1994 & & & & \\
\hline $\begin{array}{l}\text { Indicator for age } 13 \text { or younger in } \\
1994\end{array}$ & $0.116^{*}$ & $(0.052)$ & $-0.040^{*}$ & $(0.018)$ \\
\hline Observations & 3095 & & 3095 & \\
\hline Mean of the dependent variable & -1.586 & & 0.402 & \\
\hline Age 11-16 in 1994 & & & & \\
\hline $\begin{array}{l}\text { Indicator for age } 13 \text { or younger in } \\
1994\end{array}$ & $0.168^{* *}$ & $(0.052)$ & $-0.059^{* * * *}$ & $(0.016)$ \\
\hline Observations & 2298 & & 2298 & \\
\hline Mean of the dependent variable & -1.549 & & 0.396 & \\
\hline Age 12-15 in 1994 & & & & \\
\hline $\begin{array}{l}\text { Indicator for age } 13 \text { or younger in } \\
1994\end{array}$ & $0.117^{*}$ & $(0.057)$ & $-0.044^{*}$ & $(0.019)$ \\
\hline Observations & 1549 & & 1549 & \\
\hline Mean of the dependent variable & -1.558 & & 0.402 & \\
\hline
\end{tabular}

Notes: ${ }^{* * *}$ Significant at $1 \%$ level; ${ }^{* *}$ significant at $5 \%$ level; ${ }^{*}$ significant at $10 \%$ level. Robust standard errors are shown in parentheses and clustered at the region level. All models include controls for linear age slopes (above and below the age 13 cut- 
point), child's gender (=1 if female), child's age in months including its square, mother's age at first birth, mother's height (in logarithms), binary indicator for female-headed households, year of survey fixed effects, region fixed effects, Indicators for household wealth quintiles (1-5).

\subsubsection{Potential mechanisms}

The findings raise the question; what are the pathways through which years of schooling might impact linear growth? We explore child level and household level mechanisms. The IV estimates are displayed in Table 5. 7 and 5.8 .

In Table 5.7, child level proximate mechanisms are explored. They are (i) dietary choices and (ii) health service utilization proxies by health seeking for vaccinations, treatment of child illness and prenatal care. One pathway through which education improves child linear growth is by increasing knowledge of the type of foods that promote linear growth. Higher maternal education has been shown to lead to improved knowledge on health and nutrition (Choi et al., 2011). We explored the potential role of years of schooling in diversifying the diet given to toddlers, measured through the provision of animal source foods. The results are mixed. We find that maternal education significantly increases the giving of milk to toddlers. A one-year increase in schooling promotes the giving of milk to children by about 0.13 percentage points, which is significant at $1 \%$. Maternal education appears to have a positive but insignificant effect on giving meat and fish to children despite its frequency in consumption (See table 5.1). The greater consumption of milk by young children is beneficial for child growth. A randomized controlled trial has showed greater significant linear growth for children who consume milk than meat (Long et al., 2012). Although, a study by Hambidge et al. (2011) finds an effect of meat on linear growth, others do not (Nancy F. Krebs et al., 2012; Long et al., 2012). We speculate that effect of meat consumption maybe constrained by factors such as insufficient 
quantities, which we could not estimate as MDHS only collects frequency of food consumed and not quantities.

Table 5.7: Child level mechanisms through which maternal education impacts child growth in Malawi

\begin{tabular}{|c|c|c|c|c|c|c|c|c|}
\hline 2SLS Estimates & $\begin{array}{l}\text { Gave } \\
\text { child milk }\end{array}$ & & $\begin{array}{l}\text { Gave } \\
\text { child meat }\end{array}$ & & $\begin{array}{l}\text { Gave } \\
\text { fish }\end{array}$ & & $\begin{array}{l}\text { Child ever } \\
\text { vaccinated }\end{array}$ & \\
\hline $\begin{array}{l}\text { Years of } \\
\text { schooling }\end{array}$ & $0.013^{* * *+4}$ & $(0.003)$ & 0.007 & $(0.008)$ & 0.026 & $(0.014)$ & $0.011^{* *}$ & $(0.004)$ \\
\hline $\begin{array}{l}\text { First stage F- } \\
\text { statistic }\end{array}$ & 47.418 & & 50.043 & & 50.043 & & 302.410 & \\
\hline P-value & 0.029 & & 0.029 & & 0.029 & & 0.020 & \\
\hline $\begin{array}{l}\text { Mean of the } \\
\text { dependent } \\
\text { variable }\end{array}$ & 0.046 & & 0.108 & & 0.195 & & 0.902 & \\
\hline \multirow[t]{2}{*}{ Observations } & 2511 & & 2513 & & 2513 & & 743 & \\
\hline & $\begin{array}{l}\text { Any fever } \\
\text { treatment } \\
\text { (last } 2 \\
\text { weeks) }\end{array}$ & & $\begin{array}{l}\text { Number of } \\
\text { prenatal } \\
\text { care visits }\end{array}$ & & & & & \\
\hline $\begin{array}{l}\text { Years of } \\
\text { schooling }\end{array}$ & $0.044^{* * *}$ & $(0.017)$ & $0.117^{* \text { *at }}$ & $(0.030)$ & & & & \\
\hline $\begin{array}{l}\text { First stage F- } \\
\text { statistic }\end{array}$ & 25.141 & & 29.240 & & & & & \\
\hline P-value & 0.031 & & 0.021 & & & & & \\
\hline $\begin{array}{l}\text { Mean of the } \\
\text { dependent } \\
\text { variable }\end{array}$ & 0.622 & & 3.603 & & & & & \\
\hline Observations & 1409 & & 2782 & & & & & \\
\hline
\end{tabular}

Notes: ${ }^{* *}$ Significant at $1 \%$ level; ${ }^{* *}$ significant at $5 \%$ level; ${ }^{*}$ significant at $10 \%$ level.

Robust standard errors are shown in parentheses. Robust standard errors are shown in parentheses. Standard errors are clustered at the region level and mother's age in 1994. We included additional controls as described in Table 3 (main Estimates). 
Other child-level mechanisms explored were health seeking for vaccinations, treatment of childhood illness and prenatal care. In the UNICEF framework illness is a proximate cause of malnutrition (UNICEF, 1990) and recurrent illness is associated with stunting (WHO, 2006). One pathway through which maternal education minimizes disease is through the ability to seek preventive and curative services, acquired health knowledge and the adoption of protective child care actions, such as immunizations (Andersen, 1973; Frost et al., 2005; Vikram et al., 2012). We find that years of schooling increase access to prenatal care by about 0.117 antenatal visits, significant at $1 \%$ level. Similarly, mothers are likely to seek fever treatment for their toddlers about 0.44 p.p $(\mathrm{P}<0.05)$. Their children are also 1.1 p.p more likely to be vaccinated $(\mathrm{P}<0.05)$.

We also explore the mechanisms through household factors, maternal and paternal employment opportunities and other maternal related factors such as: (i) teenage pregnancy proxied by age at first birth, and child size at birth (ii) child care practices proxied by child father level of schooling and (ii) hygiene practices through sanitation facilities

We examined the effects of maternal education on the age at first birth. Studies show that teen childbearing is associated with negative birth outcomes such as low birthweight, inter uterine growth retardation resulting from competing nutrient needs between the mother and child in utero. Negative birth outcomes are a risk to stunting (Muthayya, 2009). The analysis shows that one-year of schooling increases the age of having a first birth by about 0.0637 years. This result suggests that more educated women delay having children and are thus less likely to give birth as teenagers, which would be beneficial for in-utero growth, a crucial health indicator during the first 1000 days. Furthermore, the effect on low birthweight is statistically significant at $1 \%$ suggesting that increased education is protective of giving birth to a baby with low birthweight. 
Table 5.8: Maternal and household level mechanisms through which maternal education impacts child growth in Malawi

\begin{tabular}{|c|c|c|c|c|c|c|c|c|}
\hline & $\begin{array}{l}\text { Frequency } \\
\text { reads } \\
\text { newspapers }\end{array}$ & & $\begin{array}{l}\text { Age at } \\
\text { first birth }\end{array}$ & & $\begin{array}{l}\text { Mother works } \\
\text { in agriculture }\end{array}$ & & $\begin{array}{l}\text { Father } \\
\text { works in } \\
\text { agriculture }\end{array}$ & \\
\hline $\begin{array}{l}\text { Years of } \\
\text { schooling }\end{array}$ & 0.092 & $(0.048)$ & $0.637^{* * * *}$ & $(0.185)$ & $-0.184^{*}$ & $(0.081)$ & -0.188 & $(0.152)$ \\
\hline $\begin{array}{l}\text { First stage F- } \\
\text { statistic }\end{array}$ & 11.329 & & 18.842 & & 2.833 & & 2.022 & \\
\hline P-value & 0.000 & & 0.000 & & 0.000 & & 0.000 & \\
\hline $\begin{array}{l}\text { Mean of the } \\
\text { dependent } \\
\text { variable }\end{array}$ & 0.234 & & 18.611 & & 0.681 & & 0.469 & \\
\hline Observations & 8534 & & 12021 & & 8546 & & 7958 & \\
\hline & $\begin{array}{l}\text { Birth size - } \\
\text { smaller }\end{array}$ & & $\begin{array}{l}\text { No } \\
\text { toilet } \\
\text { facility }\end{array}$ & & $\begin{array}{l}\text { Father's } \\
\text { years of } \\
\text { schooling }\end{array}$ & & $\begin{array}{l}\text { Mother } \\
\text { smokes }\end{array}$ & \\
\hline $\begin{array}{l}\text { Years of } \\
\text { schooling }\end{array}$ & $-0.051^{* * * *}$ & $(0.006)$ & -0.047 & $(0.077)$ & $0.119^{* * * *}$ & $(0.005)$ & -0.011 & $(0.012)$ \\
\hline $\begin{array}{l}\text { First stage F- } \\
\text { statistic }\end{array}$ & 51.366 & & 2.157 & & 54.286 & & 2.839 & \\
\hline P-value & 0.024 & & 0.000 & & 0.014 & & 0.000 & \\
\hline $\begin{array}{l}\text { Mean of the } \\
\text { dependent } \\
\text { variable }\end{array}$ & 2.622 & & 0.086 & & 1.262 & & 0.005 & \\
\hline Observations & 3884 & & 8456 & & 7898 & & 8542 & \\
\hline
\end{tabular}

Notes: ${ }^{* *}$ Significant at $1 \%$ level; ${ }^{* *}$ significant at $5 \%$ level; ${ }^{*}$ significant at $10 \%$ level. Robust standard errors are shown in parentheses. Robust standard errors are shown in parentheses. Standard errors are clustered at the region level and mother's age in 1994. We included additional controls as described in Table 5.3 (main Estimates). 
Similar to disease, one of the key proximate determinants of linear growth is child care and feeding frequency. We consider that being engaged in agriculture labor, away from home, affects the required frequency of child feeding which may impact child growth. We explored the mechanism via maternal agriculture labor market participation, keeping in mind that the toddler is on average 30 months (Table 5.1), therefore likely to be left at home. In Table 5.8, the result shows that maternal education increases the probability of not working in the agriculture sector by $10 \%$, and is therefore protective of child care similar to the findings by (Güneş, 2015).

Paternal education is explored as a likely mechanism for child rearing and caring practices that affect the choice of health inputs (Mani, 2012a). Since DHS collects information on husbands or partners for ever married women, we are able to examine paternal education as a mechanism, assuming that mother's exposure to FPE affects child growth through marriage to an educated father. Our results suggest that an educated father is a mechanism through which maternal education impacts on child linear growth. The result shows that a one-year increase in paternal schooling impacts child linear growth by 0.142 units $(\mathrm{P}<0.05)$. Finally we investigated the household environment as defined by ownership of sanitation facilities as a potential mechanism, since poor sanitation is a risk to diseases and stunting (Fink et al., 2011). Results suggest that mothers with additional years of schooling are less likely to report not owning a toilet facility by $4.7 \mathrm{pp}$. The effect is however insignificant. This is contrary to Desai and Alva (1998) who found a diminished effect of maternal education on child mortality and height for age when paternal education and access to water and sanitation were controlled for.

In summary, maternal education affects child growth through dietary intake, child fever treatment, child vaccination and prenatal visits. At maternal and household level, we find that education impacts child growth through increased age at first birth, the reduced likelihood of a small sized baby, 
reduced maternal agriculture labor participation and the child having an educated father.

\subsubsection{Validity tests}

To check the validity and enhance the credibility of our estimates, we have furnished a formal test of assumptions of the fuzzy RDD. First, we check the distribution of the respondent's age at policy enactment in 1994 (i.e. the assignment variable) for potential discontinuities or bunching at the age 13 cut-point (see Appendix C5.6). Here, we clearly observe no evidence of bunching in the assignment variable. Second, as is standard practice in the RDD literature, we tested or examined the smoothness in all the explanatory variables used in the fuzzy RDD models. The idea being that if we observe any discontinuity in any of the explanatory variables we include in our models, then it casts doubt on the credibility of our estimates. The results reported in Figures C51-6 in Appendix C show that there is no evidence of any discontinuities in the other explanatory variables that might influence the effect of mother's schooling on child nutrition outcomes that we observe. The results of the validity tests give us reason to be confident in the overall impact of mothers' education on child growth that we find.

\subsection{Discussion}

This chapter hypothesized that increased maternal education reduces stunting and increases HAZ scores in Malawi. Our findings suggest that the maternal FPE policy reform positively influenced the child linear growth outcomes of the next generation. We particularly established that mothers exposed to the policy were likely to have children that are taller by HAZ of about 0.20 standard deviations compared to their counterparts born from non-exposed mothers. Other studies found similar HAZ increases of about 0.20 standard deviations (Aslam \& Kingdon, 2010; Güneş, 2015). Also, we 
found that a one-year increase in schooling translates to an overall $17.6 \%$ reduction in stunting prevalence given the average stunting rates of children in our analysis sample of about $39.6 \%$. The reduction is significant at $5 \%$. The empirical strategy also revealed differences in size of effect between the OLS and 2SLS estimates. The larger 2SLS estimates might be indicative of selection effects. It is plausible that high ability students may have selfselected into primary schooling thanks to the scrapped tuition fees while low-ability students may have opted out despite the removed school fees, as other studies suggest (Chimombo et al., 2000). Thus, the 2SLS results might be reflecting the overall effect of the high-ability students. Nonetheless, we rationally find medium and large effect sizes (Ferguson, 2009). Such effect sizes in this context are critical because we showed that Malawian children at the current mean height are nearly 2 standard deviations, on average shorter than a healthy population of children globally.

Our findings are supportive of the suggested protective effect of maternal learning on child survival (W Henry Mosley \& Lincoln C Chen, 2003). The most relevant studies in a poor and low income country showed benefits with additional years in schooling to child health ranging from 3.22 to 21 percentage points (Makate, 2016; Güneş, 2015, Keats, 2016). Our results of a stunting reduction of 7 percentage points (17.6\%) are comparable. The findings are conceivable given that the F-statistic in our model is greater than 10 signifying a strong IV chosen (Staiger, 1997). To test the sensitivity of our estimates, we conducted several robustness checks. As the results suggest, our estimates are robust to the variation in age bandwidths of the mothers. Similarly, we find highly a significant intent to treat effects on linear growth and stunting for all age categories. We also conducted several validity tests and find no evidence of manipulation in the assignment variable and no evidence of any discontinuities in the other explanatory variables included in the model. This observation enhances the credibility of our RDD estimates. 
Overall, our causal estimates suggest that keeping girls in school can be an effective strategy to improve child linear growth and reduce stunting. Given these findings, we concur with other studies that educating women can have multiple and long term implications beyond the class (Behrman, 2015). It is therefore, fundamental to ensure girls stay in school, in a country where we find in our data a $90 \%$ school dropout. In economic terms stunted children are a cost to the economy (ECA \& NEPAD, 2013). Our results show an effect, despite the few years of schooling (5.6 years). While some studies demonstrate a threshold necessary to reduce the risk of stunting (Makoka, 2013), many others suggest that there is no "threshold" benefit of maternal schooling that needs to be reached and that even small levels of education improve child survival (Aslam \& Kingdon, 2010).

Despite the policy reform reducing illiteracy and affecting schooling years, the high school dropout rate is worrisome. Such dropout rates negate the true effects of education gains (Kadzamira \& Rose, 2001). Previous studies have reported many reasons behind the dropout of girls from school such as coercion into early marriages, motherhood, distances to school, workload at home, late entry schooling and little expectation of girls to advance in education in the society in general (Chimombo et al., 2000; Kadzamira \& Rose, 2003). Consistent with our findings, strong evidence now exists to suggest that an early transition to parenthood is associated with wide ranging negative outcomes for young mothers and their children (Woodward, Fergusson, \& Horwood, 2001). Woodward et al. (2001) further suggests that pregnant teenagers suffer fewer life opportunities that include: leaving school early; educational under-achievement and prolonged welfare dependence. In this regard, a key overarching policy consideration is to reexamine factors limiting the implementation of changes proposed in several studies to address what appears to be institutional systemic failures leading high school dropout. Further, a conducive learning environment for girls must be promoted at all levels in Malawi. 
A large body of empirical evidence clearly shows how mothers education captures several distinct but often attributes to child health and nutrition (Miller \& Rodgers, 2009). The analysis has demonstrated several significant pathways through which maternal education impact child linear growth. Nonetheless we found that one potential mechanism through which mother's years of schooling impact child growth is age at first birth. Specifically, we find that one year of schooling increases the age at first birth by about 0.637 years. In Malawi, teenage pregnancies compromise nutrition and birth outcomes (Kalanda et al. (2006), and our findings show that increased education delays child birth and therefore prevents the adverse effects of teenage pregnancies. Our findings further suggest that socio economic status and assortative mating may be important, as observed in the positive impact on paternal schooling.

This study is not without its limitations. First, HAZ information is only available for surviving children (i.e. those alive at the survey date). Having anthropometric data for deceased children gives a much broader perspective and allows us to have a robust impact of schooling on HAZ and stunting in Malawi. Second, it's worth noting that analyses of this nature are best studied in the context of panel data which allows us to explore any dynamic effects as well as intergenerational links between education and child nutrition. Fourth, it's important to note that factors influencing child growth are multifactorial beyond the studied mechanisms and hence would require a much careful exploration.

\subsection{Conclusion}

In conclusion, to our knowledge, our study is the first to empirically show that maternal education increases child linear growth and reduces stunting in Malawi. Despite the noted shortcomings, our study makes a vital contribution to the literature on the casual effects of schooling on child linear growth especially in sub-Saharan Africa where research has lagged. Future 
research could explore the causal effect of post primary maternal schooling levels on child growth in this setting in order to also determine the benefits of post- primary education. 
CHAPTER 6: General Discussion 


\subsection{Introduction}

The overriding purpose of this dissertation was to investigate some of the determinants of child growth: diet and maternal education. Literature on causes of undernutrition shows that diet and maternal education are determinants of early childhood growth. The focus was on diet because nutrients are essential for growth and immunity while mothers' education, influences decisions and behaviors that affect child health and nutrition outcomes. Another objective was to also study how persistent stunting is by looking at the transitions in becoming stunted and nonstunted. The research questions posed for investigation in Chapter 1 are as follows; 1) What is the evidence on impact of locally available foods, especially Animal Source Foods (ASF) on stunting? 2) What is the association between the quantity and frequency of the consumption of food groups and linear growth? 3) What are the transition probabilities stunted $v s$ nonstunted in early childhood growth, and what are their determinants? 4) Does higher maternal schooling reduce stunting among their children?

To answer the research questions, results are presented in four chapters. Chapter 2 systematically reviews evidence on the impact of supplementing local diets with ASF from RCTs conducted in Sub-Saharan Africa. Chapter 3 examines the relationship between food groups and linear growth and between interactions of food with child age, household wealth and maternal factors and linear growth. Chapter 4 examines transitions above the stunting cut off by assessing the child's nutritional status in the present state conditional on the previous stunted or non-stunted state. Chapter 5 determines the causal effect of maternal education on stunting by using a policy reform as a natural experiment.

The importance of diet and maternal education as determinants of child growth are clearly supported by the current findings. Also, child growth 
transitions are demonstrated. In brief, firstly, results from reviewed RCTs shows that supplementing local diets with ASF is feasible. Milk showed the most potential for improving linear growth and other nutrition outcomes. Secondly, results of the food groups and linear growth analysis, consistently suggest the importance of ASF foods, especially milk and eggs and how benefits may differ according age, food group and wealth status. Thirdly, using a Makov model, transitioning probabilities shows the potential for the majority of the children to become non-stunted but less likely do so if they were stunted at an early age. Slightly over a third (35\%) of the children remained stunted, mirroring the current levels of stunting in Malawi of 37\%. Children participating in nutrition programs were more likely to become non-stunted if earlier stunted and were more protected from becoming stunted. Finally, regarding maternal education impact on linear growth, a one year increase in maternal schooling makes the offspring taller by 0.202 standard deviation and reduces stunting by 7 percentage points or 17.6 at population level. Therefore, educating girls can be an effective strategy to improve child growth.

Taken together, for Malawi, these findings suggest the importance of specific ASF food groups in the diet and maternal education as determinants of child growth and also indicate that transitions from a stunted state to non-stunted state can be achieved by participating in nutrition programs.

\subsection{Concluding statements based on findings}

The main conclusions are presented in the form of four statements in this chapter. The findings are briefly discussed and policy considerations are suggested. Strengths and limitations of the dissertation are also presented and areas for future research are proposed. 


\section{Concluding Statement 1: An adequate and nutritious diet is necessary but not sufficient to promote child linear growth.}

Findings of this dissertation show that although a nutritious and adequate diet is essential for child linear growth, it is equally important to address the underlying determinants of growth faltering. The determinants span across the child, maternal and household levels (Chapter 4). Across the chapters, the determinants of linear growth include factors at child level (age, gender and history of illness), household level (maternal schooling, ASF dietary choices, participating in nutrition programs) and at household level (wealth status). This array of factors clearly shows that interventions that focus solely on improving diet are likely to be insufficient as we observe in Chapter 2 in the reviewed RCTs. The findings highlight the need for a combined set of interventions that should simultaneously seek to control other underlying determinants which can be mutually reinforcing (Chapter 4). By simultaneously demonstrating factors which improve growth and prevent worsening, such as mothers' participation in nutrition programs in this setting it is evident that diet alone, without knowledge gained from nutrition programs or other avenues will not be sufficient to improve nutrition. On the face of it, this would suggest that factors that hinder participating in nutrition programs should be considered for future research since the participating in nutrition programs was preventive of worsening and promotive of achieving a desirable HAZ status in Chapter 4.

The transition model proved useful for categorizing determinants that would inform the type of interventions for children who are at-risk as well as what to address to be more effective. Since children were unlikely to move above the cutoff point if stunted at prior state, findings suggest that preventive strategies should be focused on early childhood (Chapter 2, 4). This is the 'window of opportunity' in a child's life, from conception to the 
second birthday ideal to prevent short term and likely irreversible consequences (Prentice et al., 2013). In Chapter 4, results show that children are less likely to move above the cutt off, if stunted at prior state .

In Chapters, 2, 3 and 5, over a third of the children were ill at any given time. Recent analyses have found that the effect of illness on growth faltering during this period is more severe than previously thought(Zongrone et al., 2012). The systematic review showed a lack of effect to prevent or reverse stunting (Chapter 2). The effect may have been compromised by the reported high morbidity among children. Although households typically face two distinct seasons, the harvesting period begins in April whereas the lean season is experienced from October to March, therefore the data accounted for variation in seasonality. However, these results seem to be consistent with other research which found that in Malawi child nutritional status varies across seasons and follows a seasonal pattern of childhood illness but not that of household food availability(Chikhungu \& Madise, 2014). As demonstrated in Chapter 5, child immunisations and prenatal care were mechanisms through which maternal education improved linear growth. The barriers to optimal use of nutrition programs despite highly prevalent child morbidity is an important issue for future research.

The above findings offer suggestive evidence that children are exposed to non-diverse diets as well underlying determinants such as untreated illnesses. Poor diet and frequent illness compromise immunity and predicts stunting Espo et al. (2002). Based on these findings, in order to achieve SDG targets, the prevention and mitigation of stunting will require intergrated efforts. The effect found on reducing stunting through maternal education (Chapter 5), further reinforces the understanding that the alleviation of stunting will require a combination of strategies such as improving local diets especially the intake of animal source foods, accessing nutrition programs services and investment in girls education. By illustrating the above interrelationships between various factors, the analysis adds insights 
to the importance of sector linkages in Malawi. However, the extent to which sector strategies should be delivered together remains unknown and may vary overtime. This is an important area for future research.

This dissertation examined the role of diet, maternal factors and determinants of child growth transitions. However, the analysis was limited by the use of only two data series which informed growth transitions (Chapter 4). The two data points made it difficult to explore dynamics beyond two state transitions and dynamics between the survey rounds. Due to rapid growth in children, there are still unanswered questions and furture research could consider measuring additional transitions or catch up growth as more data points across various age categories becomes available. A similar approach to the Markov model could be used to analyse data for the multicausal dimensions of stunting.

\section{Concluding Statement 2: A transition from a stunted to a non-stunted state is feasible under certain conditions.}

In Chapter 2, as a point of departure from the ealier literature on the debate, on whether becoming non-stunted i.e. crossing the HAZ threshold signals recovery (Jef L. Leroy et al., 2015), this research adopted a transition model to explain growth patterns in early childhood. The analysis further sought to examine factors associated with a worsening growth transition or becoming nonstunted. The potential to move from being classified as stunted to nonstunted described in the introduction, is corroborated (Elizabeth A Lundeen et al., 2014) and demonstrated in Chapter 4. Whether or not children experience catch up growth and reduced growth deficits when the changes in linear growth occur, is beyond the scope of this dissertation. However, our findings suggest that among those children who become non-stunted, in the short term the risks to disease and death may have reduced. Improving 
linear growth, signifies improvements is in nutrient intake (De Pee, 2018) which boosts immunity as detailed in the introduction. In the long term, it is suggested that removing some of the risk determinants may contribute to reducing the height deficit. However, the irreversibility of some consequences of stunting, apart from low height for age are yet to be elucidated. The findings show that six in ten children transitioned to a nonstunted state and the key determinants were participation in nutrition programs, mother's years of education, wealth status, abscence of illness and a diverse diet. But, nearly one in five children worsened. Worsening was predicted by a younger age, being a female child, history of illness, residing in the central region and asset poverty. While about a third children that were stunted maintained their condition which was accumulated before the age of two years, given the mean age at baseline of 16 months (Chapter 4). Our findings support the global focus of the 1000 days. However, findings of children who worsened or remain stunted suggest that children are vulnerable throughout the first five years of their life. In the narrative, though the change from the initial stunted state, is considered "becoming non-stunted" or a transitioning in this dissertation, findings of my study do not imply catch up growth.

Scholars have argued that it is not only stunted children (i.e. those who fall below the $-2 \mathrm{z}$-score cut off) who are not developing to their full potential because where stunting prevalence is high, such as the case in Malawi, the distribution of the whole population is shifted toward the left when compared to a standard population of healthy children of the same age (De Pee, 2018; Jef L. Leroy et al., 2015; Sun et al., 2013). Therefore moving from below the $-2 \mathrm{z}$-score to above that cut off may not necessarily indicate that the child is catching up on linear growth, as the accumulated deficit compared to the median height of the reference population of the same age may still be increasing(Jef L Leroy et al., 2015). This debate however, is one of the many arguments on how to measure or define catch up growth or define growth velocity, for which there is no agreed definition (Crookston, 
Penny, Alder, Dickerson, Merrill, Stanford, et al., 2010) and which is beyond the scope of this dissertation. The contribution to the debate lies in understanding how children below or above the threshold shift thereby motivating strategies for maintaining a non-stunted state and a prevention focus on the risk factors.

Notwithstanding the debates, one of the issues that emerges from these findings in this context, is that children have a near borderline HAZ mean of -1.82 , almost at the $<-2$ cut off (Chapter 5). In a population so close to the cut off and with nearly one in five children having deteriorated (Chapter 4), the risk at population level is that children are on the verge of being, on average, shorter than a healthy group of children of the same age elsewhere. This is because HAZ measures the height distance in standard deviations to a healthy and well-nourished reference population (Hirvonen, 2013).

As earlier observed in the introduction (Chapter 1 ) since children's growth patterns have a high chance of rapid deterioration in the first 24 months (A. Lartey, 2015), the benefits of becoming non-stunted especially below the age of 24 months occur rapidly, and reduce infant and child morbidity(Anna Lartey, 2015). Therefore being above the HAZ cut off is expected to minimise the risk of illness in the short term, thereby contributing to enhanced linear growth progress and contributing to prevention of occurrence of stunting in long term.

The assessment of linear growth is essential for determining whether a child is growing adequately or has a growth problem or tendency towards a growth problem that should be addressed (de Onis \& Branca, 2016). The authors further note that the use of cut-off points is required to determine the limits of 'normality', and this practice is not unique to anthropometry but widely applied in clinical and laboratory tests. Prendergast and Humphrey (2014) observed that although stunting at a population level are declining in 
developing countries, there are widespread between-child differences in stunting patterns when individual child growth curves are examined.

As such, the present study speculates that children who become non-stunted are likely to progress towards optimal linear growth. It is expected that the deficit in height can reduce over time if determinants of stunting (Chapter 4) are removed(Luo \& Karlberg, 2000). This finding raises the possibility that health risks to stunted children can be averted by understanding their growth trajectories in early childhood with the right set of interventions. The policy implications can be to design a set of interventions that aim to address underlying determinants contributing to negative transitions. Future research on a cohort of children with more focus on how transitioning children progress in achieving the optimal catch up linear growth, which is beyond the scope of this study, is recommended.

\section{Concluding Statement 3: In order to be effective, dietary guidelines should promote specific animal source food items from a local diet that are essential for linear growth.}

Chapter 2 has presented findings of a systematic review from RCTs. The review aimed at answering the sub question on the effect of supplementing diets with locally available foods especially animal soure foods on linear growth. ASF supplementation was feasible. In the review children who consumed milk improved in linear growth and other nutrition outcomes. These results are similar to Daphna K. Dror and Lindsay H. Allen (2011)who suggested that consumption of milk and other animal-source foods improves nutrition and reduces the prevalence of morbidity. This conclusion is however to be considered in the broader sense of other factors. (Chapter 4). This finding prompted a further analysis of consumption patterns (Chapter 3) with an objective to determine whether, in a local enviroment, quantity and frequency of consuming ASF would determine child growth. 
Milk and eggs emerged as important food items for Malawi. Both food items appeared to benefit children from poorer households the most.

The above results are consistent with other research which found that older children may benefit more from nutrients in milk that promote linear growth since they are no longer breastfed (Chapter 4). Eggs are an equally rich of source nutrients (Applegate, 2000), affordable by poorer households (Iannotti et al., 2008). This finding implies that while ASF are broadly reccommeded, it is important to define in each context what type ASF from local diets promote linear growth, as demonstrated (Chapter 4). The study further highlighted the difficulty of children consuming a diverse diet, of quality and in adequate amounts.

The discussion on how diets can be improved is complex and embraces a wider food based analytical approach that takes into account what foods are locally available, appropriate, and how nutritious these foods are to children below the age of five years, beyond the scope of the dissertation. The challenge is that certain food groups must be available throughout the year, affordable by households including the poor and utilisable by a body free of illness, at all times. In early childhood, the need for nutrients like zinc, iron and essential fatty acids is high, and increases when a child is ill(De Pee, 2018). Plant based diets are insufficient to meet such nutrients required for growth. In order to meet such nutrient gaps, the recommendation is that programs may need to adjust and focus on promotion of locally-available rich sources of protein that have not received sufficient attention (Nordin, 2005). Another policy consideration may be to consider fortification of commonly consumed staples such as maize given the monotonous diets in Malawi (Chapter 4).

Nonetheless, findings in this dissertation show that the current dietary patterns not only lack diversity, but are insufficient. Milk and eggs are infrequently consumed which can limit micronutrients that promote child linear growth. Hotz and Gibson (2001) observe that that linear growth 
faltering is much more likely to be due to the inadequate intake of specific nutrients rather than shortfalls in energy intake per se. Chapters 2, 4 and 5 of this dissertation however show that despite their limited consumption in Malawi, milk and eggs were associated with linear growth unlike other food groups. Differences between the RCTs and this research may have been influenced by age, morbidity as earlier noted and duration of the interventions (Chapter 2).

Policymakers should consider promoting a diverse diet rich in source of micronutrients such as milk and eggs to remain part of complementary food to promote child growth, during the window of opportunity and throughout the first five years of a child's life. In addition, it will be essential to include Social and Behaviour Change Communication (SBCC). This includes adopting attitudes that promote child care and feeding practices.

Although our findings are corroborated (Olivier Ecker \& Matin Qaim, 2011; Teivaanmäki et al., 2015a), they are not without limitations. The consumption data used in Chapters 3 and 4 were collected using conversion factors collected at houshold level. The nature of the data used from the welfare monitoring did not allow investigating child level consumption quantities, hence the focus on per capita trends, which showed a consistent low trend. Similarly the MDHS only collects food consumption frequencies and not actual amounts consumed. Future surveys could include a child level consumption module. This would be desireble since such information can inform changes in child consumption patterns and fluctuations based on seasonality and affordability since welfare surveys collect socio economic data. 


\section{Concluding Statement 4: Girls' education is an effective strategy for improving child linear growth and reducing stunting in the short and long term.}

In Chapter 5 maternal education in Malawi emerged as a cornerstone that contributes to children growing taller, healthier as well as for the opportunity to achieve other SDGs (Chapter 3, 4 and 5). According to the World Bank, girls that go further in education tend to be healthier, marry later, and seek better health care for themselves and the next generation (World Bank 2017). These factors combined can help households and communities to benefit from broad changes in societies (Declaration 2015). The above statement holds true from the result of the dissertation. In the short term, educating girls delays motherhood and prevents adverse effects of teenage pregnancies (Chapter 5). Pregnancies in teen years are a risk to intrauterine growth retardation (IUGR) and low birth weight births. Both IUGR and LBW can affect birth size, a mechanism that negatively impact linear growth, as demonstrated (Chapter 5). Further, women gain a "bargaining position" for themselves by acquiring knowledge which enhances the autonomy in decision making, and ability to communicate with health workers on reproductive choices (Vikram et al., 2012). Other studies found that more schooling has health related benefits for girls that can impact on future offspring. Infections such as HIV, for example, are lower among girls with more years in school(J. A. Behrman, 2015) thereby limiting the possibility of the mother to child HIV transmission. Limited drugs for pediatric HIV could expose such infants to illness and consequently growth faltering and stunting.

In the long term, the stock of knowledge acquired from formal schooling helps girls as future mothers First, undernutrition, especially stunting has an intergenerational characteristic, because it impacts on further schooling ability and loss in economic gains Girls with more education are less likely 
to recycle into poverty, and less likely to be in the informal labor market, or bear a child with an uneducated father or have a stunted child (Semba et al., 2008), as we saw in Chapter 5. Secondly, wealth status is associated with improved dietary choices, such a consumption of milk important for providing a range of nutrients important for linear growth (Chapter 3, 4, 5). Thirdly, mothers with more schooling show promotive self and child care actions by utilizing prenatal care services and immunizing their children. Immunizations protect against common childhood illnesses which if repeated and uncontrolled can lead to poor linear growth (Chapters 2, 3), and a mechanism through which mothers with more schooling affected linear growth compared to their counterparts (Chapter 5). The above mechanism resonates with empirical theories that propose many pathways through which maternal education works to improve child health and growth(Andersen, 1973; Caldwell, 1994).

Findings in Chapter 5 demonstrate that the reform only increased the average education by 0.546 years resulting in the average education for the compliers of only about 5.5 years. Yet, despite the little improvement in schooling years caused by the reform, women's children still benefit as they are taller and less likely to be stunted. While the reform aimed to increase access to education and did not address any other demand side and supply side problems, based on the findings, there is a lot more to be gained from increasing maternal education by addressing previously documented barriers such as drop-out rates and supply side constraints such as inadequate human resources and poor quality of teaching (Kadzamira \& Rose, 2001). Increased retention, progression and quality of girls' learning would therefore likely further increase the magnitude of impacts of maternal education on linear growth and reducing stunting. Unless retention improves, achieving SDG 4 on primary education of ensuring inclusive and equitable education for all, may be unattainable and will impact other SDGs, health, nutrition and gender empowerment and inclusion. It is beyond the 
scope the results of this dissertation to explain the barriers to girl's school retention.

Several questions remain unanswered based on previous identified bottlenecks to girls education (Chimombo, 2009). It is not improbable, however, to consider that girls in this setting are highly vulnerable and their offspring are at risk of intergeneration cycle of poverty and undernutrition (Chapter 5). One avenue for further studies would be research into the impact of post primary education on reducing stunting.

However, there are limits as to how far the effects as well as intergenerational links between girl's education and child nutrition can be explained. Studies generally emphasize that panel data is preferred to follow girls and their offspring. It allows to exploration of any dynamics including economic returns for offspring. Malawi DHS has five survey rounds. Future research could begin to track the mother-child cohorts across decades to build a panel necessary for long term observations on girls and their children. Research findings from an intergenerational panel might provide further evidence that while educating girls may not seem obviously relevant to child nutrition, education in the short-term can be considered as an investment for the future well-being of children, as this dissertation shows.

\subsection{Concluding remarks}

This dissertation has studied local diets and the causal effects of maternal education on child linear growth. The analysis further looked into determinants of becoming stunted or nonstunted using a Makov transitional model. Our findings demonstrate the broad range of causes of stunting encompassing child, maternal and household socioeconomic factors. Findings show that diets are inadequate in quantity and frequency and children are frequently ill. Looking more closely, maternal education reduces stunting but the high dropout levels experienced by girls can be 
considered a risk factor to stunting for a future generation. This combination of findings provides some support for the conceptual premise that preventing or reducing stunting will cut across different sectors as a wide range of actors can affect these determinants of stunting in Malawi. Hence, findings and recommendations of this dissertation provide evidence on what is contextually relevant, potential entry points and need for a comprehensive approach to address the persisting levels of stunting in Malawi. 



\section{References}

Abuya, B. A., Onsomu, E. O., Kimani, J. K., \& Moore, D. (2011). Influence of Maternal Education on Child Immunization and Stunting in Kenya. Maternal and child health journal, 15(8), 1389-1399. doi:10.1007/s10995010-0670-z

Adu-Afarwuah, S., Lartey, A., Brown, K. H., Zlotkin, S., Briend, A., \& Dewey, K. G. (2007). Randomized comparison of 3 types of micronutrient supplements for home fortification of complementary foods in Ghana: effects on growth and motor development. The American journal of clinical nutrition, 86(2), 412-420.

Aheto, J. M. K., Keegan, T. J., Taylor, B. M., \& Diggle, P. J. (2015).

Childhood Malnutrition and Its Determinants among Under-Five Children in Ghana. Paediatric and Perinatal Epidemiology, 29(6), 552561. doi:10.1111/ppe.12222

Akombi, B. J., Agho, K. E., Merom, D., Renzaho, A. M., \& Hall, J. J. (2017). Child malnutrition in sub-Saharan Africa: A meta-analysis of demographic and health surveys (2006-2016). PLoS One, 12(5), e0177338. doi:10.1371/journal.pone.0177338

Ali, D., Saha, K. K., Nguyen, P. H., Diressie, M. T., Ruel, M. T., Menon, P., \& Rawat, R. (2013). Household Food Insecurity Is Associated with Higher Child Undernutrition in Bangladesh, Ethiopia, and Vietnam, but the Effect Is Not Mediated by Child Dietary Diversity. The Journal of nutrition, 143(12), 2015-2021. doi:10.3945/jn.113.175182

Allen, L. H. (2012). Global dietary patterns and diets in childhood: implications for health outcomes. Annals of Nutrition and Metabolism, 61(Suppl. 1), 29-37.

Andersen, R. (1973). [Besprechung von:] Grossman, Michael: The demand for health. A theoretical and empirical investigation. New York, London 1972. Journal of economic literature, 11(4), 1417-1419. 
Angeles, I. T., Schultink, W. J., Matulessi, P., Gross, R., \& Sastroamidjojo, S. (1993). Decreased rate of stunting among anemic Indonesian preschool children through iron supplementation. Am J Clin Nutr, 58(3), 339-342.

Angrist, J. D., Imbens, G. W., \& Rubin, D. B. (1996). Identification of Causal Effects Using Instrumental Variables. Journal of the American statistical Association, 91(434), 444-455. doi:10.2307/2291629

Applegate, E. (2000). Introduction: nutritional and functional roles of eggs in the diet. Journal of the American College of Nutrition, 19(sup5), 495S498S.

Arimond, M., \& Ruel, M. T. (2004). Dietary diversity is associated with child nutritional status: evidence from 11 demographic and health surveys. The Journal of nutrition, 134(10), 2579.

Arimond, M., Wiesmann, D., Becquey, E., Carriquiry, A., Daniels, M. C., Deitchler, M., . . Martin-Prevel, Y. (2010). Simple food group diversity indicators predict micronutrient adequacy of women's diets in 5 diverse, resource-poor settings. The Journal of nutrition, 140(11), 2059S-2069S.

Aslam, M., \& Kingdon, G. (2010). Parental Education and Child Health Understanding the Pathways of Impact in Pakistan (Vol. 40).

Avenstrup, R., Liang, X., \& Nellemann, S. (2004). Kenya, Lesotho, Malawi and Uganda: Universal primary education and poverty reduction. Retrieved from

Ayele, Z., \& Peacock, C. (2003). Improving access to and consumption of animal source foods in rural households: the experiences of a women-focused goat development program in the highlands of Ethiopia. The Journal of nutrition, 133(11), 3981S-3986S.

Baumann, S. M., Webb, P., \& Zeller, M. (2013). Validity of food consumption indicators in the Lao context: Moving toward crosscultural standardization. Food \& Nutrition Bulletin, 34(1), 105-119.

Bauserman, M., Lokangaka, A., Gado, J., Close, K., Wallace, D., Kodondi, K.-K., . . Bose, C. A cluster-randomized trial determining the 
efficacy of caterpillar cereal as a locally available and sustainable complementary food to prevent stunting and anaemia. Public health nutrition, 18(10), 1785-1792.

Bauserman, M., Lokangaka, A., Gado, J., Close, K., Wallace, D., Kodondi, K.-K., . . Bose, C. (2015). A cluster-randomized trial determining the efficacy of caterpillar cereal as a locally available and sustainable complementary food to prevent stunting and anaemia. Public health nutrition, 18(10), 1785-1792.

Baye, K. (2017). The Sustainable Development Goals cannot be achieved without improving maternal and child nutrition. J Public Health Policy, 38(1), 137-145. doi:10.1057/s41271-016-0043-y

Behrman, J. A. (2015). The effect of increased primary schooling on adult women's HIV status in Malawi and Uganda: Universal Primary Education as a natural experiment. Social Science \& Medicine, 127, 108-115.

Behrman, J. R., Pollak, R. A., \& Taubman, P. (1986). Do parents favor boys? International Economic Review, 33-54.

Behrman, J. R., \& Taubman, P. (1986). Birth order, schooling, and earnings. Journal of Labor Economics, 4(3, Part 2), S121-S145.

Beka, T., Wambui, K.-M., Zewditu, G., \& Girum, T. (2009). Magnitude and determinants of stunting in children underfive years of age in food surplus region of Ethiopia: The case of West Gojam Zone. The Ethiopian Journal of Health Development, 23(2), 98.

Béné, C., \& Heck, S. (2005). Fish and food security in Africa. NAGA, WorldFish Center Quarterly, 28(3-4), 8-13.

Bhutta, Z. A., Ahmed, T., Black, R. E., Cousens, S., Dewey, K., Giugliani, E., ... Sachdev, H. (2008). What works? Interventions for maternal and child undernutrition and survival. The Lancet, 371(9610), 417-440.

Bhutta, Z. A., Sachdev, H. P. S., Shekar, M., Ahmed, T., Black, R. E., Cousens, S., . . Child Undernutrition Study, G. (2008). What works? Interventions for maternal and child undernutrition and survival. The Lancet, 371(9610), 417-440. doi:10.1016/S0140-6736(07)61693-6 
Biadgilign, S., Ademe, A., \& Yesigat, H. (2016). Does Economic Growth Reduce Childhood Undernutrition in Ethiopia? (Vol. 11).

Black, R. E., Allen, L. H., Bhutta, Z. A., Caulfield, L. E., Onis, M., \& Ezzati, M. (2008). Maternal and child undernutrition: global and regional exposures and health consequences. Lancet, 371. doi:10.1016/s01406736(07)61690-0

Black, R. E., Victora, C. G., Walker, S. P., Bhutta, Z. A., Christian, P., \& Onis, M. (2013). Maternal and child undernutrition and overweight in low-income and middle-income countries. Lancet, 382. doi:10.1016/s0140-6736(13)60937-x

Brannon, P. M., Taylor, C. L., \& Coates, P. M. (2014). Use and Applications of Systematic Reviews in Public Health Nutrition. Annu Rev Nutr. doi:10.1146/annurev-nutr-080508-141240

Buhmann, B., Rainwater, L., Schmaus, G., \& Smeeding, T. M. (1988). Equivalence scales, well-being, inequality, and poverty: sensitivity estimates across ten countries using the Luxembourg Income Study (LIS) database. Review of income and wealth, 34(2), 115-142.

Buor, D. (2003). Mothers' education and childhood mortality in Ghana. Health Policy, 64(3), 297-309. doi:http://dx.doi.org/10.1016/S01688510(02)00178-1

Buse, R. C., \& Salathe, L. E. (1978). Adult equivalent scales: An alternative approach. American Journal of Agricultural Economics, 60(3), 460-468.

Caldwell, J. C. (1994). How is greater maternal education translated into lower child mortality? Health transition review, 4(2), 224-229.

Caputo, A., Foraita, R., Klasen, S., \& Pigeot, I. (2003). Undernutrition in Benin - an analysis based on graphical models. Social Science $\mathcal{E}$ Medicine, 56(8), 1677-1691.

Chen, T. A., Baranowski, T., Moreno, J. P., O'Connor, T. M., Hughes, S. O., Baranowski, J., ... Johnston, C. A. (2016). Obesity status transitions across the elementary years: use of Markov chain modelling. Pediatric Obesity, 11(2), 88-94. doi:10.1111/ijpo.12025 
Chhagan, M. K., Van den Broeck, J., Luabeya, K. K., Mpontshane, N., Tomkins, A., \& Bennish, M. L. (2010). Effect on longitudinal growth and anemia of zinc or multiple micronutrients added to vitamin A: a randomized controlled trial in children aged 6-24 months. BMC public health, 10, 145. doi:10.1186/1471-2458-10-145

Chicoine, L. E. (2012). Education and fertility: Evidence from a policy change in Kenya. Browser Download This Paper.

Chikhungu, L. C., \& Madise, N. J. (2014). Seasonal variation of child under nutrition in Malawi: is seasonal food availability an important factor? Findings from a national level cross-sectional study. BMC public health, 14(1), 1146.

Chimombo, J. (2009). Changing patterns of access to basic education in Malawi: a story of a mixed bag? Comparative Education, 45(2), 297312.

Chimombo, J., Chibwanna, M., Dzimadzi, C., Kadzamira, E., Kunkwenzu, E., Kunje, D., \& Namphota, D. (2000). Classroom, school and home factors that negatively affect girls' education in Malawi. UNICEF, New York.

Chirwa, E. W., \& Matita, M. M. (2009). The rate of Return of Education in Malawi.

Chirwa, E. W., \& Ngalawa, H. P. (2008). Determinants of child nutrition in Malawi. South African Journal of Economics, 76(4), 628-640.

Choi, H.-J., Lee, H.-J., Jang, H. B., Park, J. Y., Kang, J.-H., Park, K.-H., \& Song, J. (2011). Effects of maternal education on diet, anemia, and iron deficiency in Korean school-aged children. BMC public health, 11(1), 870. doi:10.1186/1471-2458-11-870

Chou, S.-Y., Liu, J.-T., Grossman, M., \& Joyce, T. (2010). Parental education and child health: evidence from a natural experiment in Taiwan. American Economic Journal: Applied Economics, 2(1), 33-61.

Claro, R. M., Levy, R. B., Bandoni, D. H., \& Mondini, L. (2010). Per capita versus adult-equivalent estimates of calorie availability in 
household budget surveys. Cadernos de Saúde Pública, 26(11), 21882195.

Cleland, J. G., \& Van Ginneken, J. K. (1988). Maternal education and child survival in developing countries: the search for pathways of influence. Social Science \& Medicine, 27(12), 1357-1368.

Coates, J., Rogers, B. L., Blau, A., Lauer, J., \& Roba, A. (2017). Filling a dietary data gap? Validation of the Adult Male Equivalent method of estimating individual nutrient intakes from household-level data in Ethiopia and Bangladesh. Food policy, 72, 27-42.

Cook, T. D., Campbell, D. T., \& Shadish, W. (2002). Experimental and quasiexperimental designs for generalized causal inference: Houghton Mifflin Boston.

Cornelsen, L., Alarcon, P., Häsler, B., Amendah, D. D., Ferguson, E., Fèvre, E. M., . . Rushton, J. (2016). Cross-sectional study of drivers of animal-source food consumption in low-income urban areas of Nairobi, Kenya. BMC Nutrition, 2(1), 70. doi:10.1186/s40795-0160109-z

Crookston, B. T., Penny, M. E., Alder, S. C., Dickerson, T. T., Merrill, R. M., \& Stanford, J. B. (2010). Children who recover from early stunting and children who are not stunted demonstrate similar levels of cognition. J Nutr, 140. doi:10.3945/jn.109.118927

Crookston, B. T., Penny, M. E., Alder, S. C., Dickerson, T. T., Merrill, R. M., Stanford, J. B., . . Dearden, K. A. (2010). Children who recover from early stunting and children who are not stunted demonstrate similar levels of cognition. J Nutr, 140(11), 1996-2001. doi:10.3945/jn.109.118927

Darapheak, C., Takano, T., Kizuki, M., Nakamura, K., \& Seino, K. (2013). Consumption of animal source foods and dietary diversity reduce stunting in children in Cambodia. International Archives of Medicine, $6,29$.

de Hoop, K. (2010). Selective secondary education and school participation in Sub-Saharan Africa: Evidence from Malawi. 
de Onis, M., \& Branca, F. (2016). Childhood stunting: a global perspective. Matern Child Nutr, 12 Suppl 1, 12-26. doi:10.1111/mcn.12231

De Pee, S. C. M. I. K. C., Whitfield KC, Green TJ, Kraemer K (eds). . (2018). The biology of the first 1,000 days. CRC Press. Taylor $\mathcal{E}$ Francis Group, New York, 221-235. .

Deaton, A. S., \& Muellbauer, J. (1986). On Measuring Child Costs: With Applications to Poor Countries. Journal of Political Economy, 94(4), 720-744. doi:10.1086/261405

Desai, S., \& Alva, S. (1998). Maternal education and child health: Is there a strong causal relationship? Demography, 35(1), 71-81.

Dewey, K. G., \& Adu-Afarwuah, S. (2008). Systematic review of the efficacy and effectiveness of complementary feeding interventions in developing countries. Matern Child Nutr, 4 Suppl 1, 24-85. doi:10.1111/j.1740-8709.2007.00124.x

Dewey, K. G., \& Huffman, S. L. (2009). Maternal, infant, and young child nutrition: combining efforts to maximize impacts on child growth and micronutrient status: SAGE Publications Sage CA: Los Angeles, CA.

Dewey, K. G., \& Mayers, D. R. (2011). Early child growth: how do nutrition and infection interact? Maternal \& child nutrition, 7(s3), 129-142.

Diggle, P. J., \& Verbyla, A. P. (1998). Nonparametric estimation of covariance structure in longitudinal data. Biometrics, 54(2), 401-415.

Dror, D. K., \& Allen, L. H. (2011). The importance of milk and other animalsource foods for children in low-income countries. Food $\mathcal{E}$ Nutrition Bulletin, 32(3), 227-243.

Dror, D. K., \& Allen, L. H. (2011). The Importance of Milk and other Animal-Source Foods for Children in Low-Income Countries. Food Nutr Bull, 32(3), 227-243. doi:doi:10.1177/156482651103200307

Duflo, E., Dupas, P., \& Kremer, M. (2012). Education and Fertility: Experimental Evidence from Kenya," mimeo, Massachusetts Institute of Technology. 
Dunbar, G. R., Lewbel, A., \& Pendakur, K. (2013). Children's Resources in Collective Households: Identification, Estimation, and an Application to Child Poverty in Malawi. The American Economic Review, 103(1), 438-471.

ECA, A., \& NEPAD, W. (2013). The cost of hunger in Africa Social and Economic Impact of Child Undernutrition in Egypt, Ethiopia, Swaziland and Uganda. Addis Ababa.

Ecker, O., Breisinger, C., Pauw, K., Fan, S., \& Pandya-Lorch, R. (2012). Growth is good, but is not enough to improve nutrition. Paper presented at the Leveraging Agriculture for Improving Nutrition and Health. Proceedings of the IFPRI International Conference, New Delhi, India, 10-12 February 2011.

Ecker, O., \& Qaim, M. (2011). Analyzing nutritional impacts of policies: an empirical study for Malawi. World Development, 39(3), 412-428.

Ecker, O., \& Qaim, M. (2011). Analyzing Nutritional Impacts of Policies: an Empirical Study for Malawi. World Dev, 39. doi:10.1016/j.worlddev.2010.08.002

Esarey, J., \& Jaffe, J. (2017). A Direct Test for Consistency of Random Effects Models that Outperforms the Hausman Test.

Espo, M., Kulmala, T., Maleta, K., Cullinan, T., Salin, M. L., \& Ashorn, P. (2002). Determinants of linear growth and predictors of severe stunting during infancy in rural Malawi. Acta paediatrica (Oslo, Norway : 1992), 91(12), 1364-1370. doi:10.1111/j.16512227.2002.tb02835.x

Fenske, N., Burns, J., Hothorn, T., \& Rehfuess, E. A. (2013). Understanding child stunting in India: a comprehensive analysis of socio-economic, nutritional and environmental determinants using additive quantile regression.

Ferguson, C. J. (2009). An effect size primer: A guide for clinicians and researchers. Professional Psychology: Research and Practice, 40(5), 532. 
Fink, G., Günther, I., \& Hill, K. (2011). The effect of water and sanitation on child health: evidence from the demographic and health surveys 1986-2007. International journal of epidemiology, 40(5), 1196-1204.

Fisher, M., \& Lewin, P. A. (2013). Household, community, and policy determinants of food insecurity in rural Malawi. Development Southern Africa, 30(4-5), 451-467.

Frongillo, J. E. A., de Onis, M., \& Hanson, K. M. (1997). Socioeconomic and demographic factors are associated with worldwide patterns of stunting and wasting of children. The Journal of nutrition, 127(12), 2302.

Frost, M. B., Forste, R., \& Haas, D. W. (2005). Maternal education and child nutritional status in Bolivia: finding the links. Social Science $\mathcal{E}$ Medicine, 60(2), 395-407.

Gelli, A., Becquey, E., Ganaba, R., Headey, D., Hidrobo, M., Huybregts, L., . . Guedenet, H. (2017). Improving diets and nutrition through an integrated poultry value chain and nutrition intervention (SELEVER) in Burkina Faso: study protocol for a randomized trial. Trials, 18. doi:10.1186/s13063-017-2156-4

Geneletti, S., O'Keeffe, A. G., Sharples, L. D., Richardson, S., \& Baio, G. (2015). Bayesian regression discontinuity designs: incorporating clinical knowledge in the causal analysis of primary care data. Stat Med, 34(15), 2334-2352. doi:10.1002/sim.6486

Ghosh, S., Smriga, M., Vuvor, F., Suri, D., Mohammed, H., Armah, S. M., \& Scrimshaw, N. S. (2010). Effect of lysine supplementation on health and morbidity in subjects belonging to poor peri-urban households in Accra, Ghana. Am J Clin Nutr, 92(4), 928-939.

doi:10.3945/ajen.2009.28834

Girard, A. W., Self, J. L., McAuliffe, C., \& Olude, O. (2012). The effects of household food production strategies on the health and nutrition outcomes of women and young children: a systematic review. Paediatric and Perinatal Epidemiology, 26(s1), 205-222. 
Golden, M. H. (1995). Specific deficiencies versus growth failure: type I and type II nutrients. SCN News(12), 10-14.

Government of Malawi. (2011). Consulting with Care Givers. Retrieved from Grepin, K. A., \& Bharadwaj, P. (2015). Maternal education and child mortality in Zimbabwe. J Health Econ, 44, 97-117. doi:10.1016/j.jhealeco.2015.08.003

Grépin, K. A., \& Bharadwaj, P. (2015). Secondary education and HIV infection in Botswana. The Lancet Global Health, 3(8), e428-e429.

Grossman, M. (1972). On the concept of health capital and the demand for health. Journal of Political Economy, 80(2), 223-255.

Grossman, M. (2006). Education and nonmarket outcomes. Handbook of the Economics of Education, 1, 577-633.

Güneş, P. M. (2015). The role of maternal education in child health: Evidence from a compulsory schooling law. Economics of Education Review, 47, 1-16.

Hambidge, K. M., Sheng, X., Mazariegos, M., Jiang, T., Garces, A., Li, D., . . . Krebs, N. F. (2011). Evaluation of meat as a first complementary food for breastfed infants: impact on iron intake. Nutr Rev, 69 Suppl 1, S57-63. doi:10.1111/j.1753-4887.2011.00434.x

Headey, D., \& Ecker, O. (2013). Rethinking the measurement of food security: from first principles to best practice. Food Security, 5(3), 327-343.

Hels, O., Hassan, N., Tetens, I., \& Thilsted, S. H. (2003). Food consumption, energy and nutrient intake and nutritional status in rural Bangladesh: changes from 1981-1982 to 1995-96. European journal of clinical nutrition, 57(4), 586.

Hirvonen, K. (2013). Measuring catch-up growth in malnourished populations. Ann Hum Biol, 4460.

Hoddinott, J., Alderman, H., Behrman, J. R., Haddad, L., \& Horton, S. (2013). The economic rationale for investing in stunting reduction. Maternal \& child nutrition, 9(S2), 69-82. 
Hoddinott, J., Behrman, J. R., Maluccio, J. A., Melgar, P., Quisumbing, A. R., Ramirez-Zea, M., . . Martorell, R. (2013). Adult consequences of growth failure in early childhood. The American journal of clinical nutrition, 98(5), 1170.

Hotz, C., \& Gibson, R. (2001). Complementary feeding practices and dietary intakes from complementary foods amongst weanlings in rural Malawi. European journal of clinical nutrition, 55(10), 841.

Iannotti, L., Barron, M., \& Roy, D. (2008). Animal source food consumption and nutrition among young children in Indonesia: Preliminary analysis for assessing the impact of HPAI on nutrition. DFID Propoor HPAI Risk Reduction Strategies Project Research Report.

Imdad, A., Yakoob, M. Y., \& Bhutta, Z. A. (2011a). Impact of maternal education about complementary feeding and provision of complementary foods on child growth in developing countries. BMC public health, 11(Suppl 3), S25.

Imdad, A., Yakoob, M. Y., \& Bhutta, Z. A. (2011b). Impact of maternal education about complementary feeding and provision of complementary foods on child growth in developing countries. BMC public health, 11(3), 1.

Islam, M. A., \& Chowdhury, R. I. (2006). A higher order Markov model for analyzing covariate dependence. Applied Mathematical Modelling, 30(6), 477-488.

James, \& Palmer. (2015). The role of animal source foods in improving nutritional health in urban informal settlements: identification of knowledge gaps and implementation barriers. International Journal of Child Health and Nutrition, 4(2), 94-102.

James, A., \& Palmer, G. (2015). The role of animal source foods in improving nutritional health in urban informal settlements: identification of knowledge gaps and implementation barriers. Annals of Global Health, 81(1), 91-92.

Jan Meerman, F. a. A. O. F. o. t. U. N., Rome, Italy and Noora-Lisa Aberman, International Food Policy Research Institute (IFPRI), 
Lilongwe, Malawi. (2014). Making nutrition a national priority: a few policy process examples. Retrieved from

Jenkins, M., Shanks, C. B., \& Houghtaling, B. (2015). Orange-Fleshed Sweet Potato Successes and Remaining Challenges of the Introduction of a Nutritionally Superior Staple Crop in Mozambique. Food Nutr Bull, 36(3), 327-353.

Joe, W., Rajaram, R., \& Subramanian, S. V. (2016). Understanding the nullto-small association between increased macroeconomic growth and reducing child undernutrition in India: role of development expenditures and poverty alleviation. Matern Child Nutr, 12 Suppl 1, 196-209. doi:10.1111/mcn.12256

Jones, A. D., Ngure, F. M., Pelto, G., \& Young, S. L. (2013). What are we assessing when we measure food security? A compendium and review of current metrics. Advances in Nutrition: An International Review Journal, 4(5), 481-505.

Kadzamira, E., \& Rose, P. (2001). Educational policy choice and policy practice in Malawi: Dilemmas and disjunctures.

Kadzamira, E., \& Rose, P. (2003). Can free primary education meet the needs of the poor?: evidence from Malawi. International journal of educational development, 23(5), 501-516.

Kalanda, B. F., Verhoeff, F. H., \& Brabin, B. J. (2006). Chronic malnutrition in pregnant adolescents in rural Malawi: An anthropometric study. Acta Obstetricia et Gynecologica Scandinavica, 85(1), 33-39. doi:10.1080/00016340500334869

Kant, A. K. (1996). Indexes of overall diet quality: a review. Journal of the American Dietetic Association, 96(8), 785-791.

Kantor, L. S. (1998). A dietary assessment of the US food supply: comparing per capita food consumption with Food Guide Pyramid serving recommendations (Vol. 772): US Department of Agriculture, Economic Research Service.

Keats, A. (2014). Women's schooling, fertility, and child health outcomes: Evidence from Uganda's free primary education program. Retrieved from 
Keats, A. (2016). Women's schooling, fertility, and child health outcomes:

Evidence from Uganda's free primary education program. Retrieved from Kennedy, G., Ballard, T., \& Dop, M. C. (2011). Guidelines for measuring household and individual dietary diversity: Food and Agriculture Organization of the United Nations.

Kennedy, G., Berardo, A., Papavero, C., Horjus, P., Ballard, T., Dop, M., . . . Brouwer, I. D. (2010). Proxy measures of household food consumption for food security assessment and surveillance: comparison of the household dietary diversity and food consumption scores. Public health nutrition, 13(12), 2010-2018. doi:doi:10.1017/S136898001000145X

Kodish, S., Aburto, N., Hambayi, M. N., Kennedy, C., \& Gittelsohn, J. (2015). Identifying the sociocultural barriers and facilitating factors to nutrition-related behavior change: formative research for a stunting prevention program in Ntchisi, Malawi. Food Nutr Bull, 36(2), 138-153.

Krebs, N. F., Mazariegos, M., Chomba, E., Sami, N., Pasha, O., Tshefu, A., . . . Wright, L. L. (2012). Randomized controlled trial of meat compared with multimicronutrient-fortified cereal in infants and toddlers with high stunting rates in diverse settings. The American journal of clinical nutrition, 96(4), 840-847.

Krebs, N. F., Wright, L. L., Koso-Thomas, M., Goco, N., Kindem, M., McClure, E. M., . . Bose, C. L. (2012). Randomized controlled trial of meat compared with multimicronutrient-fortified cereal in infants and toddlers with high stunting rates in diverse settings. The American journal of clinical nutrition, 96(4), 840-847. doi:10.3945/ajcn.112.041962

Kuusipalo, H., Maleta, K., Briend, A., Manary, M., \& Ashorn, P. (2006). Growth and change in blood haemoglobin concentration among underweight Malawian infants receiving fortified spreads for 12 weeks: a preliminary trial. Journal of pediatric gastroenterology and nutrition, 43(4), 525-532. 
Lartey, A. (2015). What would it take to prevent stunted growth in children in sub-Saharan Africa? Proc Nutr Soc, 74(4), 449-453. doi:10.1017/s0029665115001688

Lartey, A. (2015). What would it take to prevent stunted growth in children in sub-Saharan Africa? Proceedings of the Nutrition Society, 74(4), 449453. doi:10.1017/S0029665115001688

Lartey, A., Manu, A., Brown, K. H., Peerson, J. M., \& Dewey, K. G. (1999). A randomized, community-based trial of the effects of improved, centrally processed complementary foods on growth and micronutrient status of Ghanaian infants from 6 to 12 mo of age. The American journal of clinical nutrition, 70(3), 391-404.

Lassi, Z. S., Das, J. K., Zahid, G., Imdad, A., \& Bhutta, Z. A. (2013). Impact of education and provision of complementary feeding on growth and morbidity in children less than 2 years of age in developing countries: a systematic review. BMC public health, 13(3), S13.

Lefebvre, C., Manheimer, E., \& Glanville, J. (2008). Searching for studies. Cochrane handbook for systematic reviews of interventions. New York: Wiley, 95-150.

Leroy, J. L., Ruel, M., Habicht, J.-P., \& Frongillo, E. A. (2015). Using heightfor-age differences (HAD) instead of height-for-age z-scores (HAZ) for the meaningful measurement of population-level catch-up in linear growth in children less than 5 years of age. BMC Pediatrics, 15(1), 145.

Leroy, J. L., Ruel, M., Habicht, J.-P., \& Frongillo, E. A. (2015). Using heightfor-age differences (HAD) instead of height-for-age z-scores (HAZ) for the meaningful measurement of population-level catch-up in linear growth in children less than 5 years of age. BMC Pediatrics, 15(1), 1-11. doi:10.1186/s12887-015-0458-9

Long, J. K., Murphy, S. P., Weiss, R. E., Nyerere, S., Bwibo, N. O., \& Neumann, C. G. (2012). Meat and milk intakes and toddler growth: a comparison feeding intervention of animal-source foods in rural Kenya. Public health nutrition, 15(06), 1100-1107. 
Lundeen, E. A., Behrman, J. R., Crookston, B. T., Dearden, K. A., Engle, P., Georgiadis, A., ... Stein, A. D. (2014). Growth faltering and recovery in children aged 1-8 years in four low-and middle-income countries: Young Lives. Public health nutrition, 17(09), 2131-2137.

Lundeen, E. A., Stein, A. D., Adair, L. S., Behrman, J. R., Bhargava, S. K., Dearden, K. A., . . Victora, C. G. (2014). Height-for-age z scores increase despite increasing height deficits among children in 5 developing countries. Am J Clin Nutr, 100(3), 821-825. doi:10.3945/ajen.114.084368

Luo, Z. C., \& Karlberg, J. (2000). Critical Growth Phases for Adult Shortness. American journal of epidemiology, 152(2), 125-131. doi:10.1093/aje/152.2.125

Makate, M. (2016). Education Policy and Under-Five Survival in Uganda: Evidence from the Demographic and Health Surveys. Social Sciences, $5(4), 70$.

Makate, M., \& Makate, C. (2016). The causal effect of increased primary schooling on child mortality in Malawi: Universal primary education as a natural experiment. Social Science \& Medicine, 168, 7283.

Makoka, D. (2013). The impact of maternal education on child nutrition: evidence from Malawi, Tanzania, and Zimbabwe. Calverton, MD: ICF International.

Malawi, D. (2010). Malawi Demographic and Health Survey. Zomba, Malawi, and Calverton.

Maleta, K., Virtanen, S. M., Espo, M., Kulmala, T., \& Ashorn, P. (2003). Seasonality of growth and the relationship between weight and height gain in children under three years of age in rural Malawi. Acta Prdiatrica, 92(4), 491-497. doi:10.1111/j.1651-2227.2003.tb00584.x

Mani, S. (2012a). Is there complete, partial, or no recovery from childhood malnutrition?-Empirical evidence from Indonesia. Oxford Bulletin of Economics and Statistics, 74(5), 691-715. 
Mani, S. (2012b). Is there Complete, Partial, or No Recovery from Childhood Malnutrition? - Empirical Evidence from Indonesia* Is there Complete, Partial, or No Recovery from Childhood Malnutrition? - Empirical Evidence from Indonesia. Oxford Bulletin of Economics \& Statistics, 74(5).

Martorell, R., Khan, L. K., \& Schroeder, D. G. (1994). Reversibility of stunting: epidemiological findings in children from developing countries. European journal of clinical nutrition, 48, S45-57.

Mary, A., \& Marie, T. R. (2004). Dietary Diversity Is Associated with Child Nutritional Status: Evidence from 11 Demographic and Health Surveys1,2. The Journal of nutrition, 134(10), 2579.

Masset, E., Haddad, L., Cornelius, A., \& Isaza-Castro, J. (2012). Effectiveness of agricultural interventions that aim to improve nutritional status of children: systematic review. Bmj, 344 .

Maxwell, D., Ahiadeke, C., Levin, C., Armar-Klemesu, M., Zakariah, S., \& Lamptey, G. M. (1999). Alternative food-security indicators: revisiting the frequency and severity ofcoping strategies'. Food policy, 24(4), 411-429.

Meenakshi, J. V., Erika, M., Nancy, L. J., Victor, M. M., Hugo, D., Josyline, J., . . James, G. (2010). How Cost-Effective is Biofortification in Combating Micronutrient Malnutrition? An Ex ante. World Development, 38(1), 64.

Meerman, J. (2008). MAKING NUTRITION A NATIONAL PRIORITY.

Meerman, J. (2014). COUNTRY-LEVELPROGRAMMING INNUTRITIONSENSITIVEAGRICULTURE: REVIEWOFDEVELOPMENTPARTNERINITIATIVES.

Meshram, I. I., Arlappa, N., Balakrishna, N., Rao, K. M., Laxmaiah, A., \& Brahmam, G. N. V. (2012). Trends in the prevalence of undernutrition, nutrient \& food intake and predictors of undernutrition among under five year tribal children in India. Asia Pac J Clin Nutr, 21(4), 568-576. 
Meyer, B. D. (1995). Natural and quasi-experiments in economics. Journal of business \& economic statistics, 13(2), 151-161.

Miller, J. E., \& Rodgers, Y. V. (2009). Mother's education and children's nutritional status: new evidence from Cambodia. Asian Development Review, 26(1), 131.

Moher, D., Liberati, A., Tetzlaff, J., \& Altman, D. G. (2010). Preferred reporting items for systematic reviews and meta-analyses: the PRISMA statement. International Journal of Surgery, 8(5), 336-341.

Moher, D., \& Tricco, A. C. (2008). Issues related to the conduct of systematic reviews: a focus on the nutrition field. The American journal of clinical nutrition, 88(5), 1191-1199.

Mosites, E., Aol, G., Otiang, E., Bigogo, G., Munyua, P., Montgomery, J. M., .. Thumbi, S. M. (2017). Child height gain is associated with consumption of animal-source foods in livestock-owning households in Western Kenya. Public health nutrition, 1-10.

Mosley, W. H., \& Chen, L. C. (2003). An analythical framework for the study of child survival in developing countries. Bulletin of the World Health Organization, 81(2), 140-145.

Mosley, W. H., \& Chen, L. C. (2003). An analytical framework for the study of child survival in developing countries. 1984. Bull World Health Organ, 81(2), 140-145.

Murphy, S., \& Allen, L. (2003). Nutritional Importance of Animal Source Foods. J Nutr, 133.

Mussa, R., \& Paul, K. (2011). Poverty in Malawi-Current status and knowledge gaps.

Muthayya, S. (2009). Maternal nutrition \& low birth weight-what is really important. Indian J Med Res, 130(5), 600-608.

National Statistical Office/Malawi, \& ICF. (2017). Malawi Demographic and Health Survey 2015-16. Retrieved from Zomba, Malawi: http://dhsprogram.com/pubs/pdf/FR319/FR319.pdf 
Nel, J. H., \& Casey, A. (2003). Secondary data analyses of dietary surveys undertaken in South Africa to determine usual food consumption of the population. Public health nutrition, 6(7), 631-644.

Nishimura, M., Ogawa, K., Sifuna, D., Chimombo, J., Kunje, D., Ampiah, J., ... Yamada, S. (2009). A Comparative Analysis of Universal Primary Education Policy In Ghana, Kenya, Malawi and Uganda. Nordin, S. (2005). Low Input Food and Nutrition Security: growing and eating more using less. Lilongwe, World Food Programme: Malawi.

Noriega, K. E., \& Lindshield, B. L. (2014). Is the inclusion of animal source foods in fortified blended foods justified? Nutrients, 6(9), 3516-3535.

O'Keeffe, A. G., \& Baio, G. (2016). Approaches to the Estimation of the Local Average Treatment Effect in a Regression Discontinuity Design. Scand Stat Theory Appl, 43(4), 978-995. doi:10.1111/sjos.12224

Obatolu, V. A. (2003). Growth pattern of infants fed with a mixture of extruded malted maize and cowpea. Nutrition, 19(2), 174-178.

Odongo, C. O., Bisaso, K. R., Kitutu, F., Obua, C., \& Byamugisha, J. (2015). Is there a distinction between malaria treatment and intermittent preventive treatment? Insights from a cross-sectional study of antimalarial drug use among Ugandan pregnant women. Malar J, 14(1), 189.

Oelofse, A., Van Raaij, J., Benade, A., Dhansay, M., Tolboom, J., \& Hautvast, J. (2003). The effect of a micronutrient-fortified complementary food on micronutrient status, growth and development of 6-to 12-month-old disadvantaged urban South African infants. International journal of food sciences and nutrition, 54(5), 399-407.

Oldenburg, C. E., Moscoe, E., \& Barnighausen, T. (2016). Regression Discontinuity for Causal Effect Estimation in Epidemiology. Curr Epidemiol Rep, 3, 233-241. doi:10.1007/s40471-016-0080-x

Onyango, A. W. (2003). Dietary diversity, child nutrition and health in contemporary African communities. Comparative Biochemistry and Physiology, Part A, 136(1), 61-69. doi:10.1016/S1095-6433(03)00071-0 
Onyango, A. W., Borghi, E., de Onis, M., Casanovas, M. d. C., \& Garza, C. (2013). Complementary feeding and attained linear growth among 6-23-month-old children. Public health nutrition, FirstView, 1-9. doi:doi:10.1017/S1368980013002401

Osili, U. O., \& Long, B. T. (2008). Does female schooling reduce fertility? Evidence from Nigeria. Journal of Development Economics, 87(1), 5775.

Outes, I., \& Porter, C. (2013). Catching up from early nutritional deficits? Evidence from rural Ethiopia. Econ Hum Biol, 11. doi:10.1016/j.ehb.2012.03.001

Outes, I., \& Porter, C. (2013). Catching up from early nutritional deficits? Evidence from rural Ethiopia. Economics \& Human Biology, 11(2), 148-163.

Owino, V. O., Kasonka, L. M., Sinkala, M. M., Wells, J. K., Eaton, S., Darch, T., ... Filteau, S. M. (2007). Fortified complementary foods with or without $\alpha$-amylase treatment increase hemoglobin but do not reduce breast milk intake of 9-mo-old Zambian infants. The American journal of clinical nutrition, 86(4), 1094-1103.

Oxman, A. D., \& Group, G. W. (2004). Grading quality of evidence and strength of recommendations. Bmj, 328(19), 1490-1494.

Paul, K. H., Muti, M., Khalfan, S. S., Humphrey, J. H., Caffarella, R., \& Stoltzfus, R. J. (2011). Beyond food insecurity: how context can improve complementary feeding interventions. Food Nutr Bull, 32(3), 244-253.

Perry, H., Morrow, M., Davis, T., Borger, S., Weiss, J., DeCoster, M., \& Ernst, P. (2014). Care Groups-An Effective Community-based Delivery Strategy for Improving Reproductive, Maternal, Neonatal and Child Health in High-Mortality, Resource-Constrained Settings.

Phiri, T. (2014). Review of Maternal Effects on Early Childhood Stunting. Prendergast, A. J., \& Humphrey, J. H. (2014). The stunting syndrome in developing countries. Paediatr Int Child Health, 34(4), 250-265. doi:10.1179/2046905514y.0000000158 
Prentice, A. M., Ward, K. A., Goldberg, G. R., Jarjou, L. M., Moore, S. E., Fulford, A. J., \& Prentice, A. (2013). Critical windows for nutritional interventions against stunting. The American journal of clinical nutrition, 97(5), 911.

Pryer, J. A., Rogers, S., \& Rahman, A. (2004). The epidemiology of good nutritional status among children from a population with a high prevalence of malnutrition. Public health nutrition, 7(02), 311-317.

Raaijmakers, A., Jacobs, L., Rayyan, M., van Tienoven, T. P., Ortibus, E., Levtchenko, E., . . Allegaert, K. (2017). Catch-up growth in the first two years of life in Extremely Low Birth Weight (ELBW) infants is associated with lower body fat in young adolescence. PLoS One, 12(3). doi:10.1371/journal.pone.0173349

Reed, B. A., Habicht, J.-P., \& Niameogo, C. (1996). The effects of maternal education on child nutritional status depend on socioenvironmental conditions. International journal of epidemiology, 25(3), 585-592.

Remans, R., Pronyk, P. M., Fanzo, J. C., Chen, J., Palm, C. A., Nemser, B., . . . Sachs, J. D. (2011). Multisector intervention to accelerate reductions in child stunting: an observational study from 9 sub-Saharan African countries. The American journal of clinical nutrition, 94(6), 1632-1642. doi:10.3945/ajen.111.020099

Riddell, A. (2003). The introduction of free primary education in subSaharan Africa. Background paper prepared for EFA GMR 2003.

Ruel Marie, T. M. (2008). Age-based preventive targeting of food assistance and behaviour change and communication for reduction of childhood undernutrition in Haiti: a cluster randomised trial. Lancet, The, 371(9612), 588-595.

Ruel, M. T., Habicht, J.-P., Pinstrup-Andersen, P., \& Gröhn, Y. (1992). The mediating effect of maternal nutrition knowledge on the association between maternal schooling and child nutritional status in Lesotho. American journal of epidemiology, 135(8), 904-914. 
Sahn, D. (1984). Food Consumption Patterns and Parameters inSri Lanka: The Causes and Control of Malnutrition. Washington DC: International Food Policy ResearchInstitute.

Saleemi, M., Ashraf, R., Mellander, L., \& Zaman, S. (2001). Determinants of stunting at 6, 12, 24 and 60 months and postnatal linear growth in Pakistani children. Acta Paediatrica, 90(11), 1304-1308.

Schönfeldt, H. C., \& Gibson Hall, N. (2012). Dietary protein quality and malnutrition in Africa. British Journal of Nutrition, 108(S2), S69-S76.

SDGs. (2015). Sustainable development goals.

http://www.un.org/sustainabledevelopment/sustainabledevelopment-goals/. Extracted December 2017.

Semba, R. D. (2016). The Rise and Fall of Protein Malnutrition in Global Health. Ann Nutr Metab, 69(2), 79-88. doi:10.1159/000449175

Semba, R. D., de Pee, S., Sun, K., Sari, M., Akhter, N., \& Bloem, M. W. (2008). Effect of parental formal education on risk of child stunting in Indonesia and Bangladesh: a cross-sectional study. Lancet, 371(9609), 322-328. doi:10.1016/s0140-6736(08)60169-5

Sguassero, Y., de Onis, M., Bonotti, A. M., \& Carroli, G. (2012). Communitybased supplementary feeding for promoting the growth of children under five years of age in low and middle income countries. Cochrane Database Syst Rev, 6, CD005039.

Shekar, M., Kakietek, J., Dayton Eberwein, J., \& Walters, D. (2016). An Investment Framework for Nutrition. Washington DC: The World Bank Group .

Spears, D. (2012). Height and cognitive achievement among Indian children. Econ Hum Biol, 10(2), 210-219. doi:10.1016/j.ehb.2011.08.005

Stein, A. D., Wang, M., Martorell, R., Norris, S., Adair, L. S., \& Bas, I. (2010). Growth patterns in early childhood and final attained stature: data from five birth cohorts from low- and middle-income countries. Am J Hum Biol, 22. doi:10.1002/ajhb.20998

Stein, A. D., Wang, M., Martorell, R., Norris, S. A., Adair, L. S., Bas, I., . . Gigante, D. P. (2010). Growth patterns in early childhood and final 
attained stature: Data from five birth cohorts from low-and middleincome countries. American Journal of Human Biology, 22(3), 353-359.

Stevens, G. A., Finucane, M. M., Paciorek, C. J., Flaxman, S. R., White, R. A., Donner, A. J., \& Ezzati, M. (2012). Trends in mild, moderate, and severe stunting and underweight, and progress towards MDG 1 in 141 developing countries: a systematic analysis of population representative data. Lancet, 380(9840), 824-834. doi:10.1016/s01406736(12)60647-3

Stewart, C. P., Iannotti, L., Dewey, K. G., Michaelsen, K. F., \& Onyango, A. W. (2013). Contextualising complementary feeding in a broader framework for stunting prevention. Maternal \& child nutrition, 9(S2), 27-45.

Stewart, C. P., Iannotti, L., Dewey, K. G., Michaelsen, K. F., \& Onyango, A. W. (2013). Contextualising complementary feeding in a broader framework for stunting prevention. Matern Child Nutr, 9 Suppl 2, 2745. doi:10.1111/mcn.12088

Sun, J., Huo, J., Zhao, L., Fu, P., Wang, J., Huang, J., . . Ma, G. (2013). The nutritional status of young children and feeding practices two years after the Wenchuan Earthquake in the worst-affected areas in China. Asia Pac J Clin Nutr, 22(1), 100-108. doi:10.6133/apjen.2013.22.1.19

Tebug, S. F., Kasulo, V., Chikagwa-Malunga, S., Wiedemann, S., Roberts, D. J., \& Chagunda, M. G. (2012). Smallholder dairy production in Northern Malawi: production practices and constraints. Tropical animal health and production, 44(1), 55-62.

Tedford, J. R., Capps, J. O., \& Havlicek, J. J. (1986). Adult Equivalent Scales Once More-A Developmental Approach. American Journal of Agricultural Economics, 68(2), 322-333. doi:10.2307/1241434

Teivaanmäki, T., Cheung, Y. B., Kortekangas, E., Maleta, K., \& Ashorn, P. (2015a). Transition between stunted and nonstunted status: both occur from birth to 15 years of age in Malawi children. Acta Paediatrica, 104(12), 1278-1285. 
Teivaanmäki, T., Cheung, Y. B., Kortekangas, E., Maleta, K., \& Ashorn, P. (2015b). Transition between stunted and nonstunted status: both occur from birth to 15 years of age in Malawi children. Acta Paediatrica, 104(12), 1278-1285. doi:10.1111/apa.13060

Theron, M., Amissah, A., Kleynhans, I., Albertse, E., \& MacIntyre, U. (2007). Inadequate dietary intake is not the cause of stunting amongst young children living in an informal settlement in Gauteng and rural Limpopo Province in South Africa: the NutriGro study. Public health nutrition, 10(04), 379-389.

Tome, D., Jahoor, F., Kurpad, A., Michaelsen, K. F., Pencharz, P., Slater, C., \& Weisell, R. (2014). Current issues in determining dietary protein quality and metabolic utilization. Eur J Clin Nutr, 68(5), 537-538. doi:10.1038/ejcn.2014.55

Tomedi, A., Rohan-Minjares, F., McCalmont, K., Ashton, R., Opiyo, R., \& Mwanthi, M. (2012). Feasibility and effectiveness of supplementation with locally available foods in prevention of child malnutrition in Kenya. Public health nutrition, 15(04), 749-756. doi:doi:10.1017/S1368980011002217

Torres-Reyna, O. (2007). Panel data analysis fixed and random effects using Stata (v. 4.2). Data \& Statistical Services, Priceton University.

Tsai, A. C., \& Venkataramani, A. S. (2015). The causal effect of education on HIV stigma in Uganda: evidence from a natural experiment. Soc Sci Med, 142, 37-46. doi:10.1016/j.socscimed.2015.08.009

UNICEF. (1990). Conceptual framework for basic causes of malnutrition. New York: UNICEF.

UNICEF. (2015). Levels and Trends in Child Malnutrition: Key Findings of the 2015.

UNICEF. (2017). Joint Child Malnutrition estimates

Verduzco-Gallo, I., Ecker, O., \& Pauw, K. (2012). Changes in Food and Nutrition Security in Malawi. 
Verduzco-Gallo, I., Ecker, O., \& Pauw, K. (2014). Changes in food and nutrition security in Malawi: Analysis of recent survey evidence (Vol. 6): Intl Food Policy Res Inst.

Victora, C. G., de Onis, M., Hallal, P. C., Blössner, M., \& Shrimpton, R. (2010). Worldwide timing of growth faltering: revisiting implications for interventions. Pediatrics, 125(3), e473-e480. doi:10.1542/peds.2009-1519

Vikram, K., Vanneman, R., \& Desai, S. (2012). Linkages between maternal education and childhood immunization in India. Social Science $\mathcal{E}$ Medicine, 75(2), 331-339.

Wamani, H., Åstrøm, A. N., Peterson, S., Tumwine, J. K., \& Tylleskär, T. (2006). Predictors of poor anthropometric status among children under 2 years of age in rural Uganda. Public health nutrition, 9(03), 320-326.

WHO. (2006). WHO Child Growth Standards based on length/height, weight and age. Acta Paediatr Suppl, 450, 76-85.

WHO. (2014). Global targets 2025 to improve maternal, infant and young child nutrition. Retrieve from http://www. who. int/nutrition/topics/nutrition_globaltargets2025/en.

WHO, U. (2013). Child Stunting Conceptual Framework (UNICEF/WHO 1990; 2013).

Wolfe, B. L., \& Behrman, J. R. (1987). Women's schooling and children's health: Are the effects robust with adult sibling control for the women's childhood background? Journal of health economics, 6(3), 239-254.

Woodward, L., Fergusson, D. M., \& Horwood, L. J. (2001). Risk factors and life processes associated with teenage pregnancy: Results of a prospective study from birth to 20 years. Journal of Marriage and Family, 63(4), 1170-1184.

Wooldridge, J. M. (2010). Econometric analysis of cross section and panel data: MIT press. 
World Bank. (2010). ( 2010 ) Nutritional Status and Poverty in Sub-Saharan Africa.

Yeudall, F., Gibson, R. S., Cullinan, T. R., \& Mtimuni, B. (2005). Efficacy of a community-based dietary intervention to enhance micronutrient adequacy of high-phytate maize-based diets of rural Malawian children. Public health nutrition, 8(7), 826-836.

Zongrone, A., Winskell, K., \& Menon, P. (2012). Infant and young child feeding practices and child undernutrition in Bangladesh: insights from nationally representative data. Public health nutrition, 15(9), 1697-1698. doi:10.1017/S1368980012001073 

Appendices 


\section{Appendix A}

Table A3.1: Missing values by food groups and individual foods

\begin{tabular}{|c|c|c|c|c|}
\hline & & $\begin{array}{l}\text { Households } \\
\text { that answered = } \\
\text { Yes, I } \\
\text { consumed }\end{array}$ & $\begin{array}{l}\text { Conversion factor } \\
\text { availability for the total } \\
\text { number of positive } \\
\text { answers }\end{array}$ & Missing values \\
\hline & Food groups & & & \\
\hline \multirow[t]{14}{*}{2010} & Cereals & 1345 & 1260 & $6 \%$ \\
\hline & Roots and tubers & 691 & 594 & $14 \%$ \\
\hline & Pulse and nuts & 975 & 784 & $20 \%$ \\
\hline & Vegetables & 1862 & 1607 & $14 \%$ \\
\hline & Fruits & 537 & 491 & $9 \%$ \\
\hline & Milk products & 167 & 149 & $11 \%$ \\
\hline & Animal & 1053 & 960 & $9 \%$ \\
\hline & Oil & 414 & 202 & $51 \%$ \\
\hline & Sugar & 589 & 540 & $8 \%$ \\
\hline & Individual foods & & & \\
\hline & Fish & 495 & 471 & $5 \%$ \\
\hline & Meat & 366 & 304 & $17 \%$ \\
\hline & Eggs & 182 & 179 & $2 \%$ \\
\hline & Food groups & & & \\
\hline \multirow[t]{13}{*}{2013} & Cereals & 1462 & 1425 & $3 \%$ \\
\hline & Roots and tuber & 693 & 655 & $5 \%$ \\
\hline & Pulses and nuts & 1264 & 1213 & $4 \%$ \\
\hline & Vegetables & 2088 & 1923 & $8 \%$ \\
\hline & Fruits & 572 & 552 & $3 \%$ \\
\hline & Milk products & 151 & 145 & $4 \%$ \\
\hline & Animal & 1052 & 945 & $10 \%$ \\
\hline & Oil & 924 & 214 & $77 \%$ \\
\hline & Sugar & 612 & 539 & $12 \%$ \\
\hline & Individual foods & & & \\
\hline & Fish & 465 & 404 & $13 \%$ \\
\hline & Meat & 396 & 352 & $11 \%$ \\
\hline & Eggs & 185 & 185 & $0 \%$ \\
\hline
\end{tabular}

Source: Authors' calculation from data. The first column gives the actual number of person answering 'yes", to consuming a specific food group/item and the second column the total number of available conversion factor. The difference represents the missing conversion factors. 
Table A3.2: Classification and composition of food groups

\begin{tabular}{|c|c|c|}
\hline & Foods (examples) & $\begin{array}{l}\text { Food groups } \\
\text { (definitive) }\end{array}$ \\
\hline 1 & $\begin{array}{l}\text { Maize, maize porridge, rice, sorghum, millet } \\
\text { pasta, bread and other cereals (Grains and } \\
\text { cereals) }\end{array}$ & Main staples \\
\hline 2 & $\begin{array}{l}\text { Cassava, potatoes and sweet potatoes, other } \\
\text { tubers, plantains (Roots and tubers) }\end{array}$ & \\
\hline 3 & Beans. Peas, groundnuts and cashew nuts & Nuts and pulses \\
\hline 4 & Vegetables, relish and leaves & Vegetables \\
\hline 5 & Fruits & Fruit \\
\hline 6 & Beef, goat, poultry, pork, eggs and fish & $\begin{array}{l}\text { Meat and fish (Animal } \\
\text { products) }\end{array}$ \\
\hline 7 & Milk, yogurt and other dairy & Milk products \\
\hline 8 & Sugar and sugar products & Sugar \\
\hline 9 & Oils, fats and butter & Fats and oil \\
\hline 10 & $\begin{array}{l}\text { Spices, tea, coffee, salt, fish power, small } \\
\text { amounts of milk for tea. }\end{array}$ & Spices and condiments \\
\hline
\end{tabular}

Adapted from WFP technical guidance (Jones et al 2013). Weights applicable when food consumption score variable is used. 
Table A3.3: Bivariate regression: age in months and age group on quantity of food consumed

\begin{tabular}{lll}
\hline & Milk & Animal Products \\
\hline Age (in months) & 0.00031 & -0.0021 \\
& $(0.0023)$ & $(0.0024)$ \\
Observations & 1028 & 1028 \\
Age group (ref.=6-11) & & \\
12-24 & -0.170 & 0.0156 \\
& $(0.133)$ & $(0.145)$ \\
$36-47$ & -0.0870 & 0.00450 \\
& $(0.161)$ & $(0.176)$ \\
$48-59$ & -0.0791 & -0.123 \\
& $(0.131)$ & $(0.142)$ \\
Observations & 1028 & 1028 \\
\hline
\end{tabular}

Source: Authors' calculation from data. Standard errors in parentheses 
Table A3.4: Means comparison: changes in HAZ by age, wealth status and maternal education

\begin{tabular}{|c|c|c|c|c|c|c|}
\hline & 2010 & & & 2013 & & \\
\hline \multicolumn{7}{|c|}{ Wealth status } \\
\hline \multirow[t]{2}{*}{ HAZ } & Poor $=0$ & Poor=1 & t-test & Poor $=0$ & Poor $=1$ & t-test \\
\hline & -1.0332 & -1.1313 & 0.9041 & -1.214 & -1.212 & -0.0198 \\
\hline $\begin{array}{l}\text { Maternal } \\
\text { education }\end{array}$ & $\begin{array}{l}\text { Primary } \\
\text { and higher } \\
\text { education }\end{array}$ & $\begin{array}{l}\text { No } \\
\text { education }\end{array}$ & & $\begin{array}{l}\text { Primary } \\
\text { and higher } \\
\text { education }\end{array}$ & $\begin{array}{l}\text { No } \\
\text { education }\end{array}$ & \\
\hline HAZ & -1.219 & -1.044 & -1.244 & -1.287 & -1.195 & -0.7877 \\
\hline $\begin{array}{l}\text { Age group } \\
\text { (months) }\end{array}$ & $6-11$ & $12-24$ & & $36-47$ & $48-59$ & \\
\hline HAZ & -0.897 & -1.155 & $2.222^{* *}$ & -1.186 & -1.223 & 0.327 \\
\hline
\end{tabular}

Source: Authors' calculation from data 1 ) Standard errors in parentheses 2) ${ }^{* * *} \mathrm{p}<0.01$, ** $\mathrm{p}<0.05$. 
Table A3.5: Heterogeneity in the association between other food groups and linear growth: interactions with age (in months), wealth and maternal education status interactions

\begin{tabular}{|c|c|c|c|c|c|c|}
\hline & $\begin{array}{l}\text { Quantity } \\
\text { consumed }\end{array}$ & & $\begin{array}{l}\text { Number of } \\
\text { days } \\
\text { consumed }\end{array}$ & & $\begin{array}{l}\text { Consumed } \\
\text { yes or no }\end{array}$ & \\
\hline & Coefficient & S.E & Coefficient & S.E & Coefficient & S.E \\
\hline $\begin{array}{l}\text { Cereals } x>24 \\
\text { months }\end{array}$ & $6.56 \mathrm{E}-05$ & $(-0.000268)$ & 0.0162 & $(-0.0794)$ & omitted & omitted \\
\hline Observations & 1,023 & & 1,026 & & omitted & \\
\hline Cereals $x$ age & 3.67E-06 & $(-7.25 \mathrm{E}-06)$ & 0.000249 & $(-0.0021)$ & omitted & omitted \\
\hline Observations & 1,023 & & 1,028 & & 1,026 & \\
\hline Vegetables $\mathrm{x}$ poor & $-0.00241^{* *}$ & $(-0.0011)$ & -0.0805 & $(-0.0613)$ & 0.23 & $(-1.253)$ \\
\hline Observations & & 997 & & 1,028 & & 1,028 \\
\hline $\begin{array}{l}\text { Vegetables } x \\
\text { primary }\end{array}$ & -0.00112 & $(-0.000779)$ & -0.0347 & -0.055 & $-2.904^{* * *}$ & $(-0.981)$ \\
\hline $\begin{array}{l}\text { Vegetables x } \\
\text { secondary and } \\
\text { higher }\end{array}$ & -0.000153 & $(-0.00107)$ & 0.102 & $(-0.0909)$ & omitted & omitted \\
\hline Observations & 997 & & 1,028 & & 1,028 & \\
\hline Tubers $\mathrm{x}$ poor & $-0.00140^{* *}$ & $(-0.000651)$ & -0.0292 & $(-0.034)$ & -0.0738 & $(-0.21)$ \\
\hline Observations & 992 & & 1,028 & & 1,028 & \\
\hline $\begin{array}{l}\text { Pulse and nuts } x \\
\text { poor }\end{array}$ & $-0.00459^{* * *}$ & $(-0.00162)$ & -0.0419 & $(-0.0369)$ & -0.00295 & $(-0.292)$ \\
\hline Observations & 1,016 & & 1,028 & & 1,028 & \\
\hline
\end{tabular}

Source: Authors' calculations from data. 1) Standard errors in parentheses, 2) *** $\mathrm{p}<0.01,{ }^{* *} \mathrm{p}<0.05$. 3) Data source: http://go.worldbank.org/. 4) Data collected in 2010 and 2013;5) Control variables; gender of the child, age in month difference with previous child, birth order, total number of children, mother education, age groups, age as continuous variable, wealth status), amenities, external shocks, part of nutrition program, number of meals, illness in last 2 weeks, under five clinic attendance, area, region and year dummy.5) Use of random effects models. 6) The reference category for age group is 6-24, for wealth status it is non-poor and for education it is no education 7) omitted due to $99 \%$ cereal consumption. No comparison. 


\section{Appendix B}

Figure B5.1: Primary school completion (or higher) by region of residence.
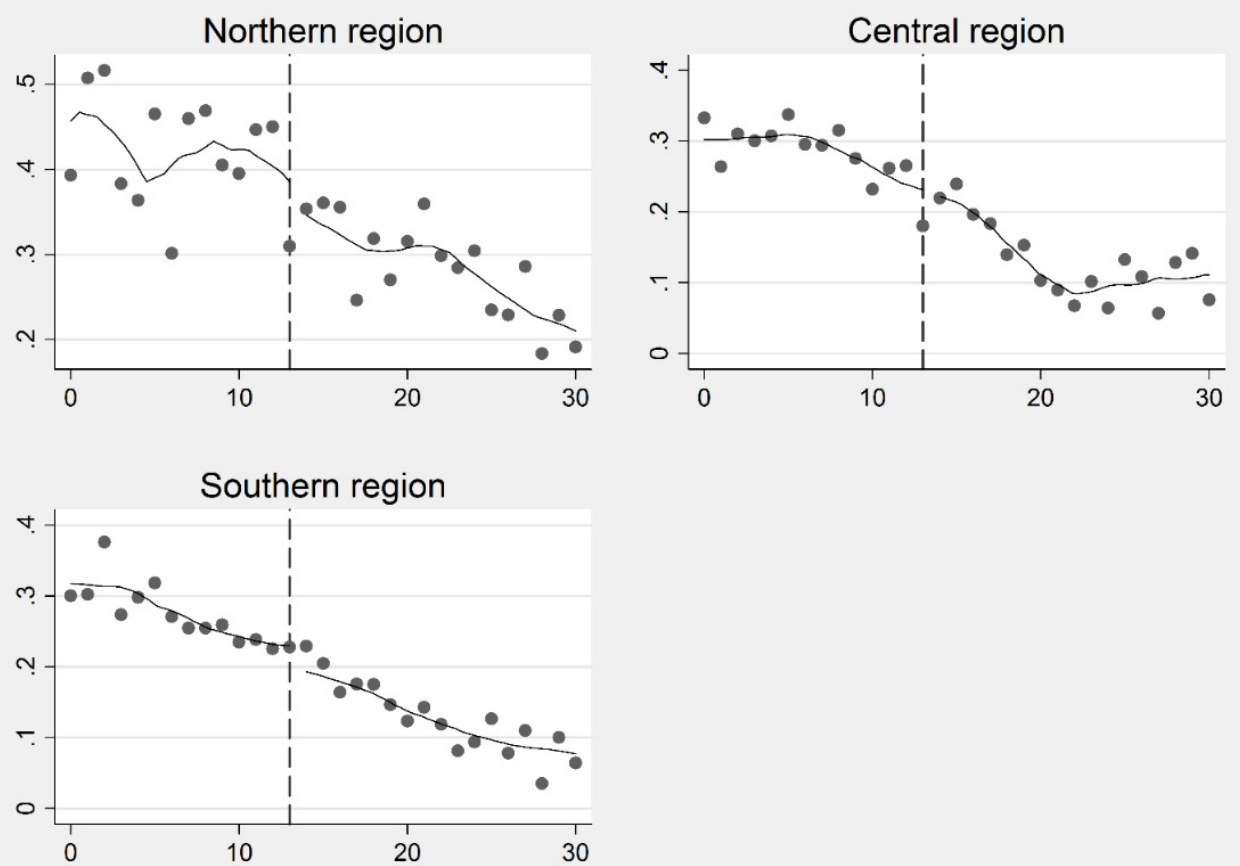
Figure B5.2: Distribution of the respondent's age at policy enactment in 1994 to check for potential discontinuities or bunching at the age 13 cut-point.

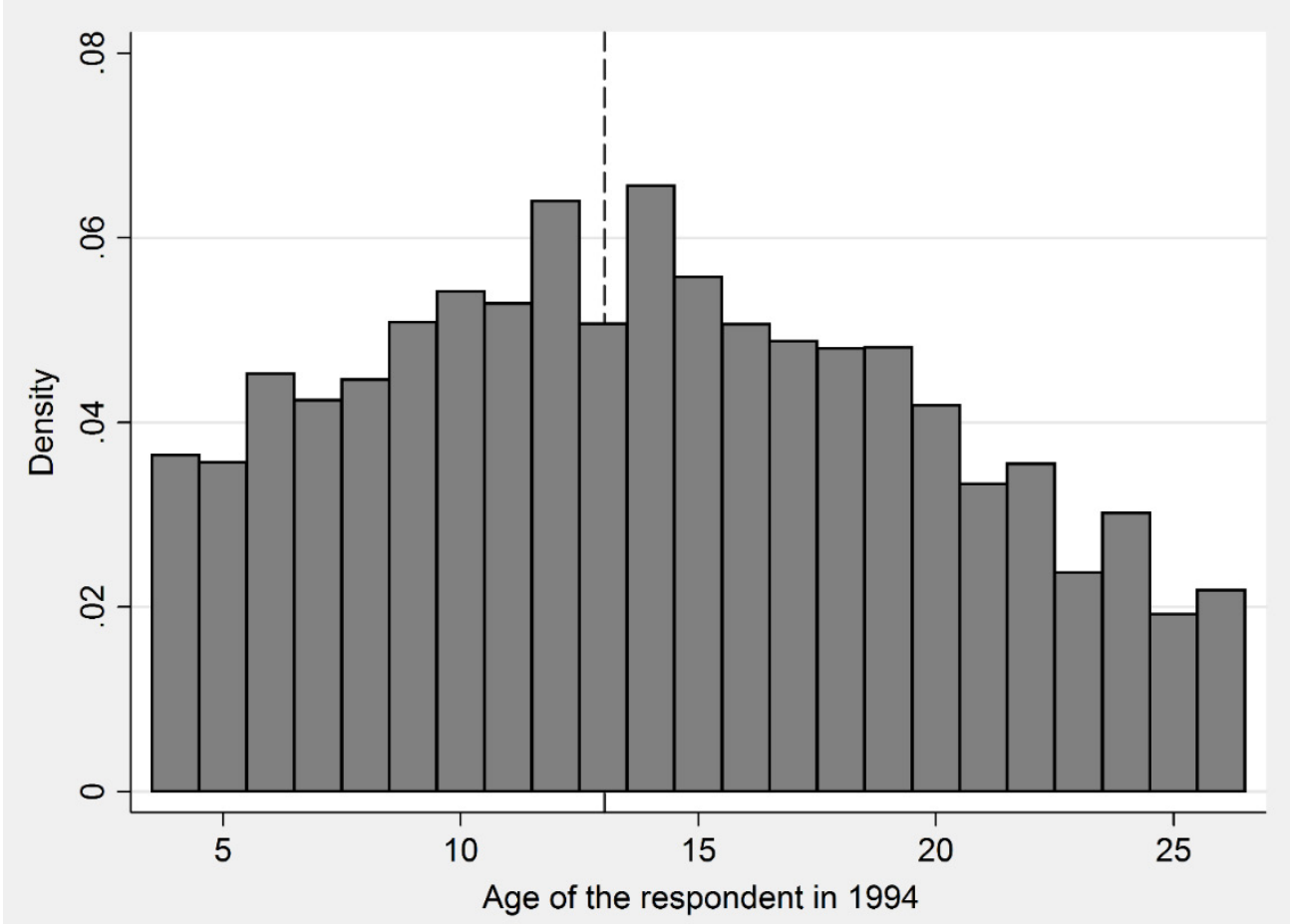


Figure B5.3: Checking the smoothness of respondent's age at policy enactment in 1994 to check for discontinuity by dataset used in the analysis - validity checks"
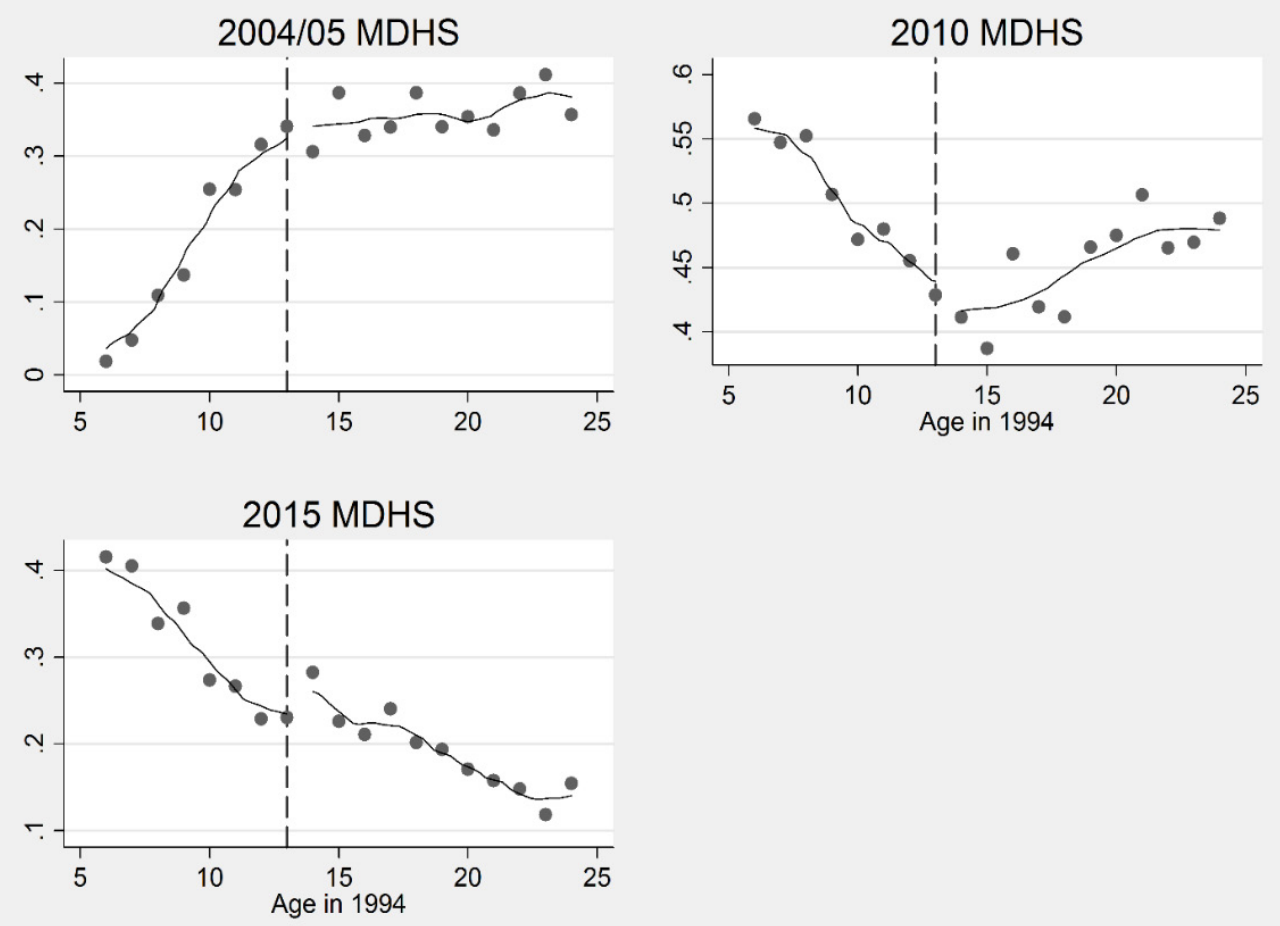

Note: We include 2005/4 to validate discontinuity. MDHS 2010 and 2015 is preferred and used for the analysis. 
Figure B5.4: Smoothness of the respondents' age at policy enactment in 1994: maternal variables.
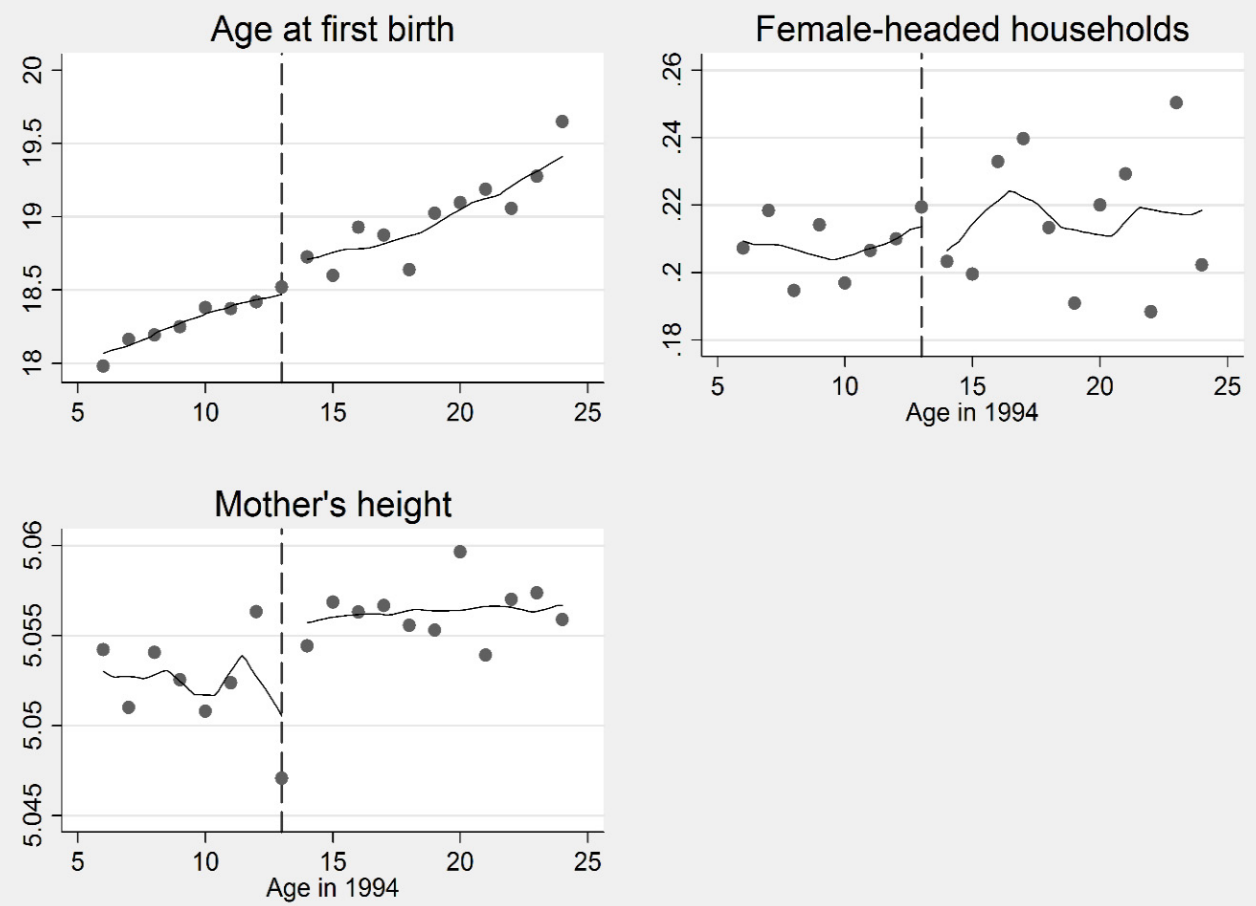
Figure B5.5: Smoothness of the respondents' child characteristics used in the analysis: child age

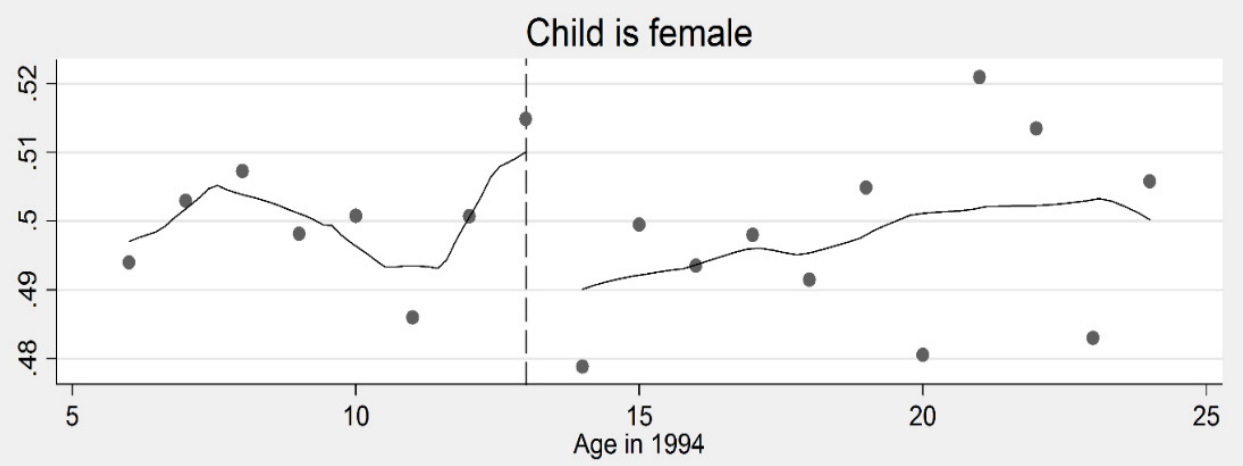

Child's age in months

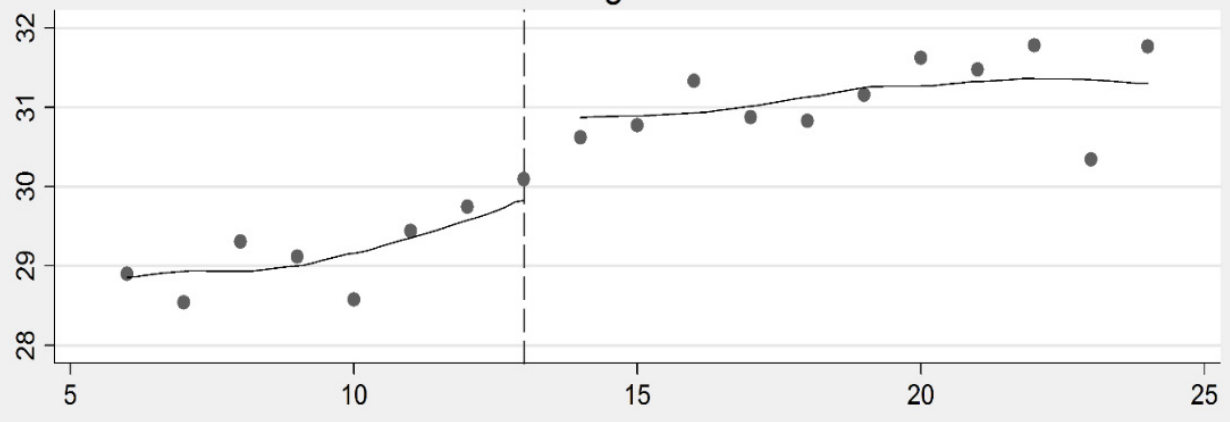


Figure B5.6: Checking the smoothness of the household wealth used in the analysis
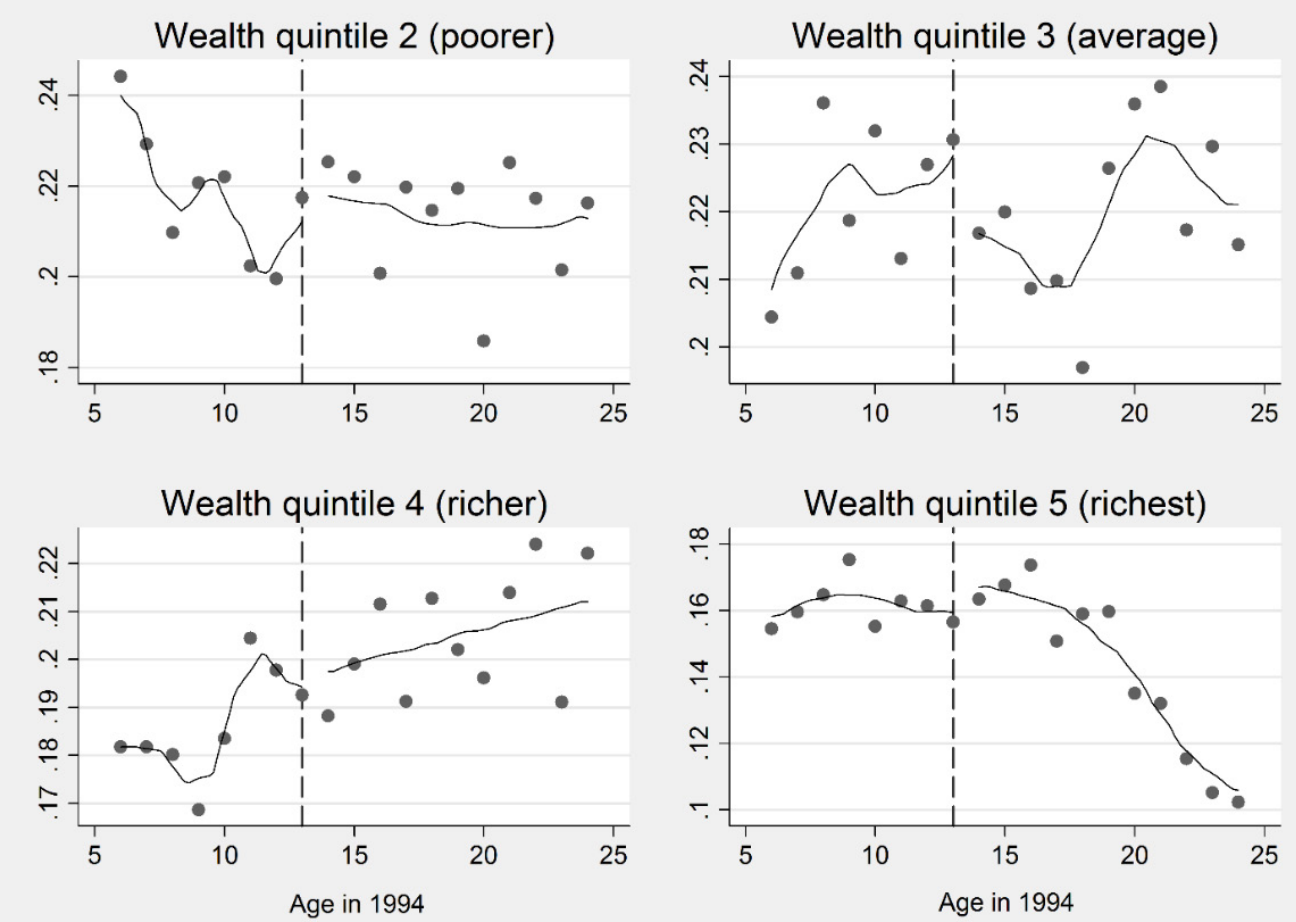
Table B5.4: Summary statistics for selected variables of the analysis (with no t-tests)

\begin{tabular}{|c|c|c|c|c|c|c|}
\hline \multirow[b]{2}{*}{ Variables } & \multicolumn{2}{|c|}{$\begin{array}{l}\text { Aged 11-16 in } \\
1994)\end{array}$} & \multicolumn{2}{|c|}{$\begin{array}{l}\text { Aged 11-13 in } \\
\text { 1994) }\end{array}$} & \multicolumn{2}{|c|}{$\begin{array}{l}\text { Aged 14-16 in } \\
\text { 1994) }\end{array}$} \\
\hline & Mean & $\mathrm{SD}$ & Mean & $\mathrm{SD}$ & Mean & $\mathrm{SD}$ \\
\hline \multicolumn{7}{|l|}{$\begin{array}{l}\text { Mother-level } \\
\text { variables }\end{array}$} \\
\hline $\begin{array}{l}\text { Years of } \\
\text { schooling }\end{array}$ & 5.324 & 3.790 & 5.599 & 3.714 & 4.977 & 3.857 \\
\hline No education & 0.141 & 0.348 & 0.117 & 0.322 & 0.172 & 0.377 \\
\hline $\begin{array}{l}\text { Incomplete } \\
\text { primary }\end{array}$ & 0.571 & 0.495 & 0.576 & 0.494 & 0.565 & 0.496 \\
\hline $\begin{array}{l}\text { Complete } \\
\text { primary }\end{array}$ & 0.085 & 0.279 & 0.087 & 0.282 & 0.082 & 0.275 \\
\hline $\begin{array}{l}\text { Incomplete } \\
\text { secondary }\end{array}$ & 0.123 & 0.328 & 0.139 & 0.346 & 0.102 & 0.303 \\
\hline $\begin{array}{l}\text { Complete } \\
\text { secondary }\end{array}$ & 0.059 & 0.235 & 0.059 & 0.235 & 0.059 & 0.235 \\
\hline $\begin{array}{l}\text { Higher } \\
\text { education }\end{array}$ & 0.021 & 0.144 & 0.022 & 0.148 & 0.019 & 0.138 \\
\hline $\begin{array}{l}\text { Age at } \\
\text { survey date }\end{array}$ & 31.125 & 3.130 & 29.787 & 2.766 & 32.816 & 2.718 \\
\hline Age in 1994 & 13.214 & 1.670 & 11.911 & 0.778 & 14.861 & 0.829 \\
\hline $\begin{array}{l}\text { Age at first } \\
\text { birth }\end{array}$ & 18.886 & 3.117 & 18.756 & 2.968 & 19.049 & 3.289 \\
\hline $\begin{array}{l}\text { Number of } \\
\text { children }\end{array}$ & 1.458 & 0.644 & 1.459 & 0.637 & 1.458 & 0.653 \\
\hline $\begin{array}{l}\text { Currently } \\
\text { breastfeeding }\end{array}$ & 0.467 & 0.499 & 0.468 & 0.499 & 0.467 & 0.499 \\
\hline $\begin{array}{l}\text { Wealth index } \\
(1-5)\end{array}$ & 3.003 & 1.422 & 3.029 & 1.436 & 2.970 & 1.404 \\
\hline Toilet - flush & 0.027 & 0.163 & 0.025 & 0.156 & 0.031 & 0.173 \\
\hline $\begin{array}{l}\text { Toilet - pit } \\
\text { latrine }\end{array}$ & 0.887 & 0.316 & 0.887 & 0.316 & 0.887 & 0.316 \\
\hline $\begin{array}{l}\text { Toilet - other } \\
\text { type }\end{array}$ & 0.006 & 0.077 & 0.007 & 0.085 & 0.004 & 0.065 \\
\hline Toilet - none & 0.079 & 0.270 & 0.081 & 0.272 & 0.077 & 0.267 \\
\hline $\begin{array}{l}\text { Number of } \\
\text { women }\end{array}$ & 6506 & & 3580 & & 10086 & \\
\hline $\begin{array}{l}\text { Number of } \\
\text { children }\end{array}$ & 9129 & & 5061 & & 14190 & \\
\hline
\end{tabular}




\begin{tabular}{|c|c|c|c|c|c|c|}
\hline $\begin{array}{l}\text { Child-level } \\
\text { variables }\end{array}$ & & & & & & \\
\hline $\begin{array}{l}\text { Age in } \\
\text { months }\end{array}$ & 31.184 & 16.926 & 31.001 & 16.877 & 31.416 & 16.986 \\
\hline $\begin{array}{l}\text { Child is } \\
\text { female }\end{array}$ & 0.499 & 0.500 & 0.495 & 0.500 & 0.504 & 0.500 \\
\hline $\begin{array}{l}\text { Child year of } \\
\text { birth }\end{array}$ & 2009.530 & 2.956 & 2009.481 & 2.949 & 2009.593 & 2.964 \\
\hline $\begin{array}{l}\text { Height-for- } \\
\text { age z-score }\end{array}$ & -1.558 & 1.542 & -1.475 & 1.589 & -1.668 & 1.472 \\
\hline Stunting & 0.396 & 0.489 & 0.374 & 0.484 & 0.424 & 0.495 \\
\hline $\begin{array}{l}\text { Child size (1- } \\
5)\end{array}$ & 2.625 & 0.949 & 2.623 & 0.933 & 2.627 & 0.968 \\
\hline $\begin{array}{l}\text { Ever } \\
\text { vaccinated }\end{array}$ & 0.898 & 0.302 & 0.906 & 0.292 & 0.888 & 0.316 \\
\hline $\begin{array}{l}\text { Had fever in } \\
\text { last } 2 \text { weeks }\end{array}$ & 0.323 & 0.468 & 0.325 & 0.469 & 0.321 & 0.467 \\
\hline $\begin{array}{l}\text { Fever } \\
\text { treatment }\end{array}$ & 0.603 & 0.489 & 0.620 & 0.485 & 0.581 & 0.494 \\
\hline Given meat & 0.112 & 0.315 & 0.118 & 0.322 & 0.104 & 0.305 \\
\hline Given milk & 0.049 & 0.216 & 0.051 & 0.220 & 0.047 & 0.211 \\
\hline Given fish & 0.210 & 0.407 & 0.216 & 0.411 & 0.202 & 0.402 \\
\hline
\end{tabular}

\section{Geographical variables}

South region

Central

$$
0.470
$$

0.499

0.457

0.498

0.486

0.500

region

North region

$\begin{array}{ll}0.114 & 0.317 \\ 0.147 & 0.354\end{array}$

0.424

0.494

0.407

0.491

Urban area

0.147

0.119

0.323

0.108

0.310

0.159

0.366

0.133

0.339

Notes: All the data are extracted from the child-recode data files of the Malawi Demographic and Health Survey (MDHS) conducted, 2010, and 2015. Summary statistics are weighted to be nationally representative of the Malawian general population. 


\section{Summary}

This PhD dissertation titled A Tall Order: Improving Child Linear Growth: Diet, Transitions and Maternal Education- studies the association between diet, maternal education and stunting. The study further assesses determinants of dynamics in childhood growth. Stunting is a sign of chronic malnutrition. Stunted children suffer poor health, poor schooling, as adults fail to contribute to or benefit socioeconomically and recycle into poverty. As an indicator, stunting reflects children's well-being and is a reflection of social inequalities(de Onis \& Branca, 2016). Subsequently, global health and development goals set targets to reduce stunting by 2030. As stunting persists, affecting 155 million children (UNICEF, 2017), it is acknowledged that strategies that are effective for preventing stunting are still unclear because the extent to which different determinants impact linear growth have yet to be elucidated.

Conceptually, addressing stunting is complex (C. P. Stewart, L. Iannotti, K. G. Dewey, K. F. Michaelsen, \& A. W. Onyango, 2013; UNICEF, 1990). On one hand diet, especially dietary diversity of ASF, is considered, a central pillar supporting linear growth (Adelheid W Onyango et al., 2013). In most cases food groups predict nutrient adequacy (Arimond et al., 2010). Yet, dietary inadequacy is such a common occurrence in resource poor settings, prompting suggestions to supplement local diets (Schönfeldt, 2012). On the other hand, maternal education is proposed as the single most factor differentiating behaviors and decisions on child care practices. However, the direct impact of maternal education on linear growth is less studied in developing countries and the impact is attenuated by levels of schooling. Adding to the complexity of research on determinants of child linear growth, is the debate on whether, once stunted, children transition back and forth the stunting cut off. The term "recovery" from stunting is contested as discussed in Chapter 1. However, the use of cut-off points is required to determine the limits of 'normality' (de Onis 
\& Branca, 2016) and risk to morbidity (Anna Lartey, 2015; Prendergast \& Humphrey, 2014).

The principle aim of this dissertation is, therefore, to assess the role of local diets and maternal education on stunting and to study the determinants of childhood growth transitions in Malawi.

In Malawi, stunting is a pressing problem affecting 1.4 million children (UNICEF, 2017). Nearly half of all child deaths and a third of child illnesses in Malawi are associated with stunting (ECA \& NEPAD, 2013; Jan Meerman, 2014). The study uses two rich sources of national wide datasets; a Malawi Welfare Monitoring Survey panel dataset $(n=530)$ and two waves of Malawi Demographic and Health Survey cross sectional dataset (women and children $n=10,086$ and $n=14,190$ respectively). The research adopts various quantitative analytical techniques: regression models, random effects, probit models and Regression Discontinuity Design and use of instrumental variables. Both data sets used in this analysis are anonymous and exempted from institutional ethical review. The data is publicly available and can be downloaded after registration with the National Statistics office of Malawi from http://go.worldbank.org/ and ICF at http://www.measuresdhs.com (National Statistical Office/Malawi \& ICF, 2017).

The four chapters underpinning the aims of the dissertation are summarized as follows;

Chapter 1 introduces the dissertation with the discussion on the scale and consequences of stunting. It then justifies the choice for assessing the role of diet and maternal education on stunting and the determinants of child growth transitions. The chapter presents the empirical debates on diet, maternal education and growth patterns. Some background information about Malawi, the topic of the dissertation, is presented as well. The study relevancy, arising research gaps and research questions are presented and then captured in the four empirical chapters of the dissertation, below. 
Chapter 2 systematically reviews literature on impact of ASF on a local nondiverse diet among children aged 6-59 months. The research question which the chapter sought to answer is: what is the evidence on impact of locally available foods, especially ASF, on stunting? The reviewed RCTs investigated a food based supplementation approach using locally available animal source foods and their impact on stunting. Only studies from Sub Saharan Africa were included in order to ensure the review contained similar local food contexts. Studies using mineral and vitamins supplementation were excluded. The search period was from 2000 to January 2017. The review followed the Preferred Reporting Items for Systematic Reviews and Meta-Analysis (PRISMA) and the methodological strength of the studies was evaluated using a commonly proposed criteria (Brannon et al., 2014; Moher \& Tricco, 2008). The criteria assess the clarity in study objective, if questions are answerable and protocol, prere-specified eligibility inclusion criteria, the reproducible methodology for stated evidence, critical statement of findings and their validity, and structured presentation of findings.

The RCTs found diverse effects of ASF supplements on child growth, micronutrients and morbidity outcomes. Only milk and eggs supplementation appear to increase linear growth in one study and, in general, other ASF did not show effect. A possible explanation for these results may be due to the fact that in all studies, stunting and morbidity were present by age six months in the study children and worsened over time. Another explanation is that stunting cannot be captured well by attempting to study the effects of a single food item only on stunting. To develop a full picture the dissertation undertook to further investigate on how food groups from local diets in a non randomised setting are associated with linear growth while controlling for underlying factors. In addition, age of child, maternal education and wealth as factors that might influence linear growth were interacted.

Therefore, Chapter 3 sought to answer a follow up question, which is: what is the association between the quantity and frequency of the consumption of food groups and linear growth? The analysis uses RE regression models to 
assess associations with the main outcome since the interacted variables were expected to differ in their effect and maternal education remained constant over time. The main independent variables were food groups and individual foods. In the analysis, foods are grouped from a list of eighty foods found in the dataset. The importance of milk and eggs from RCTs is consistently supported by the findings in chapter 3. Overall, compared to plant based food groups, ASF food group (milk and eggs) emerged as important. This is despite being consumed in small amounts, twice to three times per week. Staples remain dominant in diets. These findings match those found in earlier studies(Theron et al., 2007). The main recommendation for child feeding strategies in Malawi is to promote milk and eggs, and to consider staple fortification since stunting is associated with micronutrient deficiencies, in literature. Chapter 3 further provides evidence on per capita quantity trends and frequency of food groups' consumption. This finding can be basis to benchmark quantities for dietary guidelines in the Malawi context.

One aspect that arose from Chapter 2 is that stunting in the study group worsened and morbidity was common. In Chapter 1 we also summarized the discussion about the (ir)reversibility of stunting. In this regard, Chapter 4 examines stunting transitions. The premise is that if there is a reduced risk to morbidity when children shift up the stunting cut off, then a question being asked in Chapter 4 is: what are the growth transition probabilities in early childhood, and what are their determinants? Besides the role of diet in Chapter 2 and 3, we sought to explain what determines shifts in the child growth patterns. The analysis used a Markov model to explain current nutrition status, using absolute changes in z scores (WH0, 2006), conditioned on explainatory variables and the child's past state at baseline. We are mindful of the debate on what constitutes recovery as well as the many definations of catch up growth, which is not being implied in this finding. Rather we demonstrate children that may or maynot be atrisk, if normality is a state above the cut off in literature(de Onis \& Branca, 2016). 
The findings show that bidirectional growth transitions occurred among children in Malawi. The findings of this research are in line with other studies that reported that children become non-stunted in Malawi and as documented elsewhere. This finding is signficant because the analysis uses a panel that followed the same children who lived under the same household conditions. However, while six in ten children transitioned positively, a third of the children remained in the same state from 2010 to 2013, explaining the difficulty of transitioning. Nearly one in five children worsened. This result is nonetheless encouraging because it shows that there is a possibility to minimise the risk to morbidity and possibly to overcome any linear growth deficit, in the long term. The conditions under which positive growth transitions occurred were participation in nutrition programs, increased maternal education, wealth status, abscence of illness and a diverse diet. Worsening was predicted by a younger age, being a female child, history of illness and asset poverty. It was beyond the scope of this study to assess the extent of linear growth deficit in the sample and if catch up growth occurred. Hence a future study with more focus on catch up growth on the same cohort of children is reccommended.

Chapter 5 is about maternal education causal effect on linear growth. In previous chapters, maternal education was associated with linear growth. But only if the result is causal can we expect maternal education to impact stunting. Therefore, the main question in this chapter is: does higher maternal schooling reduce stunting among their children? We test the hypothesis that increased maternal schooling increases linear growth and reduces stunting. We use the 1994 free education policy reform as a natural experiment. The causal relationship was modelled using the exogenous variability in schooling from the policy reform and a discontinuity in age cut off. In reviewing the literature, the 1994 FPE policy reform favored girls, such as allowing pregnant girls to continue school after giving birth and waving fees for girls at all school levels. 
Findings in chapter 5 show that the policy reform yielded the expected results. Illiteracy reduced and mothers exposed to FPE increased their levels of schooling to an average of 5.5 years vs. 4.9 years. Exposed mothers had taller toddlers compared to unexposed mothers. This result suggests that exposure to and increased levels of schooling influence child linear growth outcomes of the next generation. The mechanisms through which increased maternal schooling improves height for age are through dietary intake of milk, child fever treatment, child vaccination and prenatal visits. At maternal and household level, we find that education impacts child growth through increased age at first birth, the reduced likelihood of a small sized baby, reduced maternal agriculture labor participation and the child having an educated father.

Some of the concerning issues to emerge from this chapter is how common teenage marriage, teenage motherhood and dropout rates are, despite a favorable policy. Future research could look into barriers to girl's retention and progression if maternal education is to bring about the expected transformative benefits in their offspring.

Chapter 6 discusses findings which are presented as concluding statements. The overview discussion centers around the four dissertation research questions as follows: 1) What is the evidence on impact of locally available foods, especially ASF on stunting 2) What is the association between the quantity and frequency of the consumption of food groups and linear growth? 3) What are the transition probabilities stunted versus non-stunted in early childhood growth, and what are their determinants? 4) Does higher maternal schooling reduce stunting among their children? Below we summarize the concluding statements as follows:

Concluding Statement 1: points to the fact that an adequate and nutritious diet is necessary but not sufficient to promote child linear growth. That determinants of linear growth span across the child, maternal and household levels. In all chapters, the determinants of linear growth pertain to the child's 
age, gender and history of illness. At household level, maternal schooling, ASF dietary choices especially milk and eggs, participating in nutrition programs were important, while at household level, wealth status emerged as a factor. This array of factors clearly shows that interventions that focus solely on improving diet are likely to be insufficient. The findings highlight the need for a combined set of interventions that should simultaneously seek to control other underlying determinants which can be mutually reinforcing. The interrelationships found between various factors adds insights to the importance of sector linkages in Malawi.

Concluding Statement 2: states that a transition from a stunted to a nonstunted state is feasible under certain conditions. Our findings suggest that a transition to nonstunted state may enhance individual child movement to the right side of the height distribution for optimal linear growth. This statement follows a view in literature suggesting that risk to illness reduces quickly if the child's HAZ moves above the cut off. In that case, the increase in linear growth reflects the adequacy of the diet and hence also micronutrient status improvement. Improved micronutrient status boosts immunity. Therefore, becoming nonstunted can be expected to minimise the risk of illness in the short term thereby contributing to enhanced linear growth progress and contributing to prevention of occurrence of stunting in long term. This dissertation therefore raises the possibility that health risks for stunted children can be averted by understanding determinants of their growth trajectories motivating a preventive set of interventions.

Concluding Statement 3 says that to be effective, dietary guidelines should promote specific animal source food items from a local diet, that are essential for linear growth. The choice of food items to promote should be based on evidence of what is feasible and commonly consumed. The focus of chapter 2 was to assess the feasibility of supplementing local diets with locally available ASF and their effect on linear growth. In chapter 3, we investigated the effect of various food groups and in what quantities and frequency they were associated with linear growth as a follow up to understand the effects in a non 
randomised setting that follow usual dietary patterns. While ASF supplementation was feasible, both chapters show milk and eggs as foods associated with linear growth despite their limited and infrequent consumption of two to three times a week. Both food items appeared to benefit older children from poor households in chapter 3. This result may be explained by the fact that milk is important beyond the breastfeeding age and eggs may be more affordable by poorer households. In any case milk and eggs are foods rich in growth promoting nutrients.

Concluding Statement 4 says that girls' education is an effective strategy for improving child linear growth and reducing stunting in the short and long term. We noticed that maternal education was positively associated with child growth transitions in chapter 3 and feeding patterns in chapter 4 . As a follow up to the results above, we tested the causal effect of increased maternal education on stunting. Findings show that the intergenerational consequences of stunting could be minimized by increasing levels of maternal schooling. In the short term, girls with high education delay first births thus preventing adverse effects of teenage pregnancies that contribute to stunting in chapter 5 . We show evidence that in the long term mothers with increased levels of schooling have taller children, are less likely to be in the informal labor market, or bear a child with an uneducated father. Supportive behaviors and choices we saw in chapter 5 relate to dietary choices and child illness consultation which contribute to positive linear growth transitions in chapter 3.

To conclude, this dissertation presented an analysis of the relationship between diet, maternal education and stunting. The study also established childhood growth transition patterns and determinants. Colletively, the evidence from the studies suggests that a diverse diet that includes milk and eggs, increasing levels of schooling for girls and participating in nutrition programs may be part of the solutions to prevent stunting. 


\section{Valorization Addendum}

In accordance with the Regulation Governing the attainment of Doctoral degree at Maastricht University, this section describes the relevance of findings of this dissertation. The studied topics on the relationship between diets, maternal education and stunting and the evidence presented on determinants of child growth transitions are relevant globally, as well as to various actors and sectors that aim to address stunting. At global level, it is well recognized that reducing stunting is a Tall Order (a hard task to accomplish), because preventing and mitigating effects of stunting is complex and the number of stunted children is enormous. This study comes at the right time when, there is unprecedented global consensus on the negative effects of stunting and an agreement on a lack of clarity on the extent to which different determinants impact linear growth in various contexts. Therefore, the value addition opportunities from this dissertation relate to the following contributions.

First, the dissertation contextualizes determinants of stunting for Malawi. Findings from this dissertation confirm that stunting is a result of many interconnected determinants, of inadequate diets and repeated bouts of illness (chapter 4). Since adequate diet is essential for linear growth and immunity, we show also that maternal education is inextricably linked to and enhances decisions and behaviors that limit exposure to disease, by seeking illness treatment for children, immunizing children and choosing food items essential for child growth (chapter 5). But, in literature, the risk to illness differs if the child is below or above the stunting classification (Anna Lartey, 2015). Therefore, knowing determinants of growth transitions, illustrated in this dissertation is also important for illness and stunting prevention strategies (chapter 3). If not, the consequences of stunting can perpetuate for generations, as found in (chapter 5). The 1.4 million stunted in Malawi are a cost to development(UNICEF, 2017). Findings from this dissertation therefore provides contextual clarity on the interplay of factors between diets, child 
growth transitions, maternal education and contributes to evidence based stunting solutions in Malawi.

Second, findings reveal factors that promote and those that limit child growth for Malawi. These findings may help to understand implications for a range of actors and sectors required to address stunting. The relevant sectors in our findings point to ministries of Health, to promote nutrition programs, disease treatment (Chapters 2, 3 and 4), Agriculture for milk and egg production (Chapter 3) and ministry of Education to promote girl's education (Chapter 5).

Third, findings of this research may be of direct influence to improving feeding guidelines. For example, the result showing ASF consumption of less than $50 \mathrm{~g}$ consumed per capita, and only 1-3 times in a week, is a clear indication of the poor diets in this context. Findings, may be used with other relevant literature and guidelines to benchmark the design of child feeding guidelines. It can also form basis for reconsidering what other local foods rich in micronutrients (milk and eggs) could be promoted as the country moves forward in its ambition to improve diets.

Fourth, value may also be found in further exploration of child transitions using the data generated from this research as baseline. We suggest from a perspective of examining catch up growth or growth deficit compared to the reference child population, using the same cohort of children from our analysis in the subsequent panel datasets. Especially so, since our study is first to analyse the transitions using the Markov model from the welfare monitoring panel data.

Fifth, this study is first to show the causal link between maternal education and stunting. The study makes a vital contribution to knowledge. Findings from this dissertation shows that educating girls is advantageous in terms of birth timing, dietary choices and in reducing stunting in future offspring. These findings could be relevant for wider application in Sub-Saharan Africa where such research has lagged, despite the persistent stunting levels. 
Finally, although the scope of this the thesis is not to dwell on challenges of girls' education, the findings of high drop outs concerns nutrition outcomes. The findings raise questions on whether the poor progression of girls in education is one of the reasons for the poor nutrition outcomes in this country. Findings of this research may be used for advocacy purposes to foster education campaigns to remove barriers that stop most girls from attaining high education. The economic and health dimensions of an individual and societies rests on a sound education of its population. Educating girls should be seen as a human right.

Overall, findings of this dissertation offer evidence based, and practical entry points relevant for action by policy makers. 


\section{Curriculum Vitae}

Mutinta Hambayi Nseluke was born on $6^{\text {th }}$ November 1965 in Monze, Zambia. She competed successfully to enroll at St, Mary's secondary school, an all-girls school where she completed high school. She then obtained her diploma in food and nutrition from Natural Resources Development College, awarded by the University of Zambia, graduating with a merit. Later, earning a scholarship to obtain her Master's degree in Nutrition from Queensland University in Australia and fulfilling her research requirements by undertaking field research in Thailand, as a visiting student attached to Mahidol University.

She worked briefly for the National Food and Nutrition Commission in Zambia, before starting a career with the United Nations' World Food Program (WFP). She worked as Nutritionist in war torn Sudan (2000-2004) and then as Regional Nutritionist in Southern Africa, based in Johannesburg, covering the then 12 drought affected countries at the peak of the HIV pandemic (2004-2008). She transferred to WFP HQ in Rome as HIV and Nutrition Advisor (2008-2012) before returning to Malawi (2008-2012) as Project Manager for a WFP proof of concept nutrition pilot project on prevention of stunting. Thereafter she was reassigned to lead a global portfolio as Chief and Head of Nutrition Sensitive Unit in WFP HQ, Rome (2016 to date). The unit has a global mandate to ensure that WFP builds nutrition across all its programs "in a measureable way" in support of governments to achieve SGD 2.2. During her career she has contributed to debates on food, nutrition and HIV/AIDS at various platforms.

She is a certified Public Health Nutritionist with the World Body of Public Health Nutritionists, earning a title of cPHN. Prior to her current position, in 2015, she was externally assessed and qualified for leadership competencies by the Career Development Centre UK. She is passionate about nutrition and considers herself a born and bred Nutritionist, privileged to work for an 
organization that saves millions of people through provision of food assistance. 


\section{Publications}

1. Stephen SR, Aburto NJ, Nseluke Hambayi M, Dibari F, Gittelsohn J: Patterns and determinants of small-quantity LNS utilization in rural Malawi and Mozambique: considerations for interventions with specialized nutritious foods; Maternal Child and Nutrition journal: 2017 doi: 10.1111/mcn.12234/ Epub 2016 Jan 19

2. Mutinta Nseluke Hambayi , Stephen Kodish, James Mtonga, Trust Mlambo, Nancy Arbuto: Designing a SBCC strategy for rural Malawi demonstrates potential of SUN movement ; Conference paper 2014

3. Joel Gittelsohn, Stephen Kodish, Mutinta Hambayi, Fillipo Dibari: Formative research to develop culturally-appropriate, supplementary feeding programs for children 6-23 months in rural Mozambique and Malawi.: 2014 Food Nutr Bull. 2015 Jun;36(2):138-53. doi: 10.1177/0379572115586784

4. Mutinta Nseluke A fragile situation in Sudan: review of the 2001 nutritional situation. Emergency nutrition Network, 2001 http://www.ennonline.net/fex/15/fragile

5. Household Food Security and Nutrition in Zambia, Living Conditions Monitoring II, World Bank Social. Dimensions Survey, Study Fund, Lusaka. Luma J, Nseluke -Hambayi M, Kasonde , 1999 


\section{UNU-MERIT/MGSoG Dissertation Series}

2018

\section{Elvis Korku Avenyo}

Innovations and Firm Performance

in sub-Saharan Africa: Empirical

Analyses

UNU-MERIT/MGSoG Dissertation

Series № 202

\section{Ni Zhen}

Employment Dynamics, Firm

Performance and Innovation

Persistence in the Context of

Differentiated Innovation Types:

Evidence from Luxembourg

UNU-MERIT/MGSoG Dissertation

Series № 201

\section{Caroline Wehner}

Too Scared to Achieve: The Relation

Between Neuroticism,

Conscientiousness

and Socioeconomic Outcomes

UNU-MERIT/MGSoG Dissertation

Series № 200

\section{Stefania Innocenti}

On Institutional Persistence

UNU-MERIT/MGSoG Dissertation

Series № 199
Hassen Abda Wako

Economic Globalization, Institutions and Development: Essays on Aid, Foreign Direct Investment and Trade UNU-MERIT/MGSoG Dissertation Series № 198

2017

\section{Hans-Erik Edsand}

Winds of Change

UNU-MERIT/MGSoG Dissertation

Series № 197

\section{Ana Patricia Silva Vara}

Redressing the Gender Gap

UNU-MERIT/MGSoG Dissertation

Series № 196

\section{Andrés Iván Mideros Mora}

Essays on the Economic Effects of Noncontributory Social Protection

UNU-MERIT/MGSoG Dissertation

Series № 195

\section{Tobias Broich}

New Actors in the Global Economy

UNU-MERIT/MGSoG Dissertation

Series № 194

\section{Bernard Nikaj}

From No-government to E-government UNU-MERIT/MGSoG Dissertation Series № 193 


\section{Ali Safarnejad}

Prioritizing the HIV Response

UNU-MERIT/MGSoG Dissertation

Series № 192

\section{Clovis Freire}

Diversification and Structural

Economic Dynamics

UNU-MERIT/MGSoG Dissertation

Series № 191

\section{Michael Verba}

Innovation and Knowledge Dynamics:

Essays on the Knowledge Economy

UNU-MERIT/MGSoG Dissertation

Series № 190

\section{Pui Hang Wong}

The Hearts and Minds in Conflict and

Peace: The Economics of

Counterinsurgency and the Psychology of Reconstruction

UNU-MERIT/MGSoG Dissertation Series № 189

\section{Brenda Yamba}

Schooling Despite All Odds: Evidence from Lesotho on Female Child Carers who Stayed in School

UNU-MERIT/MGSoG Dissertation Series № 188

\section{Sheng Zhong}

Moving towards An Energy Efficient

Future: Essays on Energy Efficiency,

Technology and Development

UNU-MERIT/MGSoG Dissertation

Series № 187

\section{Julieta Marotta}

Access to Justice and Legal

Empowerment of Victims of Domestic

Violence through Legal Organizations in the City of Buenos Aires: A

Qualitative Empirical Legal Study

UNU-MERIT/MGSoG Dissertation

Series, № 186

\section{Andrea Franco-Correa}

On the Measurement of

Multidimensional Poverty as a Policy

Tool: Empirical Applications to Chile,

Colombia, Ecuador and Peru

UNU-MERIT/MGSoG Dissertation

Series, № 185

2016

\section{Yesuf Awel}

Insurance for Growth: Empirical

Essays on Insurance Demand and

Impacts in Africa

UNU-MERIT Dissertation Series,

№ 108

\section{Tigist Mekonnen Melesse}

Grow More Food using Fewer

Resources: Agricultural Technology

Adoption and Innovation Practices for

Inclusive and Sustainable

Development

UNU-MERIT Dissertation Series,

№ 107

\section{Eleni Yitbarek}

Getting Ahead or left Behind? Essays on Poverty Dynamics and Social

Mobility in Africa

UNU-MERIT Dissertation Series,

№ 106 


\section{Thuy Dieu Nguyen}

Firm-Level Theory and Evidence of

Corruption

UNU-MERIT Dissertation Series, № 105

\section{Raquel Tsukada Lehman}

Essays on Household Production with

Labor-Saving Technology

UNU-MERIT Dissertation Series, № 104

\section{Eva Barteková}

Multi-Problem Challenges for a

Renewable Future: Empirical Studies on Competitive Disadvantages from

Electricity Price Differentials and

Mineral Supply Risk in an Open

Economy

UNU-MERIT Dissertation Series, № 103

\section{Jocelyn Olivari}

Entrepreneurial Traits and Innovation:

Evidence from Chile

UNU-MERIT Dissertation Series, № 102

\section{Muhammad Shafique}

Essays on the role of knowledge, RED, and Technology-based Firms in the

Evolution of Socio-techno-economic

System

UNU-MERIT Dissertation Series, № 101

\section{Serdar Türkeli}

Governance of Innovation Policy:

Empirical Studies on Applied Political

Economy by Multi-Methods Analysis

UNU-MERIT Dissertation Series,

№ 100

\section{Ayokunu Adedokun}

Pathways to Sustainable Peace

building in Divided Societies: Lessons

and Experiences from Mozambique

MGSoG Dissertation Series, № 75

\section{Luiz Rothier Bautzer}

Organizing Concurrent Engineering

through ICT Platforms

Blueprinting Product Lifecycle

Management Platforms across

Disciplinary Agencies

MGSoG Dissertation Series, № 74

\section{Natalia Popova}

Migration in the Periphery of the

European Union:

Determinants of Successful and

Sustainable Labour Market Integration of Return Migrants in Albania, Egypt, Moldova and Tunisia

MGSoG Dissertations Series, № 73

\section{Richard A. Martina}

Uncertainty and Resource Constraint in the Small Island Developing States: Essays in Entrepreneurial Cognition MGSoG Dissertations Series, № 72 


\section{Cécile Cherrier}

The Expansion of Basic Social

Protection in Low-income Countries:

An Analysis of Foreign Aid Actors'

Role in the Emergence of Social

Transfers in Sub-Saharan Africa

MGSoG Dissertations series, № 71

\section{Paul Caldron}

The Tacit Bargain in Short-Term

Medical Missions: Why U.S.

physicians go and what it costs

MGSoG Dissertation Series, № 70

\section{Mahmut Kobal}

Customs \& Excellence: A Comparative

Approach on Administrative and

Regulatory Compliance Perspectives of

the EU-Turkey Customs Union

MGSoG Dissertation Series, № 69

\section{Craig Loschmann}

Essays on Conflict-related Migration and Development in the Case of

Afghanistan

MGSoG Dissertations Series, № 68

\section{Andrea Milan}

Rural Livelihoods, Location and

Vulnerable Environments: Approaches to Migration in Mountain areas of

Latin America

MGSoG Dissertation Series, № 67

\section{Farida Lada}

On Guarding the Welfare of Clinical

Trial Subjects While Promoting Novel

Drug Innovation

A Game Theoretical Approach

MGSoG Dissertation Series, № 66
2015

\section{Hibret Belete Maemir}

Dissecting Aggregate Productivity:

International Integration and Growth with Heterogeneous Firms

UNU-MERIT Dissertation Series, № 96

\section{Giorgio Triulzi}

Looking for the Right Path: Technology Dynamics, Inventive Strategies and Catching-up in the Semiconductor Industry

UNU-MERIT Dissertation Series, № 95

\section{Abdul Baseer Qazi \\ Knowledge flows and networks in the ICT sector: The case of Pakistan UNU-MERIT Dissertation Series, № 94}

\section{Ajay Thutupalli}

Technology Paradigm Shifts in Agriculture: Drivers of Sustainability and Catch up

UNU-MERIT Dissertation Series, № 93

\section{Eduardo Urias}

Improving access to HIVIAIDS treatment in Brazil: When are Compulsory Licenses effective in Price Negotiations?

UNU-MERIT Dissertation Series, № 92 


\section{Francesca Guadagno}

Why have so few Countries

Industrialised?

UNU-MERIT Dissertation Series, № 91

\section{Daniel Opolot}

The Evolution of Beliefs and Strategic

Behaviour

UNU-MERIT Dissertation Series, № 90

\author{
Alejandro Lavopa \\ Structural Transformation and \\ Economic Development: Can \\ Development Traps be Avoided \\ UNU-MERIT Dissertation Series, \\ № 89
}

\section{Jinjin Zhao}

Urban water management reform: The

Case of China

UNU-MERIT Dissertation Series, № 88

\section{Simona Vezzoli}

Borders, Independence and Postcolonial Ties: the Role of the State in Caribbean Migration

MGSoG Dissertation Series, № 65

\section{Silvia Consuelo Gómez Soler}

Civil Conflict and Education: How

Does Exposure to Civil Conflict Affect

Human Capital Accumulation?

Evidence from Standardized Exit

Exams in Colombia

MGSoG Dissertation Series, № 64

\section{Paula Nagler}

Occupational Choice in the Developing

World

MGSoG Dissertation Series, № 63

\section{Jasmin Kientzel}

Determinants of Professional

Commitment to Environmental

Sustainability

MGSoG Dissertation Series, № 62

\section{Mehmet Güney Celbiş}

Regional Policies: Convergence, Trade, and the Allocation of Public Capital

MGSoG Dissertation Series, № 61

\section{Florian Henning}

Living Up to Standard:

Interoperability Governance and

Standards Adoption in Government

Information Networks

MGSoG Dissertation Series, № 60

\section{Niels P. Groen}

The Never-Ending Project

Understanding E-Government Project

Escalation

MGSoG Dissertation Series, № 59

\section{Derek Copp}

Teacher-Based Reactivity to Provincial

Large-scale Assessment in Canada

MGSoG Dissertation Series, № 58

\section{Michaella Vanore}

Family-Member Migration and the

Psychosocial Health Outcomes of

Children in Moldova and Georgia

MGSoG Dissertation Series, № 57 


\section{Sonja Fransen}

The Economic and Social Effects of Remittances and Return Migration in Conflict-Affected Areas: The Case of Burundi

MGSoG Dissertation Series, № 56

\section{Ibrahim Khalil Conteh}

The Impact of Floods on Primary

School Education in Zambia

MGSoG Dissertation Series, № 55

\section{Richard Bluhm}

Growth Dynamics and Development Essays in Applied Econometrics and Political Economy

MGSoG Dissertation Series, № 54

\section{Nevena P. Zhelyazkova}

Work-Family Reconciliation and Use of Parental Leave in Luxembourg:

Empirical Analysis of Administrative Records

MGSoG Dissertation Series, № 53

\section{4}

\section{Dirk Crass}

The Impact of Brands on Innovation and Firm Performance: Empirical Evidence from Germany UNU-MERIT Dissertation Series, № 87

\section{Samyukta Bhupatiraju}

The Geographic Dimensions of Growth and Development UNU-MERIT Dissertation Series, № 86

\section{François Lafond}

TheEvolution of Knowledge Systems UNU-MERIT Dissertation Series, № 85

\section{Annalisa Primi}

Promoting Innovation in Latin America: What Countries Have Learned (and What They Have Not) in Designing and Implementing Innovation and Intellectual Property Policies

UNU-MERIT Dissertation Series, № 84

\section{Fatoumata Lamarana Diallo}

Evaluation of Meal and Deworming

Programs for Primary Schools in Rural Senegal

UNU-MERIT Dissertation Series, № 83

\section{Sachin Kumar Badkas}

Metachoice and Metadata: Innovating with Environmental Policy Analysis in Europe

MGSoG Dissertation Series, № 52

\section{Irina S. Burlacu}

An Evaluation of Tax-Benefit Systems Impact on the Welfare of Frontier Worker:

The Case of Luxembourg and Belgium MGSoG Dissertation Series, № 51

\section{Özge Bilgili}

Simultaneity in Transnational Migration Research: Links Between Migrants' Host and Home Country Orientation

MGSoG Dissertation Series, № 50 


\section{Yulia Privalova Krieger}

Reshaping the Big Agenda:

Transnational Politics and Domestic

ResistanceFinancial crisis and social

protection reform in Bosnia and

Herzegovina

MGSoG Dissertation Series, № 49

\section{Marieke van Houte}

Moving Back or Moving Forward?

Return migration after Conflict

MGSoG Dissertation Series, № 48

\section{Oxana Slobozhan}

Global Governance in the Management of Natural Resources: The Case of the

Extractive Industries Transparency

Initiative (EITI)

MGSoG Dissertation Series, № 47

\section{Luis Bernardo Mejia Guinand}

The Changing Role of the Central

Planning Offices in Latin America: A

Comparative Historical Analysis

Perspective (1950-2013)

MGSoG Dissertation Series, № 46

\section{Cheng Boon Ong}

Ethnic Segregation in Housing,

Schools and Neighbourhoods in the

Netherlands

MGSoG Dissertation Series, № 45

\section{Luciana V. Cingolani}

Bureaucracies for Development:

Oxymoron or Reality? Studies on State

Capacity in Challenging Governance

Contexts

MGSoG Dissertation Series, № 44

\section{Carlos Cadena Gaitán}

Green Politics in Latin American

Cities - Sustainable Transport Agendas

MGSoG Dissertation Series, № 43

\section{Katie Kuschminder}

Female Return Migration and

Reintegration Strategies in Ethiopia

MGSoG Dissertation Series, № 42

\section{Metka Hercog}

Highly-Skilled Migration and New

Destination Countries

MGSoG Dissertation Series, № 41

\section{Margaret Agaba Rugadya}

Can Remittances Influence the Tenure

and Quality of Housing in Uganda?

MGSoG Dissertation Series, № 40

\section{Ilire Agimi}

New Governance Under Limited

Statehood: The Case of Local

Government Reform in Kosovo

MGSoG Dissertation Series, № 39

\section{3}

\section{Anant Kamath \\ Information Sharing through Informal Interaction in Low-Tech Clusters UNU-MERIT Dissertation Series, № 82}




\section{Flavia Pereira de Carvalho}

What we talk about when we talk about

Brazilian Multinationals: An

Investigation on Brazilian FDI,

Economic Structure, Innovation and

the Relationship between them

UNU-MERIT Dissertation Series, № 81

\section{Jun Hou}

Complementarity in Innovation and

Development: A Cross-country

Comparison

UNU-MERIT Dissertation Series, № 80

\section{Rufin Baghana}

Impacts of Government Incentives to $R \mathcal{E D}$, Innovation and Productivity:

A Microeconometric Analysis of the

Québec Case

UNU-MERIT Dissertation Series, № 79

\section{Lilia I. Stubrin}

High-Tech Activities in Emerging

Countries: A Network perspective on

the Argentinean Biotech Activity

UNU-MERIT/MGSoG Dissertation

Series, № 78

\section{Kristine Farla}

Empirical Studies on Institutions,

Policies and Economic Development

MGSoG Dissertation Series, № 38

\section{Marina Petrovic}

Social Assistance and Activation in the Pursuit of Happiness: Shedding New

Light on Old Policy Solutions to Social Exclusion

MGSoG Dissertation Series, № 37

\section{Laura Torvinen}

Assessing Governance Assessments:

The Case of Mozambique: Governance

Assessments in the Context of Aid

Effectiveness Discourse

MGSoG Dissertation Series, № 36

\section{Biniam Egu Bedasso}

Institutional Change in the Long

Shadow of Elite: Essays on

Institutions, Human Capital and

Ethnicity in Developing Countries

MGSoG Dissertation Series, № 35

\section{Sepideh Yousefzadeh Faal}

Deghati

Childhoods Embargoed: Constructing and Reconstructing Multidimensional

Child Poverty in Iran 1984-2009

MGSoG Dissertation Series, № 34

\section{Robert Bauchmüller}

Investing in Early Childhood Care and Education: The Impact of Quality on Inequality

MGSoG Dissertation Series, № 33

\section{Martin Rehm}

Unified Yet Separated: Empirical

Study on the Impact of Hierarchical

Positions within Communities of

Learning

MGSoG Dissertation Series, № 32 


\section{Abdul Waheed}

Innovation Determinants and

Innovation as a Determinant: Evidence

from Developing Countries

UNU-MERIT Dissertation Series,

№ 77

\section{Bilal Mirza}

Energy Poverty and Rural Energy

Markets in Pakistan

UNU-MERIT Dissertation Series, № 76

\section{Benjamin Engelstätter}

Enterprise Software and Video Games:

An Empirical Analysis

UNU-MERIT Dissertation Series, № 75

\section{Fulvia Farinelli}

Natural Resources, Innovation and

Export Growth: The Wine Industry in

Chili and Argentina

UNU-MERIT Dissertation Series

\section{Rodolfo Lauterbach}

Innovation in Manufacturing: From

Product Variety and Labor

Productivity Growth to Economic

Development in Chile

UNU-MERIT Dissertation Series

\section{Kirsten Wiebe}

Quantitative Assessment of

Sustainable Development and Growth

in Sub-Saharan Africa

UNU-MERIT Dissertation Series, № 74
Julio Miguel Rosa

Organizational Strategies, Firms'

Performance and Spatial Spillovers:

The Canadian Case in Research and

Development.

UNU-MERIT Dissertation Series, № 73

Johannes Wilhelmus Marie Boels

Joseph Schumpeter, Honderd Jaar

Economische Ontwikkeling: Een

Historisch-theoretische Beschouwing.

UNU-MERIT Dissertation Series

\section{Dorcas Mbuvi}

Utility Reforms and Performance of the

Urban Water Sector in Africa

MGSoG Dissertation Series, № 31

\section{Lina Salanauskaite}

Distributional Impacts of Public

Policies: Essays in Ex-Ante and Ex-

Post Evaluation

MGSoG Dissertation Series, № 30

\section{Esther Schüring}

To Condition or not - is that the

Question?

An Analysis of the Effectiveness of ExAnte and Ex-Post Conditionality in Social Cash Transfer Programs

MGSoG Dissertation Series, № 29

\section{Joe Abah}

Strong Organisations in Weak States:

Atypical Public Sector Performance in

Dysfunctional Environments

MGSoG Dissertation Series, № 28 


\section{Zina Samih Nimeh}

Social Citizenship Rights: Inequality and Exclusion

MGSoG Dissertation Series, № 27

2011

\section{Daniel Vertesy}

Interrupted Innovation: Emerging

Economies in the Structure of the

Global Aerospace Industry

UNU-MERIT Dissertation Series, № 72

\section{Tina Saebi}

Successfully Managing Alliance

Portfolios: AnAlliance Capability View UNU-MERIT Dissertation Series, № 71

\section{Nora Engel}

Tuberculosis in India: A Case of

Innovation and Control

UNU-MERIT/MGSoG Dissertation

Series, № 70

\section{Evans Mupela}

Connectivity and growth in Sub-

Saharan Africa: The Role of

Communication Satellites

UNU-MERIT Dissertation Series, № 69

\section{Nantawan Kwanjai}

Cross Cultural Intelligence amid Intricate Cultural Webs: A Tale of the UnDutchables in the Land of 1002 Smiles

UNU-MERIT Dissertation Series, № 68

\section{Lina Sonne}

Innovation in Finance to Finance Innovation: Supporting Pro-poor Entrepreneur-based Innovation UNU-MERIT Dissertation Series, № 67

\section{Lenka Eisenhamerová}

Legitimacy of 'Humanitarian Military Intervention'

MGSoG Dissertation Series, № 26

\section{Sonila Tomini}

Informal Payments for Health Care

Services in Albania

MGSoG Dissertation Series, № 25

\section{Jinjing Li}

Dynamic Microsimulation in Public

Policy Evaluation

MGSoG Dissertation Series, № 24

\section{Aziz Atamanov}

Rural Nonfarm Employment and International Migration as

Alternatives to Agricultural

Employment: The Case of Kyrgyzstan

MGSoG Dissertation Series, № 23

\section{Frieda Vandeninden}

Poverty Alleviation: Aid and Social

Pensions

MGSoG Dissertation Series, № 22

\section{Juliana Nyasha Tirivayi}

The Welfare Effects of Integrating AIDS Treatment with Food Transfers: Evidence from Zambia MGSoG Dissertation Series, № 21 
Agnieska Ewa Sowa

Who's Left Behind? Social Dimensions

of Health Transition and Utilization of

Medical Care in Poland

MGSoG Dissertation Series, № 20

\section{Emmanaouil Sfakianakis}

The Role of Private Actors in the

Provision of Public Goods with

Applications to Infrastructure and

Financial Stability

MGSoG Dissertation Series, № 19

\section{Siu Hing Lo}

White Collars Green Sleeves: An Inter-

organizational Comparison of

Determinants of Energy-Related

Behaviors among Office Workers

MGSoG Dissertation Series, № 18

\section{Treena $\mathbf{W u}$}

Constraints to Human Capital

Investment in Developing Countries:

Using the Asian Financial Crisis in

Indonesia as a Natural Experiment

MGSoG Dissertation Series, № 17

\section{Henry Espinoza Peña}

Impact Evaluation of a Job-Training

Programme for Disadvantaged Youths:

The Case of Projoven

MGSoG Dissertation Series, № 16
2010

\section{Fernando Santiago}

Human Resources Management

Practices and Learning for Innovation in Developing Countries:

Pharmaceutical Firms in Mexico

UNU-MERIT Dissertation Series,

№ 66

\section{Zakaria Babutsidze}

Essays on Economies with

Heterogeneous Interacting Consumers

UNU-MERIT Dissertation Series,

№ 65

\section{Bertha Vallejo}

Learning and Innovation Under

Changing Market Conditions: The

Auto Parts Industry in Mexico

UNU-MERIT Dissertation Series,

№ 64

\section{Donatus Ayitey}

Technical Change, Competitiveness

and Poverty Reduction: A Study of the

Ghanaian Apparel Industry

UNU-MERIT Dissertation Series,

№ 63

\section{Sergey Filippov}

Multinational Subsidiary Evolution:

Corporate Change in New EU Member

States

UNU-MERIT Dissertation Series, № 62 


\section{Asel Doranova}

Technology Transfer and Learning under the Kyoto Regime: Exploring the Technological Impact of CDM Projects in Developing Countries

UNU-MERIT Dissertation Series, № 61

\section{Florian Tomini}

Between Family and Friend:

Understanding the Interdependency of Private Transfers

MGSoG Dissertation Series, № 15

\section{Michał Polalowski}

The Institutional Transformation of

Social Policy in East Central Europe:

Poland and Hungary in Comparative and Historical Perspective

MGSoG Dissertation Series, № 14

\section{Maha Ahmed}

Defining, Measuring and Addressing Vulnerability: The Case of Post

Conflict Environments

MGSoG Dissertation Series, № 13

\section{Pascal Beckers}

Local Space and Economic Success:

The Role of Spatial Segregation of

Migrants in the Netherlands

MGSoG Dissertation Series, № 12

\section{Victor Cebotari}

Conflicting Demands in Ethnically

Diverse Societies: Ethno political

Contention and Identity Values in

Europe

MGSoG Dissertation Series, № 11

\section{Dennis Gyllensporre}

Competing and Complementary

Perspectives on the EU as a Crisis

Management Actor:

An Examination of the Common

Security and Defence Policy through

the Lenses of Idealism and Realism

MGSoG Dissertation Series, № 10

\section{Judit Vall Castello}

Business Cycle and Policy Effects on Labour Market Transitions of Older and Disabled Workers in Spain

MGSoG Dissertation Series, № 9

\section{Keetie Roelen}

False Positives or Hidden Dimensions:

The Definition and Measurement of

Child Poverty

MGSoG Dissertation Series, № 8

Denisa Maria Sologon

Earning Dynamics in Europe

MGSoG Dissertation Series, № 7

\section{Melissa Siegel}

Money and Mobility: Migration and

Remittances

MGSoG Dissertation Series, № 6

Jessica S. Hagen-Zanker

Modest Expectations: Causes and

Effects of Migration on Migrant

Households inSource Countries

MGSoG Dissertation Series, № 5 
Alexis Habiyaremye

From Primary Commodity Dependence to Diversification and Growth:

Absorptive Capacity and Technological Catch Up in Botswana and Mauritius. UNU-MERIT Dissertation Series, № 60

\section{Yoseph Getachew}

The Role of Public Capital in Economic Development

UNU-MERIT Dissertation Series, № 59

\section{Sandra Leitner}

Embodied Technological Change and Patterns of Investment in Austrian Manufacturing UNU-MERIT Dissertation Series, № 58

\section{Semih Akçomak}

The Impact of Social Capital on Economic and Social Outcomes UNU-MERIT Dissertation Series, № 57

\section{Abraham Garcia}

The Role of Demand in Technical Change

UNU-MERIT Dissertation Series, № 56

\section{Saurabh Arora}

Coherence in Socio-technical Systems: A Network Perspective on the Innovation Process UNU-MERIT Dissertation Series, № 55
Human Development and Autonomy in Project Aid: Experiences from four bilateral projects in Nicaragua and $E l$ Salvador

MGSoG Dissertation Series, № 4

\section{Christiane Arndt}

Governance Indicators

MGSoG Dissertation Series, № 3

\section{Britta Augsburg}

Microfinance: Greater Good or Lesser Evil?

MGSoG Dissertation Series, № 2

\section{8}

\section{Rutger Daems}

Medicines for the Developing World UNU-MERIT Dissertation Series, № 54

\section{Johannes Hanel}

Assessing Induced Technology:

Sombart's Understanding of Technical

Change in the History of Economics

UNU-MERIT Dissertation Series, № 53

\section{Rifka Weehuizen}

Mental Capital: the Economic Significance of Mental Health UNU-MERIT Dissertation Series, № 52 


\section{Danielle Cloodt}

The Relationship between RED

Partnership Formation, Social

Embeddedness and Innovative

Performance

UNU-MERIT Dissertation Series, № 51

\section{Sabine Fuss}

Sustainable Energy Development

under Uncertainty

UNU-MERIT Dissertation Series, № 50

\section{Geranda Notten}

Measuring and Managing Poverty

Risks

MGSoG Dissertation Series, № 1

2007

\section{Tobias Kronenberg}

Reconciling Environmental

Conservation with Economic

Prosperity: The Feasibility of Double

Dividends in the Short and Long Run

UNU-MERIT Dissertation Series, № 49

\section{Viktoria Kravtsova}

Assessing the Impact of Foreign Direct Investment in Transition Economies UNU-MERIT Dissertation Series, № 48

\section{Suhail Sultan}

The Competitive Advantage of Small and Medium Sized Enterprises: The Case of Jordan's Natural Stone Industry UNU-MERIT Dissertation Series, № 47

\section{6}

\section{Bulat Sanditov}

Essays on Social Learning and Imitation

UNU-MERIT Dissertation Series, № 46

\section{Mamata Parhi}

Dynamics of New Technology Diffusion: A Study of the Indian Automotive Industry

UNU-MERIT Dissertation Series, № 45

\section{Andreas Reinstaller}

Social Structures and the Innovation Process: Their Role in the Demand of Firms and Consumers

UNU-MERIT Dissertation Series, № 44

\section{Rose Kiggundu}

Innovation systems and Development: The Journey of a Beleaguered Nile Perch Fishery in Uganda UNU-MERIT Dissertation Series, № 43 
Thomas Pogue

The Evolution of Research

Collaboration in South African Gold

Mining: 1886-1933

UNU-MERIT Dissertation Series, № 42

\section{Geoffrey Gachino}

Foreign Direct Investment, Spillovers and Innovation: The Case of Kenyan

Manufacturing Industry

UNU-MERIT Dissertation Series, № 41

\section{Önder Nomaler}

Technological Change, International

Trade and Growth: An Evolutionary,

Multi-Agents-Based Modeling

Approach

UNU-MERIT Dissertation Series, № 40

2005

Samia Satti Osman Mohamed-

Nour

Change and Skill Development in the Arab Gulf Countries

UNU-MERIT Dissertation Series, № 39

\section{Elad Harison}

Intellectual Property Rights:

Economics and Policy Analysis

UNU-MERIT Dissertation Series, № 38

\section{Daniel Dalohoun}

The Relationship between RED

Partnership Formation, Social

Embeddedness and Innovative

Performance: a Multi-level Approach

of Social Embeddedness

UNU-MERIT Dissertation Series, № 37

\section{Müge Ozman}

Networks, Organizations and

Knowledge

UNU-MERIT Dissertation Series,

№ 36

\section{Bas Straathof}

Product Variety and Economic

Growth: The Counteracting Effects of

Scale and Idiosyncrasy

UNU-MERIT Dissertation Series, № 35

\section{Wilfred Schoenmakers}

Knowledge Flows between

Multinational Companies: A Patent

Data Analysis

UNU-MERIT Dissertation Series,

№ 34

\section{Myriam Cloodt}

Mergers and Acquisitions ( $M$ and As) in High-Tech Industries: Measuring the Post-M and A Innovative Performance of Companies UNU-MERIT Dissertation Series, № 33 
2004

\section{Paola Criscuolo}

$R \mathcal{E D}$ Internationalisation and

Knowledge Transfer: Impact on MNEs and their Home Countries

UNU-MERIT Dissertation Series, № 32

\section{Maarten Verkerk}

Trust and Power on the Shop Floor UNU-MERIT Dissertation Series, № 31

\section{Gottfried Leibbrandt}

Adoption, Harmonization and Succession of Network Technologies across Countries

UNU-MERIT Dissertation Series, № 30

\section{Mark Sanders}

Skill Biased Technical change: Its Origins, the Interaction with the Labour Market and Policy Implications UNU-MERIT Dissertation Series, № 29

2003

\section{Nadine Roijakkers}

Inter-firm Cooperation in High-tech Industries: a Study of RED

Partnerships in Pharmaceutical

Biotechnology

UNU-MERIT Dissertation Series, № 28
Viki Sonntag

Speed, Scale and Sustainability

UNU-MERIT Dissertation Series, № 27

\section{Masaru Yarime}

From End-of-Pipe Technology to Clean Technology

UNU-MERIT Dissertation Series, № 26

\section{Stéphane Malo}

The Combinatorial Chemistry

Revolution: Sustaining a Superior

Performance Position through

Technological Learning

UNU-MERIT Dissertation Series, № 25

2002

\section{Annelies Hogenbirk}

Determinants of Inward Foreign Direct Investment: the Case of the Netherlands

UNU-MERIT Dissertation Series, № 24

\section{Bastiaan Johan terWeel}

The Computerization of the Labour Market

UNU-MERIT Dissertation Series 


\section{Marjolein Caniëls}

\section{John Adeoti}

Technology Investment in Pollution Control in Sub-Saharan Africa: The Case of the Nigerian Manufacturing Industry

UNU-MERIT Dissertation Series, № 23

\section{Edward Huizenga}

Innovation Management: How

Frontrunners Stay Ahead: An

Empirical Study on Key Success

Factors in the ICT sector

UNU-MERIT Dissertation Series, № 22

2000

\section{Machiel van Dijk}

Technological Change and the

Dynamics of Industries: Theoretical Issues and Empirical evidence from Dutch Manufacturing

UNU-MERIT Dissertation Series, № 21

1999

\section{Jan Cobbenhagen}

Managing Innovation at the Company Level: A Study on Non-Sector-Specific Success Factors UNU-MERIT Dissertation Series, № 20
Regional Growth Differentials: The Impact of Locally Bounded Knowledge Spillovers

UNU-MERIT Dissertation Series, № 19

\section{8}

\author{
Aldo Geuna \\ Resource Allocation and Knowledge \\ production: Studies in the Economics \\ of University Research \\ UNU-MERIT Dissertation Series, \\ № 18 \\ 1996 \\ Reinoud Joosten \\ Dynamics, Equilibria, and Values \\ UNU-MERIT Dissertation Series, \\ № 17
}

\section{Hugo Kruiniger}

Investment, $R \mathcal{E} D$, and the Financing Decisions of the Firm

UNU-MERIT Dissertation Series, № 16

\section{5}

\section{Hans van Meijl}

Endogenous Technological Change: The Case of Information Technology, Theoretical Considerations and Empirical Results UNU-MERIT Dissertation Series, № 15 


\section{René Kemp}

Environmental Policy and Technical

Change: A Comparison of the

Technological Impact of Policy

Instruments

UNU-MERIT Dissertation Series, № 14

\section{Rohini Acharya}

The Impact of New Technologies on

Economic Growth and Trade: A Case

Study of Biotechnology

UNU-MERIT Dissertation Series, № 13

\section{Geert Duysters}

The Evolution of Complex Industrial Systems: The Dynamics of Major IT Sectors

UNU-MERIT Dissertation Series, № 12

\section{Marjan Groen}

Technology, Work and Organisation: A Study of the Nursing Process in Intensive Care Units

UNU-MERIT Dissertation Series, № 11

1994

\section{Huub Meijers}

On the Diffusion of Technologies in a Vintage Framework: Theoretical Considerations and Empirical Results UNU-MERIT Dissertation Series, № 10

\section{Theon van Dijk}

The Limits of Patent Protection: Essays on the Economics of Intellectual

Property Rights

UNU-MERIT Dissertation Series, № 9

\section{Hans Voordijk}

Naar Integrale Logistiek in

Bedrijfsketens: Ontwikkelingen in de Bouw

UNU-MERIT Dissertation Series, № 8

1993

\section{Paul Diederen}

Technological Progress in Enterprises and Diffusion of Innovation:

Theoretical Reflections and Empirical Evidence

UNU-MERIT Dissertation Series, № 7

\section{Ben Dankbaar}

Economic Crisis and Institutional Change: The Crisis of Fordism from the Perspective of the Automobile Industry UNU-MERIT Dissertation Series, № 6

\section{Hanno Roberts}

Accountability and Responsibility: The Influence of Organisation Design on Management Accounting UNU-MERIT Dissertation Series, № 5 


\section{Bart Verspagen}

Uneven Growth between

Interdependent Economies: An

Evolutionary View on Technology

Gaps, Trade and Growth

UNU-MERIT Dissertation Series,

№ 4

\section{Sjoerd Romme}

A Self-organization Perspective on Strategy Formation

UNU-MERIT Dissertation Series, № 3

\section{John Spangenberg}

Economies of Scale, and Atmosphere in

Research Organisations

UNU-MERIT Dissertation Series,

№ 2

1988

\section{John Hagedoorn}

Evolutionary and Heterodox

Innovation Analysis: A Study of

Industrial and Technological

Development in Process Control and

Information Technology

UNU-MERIT Dissertation Series,

№ 1 